\title{
Brain MRI in Mitochondrial Disorders
}

Citation for published version (APA):

Sankaran, B. P. (2018). Brain MRI in Mitochondrial Disorders: Correlating the Phenotype with the Genotype. [Doctoral Thesis, Maastricht University]. Datawyse / Universitaire Pers Maastricht. https://doi.org/10.26481/dis.20180921bs

Document status and date:

Published: 01/01/2018

DOI:

10.26481/dis.20180921bs

Document Version:

Publisher's PDF, also known as Version of record

\section{Please check the document version of this publication:}

- A submitted manuscript is the version of the article upon submission and before peer-review. There can be important differences between the submitted version and the official published version of record.

People interested in the research are advised to contact the author for the final version of the publication, or visit the DOI to the publisher's website.

- The final author version and the galley proof are versions of the publication after peer review.

- The final published version features the final layout of the paper including the volume, issue and page numbers.

Link to publication

\footnotetext{
General rights rights.

- You may freely distribute the URL identifying the publication in the public portal. please follow below link for the End User Agreement:

www.umlib.nl/taverne-license

Take down policy

If you believe that this document breaches copyright please contact us at:

repository@maastrichtuniversity.nl

providing details and we will investigate your claim.
}

Copyright and moral rights for the publications made accessible in the public portal are retained by the authors and/or other copyright owners and it is a condition of accessing publications that users recognise and abide by the legal requirements associated with these

- Users may download and print one copy of any publication from the public portal for the purpose of private study or research.

- You may not further distribute the material or use it for any profit-making activity or commercial gain

If the publication is distributed under the terms of Article $25 \mathrm{fa}$ of the Dutch Copyright Act, indicated by the "Taverne" license above, 


\title{
Brain MRI in Mitochondrial Disorders:
}

\author{
Correlating the Phenotype \\ with the Genotype
}

Bindu Parayil Sankaran 
(C) copyright Bindu Parayil Sankaran, Maastricht 2018

Printing: Datawyse | Universitaire Pers Maastricht

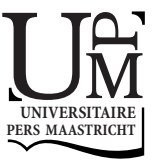

ISBN 9789493019676 


\title{
Brain MRI in Mitochondrial Disorders:
}

\author{
Correlating the Phenotype \\ with the Genotype
}

\begin{abstract}
Dissertation
to obtain the degree of Doctor at the Maastricht University, on the authority of the Rector Magnificus Prof.dr. Rianne M. Letschert in accordance with the decision of the Board of Deans, to be defended in public on $21^{\text {st }}$ September 2018 12.45 PM
\end{abstract}

Bindu Parayil Sankaran

(Born on 31st May 1971, Kerala, India) 


\section{Supervisor:}

Prof. dr. H.J.M. Smeets

Co-supervisor:

Prof. dr. Arun B Taly

\section{Assessment Committee:}

Prof. dr. H.W.M. Steinbusch (chairman)

Prof. dr. C.G. Faber

Prof. dr. E. Morava-Kozicz (UZ Leuven, Belgium)

Dr. I.F.M. de Coo (Erasmus MC Rotterdam, The Netherlands)

Dr. D.M.E.I. Hellebrekers 


\section{Contents}

$\begin{array}{lll}\text { Chapter } 1 \text { General Introduction } & 9\end{array}$

Chapter 2 Magnetic resonance Imaging Correlates of Genetically Characterized patients with Mitochondrial Disorders:

A study from South India

Chapter 3 Peripheral Neuropathy in Genetically Characterized

Patients with Mitochondrial Disorders: A Study from

South India

Chapter 4 Bilateral hypertrophic olivary nucleus degeneration on magnetic resonance imaging in children with Leigh and Leigh-like syndrome

Chapter 5 Outcome of Epilepsy in patients with Mitochondrial

Disorders: Phenotype Genotype and Magnetic Resonance Imaging Correlations

Chapter 6 Mitochondrial Leukoencephalopathies: A Border Zone between Acquired and Inherited White matter Disorders in Children?

Chapter 7 General Discussion

Summary

Valorisation

Acknowledgements

Curriculum vitae

Publications 


\begin{tabular}{|c|c|}
\hline Abbreviations & \\
\hline AARS2 & Alanyl-tRNA synthetase 2 \\
\hline ACAD9 & Acyl-CoA Dehydrogenase family member 9 \\
\hline $\mathrm{ADC}$ & Apparent diffusion coefficient \\
\hline AIMPI & Aminoacyl tRNA synthetase complex 1 \\
\hline APOPT1 & Apoptogenic protein 1 \\
\hline ATPAF2 & ATP synthase mitochondrial F1 complex factor 2 \\
\hline ATP5E & TP synthase subunit 5 epsilon \\
\hline ATP5A1 & ATP synthase subunit alpha 1 \\
\hline BCSIL & BCSI homolog,ubiquinol-cytochrome c reductase complex chaperone \\
\hline BOLA3 & bolA family member 3 \\
\hline CABC1 & Chaperone activity of bcl complex 1 \\
\hline COX & Cytocrome c oxidase \\
\hline COX6B1 & Cytochrome c oxidase subunit 6B1 \\
\hline COA7 & Cytochrome c oxidase assembly factor 7 \\
\hline COX10 & Cytochrome c oxidase assembly factor 10 \\
\hline C14ORF153 & Chromosome 14 open reading frame 153 \\
\hline COX15 & Cytochrome c oxidase assembly factor 15 \\
\hline CPEO & Chronic progressive external ophthalmoplegia \\
\hline CSF & Cerebrospinal fluid \\
\hline DARS & Aspartyl-tRNA synthetase \\
\hline DARS2 & Aspartyl-tRNA synthetase \\
\hline DTI & Diffusion tensor Imaging \\
\hline DWI & Diffusion weighted imaging \\
\hline EARS2 & Glutamyl-tRNA synthetase 2 \\
\hline ECHS1 & Short chain enoyl CoA hydratase \\
\hline EFG1 & Elongation factor G1 \\
\hline EFTu & Translation elongation factor $\mathrm{Tu}$ \\
\hline FARS2 & Phenylalanyl-tRNA synthetase \\
\hline FBXL4 & F-box and leucine -rich-repeat-4 proteins \\
\hline FILS & Fatal infantile lactic acidosis \\
\hline fMRI & functional magnetic resonance imaging \\
\hline FOXRED1 & FAD Dependent Oxidoreductase Domain Containing1 \\
\hline GLRX5 & Glutaredoxin 5 \\
\hline GRACILE & $\begin{array}{l}\text { Growth retardation, aminoaciduria, cholestasis, iron overload lactic } \\
\text { acidosis and early death }\end{array}$ \\
\hline $\mathrm{HIBCH}$ & 3-Hydroxy isobutyryl CoA hydrolase \\
\hline KSS & Kearns Sayre syndrome \\
\hline LARS2 & Leucyl-tRNA synthetase 2 \\
\hline LBSL & $\begin{array}{l}\text { Leukoencephalopathy with brainstem and spinal cord involvement and } \\
\text { elevated lactate }\end{array}$ \\
\hline LHON & Leber's hereditary optic neuropathy \\
\hline LIAS & Lipoic acid synthase \\
\hline LTBL & $\begin{array}{l}\text { Leukoencephalopathy with thalamus and brainstem involvement and } \\
\text { high lactate }\end{array}$ \\
\hline LYRM7 & LYR motif containing protein 7 \\
\hline
\end{tabular}




\begin{tabular}{|c|c|}
\hline LRPPRC & leucin-rich penta tricopeptide repeat domain protein \\
\hline MARS2 & Methionyl-tRNA synthetase 2 \\
\hline MEDGEL & $\begin{array}{l}\text { 3-methyl Glutaconic aciduria deafness encephalopathy leigh like } \\
\text { syndrome }\end{array}$ \\
\hline MELAS & Mitochondrial encephalopathy lactic acidosis and stroke like episodes \\
\hline MERRF & Myoclonic epilepsy ragged red fiber syndrome \\
\hline MNGIE & Mitochondrial neurogastrointestinal encephalopathy \\
\hline MRI & Magnetic resonance imaging \\
\hline MRS & Magnetic resonance spectroscopy \\
\hline MTCO1 & Mitochondrially encoded cytochrome c oxidase subunit 1 \\
\hline MTCO2 & Mitochondrially encoded cytochrome c oxidase subunit 2 \\
\hline MTCO3 & Mitochondrially encoded cytochrome c oxidase subunit 2 \\
\hline MTCYB & Mitochondrially encoded cytochrome B \\
\hline MTFMT & Methionyl-tRNA formyl transferase \\
\hline MT-TI & Mitochondrially encoded tRNA (Isoleucine) \\
\hline MT-TL1 & Mitochondrially encoded tRNA(Leucine) \\
\hline MT-TK & Mitochondrially encoded tRNA(Lysine) \\
\hline MT-TW & Mitochondrially encoded tRNA (Tryptophan) \\
\hline NARP & Neuropathy ataxia retinitis pigmentosa syndrome \\
\hline NDUFA1 & NADH-ubiquinone oxidoreductase 1 alpha subcomplex subunit 1 \\
\hline NDUFA2 & NADH-ubiquinone oxidoreductase 1 alpha subcomplex subunit 2 \\
\hline NDUFA9 & NADH-ubiquinone oxidoreductase 1 alpha subcomplex subunit 9 \\
\hline NDUFA10 & NADH-ubiquinone oxidoreductase 1 alpha subcomplex subunit 10 \\
\hline NDUFS1 & NADH:ubiquinone oxidoreductase core subunit $\mathrm{S} 1$ \\
\hline NDUFS2 & NADH-ubiquinone oxidoreductase core subunit S2 \\
\hline NDUFS3 & NADH-ubiquinone oxidoreductase core subunit S3 \\
\hline NDUFS4 & NADH-ubiquinone oxidoreductase core subunit S4 \\
\hline NDUFS7 & NADH-ubiquinone oxidoreductase core subunit S7 \\
\hline NDUFS8 & NADH-ubiquinone oxidoreductase core subunit S8 \\
\hline NDUFV1 & NADH-ubiquinone oxidoreductase core subunit V1 \\
\hline NDUFAF2 & NADH:Ubiquinone Oxidoreductase Complex Assembly Factor 2 \\
\hline NFU1 & NFU1 Fe-S cluster scaffold \\
\hline OXPHOS & Oxidation phosphorylation disorders \\
\hline $\mathrm{PDHc}$ & Pyruvate Dehydrogenase complex \\
\hline PGD & Peri implantation genetic diagnosis \\
\hline POLG1 & Polymerase Gamma \\
\hline RARS & Arginyl-tRNA synthetase \\
\hline RARS2 & Arginyl tRNA synthetase 2 \\
\hline RMND1 & Required for Meiotic nuclear division protein 1 \\
\hline SERAC1 & serine active site containing 1 \\
\hline SCO2 & Synthesis of cytochrome c oxidase assembly protein 2 \\
\hline SCO1 & Synthesis of cytochrome c oxidase assembly protein 1 \\
\hline $\mathrm{SDH}$ & Succinate dehydrogenase \\
\hline SDHA & Succinate dehydrogenase complex flavoprotein Subunit A \\
\hline SDHB & Succinate dehydrogenase complex iron sulfur subunit B \\
\hline SDHC & Succinate dehydrogenase complex subunit C \\
\hline
\end{tabular}




\begin{tabular}{ll}
\hline SDHD & Succinate dehydrogenase complex subunit D \\
SDHAF1 & Succinate dehydrogenase complex assembly factor 1 \\
SDHAF2 & Succinate dehydrogenase complex assembly factor 2 \\
SDHAF3 & Succinate dehydrogenase complex assembly factor 3 \\
SDHAF4 & Succinate dehydrogenase complex assembly factor 4 \\
SLC19A3 & Solute carrier family 19 member 3 \\
SUCLA2 & Succinate CoA ligase ADP forming beta subunit \\
SUCLG1 & Succinate CoA ligase alpha subunit \\
SURF1 & Surfeit Locus protein \\
TK2 & Thymidine kinase 2 \\
TTC19 & Tetratricopeptide repeat protein 19 \\
TACO1 & Translation activator of cytochrome c oxidase1 \\
TMEM70 & Transmembrane protein 70 \\
TYMP & Thymidine phosphorylase \\
\hline
\end{tabular}


Chapter $\perp$

General Introduction 


\section{Inherited metabolic disorders}

Inherited neurometabolic disorders constitute a heterogeneous group of almost seven hundred rare genetic diseases, which manifest with diverse neurological or cognitive symptoms. ${ }^{1}$ Part of them are amenable to therapy or interventions that directly target pathogenesis at the cellular and molecular level. ${ }^{2,3}$ Reaching an accurate diagnosis is a necessary prerequisite for implementation of specific therapeutic intervention since these disorders have the potential to cause irreversible injury to the developing nervous system. ${ }^{4}$ In addition, a genetic diagnosis allows reproductive choices to prevent the birth of an affected child. The signs and symptoms are often nonspecific and heterogeneous making the differential diagnosis challenging to the clinician. This is especially true in mitochondrial disorders where considerable clinical, biochemical and genetic heterogeneity exist. ${ }^{5}$ Nevertheless, a systematic and methodical approach often helps to arrive at an early diagnosis even when the presentation is nonspecific. The diagnostic algorithms available include clinical, biochemical, neuroimaging, morphologic, enzymatic, and genetic approaches. Currently, whole exome sequencing is becoming the preferred starting strategy, allowing to characterize the genetic defect in the majority of patients and paving the way for more focused follow-up clinical or functional investigations, leading to more accurate genotype-phenotype correlations and therapeutic interventions.

Among the several approaches to characterize the pathophysiology and establish genotype-phenotype correlations of neurometabolic disorders, neuroimaging investigations are particularly helpful to the clinician since it gives an objective assessment of the central nervous system structures affected, the different patterns and the extent of involvement. ${ }^{6}$ Especially, magnetic resonance imaging (MRI) has emerged as a powerful tool to evaluate the central nervous system in a noninvasive manner in the last few decades. ${ }^{4}$ In addition, it is also one of the easily accessible early diagnostic tools available to the treating physician, which can help in formulating differential diagnoses and targeted investigations. Pattern recognition on MRI has been shown to be an effective way of reaching an early diagnosis in leukoencephalopathies. ${ }^{7-9}$ Several new disorders have been identified based on the pattern recognition and/or whole exome sequencing approaches. ${ }^{10-12}$ Combination of whole exome sequencing and MRI pattern recognition in a cohort of patients with "suspected mitochondrial leukodystrophy" has yielded a molecular diagnostic rate in about $65 \%$ of the patients. ${ }^{13}$ This exemplifies the importance of linking the genetic data and neuroimaging phenotype for accurate genotype-phenotype correlations as well as understanding the complex imaging appearance of neurometabolic disorders. It is envisaged that in the future, brain imaging such as advanced MRI can be used as a 
biomarker (MR phenotype) to target genetic studies to the most probable defect in specific neurometabolic disorders ${ }^{14}$ or to establish an accurate prognosis or treatment. Exploration of large number of patients and accurate characterization of neuroimaging features are needed to identify specific neuroimaging biomarkers and patterns.

\section{Magnetic Resonance Imaging in Mitochondrial Disorders}

Mitochondrial oxidative phosphorylation disorders constitute a large heterogeneous group of metabolic disorders with an incidence of 1 in 5000 live births. ${ }^{15}$ Defects in more than 250 genes have been identified to date, making disorders of mitochondrial energy metabolism the most heterogeneous metabolic disease. ${ }^{15,16}$ The strategy for diagnosis of mitochondrial disorders included a comprehensive and meticulous analysis of family history, clinical findings, biochemical and histopathological analyses, magnetic resonance imaging findings and molecular diagnostic testing, but is currently shifting towards whole exome sequencing as the first diagnostic step. ${ }^{17,18}$ Whole exome sequencing has the highest diagnostic yield, but is neither the fastest nor the cheapest approach and might not always be readily available due to the expensive equipment and specific expertise required. Magnetic resonance imaging (MRI) is one of best alternatives to guide more rapid, targeted genetic analysis. It is an easily accessible initial tool available to the clinician for interrogating the presence and pattern of central nervous system changes in patients with mitochondrial disorders, which can be specific for the genetic defect. ${ }^{19,20}$ Even though the tremendous advances in genomics in recent years have simplified the molecular diagnosis of mitochondrial disorders, the validation process of numerous variants called by whole exome sequencing and progress in prognosis and treatment options will require meticulous clinical and imaging phenotyping. ${ }^{18}$

In addition to the routine $\mathrm{T} 1 \mathrm{~W}$ and $\mathrm{T} 2 \mathrm{~W}$ imaging, many advanced imaging techniques are available which include diffusion weighted imaging (DWI), diffusion tensor imaging (DTI), magnetic resonance spectroscopy (MRS) and functional magnetic resonance imaging (fMRI). ${ }^{20-23}$ Each modality can be combined to gain complementary information regarding the brain's structural, functional, and metabolic dimensions, and how these may be altered in pathologic states. ${ }^{23}$

\subsection{Anatomical pattern of Injury in Mitochondrial Disorders}

MRI findings in mitochondrial disorders can be specific or non-specific and the major anatomical patterns include: 1. Focal lesions in deep gray matter structures 
which can be further divided into basal ganglia lesions and brainstem lesions; 2.White matter lesions; 3 . Stroke-like lesions; 4 . Cortical and cerebellar atrophy. ${ }^{21-26}$

\subsubsection{Focal lesions in deep gray matter structures}

Bilateral lesions in the putamen and basal ganglia nuclei are recognized as being the most prevalent features of many mitochondrial syndromes. ${ }^{22,25-27}$ Bilateral symmetrical lesions of the basal ganglia and brainstem is the typical feature of Leigh syndrome, the most common mitochondrial disorder of childhood. ${ }^{28}$ The diagnosis of Leigh syndrome is based on stringent criteria, which requires that characteristic neuropathology or neuroradiology must be accompanied by progressive neurodegeneration with: 1. clinical evidence of brainstem and/or basal ganglia dysfunction, 2. intellectual and motor developmental delay, and 3. abnormal energy metabolism indicated by either a severe defect in oxidative phosphorylation (OXPHOS) or pyruvate dehydrogenase complex (PDHc) activity, a molecular diagnosis in a gene related to mitochondrial energy generation, or an elevated serum or CSF lactate. ${ }^{28,29}$ In case patients do not fulfill these stringent criteria, a diagnosis of Leigh-like syndrome can be considered, particularly in patients with atypical neuroradiology or normal lactate level. ${ }^{28,30}$

\subsubsection{White matter lesions}

Cerebral white matter involvement is more and more commonly seen in childhood onset mitochondrial disorders, as indicated by recent papers on mitochondrial leukoencephalopathies. ${ }^{11-13,31}$ Combination of whole exome sequencing and MRI pattern recognition in a cohort of patients with "suspected mitochondrial leukodystrophy" has yielded a molecular diagnostic rate in about $65 \%$ of the patients. ${ }^{13}$ The features of a mitochondrial leukoencephalopathy or leukodystrophy include cystic lesions in the abnormal white matter, additional gray matter lesions, restricted diffusion, contrast enhancement, and elevated lactate on magnetic resonance spectroscopy of the brain. ${ }^{8,32}$

\subsubsection{Stroke-like lesions}

Stroke-like lesions defined as cortical lesions not confined to defined vascular territories are characteristic for patients with Mitochondrial Encephalopathy Lactic acidosis and Stroke-like syndrome [MELAS], in most cases caused by the m.3243A>G mutation. ${ }^{33}$ The cortical lesions most commonly occur in the parieto-occipital region, which may be unilateral or bilateral and may spread to other regions over time. ${ }^{34}$ Diffusion weighted imaging findings have been used to differentiate acute from chronic stroke-like lesions. ${ }^{35,36}$ In the acute stage the initial insufficiency in 
neuronal energy causes cytotoxic edema and restricted diffusion. Subsequently there is development of extra-cellular edema causing increased apparent diffusion coefficient. As a result, chronic stroke-like lesions show free diffusion. ${ }^{33,34,36} \mathrm{~A} \mathrm{ME-}$ LAS/Leigh Syndrome overlap syndrome, in which there are stroke lesions in combination with signal changes in deep gray matter structures, has been described in association with the m.13513G $>\mathrm{A}$, the m.3243A $>\mathrm{G}$ and $M T-N D 3$ mutations. ${ }^{27,37}$ Nuclear gene mutations associated with stroke-like lesions include POLG1, TWIN$K L E$, TK2 and $C A B C 1{ }^{38-41}$

\subsubsection{Cerebral and cerebellar atrophy}

Diffuse cortical atrophy is described in about one third of the patients with encephalomyopathy. Cerebral atrophy has been the sole imaging finding in up to a quarter of the patients with respiratory chain deficiencies. ${ }^{25,42}$ Certain clinical entities, such as Alpers syndrome, a severe hepatocerebral disease, caused by mutations in the POLG1 gene, can present with volume loss predominantly in cerebellar and occipital cortices. ${ }^{43}$ Cerebellar atrophy is a common finding in childhood onset mitochondrial disorders and may be the primary neuroimaging findings in some. ${ }^{44}$ Cerebellar atrophy as a predominant feature is also seen in primary CoQ deficiency. ${ }^{45}$ In addition to cerebellar atrophy, pontocerebellar hypoplasia has been reported in patients with mitochondrial disorders and has emerged as a new phenotype caused by RARS2 mutations. ${ }^{46,47}$ The other patterns include cortical laminar necrosis, thalamic signal changes and mineralization and spinal cord signal changes. ${ }^{21,48} 49,50$

\section{Genotype and MR Imaging Correlations in Mitochondrial Disorders}

\subsection{Mutations in nuclear genes}

\subsubsection{Complex I deficiency}

Mitochondrial complex I is the largest of the respiratory chain complexes and consists of 45 subunits, 7 of which are encoded by mtDNA and the remaining by nDNA. ${ }^{51,52}$ It is the most common cause of OXPHOS disorders in infants and children. ${ }^{51}$ The clinical syndromes associated with complex I deficiency include Leigh and Leigh-like syndrome, leukoencephalopathy, Leber's hereditary optic neuropathy (LHON), fatal infantile lactic acidosis (FILS), hypertrophic cardiomyopathy and exercise intolerance. ${ }^{51}$

A retrospective study on MR imaging findings in 30 patients with complex I deficiency secondary to both mitochondrial and nuclear DNA mutations has identified 
a consistent pattern of abnormalities ${ }^{27}$, of which bilateral symmetrical brainstem lesions were noted in all 30 patients. Striatal lesions were observed in $90 \%$ of patients. Important differentiating points included the presence of isolated stroke-like lesions in MT-TL1 patients and presence of necrotizing leukoencephalopathy in patients with nuclear DNA mutations ${ }^{27}$ This is corroborated by data from a systematic review of 172 patients with complex I deficiency caused by nuclear DNA mutations, 82 patients had MRI findings available and lesions were distributed over basal ganglia (13\%), brain stem (24\%) and both basal ganglia and brain stem (24\%) and $24 \%$ showed leukoencephalopathy. ${ }^{51}$ The authors supported the notion that brain stem lesions are predominant in patients with Leigh syndrome secondary to complex I deficiency.

In conclusion, the MRI findings in patients with complex I deficiency reported so far can be broadly divided into: 1 . focal bilateral symmetrical brain lesions involving the basal ganglia, and 2. brain stem lesions, typical of Leigh and Leigh-like syndrome with leukoencephalopathy. Focal lesions in deep gray matter structures consistent with Leigh and Leigh-like syndrome have been demonstrated both in complex I deficiency due to mtDNA (see below) and nuclear DNA mutations. Mutations in 11 nuclear-encoded (NDUFS1, NDUFS2, NDUFS3, NDUFS4, NDUFS7, NDUFS8, NDUFV1, NDUFA1, NDUFA2, NDUFA9, NDUFA10) complex I subunits and four assembly factors (NDUFAF2, C8ORF38, C20ORF7 and FOXRED1) have been reported in Leigh syndrome. ${ }^{53} \mathrm{~A}$ distinct MRI pattern with predominantly brainstem involvement has also been described in patients with mutations in the NDUFA2 gene. ${ }^{54,55}$

Leukoencephalopathy is another characteristic association of mutations in nuclear encoded complex I proteins. ${ }^{56}$ A review of the MRI data of NDUFS1 or NDUFV1 patients showed that white matter signal changes was the most prominent finding in 28/30 patients. ${ }^{56}$ Other less associated findings included brain stem signal changes and striatal lesions. This showed that patients with NDUFS1 mutations present with leukoencephalopathy more often than with Leigh syndrome. Other complex I gene mutations, including NDUFS8 and NUFAF3, were less often described in association with leukoencephalopathy. ${ }^{57,58}$ The white matter changes in patients with complex I deficiency could also resemble vanishing white matter disease. ${ }^{59-61}$ Leukoencephalopathy or a mitochondrial leukodystrophy have been described in patients with NUBPL mutations as well ${ }^{11}$, which was characterized by confluent or multifocal white matter lesions predominantly affecting the deep frontal and parietal white matter sparing the ' $U$ ' fibers, internal and external capsule. Corpus callosal signal changes and swelling were noted in the early MRIs. The extensive signal abnormali- 
ties in cerebellar cortex is a characteristic finding in patients with NUBPL mutations. ${ }^{62}$

\subsubsection{Complex II Deficiency}

Succinate Dehydrogenase (SDH) is the smallest complex of the respiratory chain and includes a flavoprotein subunit (Fp, encoded by $S D H A$ ) and an iron-sulfur subunit (Fe-S, encoded by $S D H B$ ), paired with 2 subunits that anchor the complex to the inner mitochondrial membrane $(S D H C$ and $S D H D)$. In addition, the SDH protein complex comprises 4 assembly factor proteins (SDHAF1,SDHAF2, SDHAF3 and $S D H A F 4$ ). It is unique in that all the subunits are encoded by nuclear DNA and that complex II plays a role in both the mitochondrial respiratory chain and in succinate catabolism in the Kreb's cycle. ${ }^{63}$

Two different MRI patterns have been described in complex II deficient patients: Leigh syndrome and leukoencephalopathy. Characteristics of SDH related leukoencephalopathy were reported recently. ${ }^{64}$ Clinically, all individuals presented in the first two years of life with an average age at onset of 12 months. A rapid deterioration was preceded by febrile illness, injury, vaccination or sometimes by no obvious preceding event. The imaging findings included extensive cerebral white matter hyper-intensity, predominantly involving the frontal, parieto-occipital and posterior temporal region, and sparing the juxta cortical fibers. The corpus callosum had a swollen appearance and the outer and inner tables were spared. Corticospinal tract involvement was common and involved the posterior limb of the internal capsule and the transverse pontine fibers with extension into middle cerebellar peduncle. Central tegmental tract was seen in some patients, but the dorsal portion of the cervical cord was affected in the majority. Proton MRS demonstrated an abnormally elevated peak at $2.4 \mathrm{ppm}$ compatible with succinate and was found in areas of affected white matter. It was noted that involvement of anterior nucleus and pulvinar of thalamus and geniculate bodies along with corticopontine and transverse pontine fibers and middle cerebellar peduncle was unique to SDH related leukoencephalopathy. The most common cause were mutations in the SDHF1 subunit ${ }^{64,65}$, but patients with $S D H A$ and $S D H B$ mutations can also display this phenotype ${ }^{64,66}$ Mutations in $S D H C$, $S D H D$ or other assembly factor $S D H F 2$ were not reported in leukoencephalopathy patients. Leigh syndrome in relation to complex II deficiency has been reported infrequently. Two patients with $S D H A$ mutations ${ }^{67}$ and one patient with SDHFA1 mutation ${ }^{65}$ had Leigh syndrome, but no detailed magnetic resonance imaging data was available. In an adult patient with an autosomal dominant SDHA mutation with ocular, cardiac and neurologic involvement MRI was normal. ${ }^{68}$ In another 
adult patient with histopathological proven complex II deficiency MRI showed isolated pontine signal changes. ${ }^{69}$

\subsubsection{Complex III deficiency}

Mitochondrial respiratory chain complex III (ubiquinol cytochrome c reductase or cytochrome bc1 complex) transfers electrons from coenzyme Q to cytochrome c, accompanied by the translocation of protons, which is important for the generation of the mitochondrial electrochemical potential. Complex III consists of eleven subunits of which only one is encoded by mtDNA (MTCYB). ${ }^{70}$ Mutations in nuclear genes encoding other structural complex III subunits are extremely rare. ${ }^{71,72}$ On the other hand, several genetic defects have been described in complex III assembly factor genes, including TTC1971, $L Y R M 7^{73}$ and $B C S 1 L^{74}$.

MRI findings associated with complex III deficiency have been reported in patients with, TTC19, LYRM7 and BCSIL mutations. The clinical presentation of patients with TTC19 mutations was broad, with initial presentation from childhood to adulthood. Characteristic MRI findings included a variable combination of bilateral symmetrical signal changes in basal ganglia, inferior olives, dentate and cortical and olivo pontocerebellar atrophy. ${ }^{71,75-80} \mathrm{~A}$ multifocal cavitating leukoencephalopathy has been described recently in patients harboring mutations in the LYRM7 gene. ${ }^{12,73}$ All patients had a similar and distinct MRI pattern of a progressive leukoencephalopathy with numerous small cavitations in the periventricular and deep cerebral white matter. There was relative sparing of the subcortical white matter. Corpus callosum showed small cysts. Diffusion restriction was present either in diffuse distribution or in the rim of cysts. Contrast enhancement was variable. Most of them showed a severe complex III deficiency. The phenotypes associated with BCSIL mutation is heterogeneous and range from GRACILE (Growth Retardation, Amino aciduria, Cholestasis, Iron overload, Lactic acidosis, and Early death) syndrome to Björnstad syndrome, an extremely rare inherited disorder characterized by pili torti, sensorineural hearing loss and progressive encephalopathy. ${ }^{70} \mathrm{~A}$ bilateral symmetrical signal change in the putamen and thalami along with supratentorial atrophy has been described in a child with progressive encephalopathy and severe complex III deficiency due to a BCSIL mutation. ${ }^{81}$

\subsubsection{Complex IV deficiency}

Complex IV or cytochrome c oxidase (COX) deficiency is one of the most common biochemical abnormalities found in mitochondrial disorders, but mutations in the mtDNA or nuclear DNA encoding structural subunits of complex IV are rare. Conversely, mutations in COX assembly factor often cause COX deficiency and muta- 
tions have been described in the nuclear COX assembly genes SURF1, SCO2, SCO1, COX10 and COX15 in severe early infantile phenotypes. ${ }^{82}$ Most important is the SURF1 gene and SURF1 mutations characteristically present with Leigh syndrome. ${ }^{83}$ A number of reports describe MRI findings in SURF1 mutation positive patients and have tried to identify specific characteristics. ${ }^{84-86}$ However, no consistent correlations emerged from these studies. A leukoencephalopathy pattern has been described in two patients with a SURF1 mutation. ${ }^{87,88}$ In a family of patients with $T A$ CO1 mutations and COX deficiency, brain MRI showed bilateral, symmetric hyperintense lesions of the basal ganglia with variable involvement of the subcortical white matter. ${ }^{89}$ TACO1 mutations are also described in a patient with late onset Leigh syndrome..$^{90}$

Pathogenic mutations in APOPT1 (previously APOP-1 or C14ORF153) are responsible for a mitochondrial disorder characterized by marked COX deficiency and a well-characterized form of cavitating leukodystrophy. ${ }^{31}$ In the acute stage, signal changes were predominantly seen in the posterior cerebral hemispheres and corpus callosum, and contained numerous small well-delineated cysts. Multifocal restricted diffusion and contrast enhancement and presence of lactate peak on MRS also characterized this acute phase. In the later stages, the abnormalities involved the anterior part of the cerebral hemispheres and corpus callosum as well. Follow-up images showed atrophy collapse of the cysts and disappearance of the diffusion restriction and contrast enhancement and decrease in lactate levels. ${ }^{31}$ Mutations in the COX10 and $C O X 6 B 1$ genes, assembly factors of complex IV also caused mitochondrial encephalopathy with cavitating leukodystrophy ${ }^{91,92}$. Mutations in the SCO2 gene caused an infantile cardio-encephalomyopathy with severe COX deficiency in heart, brain, and muscle. MRI findings included white matter involvement with later appearance of basal ganglia lesions ${ }^{93}$ and bilateral T2 signal changes in the putamen consistent with Leigh syndrome. ${ }^{94}$

Mutations in the $L R P P R C$ gene, encoding the leucine-rich pentatricopeptide repeat domain protein (LRPPRC), involved in post-transcriptional regulation of mitochondrial gene expression, causes the French-Canadian variant of COX-deficient Leigh syndrome. ${ }^{95}$ Recently it has been demonstrated that a multisystem mitochondrial disease is caused by the mutations in the same gene outside the Saguenay-LacSaint-Jean region of Quebec region. ${ }^{96}$ In a cohort of 10 patients, in addition to the well described features consistent with Leigh syndrome and a cystic leukoencephalopathy neuroimaging, also congenital structural anomalies such as corpus callosal agenesis, unfolded hippocampi, cerebellar hypoplasia and pachygyria were observed. ${ }^{97}$ Recently, mutations in the COA7 gene (C1orf163/RESA1), a putative COX assembly factor reported to localize in the mitochondrial IMS, were associated with 
a progressive neurological disorder characterized by encephalopathy and peripheral neuropathy. MRI in this patient showed a leukoencephalopathy associated with cavitations. ${ }^{97}$

\subsubsection{Complex V Deficiency}

Complex V, consisting of 14 nuclear encoded subunits and 2 mtDNA encoded subunits, utilizes the energy of the electrochemical gradient built by translocation of protons by complexes I, III and IV to generate ATP. Finally, mutations have been identified in three other complex V subunits (mtDNA encoded ATP6 [see below] and nuclear encoded ATP5E and ATP5A1) and two assembly factors TMEM70 and ATPAF2. ${ }^{98}$ The phenotypes included psychomotor retardation, early onset cataract, hypotonia and hypertrophic cardiomyopathy. MRI findings have not been described in these patients.

\subsubsection{Multiple Complex deficiencies}

Multiple complex deficiencies are among the most frequent finding in patients with mitochondrial disorders, mainly caused by mutations in proteins involved in the translation of mtDNA-encoded proteins. These include defects in genes involved in mtDNA maintenance and replication, mitochondrial or nuclear-encoded defects of mitochondrial protein synthesis. In the multiple mitochondrial dysfunctions syndrome, the activity of PDHc is also impaired.

\section{Mitochondrial DNA maintenance and replication}

A common cause of mtDNA maintenance and replication defects are mutations in the Polymerase gamma (POLG1) gene, leading to a broad variety of clinical manifestations. MRI findings in POLG1 patients include T2/FLAIR signal changes in the cortex, pulvinar of the thalamus, bilateral inferior olivary nucleus, dorsal column and mild cerebellar atrophy. ${ }^{43,99,100}$ Bilateral olivary and pulvinar lesions were characteristic findings noted in a cohort of European patients and in a patient with ataxia and palatal tremor form India. ${ }^{99,101}$ Stroke-like lesions typically seen in patients with MELAS have also been described in patients with POLG1, TK2 and TWINKLE related mitochondrial disorders. ${ }^{39,40}$

Patients with MNGIE caused by mutations in the TYMP gene showed a unique MRI pattern characterized by leukoencephalopathy involving the centrum semiovale, pons and basal ganglia with sparing of the ' $U$ ' fibers with absence of a lactate peak. ${ }^{102}$ Mutations in the gene encoding the $ß$-subunit of the ADP-forming succinylCoA synthetase (SUCLA2) have been reported to cause mild methyl malonic aciduria (MMA), Leigh-like encephalomyopathy, dystonia and deafness in association 
with mitochondrial depletion. ${ }^{103} \mathrm{MRI}$ revealed no abnormalities or mild cerebral atrophy with enlarged subarachnoideal spaces and widening of the ventricular system in the first year of life followed by signal changes in putamen and caudate. Unlike classical MMA the globus pallidus was spared or less affected. ${ }^{104}$ Mutations in SUCLG1, encoding a subunit of the enzyme, caused a similar disorder with mild methyl malonic aciduria dystonia deafness and a Leigh like encephalomyopathy.

\section{Mitochondrial Translation disorders}

Mitochondrial protein translation is a complex process performed within mitochondria by an apparatus composed of mitochondrial DNA (mtDNA)-encoded tRNAs and rRNAs and nuclear DNA-encoded proteins. ${ }^{105}$ The important disorders in this group with specific MRI findings included the mutations in mt-aminoacyl tRNA synthetases, MTFMT, LRPPRC (see 3.1.4) and mutations in the mitochondrial elongation factors EFG1 and EFTu. Especially, the clinical phenotypes associated with mutations in the aminoacyl tRNA synthase genes are steadily increasing in the recent years. Mutations in eight genes (DARS, RARS, AIMP1, AARS2, DARS2, EARS2, LARS2 MARS2, and FARS2) have been implicated in leukodystrophies or leukoencephalopathies. ${ }^{106}$ Mutations in the DARS2 and EARS2 gene caused specific, well-characterized patterns of mitochondrial leukoencephalopathy. ${ }^{10,107}$ Patients with leukoencephalopathy with brain stem and spinal cord involvement and elevated lactate (LBSL) caused by mutations in DARS2 displayed T2/FLAIR signal changes in the dorsal column and cortico-spinal tracts, the pyramids, the cerebellar peduncles, the intraparenchymal tract of the $\mathrm{V}$ cranial nerve, the posterior arm of the internal capsule, and the splenium of the corpus callosum; the U-fibers were spared. ${ }^{108}$ In contrast, leukoencephalopathy with thalamus and brainstem involvement (LTBL), caused by mutations in the EARS2 gene, was characterized by a peculiar MRI pattern which spares the periventricular rim, but affected the deep cerebral white matter including corpus callosum, thalamus, basal ganglia, midbrain, pons, medulla oblongata, and the cerebellar white matter. ${ }^{10}$ Patients usually had an earlyonset neuroregression and a biphasic clinical course.

Hereditary leukoencephalopathy, hypomyelination with brainstem and spinal cord involvement and leg spasticity, which is caused by mutations in the aspartyl tRNA-synthetase encoding gene DARS, was noted to have steroid responsiveness, similar to an acquired demyelinating disorder. ${ }^{109,110}$ Mutations in the RARS gene, coding for the cytoplasmic arginyl-tRNA synthetase (ArgRS), caused hypomyelination. ${ }^{111}$ Complex rearrangements in the MARS2 gene, encoding the mitochondrial methionyl-tRNA synthetase, were described in a cohort of patients with autosomal recessive spastic ataxia with leukoencephalopathy. ${ }^{112}$ Mutations in the mito- 
chondrial alanyl-tRNA synthetase 2 gene (AARS2) caused progressive leukoencephalopathy and, in females, ovarian failure, a clinical presentation previously described as "ovarioleukodystrophy. ${ }^{113}$ MRI showed a leukoencephalopathy with striking involvement of left-right connections, descending tracts, and cerebellar atrophy.

Recessive mutations in the mitochondrial arginyl-transfer RNA synthetase (RARS2) gene have been associated with early onset encephalopathy with signs of oxidative phosphorylation defects, classified as pontocerebellar hypoplasia $6 .{ }^{47}$ In the first few months cerebellar vermis hypoplasia was the dominant finding and the follow-up neuroimaging revealed a progressive pontocerebellar and cerebral cortical atrophy. The FARS2 gene encodes the mitochondrial phenylalanyl-tRNA synthetase (mtPheRS), which charges the tRNAphe with phenylalanine during mitochondrial translation. Mutations in the FARS2 genes have been shown to cause infantile onset refractory epilepsy and an Alpers phenotype. ${ }^{114}$ MRI showed extensive cerebral atrophy, subdural collection and signal changes in the putamen and basal ganglia. There was relative sparing of the cerebellum. ${ }^{114}$ In another patient with infantile onset epilepsy MRI showed white matter signal changes and thinning of corpus callosum. ${ }^{115}$ The other reported imaging findings included bilateral signal changes in the dentate ${ }^{116}$ and small focal signal changes in the white matter. ${ }^{117}$

Specific MRI patterns have been described in patients harboring mutations in the mitochondrial elongation factors EFG1 and EFTu genes. ${ }^{105}$ Both patients had severe lactic acidosis and rapidly progressive, fatal encephalopathy. The EFG1-mutant patient had early-onset Leigh syndrome, whereas the EFTu-mutant patient had severe infantile macrocystic leukodystrophy. Mutations in the MTFMT gene, which encodes a mitochondrial methionyl-tRNA formyl-transferase, were first identified in two unrelated patients with Leigh syndrome and a combined complex I and complex IV deficiency. ${ }^{118}$ The MRI findings in a larger cohort ${ }^{119}$ were isolated bilateral symmetrical signal changes in basal ganglia or combination signal changes in basal ganglia and white matter or white matter signal changes alone.

\section{Other nuclear causes of multiple complex deficiencies}

A mutation in the RMND1 (Required for Meiotic Nuclear Division protein 1) gene causes multiple mitochondrial respiratory chain deficiencies and was first described in a patient with severe congenital encephalopathy, peripheral neuropathy, myopathy, and lactic acidosis. ${ }^{120}$. The clinical features included encephalopathy, renal failure, cardiac conduction defects and deafness. ${ }^{121-124}$ Of the 31 reported patients, MRI data was available for 22 and 17 of them revealed abnormalities. ${ }^{123}$ Most common observation was white matter signal changes with cystic changes and delayed mye- 
lination. Additional findings were basal ganglia calcification, signal changes and infarcts involving the parieto-temporal area.

Multiple mitochondrial dysfunctions syndrome usually affects complexes containing iron-sulphur (Fe-S) clusters (complexes I, II and III) as well as the pyruvate dehydrogenase complex. The genes responsible for the multiple mitochondrial dysfunction syndrome include those involved in the Fe-S cluster assembly homeostasis namely NFU1 $1^{125}$, BOLA3 ${ }^{119,126}$ and LIAS ${ }^{126}$ and IBA57 ${ }^{127}$ and GLRX5 ${ }^{126}$. Mutations in all these genes have been associated with leukoencephalopathy of varying severity ranging from a progressive lethal cavitating leukoencephalopathy to signal changes limited to periventricular region and cervical spinal cord.

HIBCH is a mitochondrial enzyme that catalyzes the fifth step of valine catabolism, the conversion of 3-hydroxy-isobutyryl-CoA to 3-hydroxyisobutyrate.128 The MRI findings in HIBCH patients included bilateral symmetrical signal changes in the globus pallidus, brain stem, reduction in white matter volume and cystic change in the white matter. ${ }^{128}$

Short-chain enoyl-CoA hydratase (ECHS1) encoded by the ECHS1 gene is a multifunctional mitochondrial matrix enzyme that is involved in the oxidation of fatty acids and essential amino acids such as valine. ${ }^{129}$ The clinical phenotypes of ECHS1 mutations was in most cases Leigh syndrome, but additional manifestations of deafness, epilepsy, cardiomyopathy and optic atrophy were reported as well. ${ }^{130} \mathrm{~A}$ milder phenotype characterized by exercise induced paroxysmal dystonia has also been described. ${ }^{131}$ The MRI findings in patients included bilateral symmetrical signal changes in basal ganglia, cerebral atrophy and white matter signal changes, which varied in severity from punctate signal changes in centrum semiovale to periventricular and subcortical signal changes. ${ }^{130}$

Mutations in the SERAC1 gene, encoding a phosphatidylglycerol remodeler essential for both mitochondrial function and intracellular cholesterol trafficking, are responsible for MEGDEL syndrome (3-Methyl Glutaconic aciduria, Deafness, Encephalopathy, Leigh-like syndrome), an infantile-onset dystonia deafness syndrome. ${ }^{132}$ A typical MRI pattern of basal ganglia involvement with a distinctive evolution during the course of the disease has been described.133 The first structure to be affected was the globus pallidus followed by swelling of the caudate nucleus and the putamen. The signal changes in putamen spared the mid-dorsal putamen, which is referred to as the "putaminal eye". This finding was reported to be present in all patients with MRI available after first year of life. ${ }^{133}$

Mutations in the FBXL4 gene that encodes the F-box and leucine-rich-repeat-4 proteins have been shown to cause a slowly progressive mitochondrial encephalomyopathy characterized by lactic acidemia, congenital hypotonia, and microcephaly. MRI 
brain demonstrated variable combinations of cerebral atrophy, corpus callosal thinning, signal changes in white matter, basal ganglia and ventricular dilatation. ${ }^{134,135}$

\subsection{Mutations in the $m t D N A$}

\subsubsection{Point mutations in protein encoding genes}

Mutations in six mtDNA-encoded complex I subunits (ND1, ND2, ND3, ND4, ND5 and $N D 6$ ) have been identified in patients with Leigh syndrome. Stroke-like lesions and MELAS syndrome have been reported in ND1, ND5 and ND6 mutations. ${ }^{136-138}$. Leber's hereditary optic neuropathy is another clinical phenotype resulting from specific mutations in mtDNA-encoded complex I subunits, manifesting as painless subacute bilateral visual loss usually in early adulthood, but with reduced penetrance, affecting more males than females. ${ }^{139}$ The 3 most common mtDNA mutations are $\mathrm{m} .3460 \mathrm{G}>\mathrm{A}, \mathrm{m} .11778 \mathrm{G}>\mathrm{A}$ and $\mathrm{m} .14484 \mathrm{~T}>\mathrm{C}$. Discrete small white matter lesions resembling multiple sclerosis have been typically described in LHON patients and are known as LHON-MS. ${ }^{140}$ Extensive white matter signal changes have been described in a patient homoplasmic for the m.14484T $>\mathrm{C}$ mutation. ${ }^{141}$

A blinded observational study of LHON and LHON-MS patients showed similar conventional brain MRI appearances both groups. ${ }^{139}$ There is a strong gender predilection in the susceptibility of LHON-MS. Females are more prone for developing LHON-MS than males. ${ }^{139}$ Another study has reported that the white matter lesions in LHON-MS were atypical, being larger with indistinct borders, had a tubular appearance with a large longitudinal extension and a small transverse diameter, lack of black holes on T1W images and contrast enhancement. ${ }^{140}$ Neuropathology in a patient with m.14484T $>\mathrm{C}$ mutation has shown demyelinating plaques as well as mitochondrial pathology. MRI findings in this patient were characterized by large cavitory lesions with a frontal predilection. ${ }^{141}$ These reports indicated that white matter lesions in majority of the LHON-MS patients resembled that of multiple sclerosis, but could also show atypical features such as cavitating leukoencephalopathy as in other mitochondrial leukoencephalopathies.

The only mtDNA encoded subunit of respiratory chain complex III is the MTCYB. The variety of clinical presentations associated with cyt-b mutation is largely unexplored..$^{70}$ Though the most common phenotypes described is myopathy, myoglobinuria and exercise intolerance, CNS manifestations have been described as well, but only MRI studies were reported, showing cerebral atrophy and small brain infarcts. ${ }^{142}$

There are three mtDNA encoded subunits of respiratory chain complex IV (MTCO1, MTCO2 and MTCO3). The magnetic resonance imaging findings in 
MTCO1 mutation patients included diffuse cerebellar atrophy and T2 signal changes in the basal ganglia ${ }^{143}$, cortical atrophy in the tempero-occipital region ${ }^{144}$ and stroke-like lesions. ${ }^{145}$ MTCO2 mutations are rare and the reported MRI findings included corpus callosal agenesis and brain atrophy in a patient with early onset multisystem disease ${ }^{146}$ and normal MRI observations in a boy with myopathy. ${ }^{147}$ Reports on MTCO3 gene mutations are also limited. These mutations have been identified in a patient with Leigh syndrome ${ }^{148}$ and bilateral symmetrical lesions in basal ganglia, cerebral and cerebellar atrophy on MRI. Mild Cortical and cerebellar atrophy with enlargement of the subarachnoid space has also been described in other patients with MTCO3 mutations. ${ }^{149}$

ATP6 is one of the two mtDNA encoded subunits of complex V and the only complex V subunit or assembly factor in which mutations were identified in patients with Leigh syndrome. Six different mutations have been reported in the ATP6 gene ${ }^{150}$, which is the cause of $5-6 \%$ of patients with Leigh syndrome. ${ }^{151}$ The most common ATP6 mutation is the m.8993T $>$ G mutation. High mutation loads ( $>90 \%)$ usually cause maternally inherited or de novo Leigh syndrome while lower levels (50$60 \%$ ) cause less severe phenotypes like NARP. MRI findings include variable combinations of bilateral symmetrical signal changes in basal ganglia and mild cerebral and cerebellar atrophy. ${ }^{152,153}$

\subsubsection{Point mutations in $t R N A$ genes}

Mitochondrial tRNA mutations cause a variety of phenotypes. The most common mutation is the m.3243A $>\mathrm{G}$ in the MT-TL1 gene, resulting in MELAS syndrome and stroke-like lesions on MRI. Stroke like lesions have also been described in MT-TH mutations. ${ }^{154,155}$ Other phenotypes include Leigh or Leigh-like syndrome caused by $M T-T I^{156} M T-T K^{157}$ and $M T-T W^{158}$ gene mutations. A novel m.14724G $>$ A mutation in the mitochondrial tRNA glutamic acid gene has been reported to cause leukoencephalopathy. ${ }^{159}$ A recent brain MRI study of 34 patients with the m.8344A>G mutation in $M T T K$, revealed cerebral and/or cerebellar atrophy in $43 \%$ of the patients ${ }^{160}$, while another study reported a lower frequency of atrophic changes. ${ }^{161}$ Cavitatory leukoencephalopathy has been described in a single patient with the m.8344A>G mutation in MTTK. ${ }^{162}$

\subsubsection{Large $m t D N A$ deletions}

The best-known disorders caused by large single deletions in the mtDNA are Kearns Sayre syndrome (KSS), Pearson Marrow Pancreas syndrome and chronic progressive external ophthalmoplegia (CPEO). Characteristic imaging findings in Kearns Sayre syndrome include symmetric high T2/FLAIR signals in cerebral and cerebellar white 
matter with involvement of the brain stem, globus pallidus and thalamus. ${ }^{163}$ Brain MRI in chronic progressive external ophthalmoplegia patients displayed cerebral atrophy and white matter signal changes. ${ }^{164}$

\section{Role of MRI in Prognosis and Treatment of Mitochondrial Disorders}

Apart from the diagnostic evaluation, MRI provides a useful non-invasive way of assessing the timing, extent, and potential reversibility of neural injury. ${ }^{22}$ Magnetic resonance spectroscopy has also been used to monitor the effect of treatment. ${ }^{17,25}$ Even though most of the imaging studies are based on cross sectional examinations, studies do report on follow up imaging studies. ${ }^{26,60}$ showing that the lesions may remain static, progress to involve more regions or increase in severity or they may also show regression in lesions. Progressive increase in affected areas and increase in rarefaction in follow up MRIs have been demonstrated in patients with mitochondrial leukoencephalopathy secondary to LYRM7 mutations. ${ }^{12}$ Novel imaging techniques have been particularly helpful to monitor the nature and progress of the lesions. ${ }^{165}$ Follow up studies using diffusion weighted imaging and diffusion tensor imaging in a child with mitochondrial leukoencephalopathy, revealed a stroke-like pattern with an initial strong reduction of the ADC followed by elevated values after clinical recovery ${ }^{165}$. Diffusion weighted imaging is particularly helpful to differentiate acute lesions with restricted diffusion from older/chronic lesions in patients with MELAS. 34-36, 166, 167 This is helpful in identifying stroke-like lesions before the onset of episodes clinically. In addition, repeated MRI using DTI may show progressive spread of the cortical lesion to the surrounding cortex for a few weeks, even after the onset of symptoms. An additional diagnostic value of this technique is the observation of lactate accumulation in brain areas that appeared normal on MR images, related to an exacerbation of patient symptoms. None of the patients in remission had a lactate peak demonstrated in the non-affected white matter. This makes ${ }^{1} \mathrm{H}$ MR spectroscopic study a useful investigation of relapse episodes. ${ }^{168}$

Even though there have been major advances in our understanding of the pathophysiology of mitochondrial diseases and diagnosis as outlined above, clinical management of these conditions remains largely supportive. ${ }^{169}$ A systematic Cochrane review found no evidence of an effective intervention for any mitochondrial disorder. ${ }^{170}$ However, there are a few disorders, caused by specific gene defects, which are amenable for specific intervention or prevention. Examples include the biotin thiamine responsive basal ganglia disease due to mutations in $S L C 19 A 3$, riboflavin responsiveness in $A C A D 9$ mutations and CoQ10/idebenone administration to treat 
CoQ10 deficiency. ${ }^{171-173}$ Of these disorders, SLC19A3 is particularly important, since there are fairly specific diagnostic findings on MRI and timely treating can be lifesaving. For the remainder, the major focus currently is on maintaining optimal health by preventing episodic exacerbation during times of physiologic stress and avoiding mitochondrial toxins. ${ }^{174,175}$ A further application of the MRI is the evaluation of the therapeutic intervention after a diagnosis has been made. Magnetic resonance spectroscopy (MRS) is an especially valuable tool in monitoring the therapy. Few studies have utilized MRS to monitor the brain levels of lactate in patients with MELAS and other non-syndromic mitochondrial disorders after therapeutic intervention with oral creatine phosphate ${ }^{176}$, dichloro acetate ${ }^{177}$, ketogenic diet and mitochondrial cocktail ${ }^{178}$. Similarly brain lactate reduction has also been reported in patients with Leigh syndrome after dichloroacetate therapy ${ }^{179}$ MRI has also been helpful in demonstrating that L-arginine infusion at the hyperacute phase protects the prolonged MRI abnormality in MELAS. ${ }^{180}$

The most widely used treatment options employed in mitochondrial disorders are targeted to reduce the oxidative stress and energy failure. Proposed supportive treatments include agents that are used to enhance the respiratory chain function by increasing the substrate delivery (carnitine, niacin, thiamine and the synthetic compound dichloroacetate), agents that enhance electron transfer within the respiratory chain (riboflavin and coenzymeQ10 and the synthetic compound derived from CoQ idebenone and EPI-743). Alternative strategies include biochemical 'bypass' of specific respiratory chain complexes, such as with the use of succinate, vitamin $\mathrm{C}$ and vitamin K and 'energy buffering'. Several promising small molecules have been developed for treatment in mitochondrial disorders. EPI-743 is a vitamin E analogue, which has been tried in mitochondrial disorders. ${ }^{181}$ Initial open label studies with EPI-743 in Leigh syndrome, LHON and other mitochondrial disorders have shown promising results. ${ }^{181-184}$ MRI has not been used for therapy monitoring in these studies. Various other small molecules for treatment currently being evaluated in clinical studies include KH176, MTP-131, RP103, benzafibrate, RG2133, lipoic acid, RTA408 and curcumin. ${ }^{185-187}$

Gene therapy although technically challenging provides new therapeutic options for, including mtDNA and nDNA related primary mitochondrial disorders. The strategies employed for mtDNA related disorder include replacing mutated mtDNA with reconstructed DNA, selective degradation of mutated mtDNA, heteroplasmic shifting by introducing wild-type mtDNA, or the use of restriction endonucleases to eliminate specific mutations in the mtDNA. ${ }^{188,189}$ The transmission of mitochondrial disease, due to inherited nuclear gene mutations can prevented by prenatal diagnosis. For mtDNA mutations, this is more complex. For de novo mutations with low 
recurrence risk, prenatal testing can be offered, whereas for inherited heteroplasmic mutations preimplantation genetic diagnosis (PGD) generally is the best option. Novel assisted reproductive technologies, such as cytoplasmic transfer, germinal vesicle transfer, pronuclear transfer, or spindle transfer are under development in order to prevent transmission for carriers of homoplasmic mtDNA mutations or very high heteroplasmic mutations. ${ }^{190}$

\section{Aims and Outline of the thesis}

Based on available literature, reviewed above, it is evident that major MRI findings in mitochondrial disorders can be grouped into, deep gray matter lesions suggestive of Leigh and Leigh-like syndrome, cavitatory leukoencephalopathy and stroke-likelesions and atrophic changes. Table 1 summarizes the major imaging findings and the underlying genetic defect. Stroke-like episodes were only observed, when genetic defects occurred in mtDNA replication and translation, but overlap existed among the other categories. Presumed, convergence at the level of neuroimaging in patients with heterogeneous clinical, biochemical and genetic findings is depicted in Fig.1-4, showing MRI characteristics of mitochondrial disease, but it is obvious that more detailed studies are required to elucidate further genotype-phenotype correlations.

There has been a remarkable growth in genomics-based diagnosis and development of new and promising therapeutic strategies in the field of mitochondrial medicine. The past decade also has witnessed a substantial advance in brain imaging and its application in human diseases. Imaging and genetic studies have been the main stay in the investigation of many mitochondrial disorders. "Imaging genetics" has emerged as an important research frontier to identify and characterize genetic variants that influence the anatomical or functional brain imaging findings in patients with psychiatric and neurological disorders. Noninvasive brain imaging techniques provide an objective and reproducible way of grouping highly heterogeneous clinical observations and genetic etiologies into the same diagnostic group such as 'Leigh's syndrome' or 'mitochondrial leukoencephalopathies'. Combining the genetic data and neuroimaging phenotype will make imaging a better diagnostic tool for more effective treatment and prognosis definition. Longitudinal neuroimaging follow-up data will be valuable in characterizing and defining prognosis in mitochondrial diseases. As more and more genetic etiologies are defined neuroimaging findings can be better utilized to understand the prognosis and effectively monitor the therapeutic efficacy over time 
Table 1: MR imaging findings and genotype correlations in mitochondrial disorders

\begin{tabular}{|c|c|c|c|}
\hline Classification & $\begin{array}{l}\text { MRI finding Leigh \& } \\
\text { Leigh-like syndrome }\end{array}$ & Leukoencephalopathy & $\begin{array}{l}\text { Stroke-Like } \\
\text { lesions }\end{array}$ \\
\hline \multicolumn{4}{|c|}{ Nuclear DNA mutations } \\
\hline \multicolumn{4}{|l|}{ Complex 1} \\
\hline Structural Subunits & $\begin{array}{l}\text { NDUFA2, NDUFA4, } \\
\text { NDUFA9, NDUFA10, } \\
\text { NDUFA12, NDUFS1, } \\
\text { NDUFS2, NDUFS3, } \\
\text { NDUFS4, NDUFS7, } \\
\text { NDUFS8, NDUFV1 }\end{array}$ & $\begin{array}{l}\text { NDUFS1, NDUFV1 } \\
\text { NDUFS8, NDUFAF3 }\end{array}$ & - \\
\hline Assembly factors & $\begin{array}{l}\text { NDUFAF2, NDUFAF5, } \\
\text { NDUFAF6, FOXRED1 }\end{array}$ & NUBPL & - \\
\hline \multicolumn{4}{|l|}{ Complex II } \\
\hline Structural Subunits & SDHA & SDHA, SDHB & - \\
\hline Assembly factors & SDHAF1 & SDHAF1 & \\
\hline \multicolumn{4}{|l|}{ Complex III } \\
\hline Structural Subunits & - & - & \\
\hline Assembly factors & TTC19, BCS1L & LYRM7 & \\
\hline \multicolumn{4}{|l|}{ Complex IV } \\
\hline Structural Subunits & - & - & \\
\hline Assembly factors & $\begin{array}{l}\text { COX10, COX15, } \\
\text { SURF1, SCO2, PET100 }\end{array}$ & $\begin{array}{l}\text { SURF1, COX10, COX6B1, } \\
\text { COA7 }\end{array}$ & \\
\hline \multicolumn{4}{|c|}{ Nuclear DNA mutations } \\
\hline \multicolumn{4}{|l|}{ Complex V } \\
\hline Structural Subunits & - & & \\
\hline Assembly factors & - & & \\
\hline \multicolumn{4}{|l|}{$\begin{array}{l}\text { Multiple complex } \\
\text { deficiencies }\end{array}$} \\
\hline $\begin{array}{l}\text { Mitochondrial translat } \\
\text { disorders }\end{array}$ & $\begin{array}{l}\text { LRPPRC, C12orf65, } \\
\text { GFM1, IARS2, } \\
\text { MTFMT, TACO1, } \\
\text { TRMU, TSFM, FARS2, } \\
\text { EFG1 }\end{array}$ & $\begin{array}{l}\text { TACO1, APOPT1, } \\
\text { DARS2, EARS2, DARS, } \\
\text { RARS, AIMP1, AARS2, } \\
\text { MARS2, EFTu }\end{array}$ & \\
\hline
\end{tabular}


Chapter 1

Table 1 continued

\begin{tabular}{|c|c|c|c|}
\hline Classification & $\begin{array}{l}\text { MRI finding Leigh \& } \\
\text { Leigh-like syndrome }\end{array}$ & Leukoencephalopathy & $\begin{array}{l}\text { Stroke-Like } \\
\text { lesions }\end{array}$ \\
\hline $\begin{array}{l}\text { Mitochondrial DNA } \\
\text { maintenance \& } \\
\text { Replication }\end{array}$ & SUCLG1, SUCLA2 & $\begin{array}{l}\text { TYMP, RRM2B, POLG, } \\
\text { MPV17 }\end{array}$ & $\begin{array}{l}\text { POLG, TK2, } \\
\text { TWINKLE }\end{array}$ \\
\hline Others & $\begin{array}{l}\text { HIBCH, ECHS1, } \\
\text { SERAC1, FBXL4 }\end{array}$ & $\begin{array}{l}\text { NFU1 }{ }^{125}, \text { BOLA3 }{ }^{119},{ }^{126} \\
\text { LIAS }^{126} \text { IBA57 } 7^{127} \text { GLRX5 } \\
{ }^{126}, \text { HIBCH }\end{array}$ & \\
\hline \multicolumn{4}{|c|}{ Primary mtDNA Mutations } \\
\hline tRNA mutations & $\begin{array}{l}\text { MT-TI, MT-TK, MT- } \\
\text { TW, MT-TV, MT-TL1 }\end{array}$ & MT-TK & MT-TLI,MT-TH \\
\hline Structural subunits & $\begin{array}{l}\text { ND1, ND2, ND3, ND4, } \\
\text { ND5, ND6, } \\
\text { COXIII,ATP6 }\end{array}$ & & ND1, ND5, ND6 \\
\hline tDNA Rearrangements & - & Single deletions & - \\
\hline
\end{tabular}




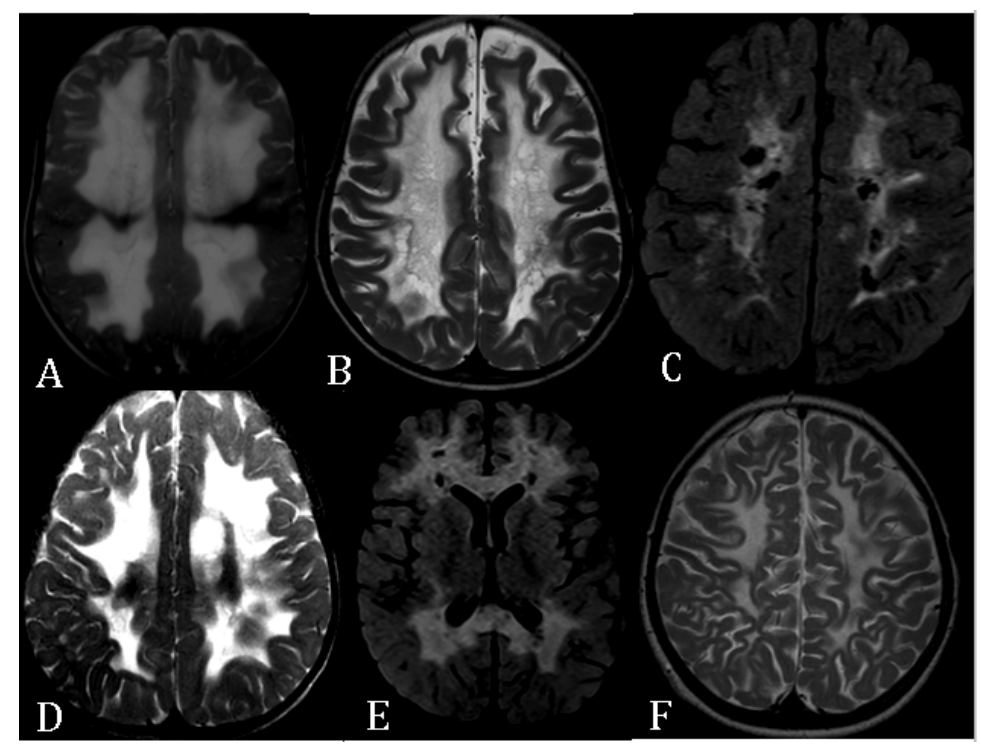

Fig.1 Mitochondrial Leukoencephalopathy in patients with different genetic etiologies

A. T2W MRI in a 2 year old boy with a compound heterozygous mutation (c.1324C>C/T, + c.236A>A/C) in NDUFS1

B. T2W MRI in a 3 year old girl with homozygous mutation (c.2032T>G, p. Tyr678Asp) in NDUFS2

C. T2 FLAIR MRI in 6 year old girl with homozygous mutation (c.1156C>T, p. Arg386Cys) in NDUFV1

D. T2W MRI in a 3 year old girl with a homozygous mutation (c.295C >T, p.R99W ) in BOLA3

E. T2 FLAIR image in a 3 year old girl with homozygous mutation (c.2T>C, p.M1T) in LYRM7

F. T2W MRI in a 10 year old girl with a homozygous mutation (c.148C>T,p.Arg50 Trp) in MPV17

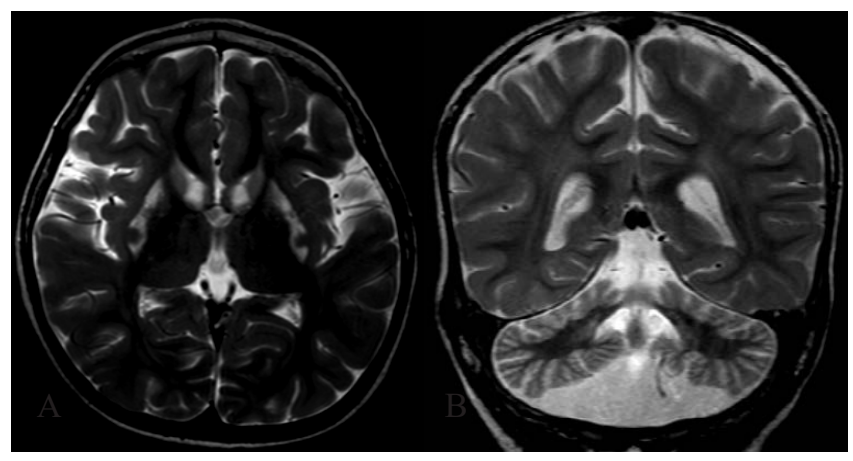

Fig.2 MRI in a 2 year old child with MEDGEL syndrome and homozygous mutation [c.442C>T,p.R148Ter] in SERAC1. A.T2W axial image showing bilateral symmetrical signal changes in putamen with a characteristic sparing in the middorsal part giving rise to "putaminal eye" B.T2W coronal sequence demonstrates cerebellar atrophy 


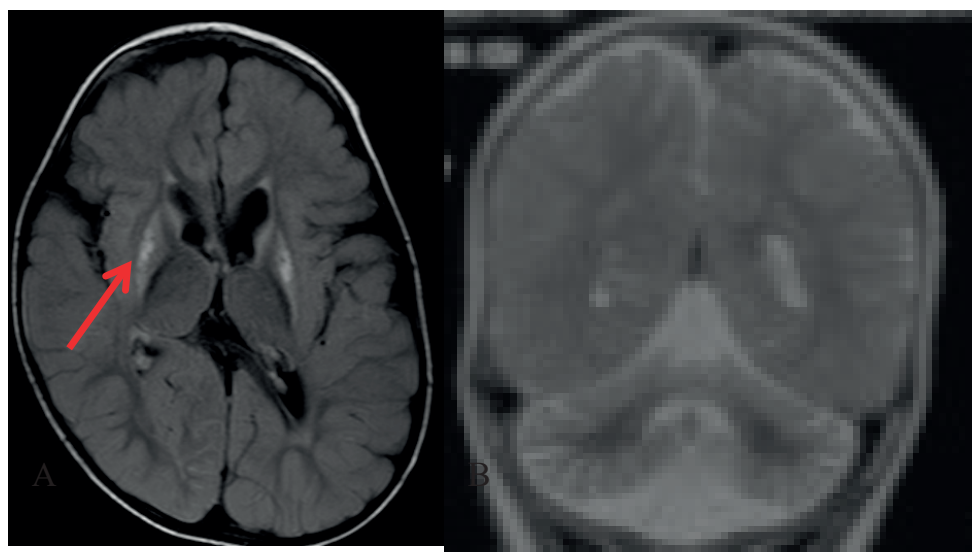

Fig.3 MRI brain in 2 year old boy with Leigh like syndrome, methyl malonic aciduria and deafness with a homozygous mutation in SUCLA2. A.T2W axial view shows bilateral symmetrical signal changes in putamen B.T2W coronal view shows cerebellar atrophy

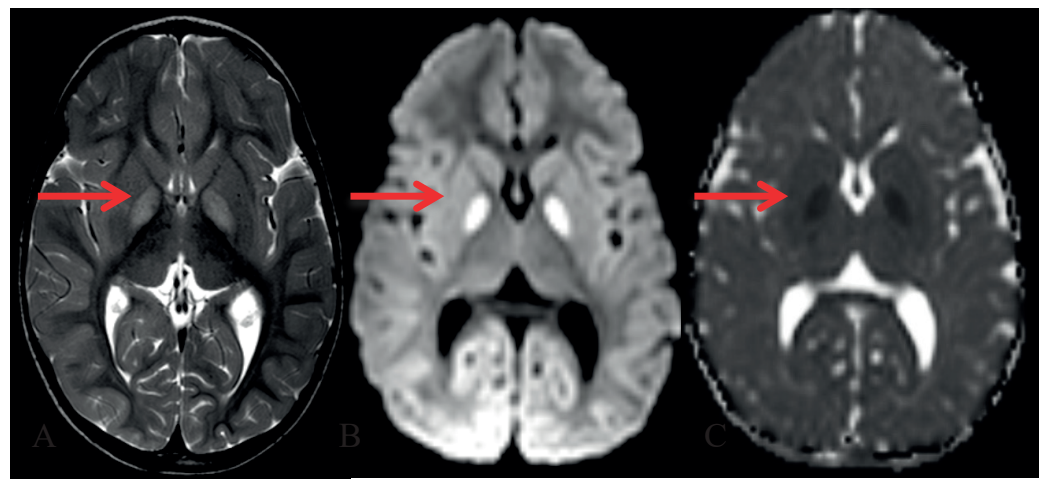

Fig.4 MRI brain in a 2 year old boy with paroxysmal exercise induced dystonia, leigh like syndrome and compound heterozygous mutations in the ECHS1 gene. (5' splice site variation, c.619+1delG \& a missense variation c.463G $>$ A (p.Gly155Ser) in exon 4. A:T2W axial image showing bilateral symmetrical signal changes in globus pallidi. B\&C: Diffusion weighted imaging and ADC maps demonstrating restricted diffusion in globus pallidi.

From the current literature, it is evident that even though there has been a tremendous advancement in the molecular diagnosis of patients with mitochondrial disorders, many areas remain unexplored especially in central nervous system imaging. Though pattern recognition has been attempted in some of the mitochondrial leukoencephalopathies, literature on comprehensive neuroimaging studies in large cohorts and phenotype genotype correlations is sparse. Many of them are cross sectional studies and follow up imaging data are not reported. An important question faced by the treating physician is whether the prognosis of mitochondrial disorders 
can be predicted based on different imaging phenotypes. There are only very limited studies which have attempted correlation of prognosis and the imaging findings. In a study on Leigh's syndrome, it was shown that the presence of brain stem lesions decided a rapidly progressive course and mortality. ${ }^{162}$ The other large group of paediatric mitochondrial disorders, mitochondrial leukoencephalopathy also pose a challenge in terms of prognostication. The same genetic mutations have shown to cause diseases with variable clinical course. ${ }^{191}$ It is worthwhile to look for anatomical factors or patterns on MRI, which determine the variable clinical course in diseases caused by the same mutations. More comprehensive and descriptive imaging studies are available to achieve this.

Another avenue, which remained largely unexplored, is the inclusion of MRI studies in natural history studies. Mitochondrial disorders exhibit extreme heterogeneity at all levels of diagnostic evaluation. The severity of the disease and clinical course vary even in patients with same genotype. Lack of natural history studies is an important factor impeding the correct prognostication and counseling in patients with mitochondrial disorders. MRI has an important role in natural history studies because of its non-invasive nature and the ability to define the anatomical pattern of brain injury overtime. This can also define if the clinical findings and the course have anatomical substrates and are correlated. The advantages of the newer imaging techniques to define the metabolic states of the brain and white matter integrity will further enhance its usefulness. It is worthwhile to correlate the clinical course and MRI in addition to the various clinical scales used. Unfortunately the follow up imaging studies are rarely available in patients with mitochondrial disorders even in natural history studies. ${ }^{192}$ Follow up MRI studies in specific subgroup of the patients are required to strengthen the natural history studies.

The presence of neuroinflammation evidenced on MR imaging in patients with mitochondrial leukoencephalopathies requires further exploration. Primary demyelinating disorders and mitochondrial leukoencephalopathies are considered distinct disorders, but may pose diagnostic challenge to clinicians especially in the early stages. The multifocal confluent nature of the white matter lesions, contrast enhancement and diffusion restriction on MRI indicates neuroinflammation. To further support this notion, many of these patients apparently respond to immunomodulation. Follow up studies on mitochondrial leukoencephalopathies have shown that the evidence of inflammation may persist or may disappear. It will be worthwhile to study the inter-relationship between mitochondrial disease and episodic CNS inflammation. It is likely that mitochondrial dysfunction leads to possible immune activation. The role of long-term immunomodulation in the treatment of the inflammatory response is unknown. Comprehensive MRI studies are required in pa- 
tients with mitochondrial leukoencephalopathies to define and ascertain the presence of neuroinflammation in mitochondrial disorders.

Management of mitochondrial disorders is mostly supportive at present, but there are many small molecules, which are under development, which may ultimately become available to the physicians for use. ${ }^{187}$ There are various ways of monitoring the effectiveness of therapy. Most clinical trials use clinical scales including the Newcastle adult and pediatric mitochondrial disease scales. ${ }^{181,182}$ Presence or absence of lactate peak has been used in some studies to monitor the effect of the therapy. When more and more molecules are available for use it becomes imperative to develop tools to objectively assess the effect of the therapy. Two important MRI phenotypes in mitochondrial disorders include Leigh syndrome and leukoencephalopathies. Both the disorders have well defined neuroimaging features though the severity and extent of involvement can vary. Even though there is heterogeneity in biochemical and genetic levels there is convergence at the imaging levels in most of the disorders. For example, presence of multifocal confluent lesions with cavities in the affected white matter, contrast enhancement and presence of lactate peak are common features, which define mitochondrial leukoencephalopathy caused by various rare genetic etiologies. This convergence at the level of magnetic resonance imaging phenotypes is a potential factor, which can be used for monitoring the effect of therapy in a large number of patients with different genetic etiology. It also allows studying the common pathophysiological dysfunction leading to the CNS manifestation and its course.

In conclusion the current data in the arena of neuroimaging in mitochondrial disorders is largely insufficient to address several concerns faced by clinician during evaluation and management of mitochondrial disorders. More comprehensive phenotypic analysis and follow up of patients to define the course, prognosis and natural history are required. MRI, being the most easily available tool to investigate the presence of central nervous system lesions needs to be utilized further in prognostication and therapy monitoring. This is also essential to translate the great advancement in the field of molecular diagnosis to bedside management of the patients. Therefore, the overall aim of the thesis is to correlate magnetic resonance imaging both to genetic defects and disease manifestations, in order to guide the prognosis and therapy. 
Specific aims are

1. To correlate magnetic resonance findings in patients with mitochondrial disorders and peripheral neuropathy with the underlying genetic defect

2. To discriminate mitochondrial disorders from other metabolic disorders by specific imaging findings

3. To apply MRI for predicting prognosis and therapy in specific subsets of patients

In Chapter 1 the current literature on the MR imaging findings is reviewed in relation to the underlying genetic defect and accompanying biochemical or other abnormalities. Several areas remain unexplored with respect to the central nervous system imaging in patients with mitochondrial disorders. Comprehensive studies describing the neuroimaging findings in large cohorts with genotype phenotype correlations are limited, necessitating further studies in this field. There is sparse literature on the role of magnetic resonance imaging in prognostication and therapy monitoring. Detailed phenotypic analysis is required to define the clinical course and prognosis in mitochondrial disorders. With these shortcomings in mind detailed analyses of three important neurological manifestations in mitochondrial disorders were undertaken. (chapter 2-4). In Chapter 2, comprehensive analysis of the magnetic resonance imaging findings in a cohort of patients with mitochondrial disorders is described. The anatomical patterns of injury in the whole cohort were studied with respect to atrophic changes involving the cerebrum and cerebellum, signal intensity changes in the basal ganglia, brainstem, white matter, spinal cord and cerebral cortex. Analysis of special sequences were done in a number of patients including, magnetic resonance spectroscopy (MRS), diffusion weighted imaging (DWI) and susceptibility weighted imaging (SWI) so as to understand the metabolic status and pathophysiological process underlying the MRI changes. Finally, MRI findings in three important genotypes were separately analyzed to identify specific correlations with the clinical course. Next, in chapter 3 , the genetic basis of peripheral neuropathy in mitochondrial disorders was studied. Detailed analysis of the clinical and electrophysiological characteristics of peripheral neuropathy in three important genetic groups were analyzed and correlations were established. Apart from correlating MRI data to the genetic cause in mitochondrial disease, we investigated the specificity of the MRI data for mitochondrial disorders compared to other metabolic disorders, focusing on hypertrophic olivary degeneration (Chapter 4) This was studied in a large cohort of 125 children with different neurometabolic disorders. Routine MRI sequences (T1 weighted, T2-weighted and fluid attenuated inversion recovery sequences) were analyzed for the presence of bilateral symmetrical olivary nucleus hypertrophy and central tegmental tract or dentate nucleus signal changes. 
Specifically, we examined whether the presence of hypertrophic olivary degeneration on MRI could differentiate mitochondrial disorders especially Leigh and Leighlike syndrome from other neurometabolic disorders in children. Finally, in Chapter 5, the prognostic and therapeutic significance of phenotype, genotype and MRI findings in patients with mitochondrial epilepsy were studied. This study specifically examined if there were anatomical correlates on MRI in patients with mitochondrial epilepsy which can predict the course and therapeutic response. In Chapter 6 we analyzed the clinical course and MRI findings in a cohort of children with mitochondrial leukoencephalopathy with special reference to evidence of immunological dysfunction. The study examined the clinical and MRI factors which differentiates mitochondrial leukoencephalopathies from an acquired demyelinating syndrome and also brought out the response to immunomodulation. In Chapter 7 the findings of these studies are discussed in a broader perspective of application in the clinical practice and future research. 


\section{References}

1. Cassis L, Cortes-Saladelafont E, Molero-Luis M, et al., Review and evaluation of the methodological quality of the existing guidelines and recommendations for inherited neurometabolic disorders. Orphanet J Rare Dis 2015;10:164.

2. van Karnebeek CD, Shevell M, Zschocke J, Moeschler JB, Stockler S. The metabolic evaluation of the child with an intellectual developmental disorder: diagnostic algorithm for identification of treatable causes and new digital resource. Mol Genet Metab 2014;111:428-438.

3. van Karnebeek CD, Stockler S. Treatable inborn errors of metabolism causing intellectual disability: a systematic literature review. Mol Genet Metab 2012;105:368-381.

4. Gropman AL. Patterns of brain injury in inborn errors of metabolism. Semin Pediatr Neurol 2012;19:203-210.

5. Tang S, Wang J, Zhang VW, et al., Transition to next generation analysis of the whole mitochondrial genome: a summary of molecular defects. Hum Mutat 2013;34:882-893.

6. Barkovich AJ. An approach to MRI of metabolic disorders in children. J Neuroradiol 2007;34:75-88.

7. van der Knaap MS, Valk J, de Neeling N, Nauta JJ. Pattern recognition in magnetic resonance imaging of white matter disorders in children and young adults. Neuroradiology 1991;33:478-493.

8. van der Knaap MS VJ. Magnetic Resonance of Myelin, Myelination and Myelin Disorders. erlin, Germany: Springer; 1995.

9. van der Knaap MS, Breiter SN, Naidu S, Hart AA, Valk J. Defining and categorizing leukoencephalopathies of unknown origin: MR imaging approach. Radiology 1999; 213:121-133.

10. Steenweg ME, Ghezzi D, Haack T, et al., Leukoencephalopathy with thalamus and brainstem involvement and high lactate 'LTBL' caused by EARS2 mutations. Brain 2012; 135(Pt 5):1387-1394.

11. Kevelam SH RR, Wolf NI, Ferreira P, Lunsing RJ, Nijtmans LG, Mitchell A AH, Rating D, Vanderver A, van Berkel CG, Abbink TE, Heutink P vdKM. NUBPL mutations in patients with complex I deficiency and a distinct MRI pattern. Neurology 2013;80:1577-1583.

12. Dallabona C, Abbink TE, Carrozzo R, et al., LYRM7 mutations cause a multifocal cavitating leukoencephalopathy with distinct MRI appearance. Brain 2016;139(Pt 3):782-794.

13. Kevelam SH, Steenweg ME, Srivastava S, et al., Update on Leukodystrophies: A Historical Perspective and Adapted Definition. Neuropediatrics 2016;47;349-354

14. Longo MG, Vairo F, Souza CF, Giugliani R, Vedolin LM. Brain imaging and genetic risk in the pediatric population, part 1: inherited metabolic diseases. Neuroimaging Clin N Am 2015;25:31-51.

15. Skladal D, Halliday J, Thorburn DR. Minimum birth prevalence of mitochondrial respiratory chain disorders in children. Brain 2003;126(Pt 8):1905-1912.

16. Mayr JA, Haack TB, Freisinger P, et al., Spectrum of combined respiratory chain defects. J Inherit Metab Dis 2015;38:629-640.

17. Haas RH, Parikh S, Falk MJ, et al., The in-depth evaluation of suspected mitochondrial disease. Mol Genet Metab 2008;94:16-37.

18. Wortmann SB, Koolen DA, Smeitink JA, van den Heuvel L, Rodenburg RJ. Whole exome sequencing of suspected mitochondrial patients in clinical practice. J inherit Metab Dis 2015;38:437-443.

19. Bricout M, Grevent D, Lebre AS, et al., Brain imaging in mitochondrial respiratory chain deficiency: combination of brain MRI features as a useful tool for genotype/phenotype correlations. J Med Genet 2014;51:429-435.

20. Saneto RP, Friedman SD, Shaw DW. Neuroimaging of mitochondrial disease. Mitochondrion 2008;8:396-413.

21. Finsterer J. Central Nervous System Imaging in Mitochondrial Disorders. Can J Neurol Sci 2009; 36:143-153. 


\section{Chapter 1}

22. Friedman SD, Shaw DW, Ishak G, Gropman AL, Saneto RP. The use of neuroimaging in the diagnosis of mitochondrial disease. Dev Disabil Res Rev 2010;16:129-135.

23. Gropman AL. Neuroimaging in mitochondrial disorders. Neurotherapeutics 2013;10:273-285.

24. Barkovich AJ, Good WV, Koch TK, Berg BO. Mitochondrial disorders: analysis of their clinical and imaging characteristics. AJNR. Am J Neuroradiol 1993;14:1119-1137.

25. Haas R, Dietrich R. Neuroimaging of mitochondrial disorders. Mitochondrion 2004;4:471-490.

26. Sofou K, Steneryd K, Wiklund LM, Tulinius M, Darin N. MRI of the brain in childhood-onset mitochondrial disorders with central nervous system involvement. Mitochondrion 2013;13:364-371.

27. Lebre AS, Rio M, Faivre d'Arcier L, et al., A common pattern of brain MRI imaging in mitochondrial diseases with complex I deficiency. J Med Genet 2011;48:16-23.

28. Lake NJ, Compton AG, Rahman S, Thorburn DR. Leigh syndrome: One disorder, more than 75 monogenic causes. Ann Neurol 2016;79:190-203.

29. Rahman S, Blok RB, Dahl HH, et al., Leigh syndrome: clinical features and biochemical and DNA abnormalities. Ann Neurol 1996;39:343-351.

30. Finsterer J. Leigh and Leigh-like syndrome in children and adults. Pediatr Neurol 2008;39:223-235.

31. Melchionda L, Haack TB, Hardy S, et al., Mutations in APOPT1, encoding a mitochondrial protein, cause cavitating leukoencephalopathy with cytochrome c oxidase deficiency. Am J Hum Genet 2014;95:315-325.

32. Naidu S, Bibat G, Lin D, et al., Progressive cavitating leukoencephalopathy: a novel childhood disease. Ann Neurol 2005;58:929-938.

33. Iizuka T, Sakai F, Suzuki N, et al., Neuronal hyperexcitability in stroke-like episodes of MELAS syndrome. Neurology 2002;59:816-824.

34. Iizuka T, Sakai F, Kan S, Suzuki N. Slowly progressive spread of the stroke-like lesions in MELAS. Neurology 2003;61:1238-1244.

35. Ito H, Mori K, Harada M, et al., Serial brain imaging analysis of stroke-like episodes in MELAS. Brain Dev 2008;30:483-488.

36. Ito H, Mori K, Kagami S. Neuroimaging of stroke-like episodes in MELAS. Brain Dev 2011;33:283288.

37. Wang Z, Qi XK, Yao S, et al., Phenotypic patterns of MELAS/LS overlap syndrome associated with m.13513G>A mutation, and neuropathological findings in one autopsy case. Neuropathology 2010; 30:606-614.

38. Tzoulis C, Neckelmann G, Mork SJ, et al., Localized cerebral energy failure in DNA polymerase gamma-associated encephalopathy syndromes. Brain 2010;133(Pt 5):1428-1437.

39. Lonnqvist T, Paetau A, Valanne L, Pihko H. Recessive twinkle mutations cause severe epileptic encephalopathy. Brain 2009; 132(Pt 6): 1553-1562.

40. Gotz A, Isohanni P, Pihko $\mathrm{H}$, et al., Thymidine kinase 2 defects can cause multi-tissue mtDNA depletion syndrome. Brain 2008; 131(Pt 11): 2841-2850.

41. Mollet J, Delahodde A, Serre V, et al., CABC1 gene mutations cause ubiquinone deficiency with cerebellar ataxia and seizures. Am J Hum Genet 2008;82:623-630.

42. Kim J, Lee SK, Kim EY, et al., Neuroradiologic findings in children with mitochondrial disorder: correlation with mitochondrial respiratory chain defects. Eur Radiol 2008; 18(8):1741-1748.

43. Ferrari G, Lamantea E, Donati A, et al., Infantile hepatocerebral syndromes associated with mutations in the mitochondrial DNA polymerase-gammaA. Brain 2005; 128(Pt 4): 723-731.

44. Scaglia F, Wong LJ, Vladutiu GD, Hunter JV. Predominant cerebellar volume loss as a neuroradiologic feature of pediatric respiratory chain defects. AJNR. Am J Neuroradiol. 2005;26: 1675-1680.

45. Lamperti C, Naini A, Hirano M, et al., Cerebellar ataxia and coenzyme Q10 deficiency. Neurology 2003;60: 1206-1208. 
46. de Koning TJ, de Vries LS, Groenendaal F, et al., Pontocerebellar hypoplasia associated with respiratory-chain defects. Neuropediatrics 1999;30:93-95.

47. Cassandrini D, Cilio MR, Bianchi M, et al., Pontocerebellar hypoplasia type 6 caused by mutations in RARS2: definition of the clinical spectrum and molecular findings in five patients. J Inherit Metab Dis 2013;36:43-53.

48. Renard D, Campello C, Le Floch A, Castelnovo G, Taieb G. Globus pallidus and substantia nigra hypointensities on T2-weighted imaging in MELAS. J Neurol 2012;259:2720-2722.

49. Souza PV, Pinto WB, Oliveira AS. Teaching NeuroImages: Longitudinally extensive transverse myelitis in MELAS. Neurology. 2016;86:e37.

50. Jaros E, Mahad DJ, Hudson G, et al., Primary spinal cord neurodegeneration in Leber hereditary optic neuropathy. Neurology 2007;69:214-216.

51. Fassone E, Rahman S. Complex I deficiency: clinical features, biochemistry and molecular genetics. J Med Genet 2012;49:578-590.

52. Koene S, Rodenburg RJ, van der Knaap MS, et al., Natural disease course and genotype-phenotype correlations in Complex I deficiency caused by nuclear gene defects: what we learned from 130 cases. J Inherit Metab Dis 2012;35:737-747.

53. Gerards M, Sallevelt SC, Smeets HJ. Leigh syndrome: Resolving the clinical and genetic heterogeneity paves the way for treatment options. Mol Genet Metab 2016;117:300-312.

54. Barghuti F, Elian K, Gomori JM, et al., The unique neuroradiology of complex I deficiency due to NDUFA12L defect. Mol Genet Metab 2008;94:78-82.

55. Herzer M, Koch J, Prokisch H, et al., Leigh disease with brainstem involvement in complex I deficiency due to assembly factor NDUFAF2 defect. Neuropediatrics 2010;41:30-34.

56. Bjorkman K, Sofou K, Darin N, et al., Broad phenotypic variability in patients with complex I deficiency due to mutations in NDUFS1 and NDUFV1. Mitochondrion 2015;21:33-40.

57. Calvo SE, Tucker EJ, Compton AG, et al., High-throughput, pooled sequencing identifies mutations in NUBPL and FOXRED1 in human complex I deficiency. Nat Genet 2010;42(10):851-858.

58. Saada A, Vogel RO, Hoefs SJ, et al., Mutations in NDUFAF3 (C3ORF60), encoding an NDUFAF4 (C6ORF66)-interacting complex I assembly protein, cause fatal neonatal mitochondrial disease. Am J Hum Genet 2009;84:718-727.

59. Ogilvie I, Kennaway NG, Shoubridge EA. A molecular chaperone for mitochondrial complex I assembly is mutated in a progressive encephalopathy. J Clinic Invest 2005;115:2784-2792.

60. Zafeiriou DI, Rodenburg RJ, Scheffer H, et al., MR spectroscopy and serial magnetic resonance imaging in a patient with mitochondrial cystic leukoencephalopathy due to complex I deficiency and NDUFV1 mutations and mild clinical course. Neuropediatrics 2008;39:172-175.

61. Pagniez-Mammeri H, Landrieu P, Legrand A, Slama A. Leukoencephalopathy with vanishing white matter caused by compound heterozygous mutations in mitochondrial complex I NDUFS1 subunit. Mol Genet Metab 2010;101:297-298.

62. Tenisch EV LA, Gre'vent D, Lonlay $\mathrm{P}$, et al., Massive and exclusive pontocerebellar damage in mitochondrial disease and NUBPL mutations. Neurology 2012;79:391.;79:391.

63. Jain-Ghai S, Cameron JM, Al Maawali A, et al., Complex II deficiency--a case report and review of the literature. Am J Med Genet A 2013;161a:285-294.

64. Helman G, Caldovic L, Whitehead MT, et al., Magnetic resonance imaging spectrum of succinate dehydrogenase-related infantile leukoencephalopathy. Ann Neurol 2016;79:379-386.

65. Ohlenbusch A, Edvardson S, Skorpen J, et al., Leukoencephalopathy with accumulated succinate is indicative of SDHAF1 related complex II deficiency. Orphanet J Rare Dis 2012;7:69.

66. Alston CL, Davison JE, Meloni F, et al., Recessive germline SDHA and SDHB mutations causing leukodystrophy and isolated mitochondrial complex II deficiency. J Med Genet 2012;49:569-577. 


\section{Chapter 1}

67. Bourgeron $\mathrm{T}$, Rustin $\mathrm{P}$, Chretien $\mathrm{D}$, et al., Mutation of a nuclear succinate dehydrogenase gene results in mitochondrial respiratory chain deficiency. Nat. Genet 1995;11:144-149.

68. Taylor RW, Birch-Machin MA, Schaefer J, et al., Deficiency of complex II of the mitochondrial respiratory chain in late-onset optic atrophy and ataxia. Ann Neurol 1996;39:224-232.

69. Sonam K, Bindu PS, Taly AB, et al., Mitochondrial myopathy, cardiomyopathy, and pontine signal changes in an adult patient with isolated complex II deficiency. J Clin Neuromuscul Dis 2014;16:6973.

70. Benit P, Lebon S, Rustin P. Respiratory-chain diseases related to complex III deficiency. Biochim Biophys Acta 2009;1793:181-185.

71. Ghezzi D, Arzuffi P, Zordan M, et al., Mutations in TTC19 cause mitochondrial complex III deficiency and neurological impairment in humans and flies. Nat Genet 2011;43:259-263.

72. Miyake N, Yano S, Sakai C, et al., Mitochondrial complex III deficiency caused by a homozygous UQCRC2 mutation presenting with neonatal-onset recurrent metabolic decompensation. Hum $\mathrm{Mu}-$ tat 2013;34:446-452.

73. Invernizzi F, Tigano M, Dallabona C, et al., A homozygous mutation in LYRM7/MZM1L associated with early onset encephalopathy, lactic acidosis, and severe reduction of mitochondrial complex III activity. Hum Mutat 2013;34:1619-1622.

74. de Lonlay P, Valnot I, Barrientos A, et al., A mutant mitochondrial respiratory chain assembly protein causes complex III deficiency in patients with tubulopathy, encephalopathy and liver failure. Nat Genet 2001;29:57-60.

75. Atwal PS. Mutations in the Complex III Assembly Factor Tetratricopeptide 19 Gene TTC19 Are a Rare Cause of Leigh Syndrome. JIMD Rep 2014;14:43-45.

76. Nogueira C, Barros J, Sa MJ, et al., Novel TTC19 mutation in a family with severe psychiatric manifestations and complex III deficiency. Neurogenetics 2013;14:153-160.

77. Kunii M, Doi H, Higashiyama Y, et al., A Japanese case of cerebellar ataxia, spastic paraparesis and deep sensory impairment associated with a novel homozygous TTC19 mutation. J Hum Genet 2015;60:187-191.

78. Morino H, Miyamoto R, Ohnishi S, Maruyama H, Kawakami H. Exome sequencing reveals a novel TTC19 mutation in an autosomal recessive spinocerebellar ataxia patient. BMC Neurol 2014;14:5.

79. Melchionda L, Damseh NS, Abu Libdeh BY, et al., A novel mutation in TTC19 associated with isolated complex III deficiency, cerebellar hypoplasia, and bilateral basal ganglia lesions. Front Genet 2014;5:397.

80. Ardissone A, Granata T, Legati A, et al., Mitochondrial Complex III Deficiency Caused by TTC19 Defects: Report of a Novel Mutation and Review of Literature. JIMD Rep 2015; 22:115-120.

81. Fernandez-Vizarra E, Bugiani M, Goffrini P, et al., Impaired complex III assembly associated with BCS1L gene mutations in isolated mitochondrial encephalopathy. Hum Mol Genet. 2007;16:12411252.

82. Fernandez-Vizarra E, Tiranti V, Zeviani M. Assembly of the oxidative phosphorylation system in humans: what we have learned by studying its defects. Biochim Biophys Acta 2009;1793:200-211.

83. Tiranti V, Hoertnagel K, Carrozzo R, et al., Mutations of SURF-1 in Leigh disease associated with cytochrome c oxidase deficiency. Am J Hum Genet. 1998;63: 1609-1621.

84. Sonam K, Khan NA, Bindu PS, et al., Clinical and magnetic resonance imaging findings in patients with Leigh syndrome and SURF1 mutations. Brain Dev. 2014; 36:807-812.

85. Farina L, Chiapparini L, Uziel G, Bugiani M, Zeviani M, Savoiardo M. MR findings in Leigh syndrome with COX deficiency and SURF-1 mutations. AJNR. Am J Nneuroradiol 2002; 23:1095-1100.

86. Xie S, Xiao JX, Qi ZY, Yang YL, Jiang XX. Heterogeneity of magnetic resonance imaging in Leigh syndrome with SURF1 gene 604G-->C mutation. Clin Imaging 2009; 33:1-6. 
87. Rahman S, Brown RM, Chong WK, Wilson CJ, Brown GK. A SURF1 gene mutation presenting as isolated leukodystrophy. Ann Neurol 2001; 49:797-800.

88. Timothy J, Geller T. SURF-1 gene mutation associated with leukoencephalopathy in a 2-year-old. J Child Neurol 2009;24:1296-1301.

89. Seeger J, Schrank B, Pyle A, et al., Clinical and neuropathological findings in patients with TACO1 mutations. Neuromuscul Disord 2010; 20:720-724.

90. Weraarpachai W, Antonicka H, Sasarman F, et al., Mutation in TACO1, encoding a translational activator of COX I, results in cytochrome c oxidase deficiency and late-onset Leigh syndrome. Nat Genet 2009; 41:833-837.

91. Antonicka H, Leary SC, Guercin GH, et al., Mutations in COX10 result in a defect in mitochondrial heme A biosynthesis and account for multiple, early-onset clinical phenotypes associated with isolated COX deficiency. Hum Mol Genet 2003;12:2693-2702.

92. Massa V, Fernandez-Vizarra E, Alshahwan S, et al., Severe infantile encephalomyopathy caused by a mutation in COX6B1, a nucleus-encoded subunit of cytochrome c oxidase. Am J Hum Genet 2008;82:1281-1289.

93. Jaksch M, Ogilvie I, Yao J, et al., Mutations in SCO2 are associated with a distinct form of hypertrophic cardiomyopathy and cytochrome c oxidase deficiency. Hum Mol Genet 2000; 9:795-801.

94. Joost K, Rodenburg R, Piirsoo A, van den Heuvel B, Zordania R, Ounap K. A novel mutation in the SCO2 gene in a neonate with early-onset cardioencephalomyopathy. Pediatr Neurol 2010; 42:227230.

95. Mootha VK, Lepage P, Miller K, et al., Identification of a gene causing human cytochrome c oxidase deficiency by integrative genomics. Proc Natl Acad Sci USA 2003;100:605-610.

96. Olahova M, Hardy SA, Hall J, et al., LRPPRC mutations cause early-onset multisystem mitochondrial disease outside of the French-Canadian population. Brain 2015;138(Pt 12):3503-3519.

97. Martinez Lyons A, Ardissone A, Reyes A, et al., COA7 (C1orf163/RESA1) mutations associated with mitochondrial leukoencephalopathy and cytochrome c oxidase deficiency. J Med Genet 2016;53:846849

98. Hejzlarova K, Mracek T, Vrbacky M, et al., Nuclear genetic defects of mitochondrial ATP synthase. Physiol Res 2014;63 Suppl 1:S57-71.

99. Tzoulis C, Engelsen BA, Telstad W, et al., The spectrum of clinical disease caused by the A467T and W748S POLG mutations: a study of 26 cases. Brain 2006;129(Pt 7):1685-1692.

100. Horvath R, Hudson G, Ferrari G, et al., Phenotypic spectrum associated with mutations of the mitochondrial polymerase gamma gene. Brain 2006;129(Pt 7):1674-1684.

101. Nagappa M, Bindu PS, Taly AB, et al., Palatal Tremor in POLG-Associated Ataxia. Mov Disord Clin Pract. 2015;2:318-320.

102. Mauro Scarpelli GKR, Alberto Beltramello A, Isabella Zocca FC, et al.,The Role of Brain MRI in Mitochondrial Neurogastrointestinal Encephalomyopathy. Neuroradiol J 2013;26:520-530.

103. Carrozzo R, Dionisi-Vici C, Steuerwald U, et al., SUCLA2 mutations are associated with mild methylmalonic aciduria, Leigh-like encephalomyopathy, dystonia and deafness. Brain 2007;130(Pt 3):862-874.

104. Trinh BC, Melhem ER, Barker PB. Multi-slice proton MR spectroscopy and diffusion-weighted imaging in methylmalonic acidemia: report of two cases and review of the literature. AJNR. Am J Neuroradiol 2001;22:831-833.

105. Valente L, Tiranti V, Marsano RM, et al., Infantile encephalopathy and defective mitochondrial DNA translation in patients with mutations of mitochondrial elongation factors EFG1 and EFTu. Am J Hum Genet 2007;80:44-58. 


\section{Chapter 1}

106. Simons C, Griffin LB, Helman G, et al., Loss-of-function alanyl-tRNA synthetase mutations cause an autosomal-recessive early-onset epileptic encephalopathy with persistent myelination defect. Am J Hum Genet 2015;96:675-681.

107. van Berge L, Hamilton EM, Linnankivi T, et al., Leukoencephalopathy with brainstem and spinal cord involvement and lactate elevation: clinical and genetic characterization and target for therapy. Brain 2014;137(Pt 4):1019-1029.

108. Serkov SV, Pronin IN, Bykova OV, et al., Five patients with a recently described novel leukoencephalopathy with brainstem and spinal cord involvement and elevated lactate. Neuropediatrics 2004;35:1-5.

109. Taft RJ, Vanderver A, Leventer RJ, et al., Mutations in DARS cause hypomyelination with brain stem and spinal cord involvement and leg spasticity. Am J Hum Genet 2013;92:774-780.

110. Wolf NI, Toro C, Kister I, et al., DARS-associated leukoencephalopathy can mimic a steroidresponsive neuroinflammatory disorder. Neurology 2015;84:226-230.

111. Wolf NI, Salomons GS, Rodenburg RJ, et al., Mutations in RARS cause hypomyelination. Ann Neurol 2014;76:134-139.

112. Bayat V, Thiffault I, Jaiswal M, et al., Mutations in the mitochondrial methionyl-tRNA synthetase cause a neurodegenerative phenotype in flies and a recessive ataxia (ARSAL) in humans. PLoS Biol 2012;10:e1001288.

113. Dallabona C, Diodato D, Kevelam SH, et al., Novel (ovario) leukodystrophy related to AARS2 mutations. Neurology 2014;82:2063-2071.

114. Elo JM, Yadavalli SS, Euro L, et al., Mitochondrial phenylalanyl-tRNA synthetase mutations underlie fatal infantile Alpers encephalopathy. Hum Mol Genet 2012;21:4521-4529.

115. Almalki A, Alston CL, Parker A, et al., Mutation of the human mitochondrial phenylalanine-tRNA synthetase causes infantile-onset epilepsy and cytochrome c oxidase deficiency. Biochim Biophys Acta 2014;1842:56-64.

116. Raviglione F, Conte G, Ghezzi D, et al., Clinical findings in a patient with FARS2 mutations and early-infantile-encephalopathy with epilepsy. Am J Med Genet A 2016;170:3004-3007

117. Vernon HJ, McClellan R, Batista DA, Naidu S. Mutations in FARS2 and non-fatal mitochondrial dysfunction in two siblings. Am J Med Genet A 2015;167A:1147-1151.

118. Tucker EJ, Hershman SG, Kohrer C, et al., Mutations in MTFMT underlie a human disorder of formylation causing impaired mitochondrial translation. Cell Metab 2011;14:428-434.

119. Haack TB, Gorza M, Danhauser K, et al., Phenotypic spectrum of eleven patients and five novel MTFMT mutations identified by exome sequencing and candidate gene screening. Mol Genet Metab 2014;111:342-352.

120. Garcia-Diaz B, Barros MH, Sanna-Cherchi S, et al., Infantile encephaloneuromyopathy and defective mitochondrial translation are due to a homozygous RMND1 mutation. Am J Hum Genet 2012;91:729-736.

121. Janer A, van Karnebeek CD, Sasarman F, et al., RMND1 deficiency associated with neonatal lactic acidosis, infantile onset renal failure, deafness, and multiorgan involvement. Eur J Hum Genet 2015;23:1301-1307.

122. Gupta A, Colmenero I, Ragge NK, et al., Compound heterozygous RMND1 gene variants associated with chronic kidney disease, dilated cardiomyopathy and neurological involvement: a case report. BMC Res Notes 2016;9:325.

123. Ng YS, Alston CL, Diodato D, et al., The clinical, biochemical and genetic features associated with RMND1-related mitochondrial disease. J Med Genet 2016.

124. Ravn K, Neland M, Wibrand F, Duno M, Ostergaard E. Hearing impairment and renal failure associated with RMND1 mutations. Am J Med Genet A 2016;170a:142-147. 
125. Invernizzi F, Ardissone A, Lamantea E, et al., Cavitating leukoencephalopathy with multiple mitochondrial dysfunction syndrome and NFU1 mutations. Front Genet. 2014;5:412.

126. Baker PR, 2nd, Friederich MW, Swanson MA, et al., Variant non ketotic hyperglycinemia is caused by mutations in LIAS, BOLA3 and the novel gene GLRX5. Brain 2014;137(Pt 2):366-379.

127. Debray FG, Stumpfig C, Vanlander AV, et al., Mutation of the iron-sulfur cluster assembly gene IBA57 causes fatal infantile leukodystrophy. J Inherit Metab Dis 2015;38:1147-1153.

128. Ferdinandusse S, Waterham HR, Heales SJ, et al., HIBCH mutations can cause Leigh-like disease with combined deficiency of multiple mitochondrial respiratory chain enzymes and pyruvate dehydrogenase. Orphanet J Rare Dis 2013;8:188.

129. Peters H, Buck N, Wanders R, et al., ECHS1 mutations in Leigh disease: a new inborn error of metabolism affecting valine metabolism. Brain 2014;137(Pt 11):2903-2908.

130. Haack TB, Jackson CB, Murayama K, et al., Deficiency of ECHS1 causes mitochondrial encephalopathy with cardiac involvement. Ann Clin Transl 2015;2:492-509.

131. Olgiati S, Skorvanek M, Quadri M, et al., Paroxysmal exercise-induced dystonia within the phenotypic spectrum of ECHS1 deficiency. Mov Disord 2016;31:1041-1048.

132. Wortmann SB, Vaz FM, Gardeitchik T, et al., Mutations in the phospholipid remodeling gene SERAC1 impair mitochondrial function and intracellular cholesterol trafficking and cause dystonia and deafness. Nat Genet 2012;44:797-802.

133. Wortmann SB, van Hasselt PM, Baric I, et al., Eyes on MEGDEL: distinctive basal ganglia involvement in dystonia deafness syndrome. Neuropediatrics 2015;46:98-103.

134. Gai X, Ghezzi D, Johnson MA, et al., Mutations in FBXL4, encoding a mitochondrial protein, cause early-onset mitochondrial encephalomyopathy. Am J Hum Genet 2013;93:482-495.

135. Bonnen PE, Yarham JW, Besse A, et al., Mutations in FBXL4 cause mitochondrial encephalopathy and a disorder of mitochondrial DNA maintenance. Am J Hum Genet 2013;93:471-481.

136. Kirby DM, McFarland R, Ohtake A, et al., Mutations of the mitochondrial ND1 gene as a cause of MELAS. J Med Genet 2004;41:784-789.

137. Liolitsa D, Rahman S, Benton S, Carr LJ, Hanna MG. Is the mitochondrial complex I ND5 gene a hot-spot for MELAS causing mutations? Ann Neurol 2003;53:128-132.

138. Ravn K, Wibrand F, Hansen FJ, Horn N, Rosenberg T, Schwartz M. An mtDNA mutation, 14453G-$>\mathrm{A}$, in the NADH dehydrogenase subunit 6 associated with severe MELAS syndrome. Eur J Hum Genet 2001;9:805-809.

139. Matthews L, Enzinger C, Fazekas F, et al., MRI in Leber's hereditary optic neuropathy: the relationship to multiple sclerosis. J Neurol Neurosurg Psychiatry 2015;86:537-542.

140. Kuker W, Weir A, Quaghebeur G, Palace J. White matter changes in Leber's hereditary optic neuropathy: MRI findings. Eur J Neurol 2007;14:591-593.

141. Kovacs GG, Hoftberger R, Majtenyi K, et al., Neuropathology of white matter disease in Leber's hereditary optic neuropathy. Brain 2005;128(Pt 1):35-41.

142. Rana M dCI, Diaz F, Smeets H, et al., An out-of-frame cytochrome b gene deletion from a patient with parkinsonism is associated with impaired complex III assembly and an increase in free radical production. Ann Neurol 2000; 48:774-781.

143. Bruno C MA, Tang Y, Andreu AL, et al., A stop-codon mutation in the human mtDNA cytochrome c oxidase I gene disrupts the functional structure of complex IV.Am J Hum Genet 1999 ;65:611-20.

144. Varlamov DA, Kudin, A. P., Vielhaber, S. et al., Metabolic consequences of a novel missense mutation of the mtDNA CO I gene. Hum Mol. Genet 2002;11:1797-1805.

145. Lucioli S, Hoffmeier K, Carrozzo R, et al., Introducing a novel human mtDNA mutation into the Paracoccus denitrificans COX I gene explains functional deficits in a patient. Neurogenetics 2006;7:51-57. 


\section{Chapter 1}

146. Campos Y G-RA, Fernández-Moreno MA, Martínez-Pardo M, et al., Early-onset multisystem mitochondrial disorder caused by a nonsense mutation in the mitochondrial DNA cytochrome $\mathrm{C}$ oxidase II gene. Ann Neurol $2001 ; 50: 409-13$.

147. Rahman S, Taanman JW, Cooper JM, et al., A missense mutation of cytochrome oxidase subunit II causes defective assembly and myopathy. Am J Hum Genet 1999;65:1030-1039.

148. Tiranti V, Corona P, Greco M, et al., A novel frameshift mutation of the mtDNA COIII gene leads to impaired assembly of cytochrome c oxidase in a patient affected by Leigh-like syndrome. Hum Mol Genet 2000;9:2733-2742.

149. Horváth R SC, Hoeltzenbein M, Do BH, et al., Childhood onset mitochondrial myopathy and lactic acidosis caused by a stop mutation in the mitochondrial cytochrome c oxidase III gene. J Med Genet 2002;39:812-816.

150. Kucharczyk R, Zick M, Bietenhader M, et al., Mitochondrial ATP synthase disorders: molecular mechanisms and the quest for curative therapeutic approaches. Biochim Biophys Acta 2009;1793:186-199.

151. Ruhoy IS, Saneto RP. The genetics of Leigh syndrome and its implications for clinical practice and risk management. Appl Clin Genet 2014;7:221-234.

152. Kara B, Arikan M, Maras H, Abaci N, Cakiris A, Ustek D. Whole mitochondrial genome analysis of a family with NARP/MILS caused by m.8993T>C mutation in the MT-ATP6 gene. Mol Genet Metab 2012;107:389-393.

153. Uziel G, Moroni I, Lamantea E, et al., Mitochondrial disease associated with the T8993G mutation of the mitochondrial ATPase 6 gene: a clinical, biochemical, and molecular study in six families. J Neurol Neurosurg Psychiatry 1997;63:16-22.

154. Melone MA, Tessa A, Petrini S, et al., Revelation of a new mitochondrial DNA mutation (G12147A) in a MELAS/MERFF phenotype. Arch Neurol 2004;61:269-272.

155. Taylor RW, Schaefer AM, McDonnell MT, et al., Catastrophic presentation of mitochondrial disease due to a mutation in the tRNA(His) gene. Neurology 2004;62:1420-1423.

156. Cox R, Platt J, Chen LC, Tang S, Wong LJ, Enns GM. Leigh syndrome caused by a novel m.4296G>A mutation in mitochondrial tRNA isoleucine. Mitochondrion 2012;12:258-261.

157. Sweeney MG, Hammans SR, Duchen LW, et al., Mitochondrial DNA mutation underlying Leigh's syndrome: clinical, pathological, biochemical, and genetic studies of a patient presenting with progressive myoclonic epilepsy. J Neurol Sci 1994;121:57-65.

158. Santorelli FM, Tanji K, Sano M, et al., Maternally inherited encephalopathy associated with a singlebase insertion in the mitochondrial tRNATrp gene. Ann Neurol 1997;42:256-260.

159. Pereira C, Nogueira C, Barbot C, et al., Identification of a new mtDNA mutation (14724G>A) associated with mitochondrial leukoencephalopathy. Biochem Biophys Res Commun 2007;354:937-941.

160. Altmann J, Buchner B, Nadaj-Pakleza A, et al., Expanded phenotypic spectrum of the m.8344A>G "MERRF" mutation: data from the German mitoNET registry. J Neurol 2016; 263:961-972.

161. Mancuso M, Orsucci D, Angelini C, et al., Phenotypic heterogeneity of the $8344 \mathrm{~A}>\mathrm{G} \mathrm{mtDNA}$ "MERRF" mutation. Neurology 2013;80:2049-2054.

162. Arii J TY. Leigh syndrome: serial MR imaging and clinical follow-up. AJNR Am J Neuroradiol 2000;21:1502-1509.

163. Yu M, Zhang Z, Wang QQ et al., Clinical and Brain Magnetic Resonance Imaging Features in a Cohort of Chinese Patients with Kearns-Sayre Syndrome. Chin Med J 2016;129: 1419-1424.

164. Heidenreich JO, Klopstock T, Schirmer T, Saemann P, Mueller-Felber W, Auer DP. Chronic progressive external ophthalmoplegia: MR spectroscopy and MR diffusion studies in the brain. AJR. Am J Roent 2006;187:820-824. 
165. Brockmann K, Finsterbusch J, Schara U, Wilichowski E, Frahm J, Hanefeld F. Stroke-like pattern in DTI and MRS of childhood mitochondrial leukoencephalopathy. Neuroradiology 2004;46:267-271.

166. Wang XY, Noguchi K, Takashima S, Hayashi N, Ogawa S, Seto H. Serial diffusion-weighted imaging in a patient with MELAS and presumed cytotoxic oedema. Neuroradiology 2003; 45:640-643.

167. Tzoulis C, Bindoff LA. Serial diffusion imaging in a case of mitochondrial encephalomyopathy, lactic acidosis, and stroke-like episodes. Stroke 2009;40:e15-17.

168. Bianchi MC, Tosetti M, Battini R, et al., Proton MR spectroscopy of mitochondrial diseases: analysis of brain metabolic abnormalities and their possible diagnostic relevance. AJNR. Am J Neuroradiol 2003;24:1958-1966.

169. Pfeffer G, Horvath R, Klopstock T, et al., New treatments for mitochondrial disease-no time to drop our standards. Nat Rev Neurol 2013;9:474-481.

170. Pfeffer G MK, Turnbull DM, Thorburn D, Chinnery PF. Cochrane Database of Systematic Reviews (4) Art. No.: CD004426. http://dx.doi.org/10.1002/14651858.).

171. Kassem H, Wafaie A, Alsuhibani S, Farid T. Biotin-responsive basal ganglia disease: neuroimaging features before and after treatment. AJNR. Am J Neuroradiol 2014;35:1990-1995.

172. Gerards M, van den Bosch BJ, Danhauser K, et al.,, Riboflavin-responsive oxidative phosphorylation complex I deficiency caused by defective ACAD9: new function for an old gene. Brain 2011;134(Pt 1):210-219.

173. Desbats MA, Lunardi G, Doimo M, Trevisson E, Salviati L. Genetic bases and clinical manifestations of coenzyme Q10 (CoQ 10) deficiency. J Inherit Metab Dis 2015;38:145-156.

174. Avula S, Parikh S, Demarest S, Kurz J, Gropman A. Treatment of mitochondrial disorders. Curr Treat Options Neurol 2014;16:292.

175. Parikh S, Saneto R, Falk MJ, et al., A modern approach to the treatment of mitochondrial disease. Curr Treat Options Neurol 2009;11:414-430.

176. Moller HE, Wiedermann D, Kurlemann G, Hilbich T, Schuierer G. Application of NMR spectroscopy to monitoring MELAS treatment: a case report. Muscle nerve 2002;25:593-600.

177. Pavlakis SG, Kingsley PB, Kaplan GP, Stacpoole PW, O'Shea M, Lustbader D. Magnetic resonance spectroscopy: use in monitoring MELAS treatment. Arch Neurol 1998;55:849-852.

178. Lee SK, Kim J, Kim HD, Lee JS, Lee YM. Initial experiences with proton MR spectroscopy in treatment monitoring of mitochondrial encephalopathy. Yonsei Med J 2010;51:672-675.

179. Kimura S, Ohtuki N, Nezu A, Tanaka M, Takeshita S. Clinical and radiologic improvements in mitochondrial encephalomyelopathy following sodium dichloroacetate therapy. Brain Dev 1997;19:535540 .

180. Kitamura M, Yatsuga S, Abe T, et al., L-Arginine intervention at hyper-acute phase protects the prolonged MRI abnormality in MELAS. J Neurol 2016;263:1666-1668.

181. Enns GM, Kinsman SL, Perlman SL, et al., Initial experience in the treatment of inherited mitochondrial disease with EPI-743. Mol Genet Metab 2012;105:91-102.

182. Martinelli D, Catteruccia M, Piemonte F, et al., EPI-743 reverses the progression of the pediatric mitochondrial disease--genetically defined Leigh Syndrome. Mol Genet Metab 2012;107:383-388.

183. Sadun AA, Chicani CF, Ross-Cisneros FN, et al., Effect of EPI-743 on the clinical course of the mitochondrial disease Leber hereditary optic neuropathy. Arch Neurol. 2012;69:331-338.

184. Blankenberg FG, Kinsman SL, Cohen BH, et al.,, Brain uptake of Tc99m-HMPAO correlates with clinical response to the novel redox modulating agent EPI-743 in patients with mitochondrial disease. Mol Genet Metab 2012;107:690-699.

185. Rai PK, Russell OM, Lightowlers RN, Turnbull DM. Potential compounds for the treatment of mitochondrial disease. Br Med Bull 2015;116:5-18. 


\section{Chapter 1}

186. Kerr DS. Review of clinical trials for mitochondrial disorders: 1997-2012. Neurotherapeutics 2013;10:307-319.

187. Koopman WJ, Beyrath J, Fung CW, et al., Mitochondrial disorders in children: toward development of small-molecule treatment strategies. EMBO Mol Med 2016;8:311-327.

188. Tanaka M, Borgeld HJ, Zhang J, et al., Gene therapy for mitochondrial disease by delivering restriction endonuclease SmaI into mitochondria. J Biomed Sci 2002;9(6 Pt 1):534-541.

189. Kyriakouli DS, Boesch P, Taylor RW, Lightowlers RN. Progress and prospects: gene therapy for mitochondrial DNA disease. Gene Ther 2008;15:1017-1023.

190. Tachibana M, Amato P, Sparman M, et al., Towards germline gene therapy of inherited mitochondrial diseases. Nature 2013;493:627-631.

191. Taskin BD, Karalok ZS, Gurkas E, et al., Early-Onset Mild Type Leukoencephalopathy Caused by a Homozygous EARS2 Mutation. J Child Neurol 2016;31:938-941.

192. Wedatilake Y BR, McFarland R, Yaplito-Lee J, et al.,SURF1 deficiency: a multi-centre natural history study. Orphanet J Rare Dis 2013 5;8:96.:96. 


\section{Chapter}

\section{Magnetic resonance Imaging Correlates of Genetically Characterized patients with Mitochondrial Disorders: A study from South India}

Bindu PS, Arvinda HR, Taly AB, Govindaraju C, Sonam K, Chiplunkur S, kumar R, Gayathri N, Srinivas Bharath MM, Nagappa M, Sinha S, Khan NA, Govindraj P, Nunia V, Paramsivam A, Thangaraj K .

Mitochondrion 2015; 25:6-16 


\section{Abstract}

Background: Large studies analyzing magnetic resonance imaging correlates in different genotypes of mitochondrial disorders are far and few. This study sought to analyze the pattern of magnetic resonance imaging findings in a cohort of genetically characterized patients with mitochondrial disorders.

Methods: The study cohort included 33 patients (age range 18 months-50 years, M:F 0.9:1) with definite mitochondrial disorders seen over a period of 8 yrs. (2006-2013). Their MR imaging findings were analyzed retrospectively.

Results: The patientswere classified into three groups according to the genotype, Mitochondrial point mutations and deletions $(n=21)$, SURF1 mutations $(n=7)$ and POLG1 ( $\mathrm{n}=5)$. The major findings included cerebellar atrophy $(51.4 \%)$, cerebral atrophy (24.2\%), signal changes in basal ganglia (45.7\%), brainstem $(34.2 \%)$ \& whitematter (18.1\%) and stroke like lesions (25.7\%). Spinal cord imaging showed signal changes in 4/6 patients. Analysis of the special sequences revealed, basal ganglia mineralization $(7 / 22)$, lactate peak on magnetic resonance spectrometry (10/15), and diffusion restriction (6/22). Follow-up images in six patients showed that the findings are dynamic. Comparison of the magnetic resonance imaging findings in the three groups showed that cerebral atrophy and cerebellar atrophy, cortical signal changes and basal ganglia mineralization were seen mostly in patients with mitochondrial mutation. Brainstem signal changes with or without striatal lesions were characteristically noted in SURF1 group. There was no consistent imaging pattern in POLG1 group.

Conclusion: Magnetic resonance imaging findings in mitochondrial disorders are heterogeneous. Definite differences were noted in the frequency of anatomical involvement in the three groups. Familiarity with the imaging findings in different genotypes of mitochondrial disorders along with careful analysis of the family history, clinical presentation, biochemical findings, histochemical and structural analysis will help the physician for targeted metabolic and genetic testing. 


\section{Introduction}

Mitochondrial disorders are clinically and genetically heterogeneous group of disorders resulting from dysfunction of the respiratory chain complexes. ${ }^{1}$ The wide range of clinical, biochemical and genetic heterogeneity often pose diagnostic challenge to the clinician. ${ }^{2}$ The current strategy for diagnosis and classification of mitochondrial disorders includes a comprehensive and meticulous analysis of family history, clinical findings, biochemical and histopathological analyses, magnetic resonance imaging findings and molecular diagnostic testing. ${ }^{3}$ Among these, magnetic resonance imaging (MRI) is one of the easily accessible initial tools available to the clinician for interrogating the presence and pattern of central nervous system changes in patients with mitochondrial disorders. ${ }^{4,5}$ Apart from the structural imaging, the advanced imaging techniques also help to define the anatomical lesions, metabolism and hemodynamics in these patients. ${ }^{6,7}$

The central nervous system is the second most frequently affected system after the muscular system in mitochondrial disorders. ${ }^{8}$ The neurological manifestations are extremely diverse reflecting the wide range of neuropathological changes and the same is extrapolated in the heterogeneous magnetic resonance imaging findings ${ }^{9}$ Studies have classified the magnetic resonance imaging findings based on the phenotypes ${ }^{10,11}$ respiratory chain abnormalities. ${ }^{12-14}$ and genetic findings. ${ }^{15,16}$ Studies on genetically characterized patients have suggested that certain neuroanatomical involvement may suggest the underlying genetic etiology. ${ }^{15}$ This study sought to analyze the magnetic resonance imaging patterns in a cohort of genetically characterized patients with mitochondrial disorders.

\section{Patients and Methods:}

The institutional ethics committee of National Institute of Mental Health \& Neurosciences, Bangalore, India approved the study protocol. Over a period of eight years (2006-2013) a total of 605 patients were recruited as part of a study on neurological disorders associated with mitochondrial DNA mutations. All patients underwent a complete clinical and laboratory evaluation and follow up by a single clinical team (ABT, PSB, SS, MN). Patients were recruited into the study when clinical, biochemical, histopathological, magnetic resonance imaging, nerve conduction studies, electroencephalography and evoked potential studies suggested a diagnosis of mitochondrial disorder. Standard definitions were used for the phenotypic characterization of the classical mitochondrial syndromes as specified in the supplementary table (Table 
S1). Complete mitochondrial genome sequencing was done in all the patients. Genetic evaluation also included sequencing of the nuclear genes, POLG $(\mathrm{n}=304)$ and SURF1 ( $\mathrm{n}=91)$. Mitochondrial gene sequencing revealed 128 variations in 135 patients, which included known pathogenic mutations $(\mathrm{n}=20)$, benign polymorphisms /possible disease associated mutations $(n=37)$ and novel variations $(n=70)$. Mitochondrial rearrangements were looked for in eight patients and one showed single large deletion. POLG screening revealed mutations in 24 patients ( $P O L G 1 n=12, P O L G 2$ $n=12$ ) and SURF1 screening in seven patients. Patients without mutations, novel mutations \& benign polymorphisms, patients with myopathic presentations and those without an MRI available for review were excluded. The final cohort included 33 patients with a definite genetic diagnosis. All had clinical features consistent with a mitochondrial disorder along with the presence of a mitochondrial or nuclear mutation and /or muscle biopsy showing histopathological evidence of ragged red fibers, ragged blue fibers, complete COX deficiency \& respiratory chain complex IIV deficiencies less than $20 \%$.

\subsection{Magnetic resonance imaging:}

Magnetic resonance imaging was done on Aera 1.5 Tesla MRI scanner (Siemens Medical Systems, Erlangen, Germany, $\mathrm{n}=10$ )/ Achieva $3 \mathrm{~T}$ MR imaging scanner (Philips Medical Systems, Netherlands, $n=15$ ) using standard protocols and methods described previously. ${ }^{17}$ For eight patients, Magnetic resonance imaging acquired elsewhere were reviewed. MRI findings were evaluated by two neurologists (ABT\&PSB) and one neuroradiologist (HRA) independently. The sequences analyzed included T1W, T2W, and FLAIR sequences for all. The special sequences, diffusion weighted imaging (DWI, $\mathrm{n}=24$ ), Susceptibility weighted (SWI)/ venobold sequences/ Gradient echo imaging $(n=20)$, Magnetic resonance spectroscopy $(n=16)$ and Magnetic resonance angiography $(n=6)$ were reviewed whenever available. Contrast study was available in 22 patients and spinal cord imaging in six.

\section{Results:}

The study included 33 patients (Age range, 7mo-50yrs; Male: female ratio, 0.9:1) with mitochondrial disease and definite genetic diagnoses seen over a period of eight years (2006-2013). The clinical diagnosis, genetic and MRI findings of the entire cohort is summarized in Table 1. 


\subsection{Phenotypic features:}

The clinical syndromes included mitochondrial encephalopathy lactic acidosis and stroke like episodes (MELAS, n=7), MELAS-Leighs overlap syndrome (n=2) Myoclonic epilepsy ragged red fiber syndrome (MERRF, $n=4)$, Leigh and Leigh like syndrome ( $n=9)$, Kearns Sayre syndrome (KSS, n=1), Lebers hereditary optic neuropathy (LHON) plus syndrome $(\mathrm{n}=1)$, Neuropathy ataxia, retinitis pigmentosa (NARP) syndrome $(n=1)$, Sensory ataxic neuropathy, dysarthria and ophthalmoparesis (SANDO) syndrome $(\mathrm{n}=1)$, and mitochondrial spinocerebellar ataxia epilepsy syndrome (MSCAE, $\mathrm{n}=2$ ). The rest of the patients had non syndromic diagnoses.

\subsection{Genetic findings:}

The patients were divided into three groups according to the genotype; mitochondrial point mutations and deletions ( $\mathrm{n}=21$; Point mutations-20, single deletion-1); SURF1 mutations ( $\mathrm{n}=7$, homozygous mutations in six and heterozygous mutations in one); POLG1 mutations ( $n=5$, homozygous mutations in POLG1-5, combined $P O L G 1 \& P O L G 2$ mutation in one)

\subsection{MRI findings:}

Salient findings in each patient are summarized in Table1. The summary of the findings in the whole cohort and the frequency of involvement of various structures in each group are shown in Table 2. The major findings included cerebellar atrophy (54.5\%), cerebral atrophy $(24.2 \%)$, basal ganglia lesions $(48.4 \%)$, brainstem signal changes (36.3\%), stroke like lesions (25.7\%) and white matter lesions (18.1\%). Four of the six patients who underwent spinal cord imaging showed signal changes. Analysis of the special sequences revealed, basal ganglia mineralization (7/20), lactate peak on MRS (10/15), and diffusion restriction (6/22). Analysis of the magnetic resonance spectroscopy did not reveal any other findings other than lactate peak.

\subsection{Magnetic resonance imaging findings \& genotype correlations}

Cerebral \& Cerebellar atrophy: Cerebral and cerebellar atrophy was mostly noted in patients with mitochondrial mutations. None of the patients in the SURF1 group had cerebral or cerebellar atrophy. Severe cerebral atrophy along with ventricular dilatation was seen in two children with MELAS who had an earlier age of onset and long duration of the illness (Fig.1). The blood heteroplasmy levels of the MELAS patients ranged from 50-90\% $(n=8)$. The heteroplasmy levels did not correlate with the age of onset or severity of the disease. On the other hand, cerebral atrophy was 
prominent in three patients with longer duration of illness (Patients, 2, 6 \& 8). Cerebellar atrophy was prominent in patients with LHON plus, NARP, and Kearns Sayre syndrome.

Basal ganglia and thalamic lesions: The abnormalities were in the form of either signal changes or mineralization (Table 2). Unilateral or asymmetric lesions were seen in two. Signal intensity changes in the basal ganglia were seen in both mitochondrial and nuclear DNA mutations. Blooming of the globus pallidus on susceptibility weighted /veno-bold sequences, as noted in 7/20 patients were more commonly seen in patients with mitochondrial DNA mutations than in the nuclear mutations. Follow up imaging in the patient with $\mathrm{m} .8363$ mutations showed progressive atrophy and mineralization of the basal ganglia (Fig.2). Unilateral Thalamic involvement on the same side of the stroke like episode occurred in two patients with MELAS and bilateral thalamic involvement in SURF1, POLG1 and m.13514 mutation one each.

Brain stem lesions: This involved specific nuclei and anatomic structures and mostly associated with SURF1 mutations (Fig.5a-f) but also was noted in patients with $M T D N A$ mutations and POLG1. The inferior olivary nuclei signal changes were consistently noted in patients with $S U R F 1$ mutation, but also was noted in POLG1 and $\mathrm{m} .13514 \mathrm{G}>\mathrm{A}$ mutations. The other specific tract commonly involved was the central tegmental tract.

Cortical stroke like lesions: The combination of cortical lesions along with bilateral globus pallidi calcification and atrophy was commonly seen in patients with the m.3243A > G mutations (Fig.1). Diffusion restriction was seen in four stroke like lesions suggesting acute nature of the lesions. The location of the cortical lesions were temporal, occipital, parietal and frontal. The posterior part of the temporal lobe was most commonly involved though the anterior and medial parts were also involved. Contrast enhancement of these stroke like lesions was noted in two. Patients with chronic lesions and longer duration of the illness had small cortical lesions compared to patients with short duration of the illness (Patient 2\&8.Fig.1a-c). The additional sites of involvement in m.3243 mutations included bilateral symmetrical basal ganglia lesions (n=2; Fig.1b) and thalamic lesions ipsilateral to the side of the stroke like lesions ( $\mathrm{n}=2$, Fig.1e) and speck of cerebellar cortical hyperintensity. Laminar necrosis was noted in one (Fig.1d). Six patients underwent magnetic resonance angiogram during the stroke like episodes and all revealed normal findings. MRS showed a lactate peak in 7/8 strokes like lesions. Mineralization of the basal ganglia in the form of calcification evident on CT scan and blooming on susceptibility weighted / venobold sequences were present in $7 / 8$ of patients with stroke like lesions and m.3243A $>$ G mutation (Fig.1c). In the patient with $P O L G$ related disorder the corti- 
cal lesions were associated with bilateral globus pallidi signal changes and cerebral atrophy, but the associated mineralization of basal ganglia was absent.

Leukoencephalopathy as the main or only abnormality occurred only in one patient with Kearns Sayre syndrome (Fig.4). Non specific white matter abnormalities were in the form of posterior periventricular signal changes with cyst formation, and focal white matter signal changes. Cerebellar white matter involvement was seen in four patients. The extent of cerebellar white matter signal changes also varied from speck of hyperintensity to signal changes in the peri-dentate white matter and subcortical region.

Spinal cord signal changes: Four of the six patients who underwent spinal cord imaging showed signal changes. In the mitochondrial group this was noted in one patient with $\mathrm{m} .11778 \mathrm{G}>\mathrm{A}$ and $\mathrm{LHON}$ plus syndrome $\&$ in one patient with single deletion and Kearns Sayre syndrome. Dorsal column degeneration was seen in all while lateral column abnormality occurred in addition in patient with m.11778G $>$ A (Fig.3) mutation.

Mineralization: Susceptibility weighted imaging revealed mineralization in 13/22 patients. Pattern of mineralization in this cohort was heterogeneous and included, bilateral globus pallidi calcification, punctate basal ganglia calcification and diffuse dense calcification of caudate and putamen. Mineralization was seen in both MTDNA mutations $(\mathrm{n}=12)$ and POLG1 ( $n=1)$, but none of the patients with SURF1.

Follow up study: Follow up scans were available in 6 patients. All showed progressive changes either in the form of progressive volume loss in the involved structures (Fig.2) or the appearance of new anatomical lesions. 


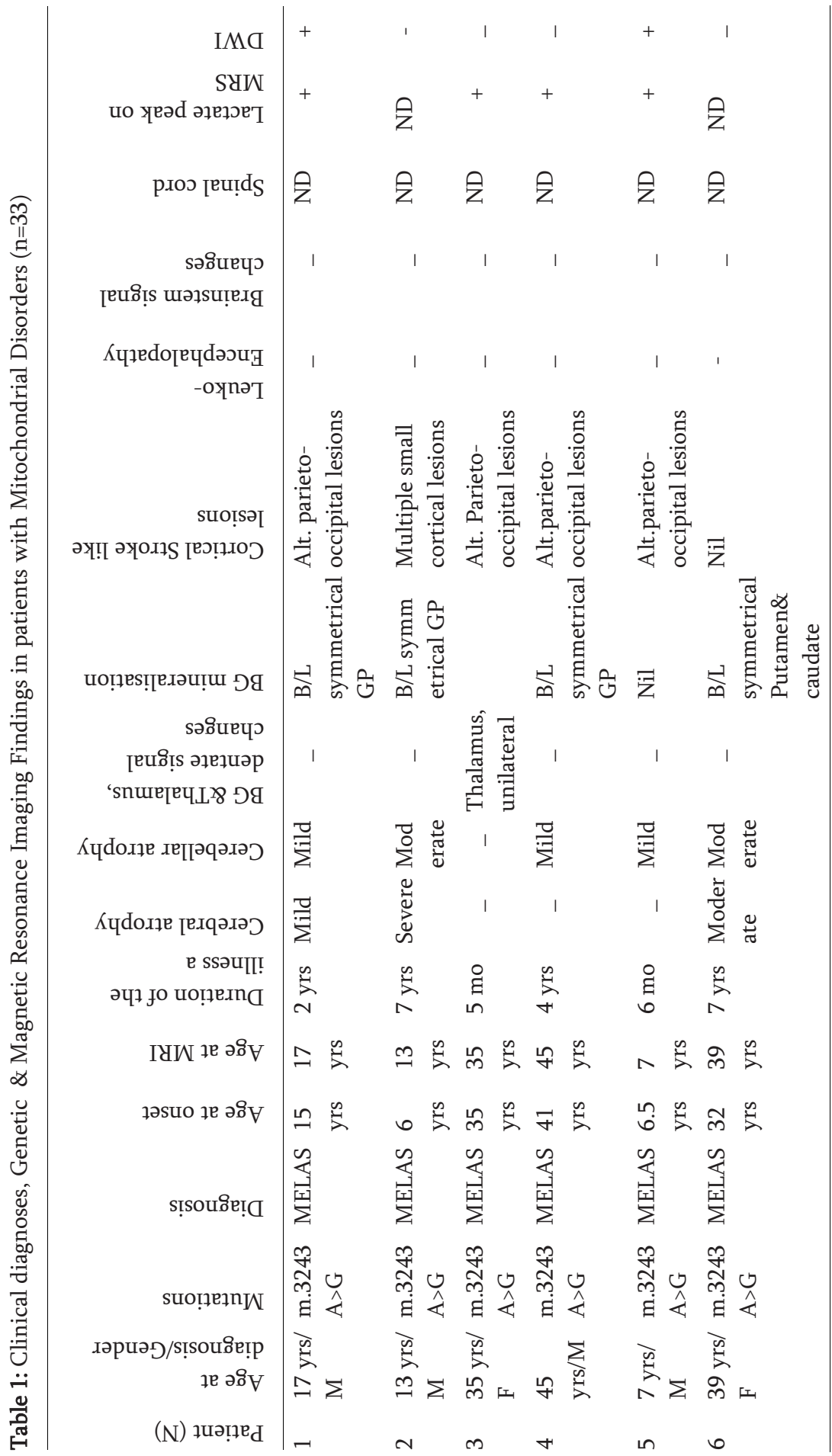




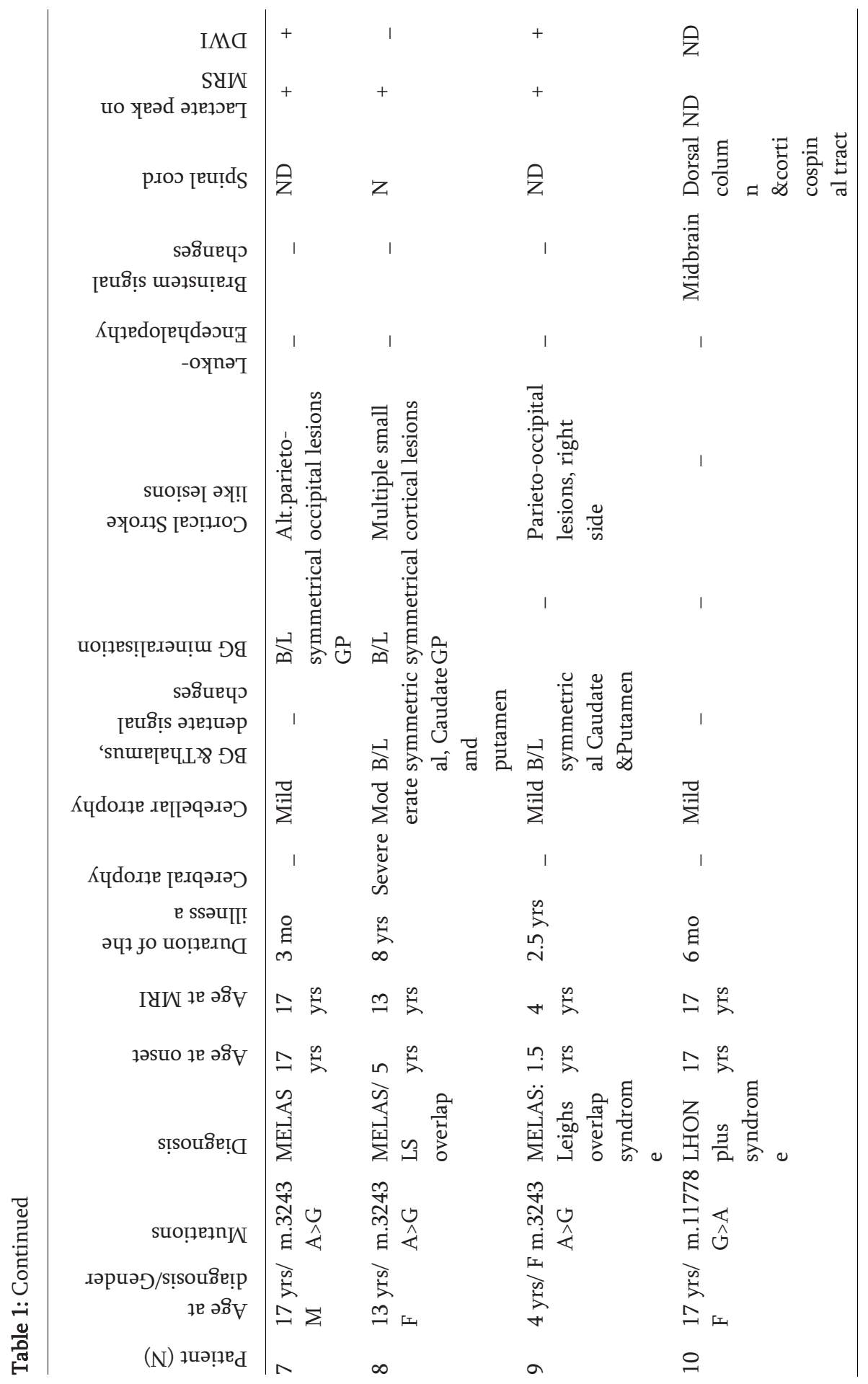




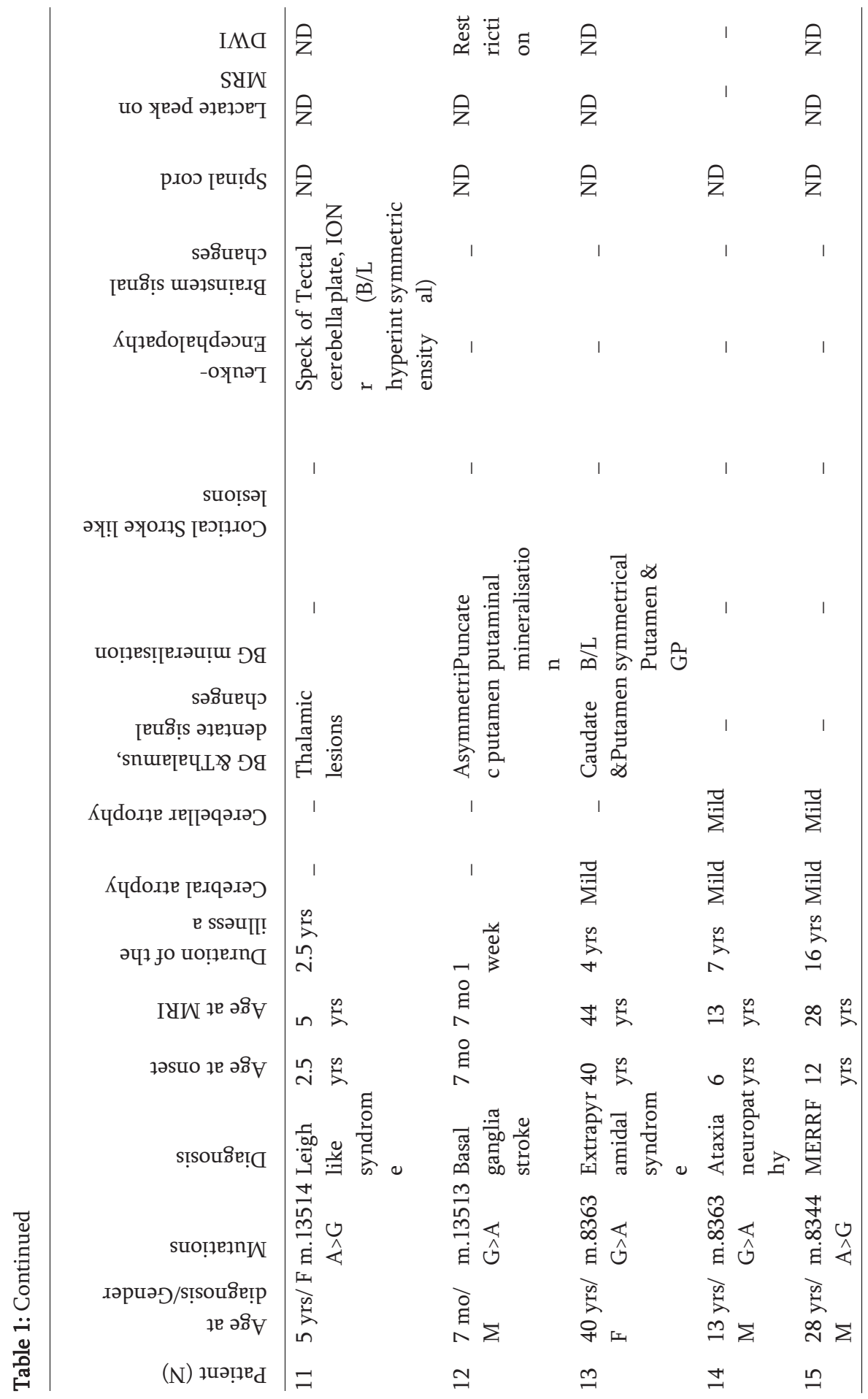




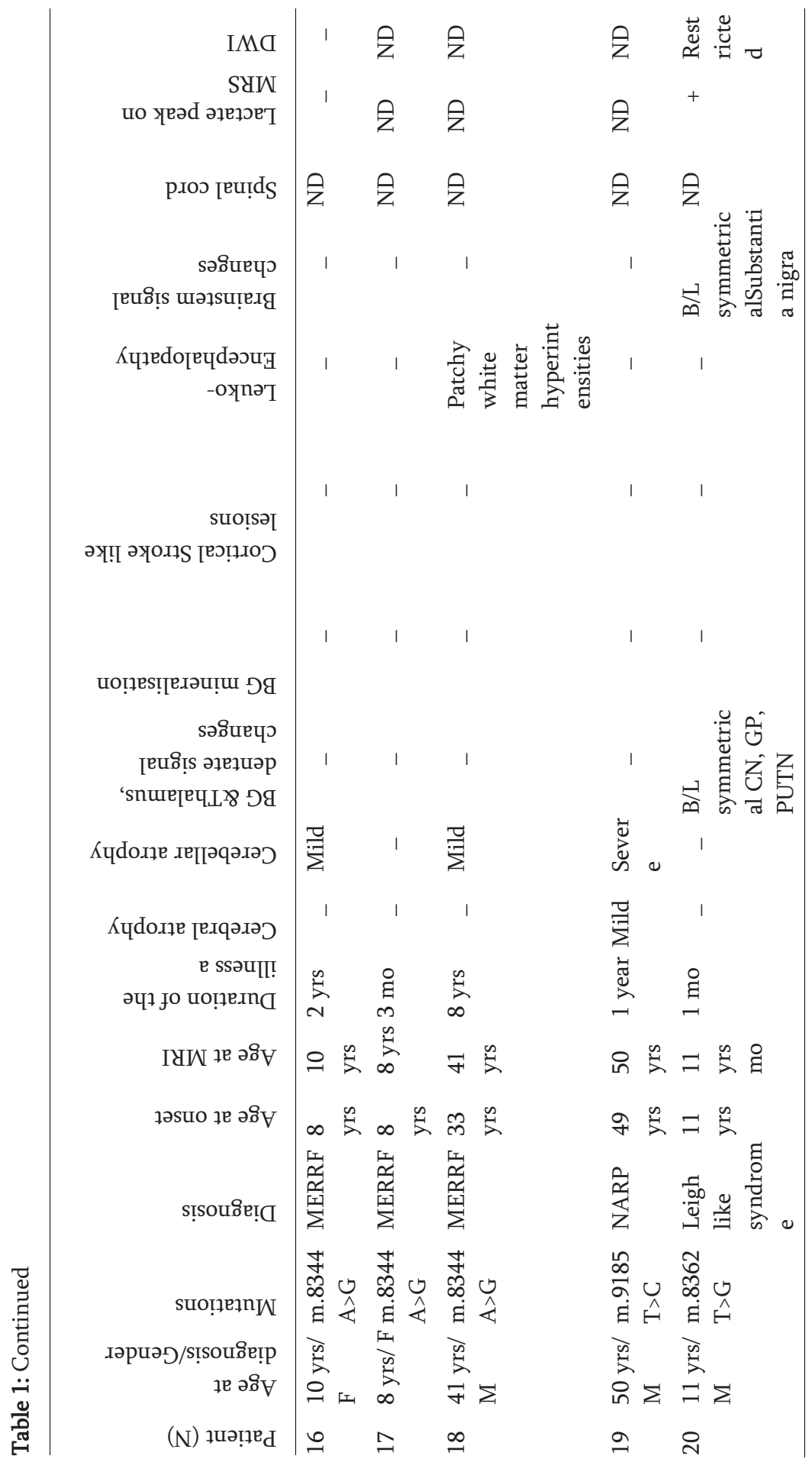




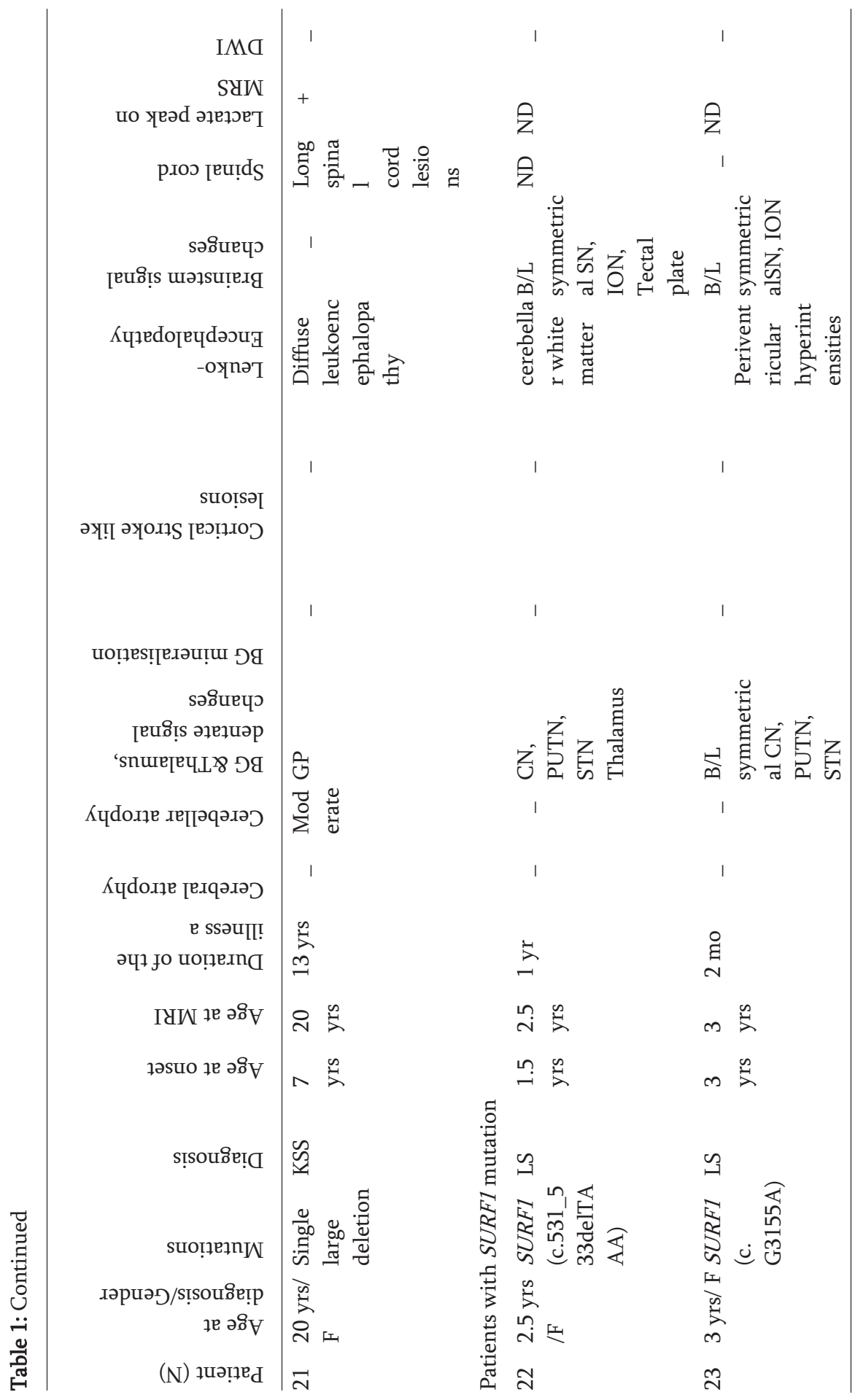




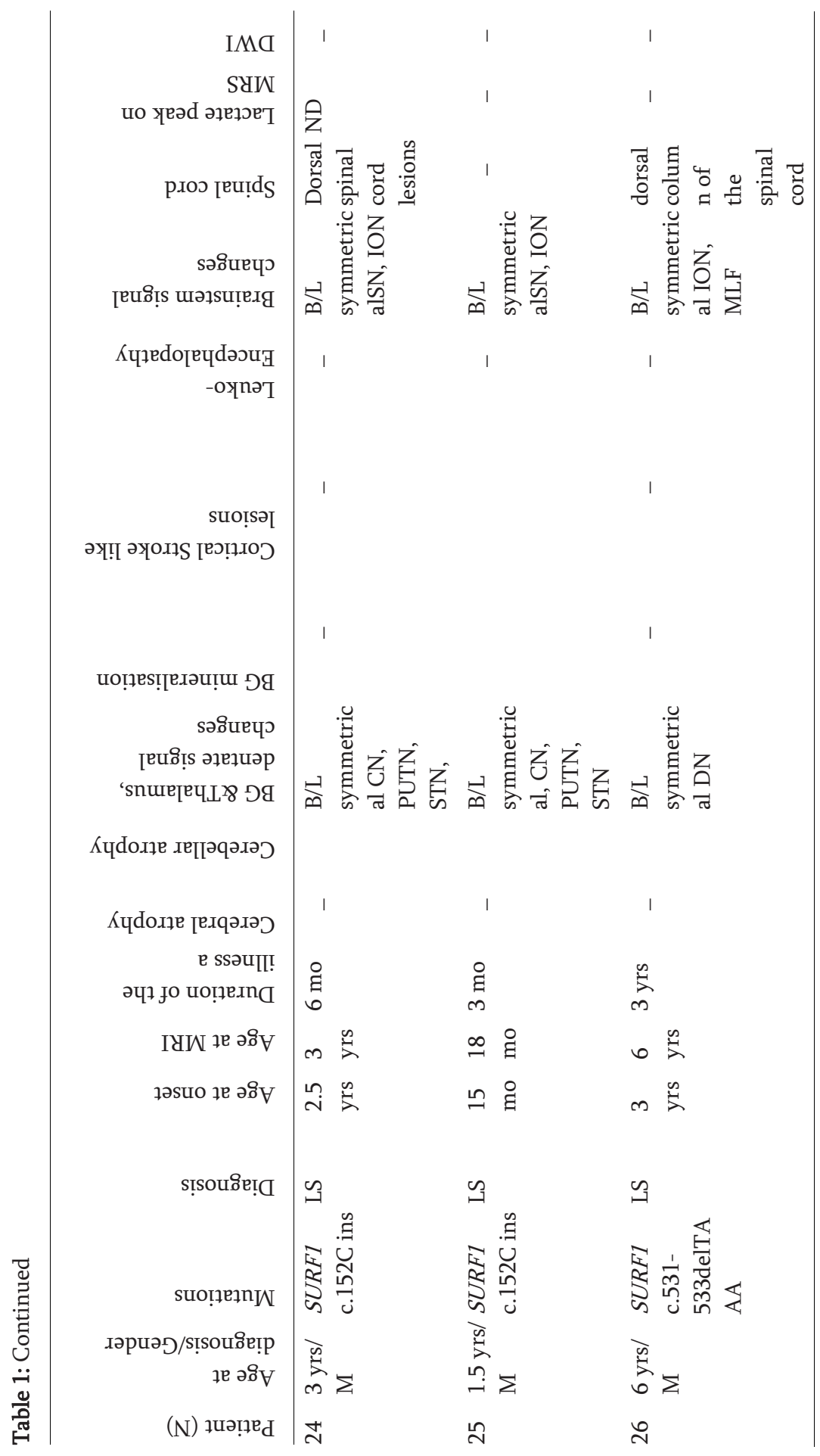




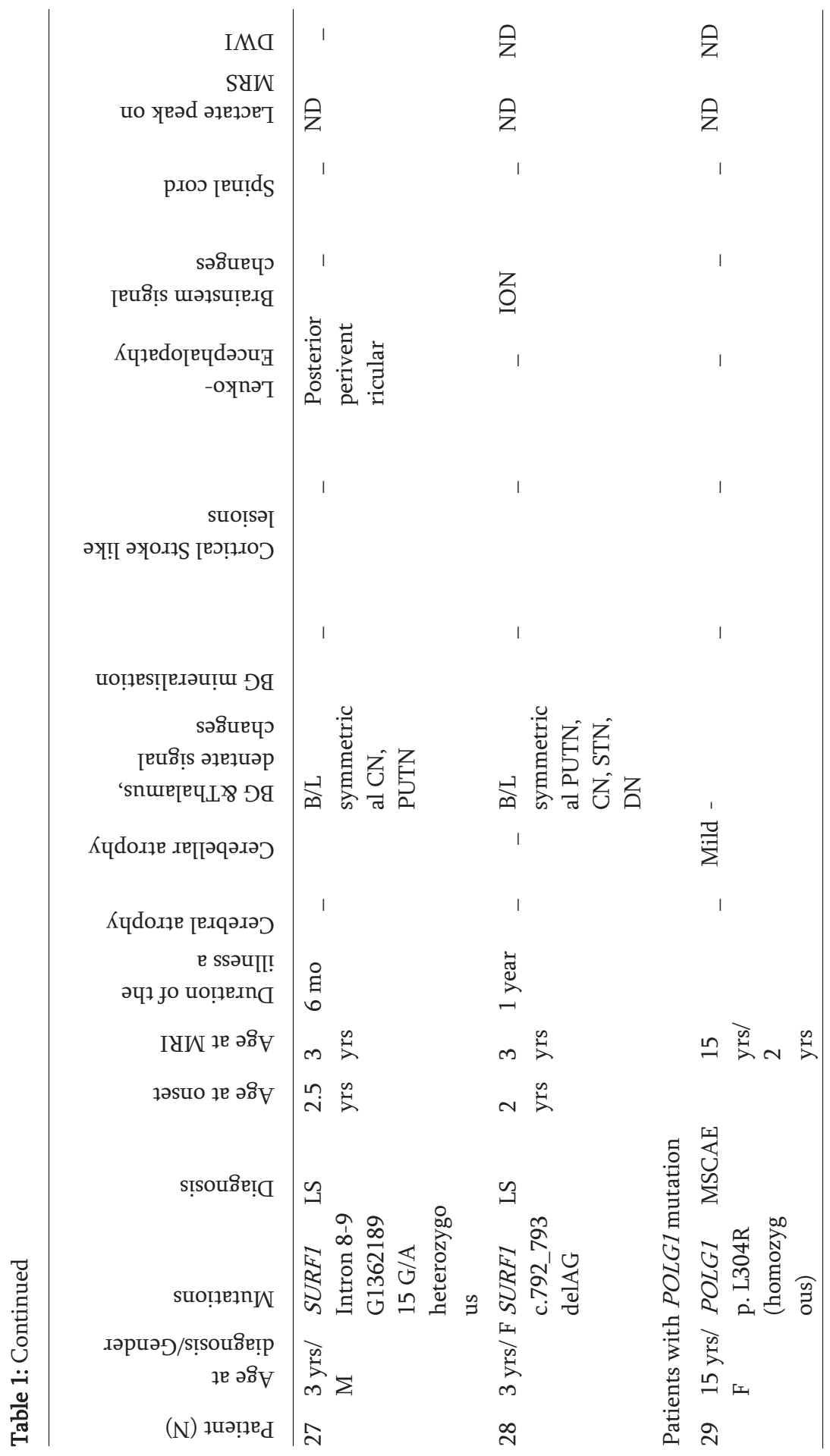




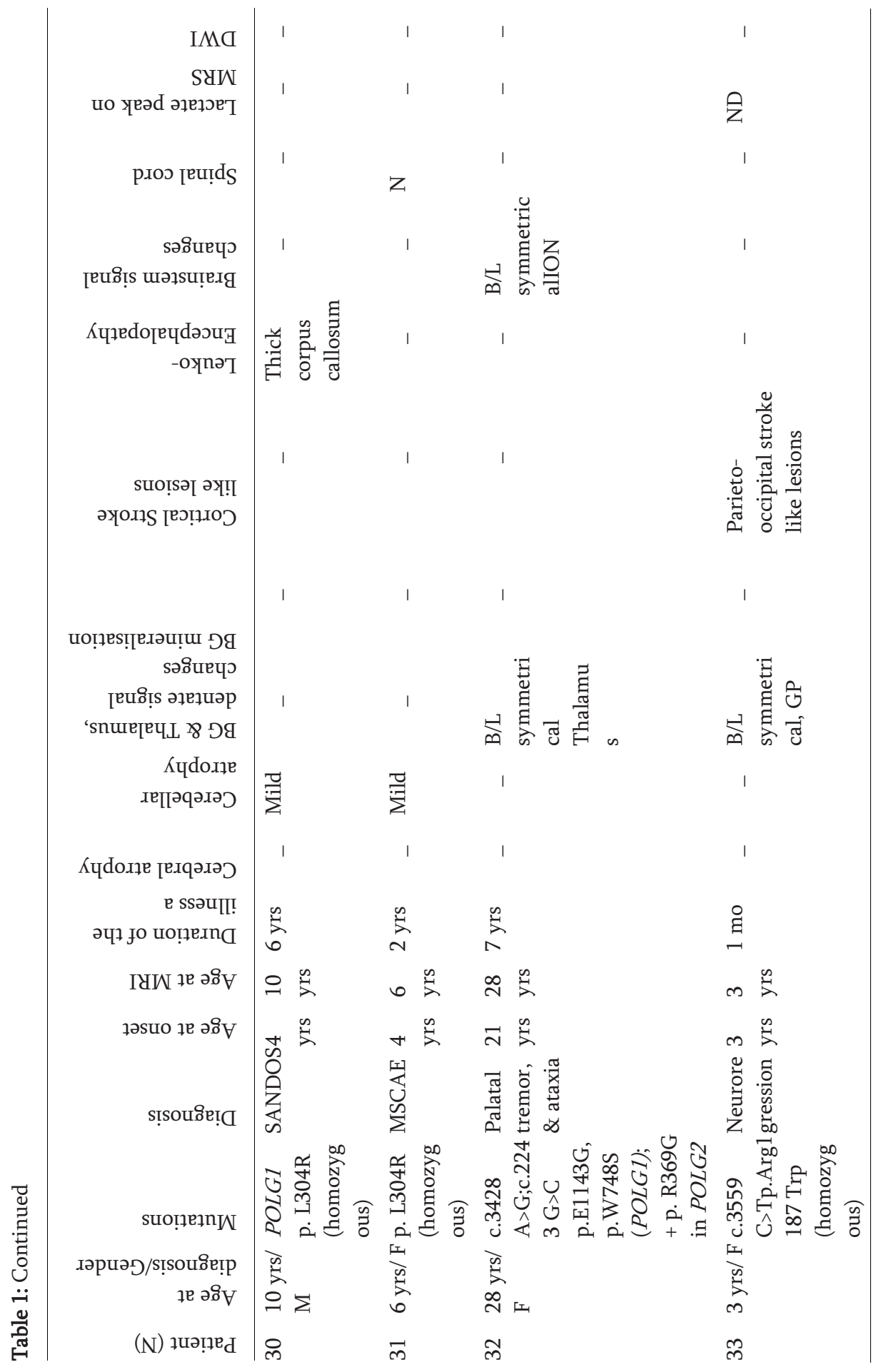


Table 2: Summary of the Magnetic Resonance Imaging findings in Patients with Mitochondrial Disorders.

\begin{tabular}{|c|c|c|c|c|}
\hline Neuro-imaging Findings & All (N=33) & $\begin{array}{l}M T-D N A \\
(\mathrm{n}=21)\end{array}$ & SURF1 $(\mathrm{n}=7)$ & POLG1 $(\mathrm{n}=5)$ \\
\hline Cerebellar atrophy & $18(54.5 \%)$ & 15 & - & 3 \\
\hline Mild & 13 & 10 & - & 3 \\
\hline Mod-Severe & 5 & 5 & - & - \\
\hline Cerebral atrophy & $8(24.2 \%)$ & 8 & - & - \\
\hline $\begin{array}{l}\text { Basal ganglia Signal } \\
\text { Changes }\end{array}$ & $16(48.4 \%)$ & 10 & 5 & 1 \\
\hline \multicolumn{5}{|l|}{ Caudate } \\
\hline T2 signal changes & 10 & 5 & 5 & - \\
\hline Mineralisation & $3 / 22$ & 2 & - & 1 \\
\hline Putamen & & & & - \\
\hline T2 signal changes & 10 & 5 & 5 & - \\
\hline Mineralisation & $3 / 22$ & 2 & - & 1 \\
\hline \multicolumn{5}{|l|}{ Globus Pallidus } \\
\hline T2 Signal changes & 3 & 1 & 1 & 1 \\
\hline Mineralisation & $7 / 22$ & 8 & - & 1 \\
\hline Stroke like lesions & $9(25.7 \%)$ & 8 & - & 1 \\
\hline $\begin{array}{l}\text { Supra-tentorial white matter } \\
\text { Leukoencephalopathy }\end{array}$ & 6 & & & \\
\hline Non specific white & 2 & 2 & 1 & - \\
\hline $\begin{array}{l}\text { matter } \\
\text { signal changes }\end{array}$ & 4 & 3 & 1 & - \\
\hline Thalamus & 3 & 2 & - & 1 \\
\hline Subthalamic nucleus & 4 & - & 4 & - \\
\hline Brainstem & $12(36.3 \%)$ & 4 & 7 & 1 \\
\hline Substantia Nigra & 4 & 1 & 3 & - \\
\hline $\begin{array}{l}\text { Tectal Plate } \\
\text { hyperintensity }\end{array}$ & 4 & 2 & 2 & - \\
\hline $\begin{array}{l}\text { Inferior Olivary } \\
\text { Nucleus }\end{array}$ & 9 & 1 & 7 & 1 \\
\hline Dentate Nucleus & 5 & 1 & 3 & 1 \\
\hline Cerebellar white matter & 3 & 1 & 2 & - \\
\hline Spinal cord signal changes & $4 / 6$ & $2 / 3$ & $2 / 2$ & $-/ 1$ \\
\hline Lactate Peak on MRS & $10 / 15$ & $9 / 10$ & $1 / 3$ & $-/ 2$ \\
\hline
\end{tabular}




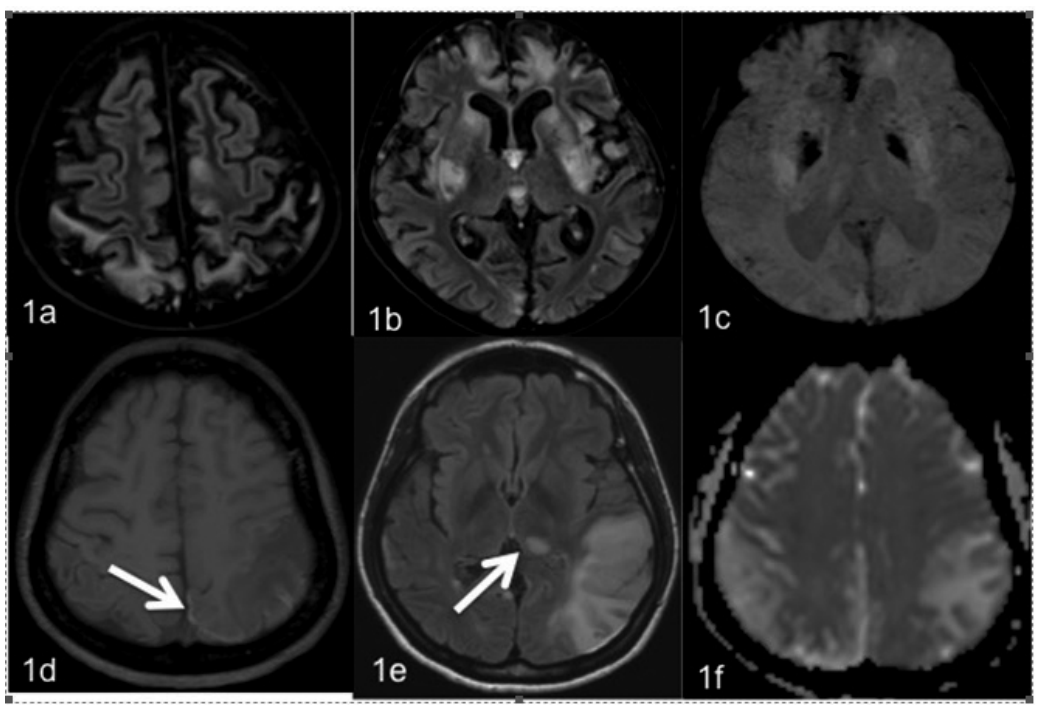

Fig 1 Spectrum of MRI findings in patients with $\mathrm{m} .3243 \mathrm{~A}>\mathrm{G}$ mutations:

1a-c MRI brain in patient 8 with MELAS Leighs overlap syndrome: a) FLAIR image demonstrating cerebral atrophy, multiple cortical lesions. b) bilateral symmetrical basal ganglia signal changes and c. mineralization on SWI imaging. 1(d-f)- MRI brain in Patient 3: d) T1W image demonstrate cortical laminar necrosis (Arrow). e) FLAIR image shows stroke like lesions and pulvinar lesions (Arrow). f) The lesions show free diffusion on apparent diffusion coefficient (ADC) maps

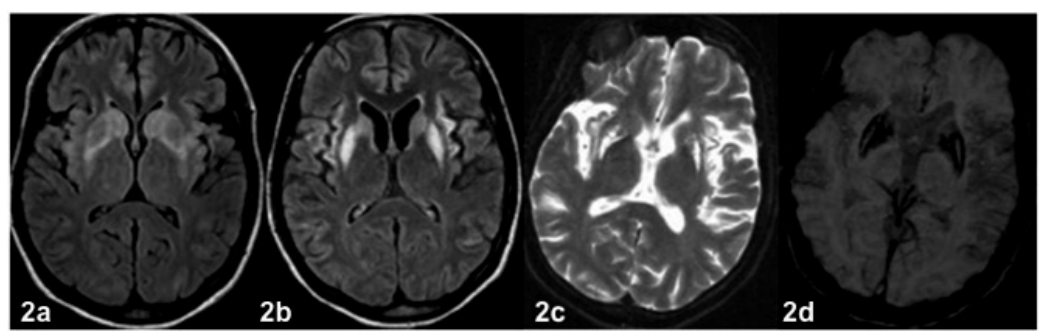

Fig 2 Progressive basal ganglia signal changes and atrophy and mineralization in a 40 year old lady with m.8363G >A mutations (Patient 13) a) MRI brain at presentation shows bilateral signal changes in caudate and putamen (FLAIR) b) MRI after six months-signal changes are persisting but there is atrophy c) T2W MRI, four years after the onset of the disease shows progressive atrophy and gliotic changes in the MRI. d) Susceptibility weighted imaging shows mineralization of the basal ganglia. 


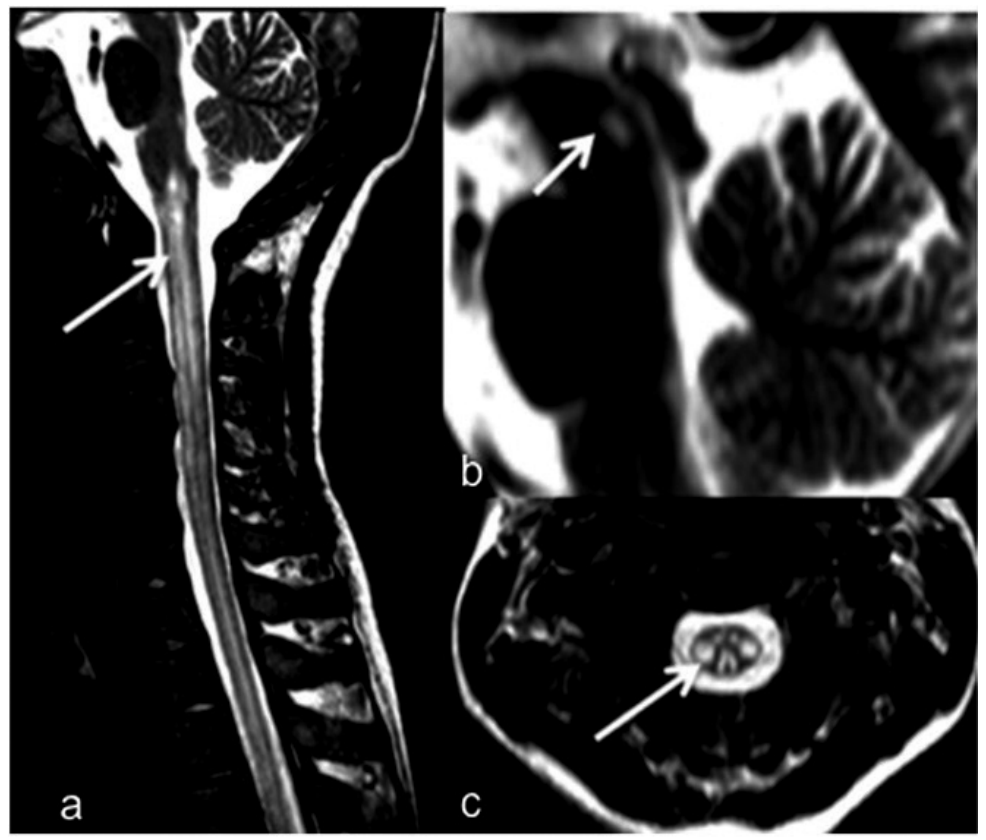

Fig. 3. Spinal cord signal changes in a 17 year old girlwithm.11778GNAmutation (Patient 10). 3a) T2Wsagittal image shows longitudinally extensive signal changes in the spinal cord and 3b) dorsal midbrain and 3c) T2W axial images of the spinal cord demonstrating the selective lateral and dorsal column signal changes.

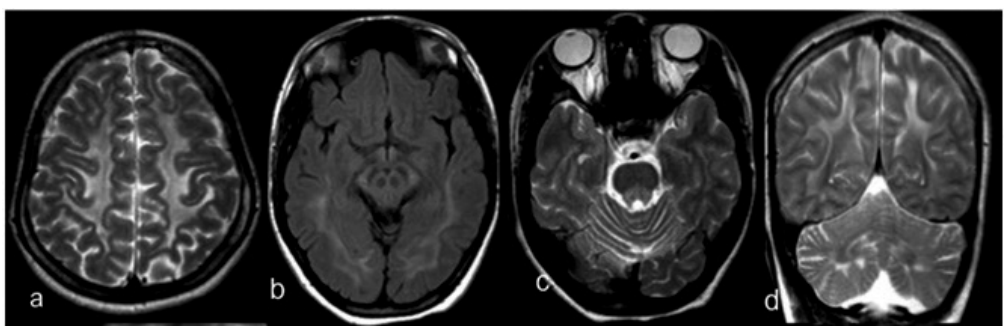

Fig.4.4a-d Leukoencephalopathy in KSS(Patient21).4a) Bilateral symmetrical signal changes in white matter on T2Wimages. $4 \mathrm{~b}$ ) FLAIR sequences showing brainstem signal changes. 4c) T2W sequences showing tectal plate hyperintensities. 4d) T2W coronal images showing bilateral symmetrical signal changes in cerebellar white matter. 


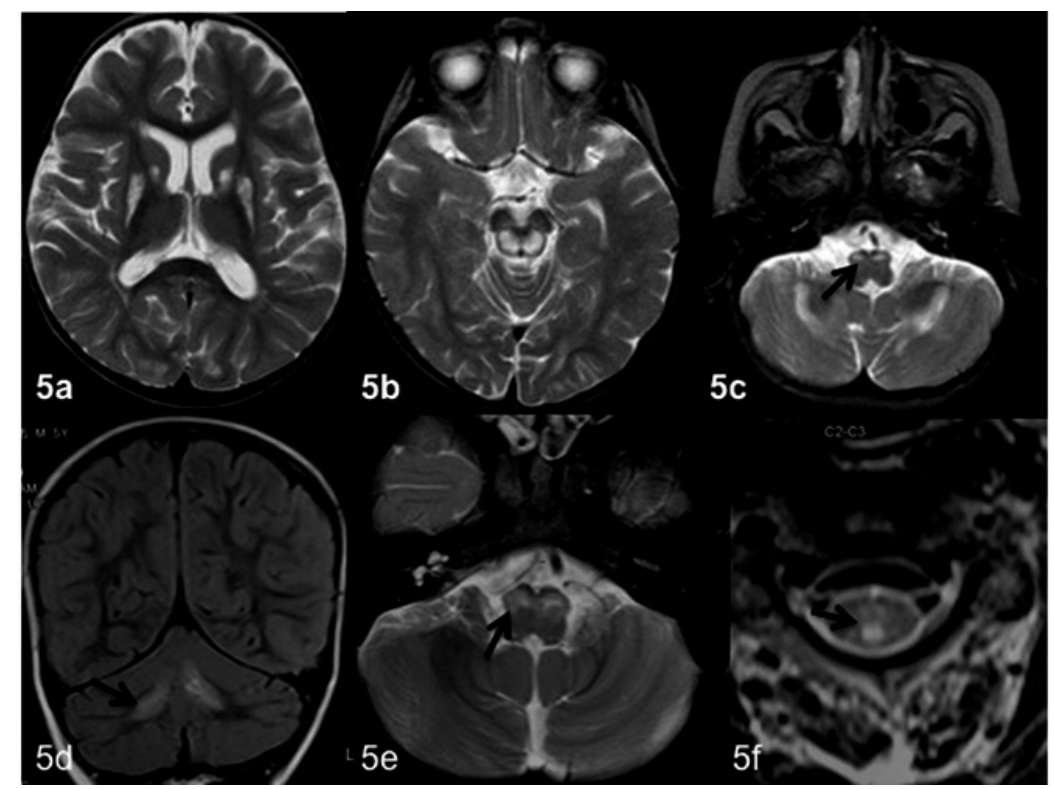

Fig. 5. Spectrum of MRI findings in patients with SURF1 mutation. 5a-c (Patient 22). T2W images showing bilateral symmetrical signal changes in caudate, putamen, tectal plate, inferior olivary nucleus and cerebellarwhitematter. 5d-f (Patient 26) FLAIR (5e), T2Waxial (5f) nd axial spinal cord (5f) images showing bilateral symmetrical signal changes in dentate, inferior olivary nucleus and dorsal column. 


\section{Chapter 2}

Supplementary Table: Definitions of well-characterized Mitochondrial syndromes based on phenotypes.

\begin{tabular}{|c|c|c|}
\hline $\begin{array}{l}\text { Mitochondrial } \\
\text { Syndromes }\end{array}$ & $\begin{array}{l}\text { Clinical \& Radiological } \\
\text { features }\end{array}$ & $\begin{array}{l}\text { Histopathological, Biochemical \& } \\
\text { Genetic characteristics }\end{array}$ \\
\hline $\begin{array}{l}\text { Mitochondrial } \\
\text { Encephalomyopathy } \\
\text { Lactic Acidosis and } \\
\text { Stroke like Episodes } \\
\text { (MELAS) }\end{array}$ & $\begin{array}{l}\text { Age of onset }<40 \text { years } \\
\text { Stroke-like episodes } \\
\text { Seizures and/or dementia } \\
\text { Short stature } \\
\text { Lactic acidosis } \\
\text { Cortical stroke like lesions on } \\
\text { Magnetic resonance imaging } \\
\text { findings, bilateral basal ganglia } \\
\text { calcification }\end{array}$ & $\begin{array}{l}\text { Histopathology: Ragged Red and } \\
\text { Blue fibers on muscle biopsy. } \\
\text { Strongly SDH positive vessels } \\
\text { Biochemical: Multiple complex } \\
\text { deficiencies } \\
\text { Genetic: m.3243 A>G mutation of } \\
\text { tRNA }{ }^{\text {leu }}\end{array}$ \\
\hline $\begin{array}{l}\text { Myoclonic Epilepsy with } \\
\text { Ragged Red Fibres } \\
\text { (MERRF) syndrome }\end{array}$ & $\begin{array}{l}\text { Onset around late childhood to } \\
\text { adulthood. } \\
\text { Progressive myoclonic epilepsy } \\
\text { Myopathy with ragged red } \\
\text { fibers } \\
\text { Slowly progressive dementia } \\
\text { Cerebellar ataxia. } \\
\text { Additional features: Optic } \\
\text { atrophy, Bilateral deafness, } \\
\text { Peripheral neuropathy, } \\
\text { Spasticity, Multiple lipomata }\end{array}$ & $\begin{array}{l}\text { Histopathology: Ragged red and } \\
\text { ragged blue fibers on muscle biopsy. } \\
\text { Biochemical assay: consistent } \\
\text { protein synthesis defect in } \\
\text { complexes } 1 \text { and } 4 \text {. Few cases may } \\
\text { show deficiencies of complexes } 3 \\
\text { and } 2 \text {. } \\
\text { Genetics: } \mathrm{m} .8344 \mathrm{G}>\mathrm{A} \text { and } \\
\mathrm{m} .8356 \mathrm{~T}>\mathrm{C} \text { of } \mathrm{tRNA} \text { lys }\end{array}$ \\
\hline Leigh's syndrome & $\begin{array}{l}\text { Progressive neurologic disease } \\
\text { with motor and intellectual } \\
\text { developmental delay } \\
\text { Signs and symptoms of brain } \\
\text { stem and/or basal ganglia } \\
\text { disease } \\
\text { Raised lactate concentration in } \\
\text { blood and/or cerebrospinal } \\
\text { fluid (CSF) } \\
\text { One or more of the following: } \\
\text { Characteristic features of Leigh } \\
\text { syndrome on neuro-imaging } \\
\text { Typical neuropathologic } \\
\text { changes: multiple focal } \\
\text { symmetric necrotic lesions in } \\
\text { the basal ganglia, thalamus, } \\
\text { brain stem, dentate nuclei, and } \\
\text { optic nerves. } \\
\text { Typical neuropathology in a } \\
\text { similarly affected sibling }\end{array}$ & $\begin{array}{l}\text { Heterogeneity in biochemical and } \\
\text { genetic findings. } \\
\text { Disruption of complex IV, also } \\
\text { called cytochrome } c \text { oxidase or } \\
\text { COX, is the most common cause of } \\
\text { Leigh syndrome. The most } \\
\text { frequently mutated gene in COX- } \\
\text { deficient Leigh syndrome is called } \\
\text { SURF1. } \\
\text { The most common mitochondrial } \\
\text { DNA mutation in Leigh syndrome } \\
\text { affects the MT-ATP6gene }\end{array}$ \\
\hline
\end{tabular}


Supplementary Table: Continued

\begin{tabular}{|c|c|c|}
\hline $\begin{array}{l}\text { Mitochondrial } \\
\text { Syndromes }\end{array}$ & $\begin{array}{l}\text { Clinical \& Radiological } \\
\text { features }\end{array}$ & $\begin{array}{l}\text { Histopathological, Biochemical \& } \\
\text { Genetic characteristics }\end{array}$ \\
\hline Leigh-like syndrome & $\begin{array}{l}\text { This term is often used for } \\
\text { individuals with clinical and } \\
\text { other features that are strongly } \\
\text { suggestive of Leigh syndrome } \\
\text { but who do not fulfill the } \\
\text { stringent diagnostic criteria } \\
\text { because of atypical } \\
\text { neuropathology (variation in } \\
\text { the distribution or character of } \\
\text { lesions or additional presence } \\
\text { of unusual features such as } \\
\text { extensive cortical destruction), } \\
\text { atypical or normal } \\
\text { neuroimaging, normal blood } \\
\text { and CSF lactate levels, or } \\
\text { incomplete evaluation }\end{array}$ & Same as that of Leighs syndrome \\
\hline $\begin{array}{l}\text { MELAS-Leighs overlap } \\
\text { syndrome }\end{array}$ & $\begin{array}{l}\text { Patients manifest clinical } \\
\text { features of MELAS \& Leighs } \\
\text { syndrome. Clinical } \\
\text { presentation could be variable }\end{array}$ & $\begin{array}{l}\text { MRI shows features of both MELAS } \\
\text { \& Leighs syndrome and includes } \\
\text { cortical stroke-like lesions and } \\
\text { bilateral symmetrical lesions of } \\
\text { basal ganglia and brainstem. }\end{array}$ \\
\hline Alpers syndrome & $\begin{array}{l}\text { Hypotonia } \\
\text { Seizures } \\
\text { Liver failure }\end{array}$ & Genetics: POLG1 mutations \\
\hline $\begin{array}{l}\text { Neurogenic muscle } \\
\text { weakness, ataxia, } \\
\text { retinitis pigmentosa } \\
\text { (NARP) syndrome }\end{array}$ & $\begin{array}{l}\text { Neurogenic muscle weakness. } \\
\text { Electromyography (EMG) and } \\
\text { nerve conduction studies may } \\
\text { demonstrate peripheral } \\
\text { neuropathy (which may be a } \\
\text { sensory or sensorimotor axonal } \\
\text { polyneuropathy). } \\
\text { Ataxia. Cerebral and cerebellar } \\
\text { atrophy may be noted on MRI. } \\
\text { Retinitis pigmentosa. }\end{array}$ & $\begin{array}{l}\text { Histopathology often normal } \\
\text { Genetics: Most common are point } \\
\text { mutations in the ATPAse } 6 \text { gene of } \\
\text { mitochondrial DNA }\end{array}$ \\
\hline
\end{tabular}


Chapter 2

Supplementary Table: Continued

\begin{tabular}{|c|c|c|}
\hline $\begin{array}{l}\text { Mitochondrial } \\
\text { Syndromes }\end{array}$ & $\begin{array}{l}\text { Clinical \& Radiological } \\
\text { features }\end{array}$ & $\begin{array}{l}\text { Histopathological, Biochemical \& } \\
\text { Genetic characteristics }\end{array}$ \\
\hline Kearns Sayre syndrome & $\begin{array}{l}\text { Progressive External } \\
\text { ophthalmoplegia, onset at age } \\
<20 \text { years } \\
\text { Pigmentary retinopathy } \\
\text { One of the following: High } \\
\text { CSF protein, cerebellar ataxia, } \\
\text { heart block } \\
\text { Additional features include } \\
\text { diabetes, hearing loss, } \\
\text { myopathy }\end{array}$ & $\begin{array}{l}\text { Histopathology: Ragged Red \& blue } \\
\text { fibers in muscle biopsy } \\
\text { Genetics: Large single deletion }\end{array}$ \\
\hline $\begin{array}{l}\text { Leber's Hereditary Optic } \\
\text { Neuropathy (LHON) }\end{array}$ & $\begin{array}{l}\text { Bilateral, painless, subacute } \\
\text { visual failure that develops } \\
\text { during young adult life. } \\
\text { Males are four to five times } \\
\text { more likely to be affected than } \\
\text { females }\end{array}$ & $\begin{array}{l}\text { Genetics: } 90 \% \text { have one of three } \\
\text { point mutations of mitochondrial } \\
\text { DNA: } m .3460 \mathrm{G}>\mathrm{A}, \mathrm{m} .11778 \mathrm{G}>\mathrm{A} \text {, or } \\
\text { m. } 14484 \mathrm{~T}>\mathrm{C} \text {. }\end{array}$ \\
\hline $\begin{array}{l}\text { Mitochondrial } \\
\text { spinocerebellar ataxia } \\
\text { Epilepsy syndrome }\end{array}$ & $\begin{array}{l}\text { Onset usually in teenage } \\
\text { Progressive gait unsteadiness } \\
\text { due to combined cerebellar } \\
\text { and sensory ataxia } \\
\text { Epileptic seizures } \\
\text { Head ache often migrainous in } \\
\text { nature }\end{array}$ & $\begin{array}{l}\text { Most commonly due to mutations } \\
\text { in POLG1 gene }\end{array}$ \\
\hline
\end{tabular}




\section{Discussion}

The present study analyzed the brain MRI findings in a cohort of patients with mitochondrial disorders and compared the findings in three important genotypes of mitochondrial disorders, namely mitochondrial point mutations and deletions, POLG1 and SURF1. The major studies on magnetic resonance imaging findings in cohort of patients with mitochondrial disorders have used varied classification systems and differ in the frequency of involvement of the anatomical structures ${ }^{12-16}$ Most of the studies have utilized a classification system, which include progressive cerebral and cerebellar atrophy, signal changes in deep gray matter, white matter and cortex. In a study on forty children with respiratory chain enzyme deficiencies, rapid progression of the atrophy involving all structures of the brain with variable involvement of the deep gray and white matter involvement were the most frequent findings. ${ }^{14}$ On the other hand, wide spread white matter hyperintensity, supratentorial cortical atrophy and cerebellar atrophy were the major findings in the study by Barragan-Campos et al., ${ }^{12}$ Myelin abnormalities also figure out as an important finding especially in studies involving children. In a recent study, which involved childhood onset mitochondrial disorders, the major findings included cerebral cortical involvement, basal ganglia/ diencephalic lesions and predominant lesions in the white matter. ${ }^{15}$ In the present series, cerebellar atrophy was predominant followed by basal ganglia and brainstem signal changes. The proportion of different phenotypes or genotypes in each study may explain the difference in frequency of the anatomical structure involvement in various studies. In addition to the usual anatomical areas stressed in previous studies our study also brings out the spinal cord signal changes in a significant proportion of the patients who underwent spinal cord imaging.

Studies analyzing magnetic resonance imaging findings and genotype correlations in large cohorts are far and few. In the study by Lebre et al, unique with its genotype correlations, the brain MRIs of thirty patients carrying known mutations in genes involved in complex I were compared with the brain MRIs of patients carrying known mutations in genes involved in the pyruvate dehydrogenase (PDH) complex as well as patients with MT-TL1 mutations. ${ }^{16}$ The study highlighted the predominant brain stem signal changes with at least one striatal anomaly in patients with complex I deficiency. ${ }^{16}$ These findings if present along with cortical lesions and cerebellar atrophy indicated a mitochondrial DNA mutation. Necrotizing white matter signal changes also correlated with complex I nuclear mutations. The present series showed that the findings associated with mitochondrial mutations were cerebral and cerebellar atrophy and cortical signal changes and basal ganglia mineraliza- 
tion. SURF1 mutation patients had the brain stem signal changes with or without the basal ganglia signal changes. No consistent pattern emerged in patients with POLG1 related disorder.

The presence of cerebral \& cerebellar atrophy as a major finding in the present study underscores the role of mitochondrial dysfunction in neurodegeneration. Diffuse cortical atrophy is described in about one third of the patients with encephalomyopathy ${ }^{6}$ and cerebral atrophy has been the sole imaging findings in upto a quarter of the patients with respiratory chain deficiencies. ${ }^{14}$ Even though the understanding of mechanisms underpinning the neurodegenerative changes are limited, post mortem examination of brain of patients with mitochondrial disorders have given robust evidence for the neurodegenerative changes occurring in mitochondrial disorders. ${ }^{18}$ In the New-Castle series of 15 brains dissected at postmortem from patients with genetically diverse mitochondrial disorders, evidence of atrophy was present in 12 with 50\% having MELAS syndrome secondary to $\mathrm{m} .3243$ mutations. It is noteworthy that in the present study the most severe cerebral atrophy was noted in two pediatric patients with $\mathrm{m} .3243 \mathrm{~A}>\mathrm{G}$ mutations and a long-standing disease of more than five years. Previous neuroimaging studies also have highlighted cerebral atrophy in long standing disease of patients with m.3243 mutations and the degree of atrophy did not correlate with the number of stroke like episodes. ${ }^{7,19}$ Both sudden loss as well as gradual attrition of the neuronal cells have been suggested as the mechanism. In the present study, the levels of heteroplasmy did not correlate with the age at onset or severity of the disease. The relationship of mtDNA mutation load, mitochondrial dysfunction and neuropathological features has been studied earlier in patients with MELAS ${ }^{20}$. There appeared to be no correlation between the heteroplasmy levels to cause COX deficiency within single neurons and the degree of pathology in affected region. ${ }^{20}$ It is unclear why patients with particular mutations show greater susceptibility to neurodegeneration. Progressive neuronal atrophy is also a feature of $P O L G$ related disorder and an Alpers syndrome phenotype. ${ }^{15}$ None of the patients in this series had Alpers syndrome phenotype and may explain the absence of atrophy in $P O L G$ group.

Cerebellar atrophy was the primary neuroimaging abnormality in a large series of pediatric patients. ${ }^{21}$ Even though cerebellar atrophy has been described in patients with cytochrome c oxidase deficiency and SURF1 deficiency, none of the patients with $S U R F 1$ deficiency in our series had cerebellar atrophy. Cerebellar atrophy as a predominant feature is also seen in primary CoQ deficiency. ${ }^{22}$ In addition to cerebellar atrophy, pontocerebellar hypoplasia also has been reported in patients with mitochondrial disorders and has now been emerged as a new phenotype of mitochondrial disorders caused by $R A R S 2$ mutation. ${ }^{23,24}$ Cerebellar atrophy was a prominent 
finding in patient with the m.9185T $>\mathrm{C}$ mutation. This patient presented with history of visual impairment, ataxia and parasthesias. Evaluation showed muscle weakness, retinitis pigmentosa, peripheral neuropathy and cerebellar ataxia suggesting neurogenic muscle weakness, ataxia retinitis pigmentosa (NARP) syndrome. This mutation in the ATPase gene is described only in few families and reported to cause heterogeneous phenotypes including Leighs syndrome, NARP, Charcot Marie Tooth disease, spinocerebellar ataxia, episodic weakness and motor neuron disease. ${ }^{25,}{ }^{29} \mathrm{MRI}$ findings in patients with the m.9185T >C mutation include that of Leighs syndrome, cerebellar atrophy and normal findings. ${ }^{25,27-29}$

The stroke like lesions, cortical lesions not confined to defined vascular territories were seen with the $\mathrm{m} .3243 \mathrm{~A}>\mathrm{G}$ mutations and in a child with $P O L G 1$. The characteristics of the stroke like lesions in $\mathrm{m} .3243$ mutations in this cohort were in accordance with the literature. ${ }^{30-32}$ Diffusion weighted imaging findings of the stroke like lesions depended on the time of imaging and diffusion restriction was seen only in those who have imaged at the acute stage. The initial insufficiency in neuronal energy causes cytotoxic edema and subsequent development of extra cellular edema increase the apparent diffusion coefficient. As a result those who are imaged later in the course of the stroke like episodes shows free diffusion of the lesions. ${ }^{30-32}$ Peculiar vascular changes known as mitochondrial angiopathy has been suggested as the pathogenic basis of the brain lesions in MELAS. ${ }^{33}$ This mitochondrial angiopathy was characterized by marked accumulation of mitochondria in the cell bodies of smooth muscle cells and endothelial cells. In addition, numerous smooth muscle cells in the tunica media also showed degeneration or necrosis, sporadically or in clusters. These abnormalities were most prominent in the walls of pial arterioles and small arteries up to $250 \mu$ in diameter and were less frequent and severe in the larger pial arteries, intracerebral arterioles and small arteries. ${ }^{33}$ Electron microscopic studies of brain capillaries in another patient with MELAS has shown hypertrophy of the endothelial cells, increased mitochondria in sub endothelial space and narrowing of the capillary lumen". ${ }^{34}$ These studies suggest the unique nature of the vascular lesions in MELAS patients.

The patients with bilateral symmetrical basal ganglia signal changes and m.3243A $>$ G mutation may represent MELAS-Leighs overlap syndrome. The MELAS/LS overlap syndrome has been previously described in association with $13513 \mathrm{G}>\mathrm{A}$ mutations in three patients. ${ }^{35}$ Brain autopsy in one case revealed infarctlike lesions in the cerebral cortex, basal ganglia and brainstem providing further insight into the distribution of the pathological lesions in MELAS/LS overlap syndrome ${ }^{35}$ Clinical features in these patients are characterized by features of both MELAS \& Leighs syndrome and presentation could be variable depending on the rela- 
tive contribution of the MELAS, Leighs or both. Our patients had presented with features of MELAS and the neuroimaging has revealed bilateral symmetrical basal ganglia lesions in addition to stroke like lesions. Both the patients developed brainstem dysfunction towards the end stage of the disease. This pattern of lesions also have been described in patients with complex I deficiency secondary to mitochondrial mutations. ${ }^{16}$

The additional findings of laminar necrosis and thalamic involvement noted in the cohort of 3243 mutation patients have been highlighted earlier. ${ }^{36,37}$ Mitochondrial diseases are the third common cause of laminar necrosis after cerebral ischemia and hypoxia. ${ }^{36}$ Though most frequently described in MELAS, it has also been described in TK2 related and TWINKLE related mitochondrial disorders. ${ }^{38,39}$ Thalamus is one of the areas other than cortical lesions involved in MELAS and at times may mimic Creutzfeld Jacob disease. ${ }^{40}$ Thalamic involvement as a sign of mitochondrial disorders have been also noted in POLG1 related disorders. It typically involves pulvinar and often occurs ipsilateral to the stroke like lesions. ${ }^{41}$

Pattern of mineralization in this cohort was heterogeneous and included, bilateral globus pallidi calcification, punctate basal ganglia calcification and diffuse dense calcification of caudate and putamen. Mineralisation was seen in both $M T D N A \mathrm{mu}-$ tations and POLG1, but none of the patients with SURF1 probably due to the early age of these patients. It is noteworthy that susceptibility weighted imaging revealed mineralization in all patients with $\mathrm{m} .3243$ mutations who have undergone the test. Globus pallidus hypointensity on T2 weighted images has been described as the earliest finding in patients with MELAS. ${ }^{42}$ Neuropathological studies have shown that the calcification in the basal ganglia is localized to the walls of the blood vessels within the basal ganglia. ${ }^{18,34}$ The neuronal populations are spared and there are no intraneuronal calcium deposits. This suggests the role of mitochondrial dysfunction causing mineralising microangiopathy as reported in one of the patients in this cohort earlier. ${ }^{43}$

Focal necrotic lesions involving the brainstem has been consistently reported in patients harboring complex I deficiency and both nuclear and mitochondrial DNA mutations. ${ }^{16}$ Present study showed brainstem signal changes in all the three groups. but significantly with SURF1 mutations. Inferior olivary nucleus was the most commonly involved nuclei in the brainstem. Hypertrophic olivary degeneration in patients with SURF1 \& POLG1 mutation as well as in children with mitochondrial disorders has already been highlighted. ${ }^{17,44}$

Spinal cord involvement is a recognized feature of certain mitochondrial disorders. ${ }^{45}$ The Spinal cord signal changes, as the predominant manifestation of mitochondrial disorder is an exceptional finding and reported in patients with clinical 
diagnosis of Leber's hereditary optic neuropathy and in patients with m.3460 mutations. ${ }^{46}$ Similar to the patient described by Jaros et al, the spinal cord signal changes in our patient with $\mathrm{m} .11778 \mathrm{G}>\mathrm{A}$ mutation was localized to the posterior and lateral columns. ${ }^{46}$ Spinal cord degeneration confined to posterior column is also seen in POLG1 related disorders and has been supported by histopathological studies. ${ }^{47,48}$ Spinal cord pathology is also reported in patients with mitochondrial myopathy encephalopathy, lactic acidosis and stroke like episodes syndrome. ${ }^{49}$ Spinal cords showed spongy state due to the presence of distended myelinated fibers with enlarged periaxonal spaces. The affected fibers had extensive microvacuolation of the inner myelin sheath with occasional vesicular changes. There was also presence of macrophages near the degenerated myelin and stripping of the myelin lamelle by macrophage. Prominent morphological changes were also observed in oligodendrocytes. Authors concluded that demyelination secondary to degeneration of oligodendrocytes occurs in MELAS. The long segment demyelination, as observed in our patient also support this. Identifying the mitochondrial etiology in patients with primary spinal cord involvement has important therapeutic and prognostic implications.

Leukoencephalopathy in the context of mitochondrial disorders have been largely described in mitochondrial syndromes associated with KSS, MNGIE and in patients harboring mutations in the gene encoding complex I, complex II and complex IV assembly factors. ${ }^{50,51}$ They are increasingly recognized in various tRNA acyl synthase deficiencies. ${ }^{52}$ The presence of leukoencephalopathy in this cohort was less compared to the earlier and recent reports and was noted in one patient each from the primary mitochondrial group \& SURF1. One reason for the less number of patients with leukoencephalopathy in this series may be due to lack of screening for the complex I nuclear mutations. Myelinopathy or white matter disease as seen in our patient is described as the hallmark of Kearns Sayre syndrome. ${ }^{53}$ Experimental studies have suggested preferential loss of myelin associated glycoprotein in patients with KSS to account for the leukoencephalopathy. ${ }^{54}$ Leukoencephalopathy as seen in the patient with $S U R F 1$ mutation has been described earlier. ${ }^{55}$ Leukoencephalopathy in the context of SURF1 \& POLG1 mutation is described earlier, but less commonly reported in $P O L G 1$ patients. ${ }^{56,57}$

MRI findings in POLG1 patients were heterogeneous and there was no consistent pattern. Three patients had the p.L304R mutation in a homozygous state as reported previously in patients with South East Asian ethnicity and in a French cohort. ${ }^{58,59}$ Findings in previous reported $P O L G 1$ cohorts include stroke like lesions as in MELAS, bilateral inferior olivary nucleus degeneration, dorsal column degeneration and mild cerebellar atrophy. ${ }^{60-63}$ Bilateral olivary lesions and pulvinar lesions 
were noted in the patient with p.W748S + p.E1143G mutation as reported in European patients. ${ }^{60}$ This patient also had a homozygous p.R369G mutation in POLG2. This POLG2 mutation has proven pathogenicity by reducing affinity of the p55 accessory subunit for the p140 catalytic subunit of POLG by 4.5 fold. Since POLG1 and POLG2 act in tandem in mtDNA replication, mutations in POLG2 might have exacerbated POLG1 dysfunction and stalled DNA replication, resulting in the clinical phenotype. ${ }^{64}$

All patients with SURF1 mutation had Leighs syndrome and the imaging findings were mainly characterized by variable combination of bilateral symmetrical signal changes in the basal ganglia, brainstem, dentate nuclei and cerebellar white matter. In a large retrospective multicenter study on children with cytochrome c oxidase deficiency, 47 children had SURF1 mutation. All children with SURF1 mutation had Leighs syndrome as defined by the bilateral symmetrical signal changes in the basal ganglia and /or in the brain stem. ${ }^{65}$ Similar to the study by Bohm et al, all patients with SURF1 mutation in the present study also had a Leighs syndrome phenotype.

Two patients had normal MRI findings. Mitochondrial disorders may follow a very slowly progressive course and the neuroradiological findings may be subtle or atypical initially. ${ }^{10}$ The need for regular and vigilant follow up and serial studies in patients with mitochondrial disease has been stressed earlier. ${ }^{65}$ All follow up scans in this series showed progressive changes either in the form of volume loss in the involved structures or appearance of new anatomical lesions. These findings indicate that the changes are dynamic in nature and follow up imaging studies should be carried out routinely in patients with mitochondrial disorders.

In conclusion this study highlights the heterogeneous magnetic resonance imaging findings of genetically well-characterized cohort of patients with mitochondrial disorders. Definite differences were noted in the frequency of anatomical involvement in the three groups. Limitations of the study include the small sample size and the fact that the nuclear gene screening was limited to two genes. Nevertheless, this study is important since constantly growing number of genes implicated in mitochondrial dysfunctions requires regular reevaluation of correlations between the genotype and the magnetic resonance imaging phenotypes. Analysis of the brain MRI correlates of newly discovered genetic alterations might establish more robust and specific imaging phenotypes, helping with a more confident diagnosis. Familiarity with the imaging findings in different genotypes of mitochondrial disorders along with careful analysis of the family history, clinical presentation, biochemical findings, histochemical and structural analysis will help the physician for targeted metabolic and genetic testing. 


\section{References}

1. Wong LJ. Next generation molecular diagnosis of mitochondrial disorders. Mitochondrion 2013; 13:379-87.

2. Tang S, Wang J, Zhang VW, et al., Transition to next generation analysis of the whole mitochondrial genome: a summary of molecular defects. Hum Mutat 2013; 34:882-93.

3. Graham BH. Diagnostic challenges of mitochondrial disorders: complexities of two genomes. Methods Mol Biol 2012; 837:35-46.

4. Bricout M, Grévent D, Lebre AS, et al., Brain imaging in mitochondrial respiratory chain deficiency: combination of brain MRI features as a useful tool for genotype/phenotype correlations. J Med Genet 2014; 51:429-35.

5. Saneto RP, Friedman SD, Shaw DW. Neuroimaging of mitochondrial disease. Mitochondrion 2008; 8: 396-413.

6. Haas R, Dietrich R. Neuroimaging of mitochondrial disorders. Mitochondrion 2004; 4:471-490

7. Finsterer J. Central nervous system imaging in mitochondrial disorders. Can J Neurol Sci 2009; 36:143-153.

8. Finsterer J. Central nervous system manifestations of mitochondrial disorders. Acta Neurol Scand 2006; 114:217-38.

9. Brown GK, Squier MV. Neuropathology and pathogenesis of mitochondrial diseases. J Inherit Metab Dis 1996; 19:553-72.

10. Barkovich AJ, Good WV, Koch TK, Berg BO. Mitochondrial disorders: analysis of their clinical and imaging characteristics. AJNR Am J Neuroradiol 1993; 14: 1119-37.

11. Valanne L, Ketonen L, Majander A, et al., Neuroradiologic findings in children with mitochondrial disorders. AJNR Am J Neuroradiol 1998; 19:369-77.

12. Barragán-Campos HM, Vallée JN, Lô D, et al., Brain magnetic resonance imaging findings in patients with mitochondrial cytopathies. Arch Neurol. 2005; 62:737-42.

13. Muñoz A, Mateos F, Simón R,et al., Mitochondrial diseases in children: neuroradiological and clinical features in 17 patients. Neuroradiology 1999; 41:920-8.

14. Kim J, Lee SK, Kim EY, et al., Neuroradiologic findings in children with mitochondrial disorder: correlation with mitochondrial respiratory chain defects. Eur Radiol 2008; 18:1741-8

15. Sofou K, Steneryd K, Wiklund LM, Tulinius M, Darin N. MRI of the brain in childhood-onset mitochondrial disorders with central nervous system involvement. Mitochondrion 2013; 13:364-71.

16. Lebre AS, Rio M, Faivre d'Arcier L, et al., A common pattern of brain MRI imaging in mitochondrial diseases with complex I deficiency. J Med Genet 2001; 48:16-23.

17. Bindu PS, Taly AB, Sonam K et al., Bilateral hypertrophic olivary nucleus degeneration on magnetic resonance imaging in children with Leigh and Leigh-like syndrome. Br J Radiol 2014; 87:20130478

18. Lax NZ, Jaros E. Neurodegeneration in primary mitochondrial disorders. In mitochondrial dysfunction in neurodegenerative disorders. Reev AK (eds) Springer-Verlag London Limited. 2012 p. 21-41

19. Sue CM, Crimmins DS, Soo YS, et al., Neuroradiological features of six kindreds with MELAS tRNALeu A3243G point mutation: implications for pathogenesis. J Neurol Neurosurg Psychiatry 1998; 65:233-240

20. Betts J, Jaros E, Perry RH, et al., Molecular neuropathology of MELAS: level of heteroplasmy in individual neurons and evidence of extensive vascular involvement. Neuropathol Appl Neurobiol 2006; 32:359-73.

21. Scaglia F, Wong LJ, Vladutiu GD, Hunter JV. Predominant cerebellar volume loss as a neuroradiologic feature of pediatric respiratory chain defects. AJNR Am J Neuroradiol 2005; 26:1675-80. Erratum in: AJNR Am J Neuroradiol. 2005; 26: 2165. 


\section{Chapter 2}

22. Lamperti C, Naini A, Hirano M, et al., Cerebellar ataxia and coenzyme Q10 deficiency. Neurology 2003; 60:1206-1208

23. De Koning TJ, de Vries LS, Groenendaal F, et al., Pontocerebellar hypoplasia associated with respiratory-chain defects. Neuropediatrics 1998;30:93-95

24. Cassandrini D, Cilio MR, Bianchi M, et al., Pontocerebellar hypoplasia type 6 caused by mutations in RARS2: definition of the clinical spectrum and molecular findings in five patients. J Inherit Metab Dis 2013;36:43-53.

25. Childs AM, Hutchin T, Pysden K, et al.,Variable phenotype including Leigh Syndrome with a 9185T $>C$ mutation in the mtATP6 gene Neuropediatrics 2007; 38: 313-316.

26. Pitceathly RD, Murphy SM, Cottenie E, et al., Genetic dysfunction of MT-ATP6 causes axonal Charcot-Marie-Tooth disease. Neurology 2012;11; 79:1145-54

27. Pfeffer G, Blakely EL, Alston CL et al., Adult-onset spinocerebellar ataxia syndromes due to MTATP6 mutations Journal of Neurology, Neurosurgery and Psychiatry 2012;83: 883-886

28. Aure K, Dubourg O, Jardel C, et al., Episodic weakness due to mitochondrial DNA MT-ATP6/8 mutations Neurology 2013; 81: 1810-1818 .

29. Brum M, Semedo C, Guerreiro R, Pinto Marques J et al., Motor Neuron Syndrome as a New Phenotypic Manifestation of Mutation 9185T>C in Gene MTATP6. Case Rep Neurol Med. 2014:701761

30. Iizuka T, Sakai F, Suzuki N, Hata T, Tsukahara S, Fukuda M, et al., Neuronal hyperexcitability in stroke-like episodes of MELAS syndrome. Neurology 2002; 59:816-24.

31. Iizuka T, Sakai F, Kan S, Suzuki N. Slowly progressive spread of the stroke-like lesions in MELAS. Neurology 2003; 61:1238-44

32. Ito H, Mori K, Kagami S.Neuroimaging of stroke-like episodes in MELAS. Brain Dev 2011; 33:283-8

33. Ohama E, Ohara S, Ikuta F, Tanaka K, Nishizawa M, Miyatake T. [Mitochondrial angiopathy in the cerebral blood vessels of MELAS (mitochondrial myopathy, encephalopathy, lactic acidosis and strokelike episodes)]. No To Shinkei 1988; 40:109-18.

34. Kishi M, Yamamura Y, Kurihara T, et al., An autopsy case of mitochondrial encephalomyopathy: biochemical and electron microscopic studies of the brain. J Neurol Sci 1988; 86:31-40

35. Wang Z, Qi XK, Yao S, Chen B, et al., Phenotypic patterns of MELAS/LS overlap syndrome associated with m.13513G $>$ A mutation, and neuropathological findings in one autopsy case. Neuropathology 2010; 30:606-14.

36. Finsterer J. Laminar cortical necrosis in mitochondrial disorders. Clin Neurol Neurosurg 2009; 111:655-8.

37. Valanne L, Paetau A, Suomalainen A, Ketonen L, Pihko H. Laminar cortical necrosis in MELAS syndrome: MR and neuropathological observations. Neuropediatrics 1996; 27:154-60.

38. Lönnqvist T, Paetau A, Valanne L, Pihko H. Recessive twinkle mutations cause severe epileptic encephalopathy Brain 2009; 132:1553-62

39. Götz A, Isohanni P, Pihko H, Paetau A, Herva R, Saarenpää-Heikkilä O, et al., Thymidine kinase 2 defects can cause multi-tissue mtDNA depletion syndrome. Brain 2008; 131:2841-50.

40. Weiss D, Brockmann K, Nägele T, Gasser T, Krüger R. Rapid emergence of temporal and pulvinar lesions in MELAS mimicking Creutzfeldt-Jakob disease. Neurology 2011; 77:914.

41. Tzoulis C, Neckelmann G, Mørk SJ, Engelsen BE, Viscomi C, Moen G, Ersland L, Zeviani M, Bindoff LA. Localized cerebral energy failure in DNA polymerase gamma-associated encephalopathy syndromes. Brain 2010; 133(Pt 5):1428-37.

42. Renard D, Campello C, Le Floch A, Castelnovo G, Taieb G. Globus pallidus and substantia nigra hypointensities on T2-weighted imaging in MELAS. J Neurol 2012; 259: 2720-2.

43. Sonam K, Bindu PS, Taly AB, et al., Clinical and Neuroimaging Featuresin Two Children with Mutations in the Mitochondrial ND5 Gene. Neuropediatrics. 2015; 46; 277-281 
44. Kinghorn KJ, Kaliakatsos M, Blakely EL, et al., Hypertrophic olivary degeneration on magnetic resonance imaging in mitochondrial syndromes associated with POLG and SURF1 mutations. J Neurol 2013;260:3-9.

45. Scheper GC, van der Klok T, van Andel RJ, et al., Mitochondrial aspartyl-tRNA synthetase deficiency causes leukoencephalopathy with brainstem and spinal cord involvement and lactate elevation. Nat Genet 2007; 39: 534-9.

46. Jaros E, Mahad DJ, Hudson G, et al., Primary spinal cord neurodegeneration in Leber hereditary optic neuropathy. Neurology 2007; 69:214-6.

47. Hopkins SE, Somoza A, Gilbert DL. Rare autosomal dominant POLG1 mutation in a family with metabolic strokes, posterior column spinal degeneration, and multi-endocrine disease. J Child Neurol 2010; 25:752-6.

48. Lax NZ, Whittaker RG, Hepplewhite PD, et al., Sensory neuronopathy in patients harbouring recessive polymerase $\gamma$ mutations. Brain 2012;135(Pt 1): 62-71.

49. Ohara S, Ohama E, Takahashi H, et al., Alterations of oligodendrocytes and demyelination in the spinal cord of patients with mitochondrial encephalomyopathy. J Neurol Sci 1988; 86: 19-29

50. Wong LJ. Mitochondrial syndromes with leukoencephalopathies. Semin Neurol 2012;32:55-61.

51. Morató L, Bertini E, Verrigni D, et al., Mitochondrial dysfunction in central nervous system white matter disorders. Glia 2014; 62:1878-94.

52. Steenweg ME, Ghezzi D, Haack T, et al., Leukoencephalopathy with thalamus and brainstem involvement and high lactate 'LTBL' caused by EARS2 mutations. Brain 2012; 135:1387-94.

53. Filosto M, Tomelleri G, Tonin P, et al., Neuropathology of mitochondrial diseases. Biosci Rep 27:2330.

54. Lax NZ, Campbell GR, Reeve AK, et al., Loss of myelin-associated glycoprotein in kearns-sayre syndrome. Arch Neurol 2012; 69:490-9.

55. Rahman S, Brown RM, Chong WK, et al., A SURF1 gene mutation presenting as isolated leukodystrophy. Ann Neurol 2001;49:797-800.

56. Bao X, Wu Y, Wong LJ, et al., Alpers syndrome with prominent white matter changes. Brain Dev 2008; 30:295-300.

57. Echaniz-Laguna A, Chassagne M, de Sèze J, et al., POLG1 variations presenting as multiple sclerosis. Arch Neurol 2010; 67:1140-3.

58. Tang S, Wang J, Lee NC, et al., Mitochondrial DNA polymerase gamma mutations: an ever expanding molecular and clinical spectrum. J Med Genet. 2011; 48:669-81

59. Rouzier C, Chaussenot A, Serre V, et al., Quantitative multiplex PCR of short fluorescent fragments for the detection of large intragenic POLG rearrangements in a large French cohort. Eur J Hum Genet. 2014; 22:542-50.

60. Tzoulis C, Engelsen BA, Telstad W, et al., The spectrum of clinical disease caused by the A467Tand W748S POLG mutations: a study of 26 cases. Brain 2006; 129 (Pt 7): 1685-92

61. Ferrari G, Lamantea E, Donati A, et al., Infantile hepatocerebral syndromes associated with mutations in the mitochondrial DNA polymerase-gamma A. Brain 2005; 128(Pt4): 723-3

62. Horvath R, Hudson G, Ferrari G, et al., Phenotypic spectrum associated with mutations of the mitochondrial polymerase gamma gene. Brain 2006; 129(Pt7): 1674-84

63. Young MJ, Longley MJ, Li F-Y, et al., Biochemical analysis of human POLG2 variants associated with mitochondrial disease. Hum Mol Genet 2011; 20:3052-3066.

64. Böhm M, Pronicka E, Karczmarewicz E, et al., Retrospective, multicentric study of 180 children with cytochrome C oxidase deficiency. Pediatr Res. 2006; 59:21-6.

65. Finsterer J. Mitochondriopathies. Eur J Neurol 2004; 11:163-86. 



\section{Chapter}

\section{Peripheral Neuropathy in Genetically Characterized Patients with Mitochondrial Disorders: A Study from South India}

Bindu PS,, Govindaraju C, Sonam K, Nagappa M, Chiplunkar S , Kumar R, Gayathri N, Srinivas Bharath MM, Arvinda HR, Sinha S, Khan NA, Govindaraj P, Nunia V, Paramasivam A, Thangaraj K, Taly AB.

Mitochondrion. 2016; 27:1-5 


\section{Abstract}

Background: There are relatively few studies, which focus on peripheral neuropathy in large cohorts of genetically characterized patients with mitochondrial disorders. This study sought to analyse the pattern of peripheral neuropathy in a cohort of patients with mitochondrial disorders.

Methods: The study subjects were derived from a cohort of 52 patients with a genetic diagnosis of mitochondrial disorders seen over a period of 8 years (2006-2013). All patients underwent nerve conduction studies and those patients with abnormalities suggestive of peripheral neuropathy were included in the study. Their phenotypic features, genotype, pattern of peripheral neuropathy and nerve conduction abnormalities were analysed retrospectively.

Results: The study cohort included 18 patients (Age range: 18 months-50 years, M:F1.2:1). The genotype included mitochondrial DNA point mutations $(\mathrm{n}=11), S U R F 1$ mutations $(\mathrm{n}=4)$ and $P O L G 1(\mathrm{n}=3)$. Axonal neuropathy was noted in 12 patients (sensorimotor: $\mathrm{n}=4$; sensory: $\mathrm{n}=4$; motor: $\mathrm{n}=4$ ) and demyelinating neuropathy in 6 . Phenotype-genotype correlations revealed predominant axonal neuropathy inmitochondrial DNA point mutations and demyelinating neuropathy in SURF1. Patients with $P O L G$ related disorders had both sensory ataxic neuropathy and axonal neuropathy.

Conclusion: A careful analysis of the family history, clinical presentation, biochemical, histochemical and structural analysis may help to bring out the mitochondrial etiology in patients with peripheral neuropathy and may facilitate targeted gene testing. Presence of demyelinating neuropathy in Leighs syndrome may suggest underlying SURF1 mutations. Sensory ataxic neuropathy with other mitochondrial signatures should raise the possibility of $P O L G$ related disorder. 


\section{Introduction}

Mitochondria have a number of essential roles in neuronal growth, survival and function. ${ }^{1}$ In addition to maintaining energy milieu within the cell body, dendrites and axons, mitochondrial ATP production also supports synapse assembly, generation of action potentials and synaptic transmission in peripheral nerves. ${ }^{2}$ The peculiar morphological features of peripheral nerves such as small cell body, arborizing dendrites with elaborate anchors and thin long axons necessitates specialized mechanisms to efficiently distribute mitochondria to distal areas of nerves. ${ }^{1}$ Mitochondria are concentrated on the nodes of Ranvier and nerve terminals and transmission of energy across long distances in peripheral nerves is facilitated by both anterograde and retrograde mitochondrial transport. ${ }^{3}$ This is regulated by a continuous process of mitochondrial fusion and fission referred to as mitochondrial 'dynamics'. Abnormalities in mitochondrial dynamics are being increasingly identified as a cause of peripheral nerve dysfunction and they form an important subgroup of mitochondrial neuropathies with a Charcot-Marie-Tooth (CMT) disease like phenotype. ${ }^{4}$ Given the important role of mitochondria in neuronal function, peripheral neuropathy is often seen in patients with mitochondrial disorders. ${ }^{5,6}$ Peripheral neuropathy is reported in one-third of patients with mitochondrial disorders, but is often under-recognized due to overwhelming involvement of the central nervous system. ${ }^{7}$ The severity of neuropathy varies from mild or subclinical, to severe and may be the main or only feature of a mitochondrial disorder. ${ }^{8}$

Molecular genetic classification of peripheral neuropathies related to mitochondrial disorders is still evolving. Peripheral neuropathy is uncommon and a nonprominent feature of disorders arising from point mutations of mitochondrial DNA (mtDNA).,8,9 However neuropathy is a predominant feature in neuropathy, ataxia, and retinitis pigmentosa (NARP) syndrome secondary to mutations in Mitochondrial Encoded ATP Synthase 6 (MTATP6). ${ }^{10,11}$ Neuropathy is more frequently related to a defect in nuclear DNA (nDNA) especially in nuclear-mitochondrial inter-genomic communication disorders. ${ }^{12}$ In addition peripheral neuropathy occurs as a unique or sole manifestation in disorders of mitochondrial dynamics associated with mutations in Mitofusin-2 (MFN2) and Ganglioside-induced Differentiation Associated Protein$1\left(\right.$ GDAPI) ${ }^{6}$

The recognition of mitochondrial disorder as the underlying etiology of peripheral neuropathy is important in clinical practice for targeted metabolic and genetic testing. Phenotype genotype correlations in mitochondrial neuropathies are still evolving and need to be defined further. This study reports the profile of peripheral 
neuropathy in a cohort of patients with genetically characterized mitochondrial disorder.

\section{Patients and methods:}

The Institute Ethics Committee of National Institute of Mental Health and Neurosciences, Bangalore, India, approved the study protocol. The recruitment and selection of the patients were done as per the methods described previously. ${ }^{13}$ Over a period of eight years (2006-2013) a total of 605 patients were recruited as part of a study on neurological disorders associated with mitochondrial DNA mutations. All patients underwent a complete clinical and laboratory evaluation and follow-up by a single clinical team (ABT, PSB, SS, MN). Patients were recruited into the study when a comprehensive evaluation, with serum lactate, muscle histopathology, respiratory chain complex assays, brain magnetic resonance imaging, nerve conduction studies, electroencephalography and evoked potential studies, tailored to the clinical phenotype suggested a probable diagnosis of mitochondrial disorder. The evaluation also included estimation of fasting blood sugar, thyroid function tests, and serum vitamin B12 levels as a part of diagnostic work up of peripheral neuropathy.

Standard definitions were used for the phenotypic characterization of the classical mitochondrial syndromes. Complete mitochondrial genome sequencing was done in all the patients. Genetic evaluation also included sequencing of the nuclear genes: Polymerase gamma 1 and 2 (POLG 1 and 2$)(\mathrm{n}=304)$ and Surfeit Locus Protein $1(S U R F 1)(\mathrm{n}=91)$. Mitochondrial gene sequencing revealed 128 variations in 135 patients, which included known pathogenic mutations $(\mathrm{n}=20)$, benign polymorphisms/ possible disease associated mutations $(\mathrm{n}=37)$ and novel variations $(\mathrm{n}=$ 70). Mitochondrial rearrangements were looked for in eight patients and one showed single large deletion. $P O L G$ screening revealed mutations in 24 patients ( $P O L G 1 \mathrm{n}=12, P O L G 2 \mathrm{n}=12$ ), while mutations in SURF1 were noted in seven. All 52 patients with a genetic diagnosis underwent nerve conduction studies and those patients who had electrophysiological evidence of neuropathy $(n=18)$ were included in final analysis. Their phenotypic features, nerve conduction abnormalities and genetic diagnoses were reviewed.

\subsection{Nerve conduction studies:}

Nerve conduction studies were performed using standard techniques. Median, ulnar, common peroneal and sural nerve recordings were done. Difference in recorded values greater than two standard deviation from the mean values standardized at 
our laboratory was considered abnormal (supplementary table 1). The normative values have been collected using the methods described previously. ${ }^{14,15}$ For children included in the study, we used the reference values given by Parano et al and Gamstorp et al., ${ }^{16,17}$ Based on the nature of electrophysiological abnormalities, patients were categorised to (i) axonal or demyelinating neuropathy; and (ii) sensory, motor or sensorimotor neuropathy. Demyelination in children was defined using the criteria for Chronic Inflammatory Demyelinating Polyneuropathy by Nevo et al., ${ }^{18}$

\section{Results:}

There were 18 patients (Age range: 18 months-50 years, M:F- 1.2:1) in the study. The phenotypes, genotypes and the type of neuropathy of these patients are summarised in Table 1. Consanguinity was noted in 10 (50\%) and a positive family history in 5 (25\%). Phenotypes included Leighs and Leigh like syndrome ( $\mathrm{n}=5)$, Myoclonic Epilepsy with Ragged Red Fibers syndrome (MERRF,n=4), Mitochondrial Encephalopathy Lactic Acidosis Stroke like syndrome (MELAS, $n=3$ ), and one patient each of ataxia neuropathy, Mitochondrial Spinocerebellar Ataxia Epilepsy (MSCAE), Neuropathy Ataxia Retinitis Pigmentosa syndrome (NARP), chronic progressive ophthalmoplegia, Lebers Hereditary Optic Neuropathy (LHON)plus syndrome, and sensory ataxic neuropathy, dysarthria, ophthalmoparesis (SANDO) syndrome. Signs of peripheral neuropathy such as wasting of the distal muscles of the lower limb, weakness and hyporeflexia were noted in 14 (77.8\%) patients. Positive sensory symptoms were present in two and autonomic symptoms in one. One patient with MERRF syndrome (Patient 3) had diabetes. Diagnostic evaluation for other causes of peripheral neuropathy was negative in rest of the patients.

\subsection{Genotypic Findings:}

The genotype of patients included: Mitochondrial point mutations, $\mathrm{n}=11$; SURF1 mutations, $\mathrm{n}=4$; and POLG1 Mutations, $\mathrm{n}=3$.

\subsection{Histopathological findings:}

One patient underwent nerve biopsy (Patient 1), which showed significant loss of large fibers in Kulchitsky Pal stain. Other findings included schwann cell proliferation and regenerating clusters. 


\subsection{Nerve conduction abnormalities:}

Details of nerve conduction studies of the entire cohort is given in supplementary table 1. Axonal neuropathy was noted in 12 (66.6\%) patients. This could be further classified as sensory axonal $(n=4,22.2 \%)$, motor axonal $(n=4,22.2 \%)$ and sensorimotor axonal $(n=4,22.2 \%)$. Sensorimotor demyelinating neuropathy was noted in six patients (30\%). Majority had axonal neuropathy which was length dependent and involved the sensory more than motor nerves. In majority of the patients, neuropathy was mild and was detected based on the presence of signs of neuropathy and confirmed by electrophysiological studies. Positive sensory symptoms were noted in two patients, one with NARP syndrome and other with MELAS syndrome. Three patients had a sensory ataxic neuropathy and their genetic analysis revealed mutations in POLG1 $(\mathrm{n}=2)$ and $\mathrm{m} .8363 \mathrm{~A}>\mathrm{G}(\mathrm{n}=1)$.

\subsection{Peripheral neuropathy, phenotype and genotype correlations.}

\subsubsection{Mitochondrial point mutations:}

Of the 20 patients with a known pathogenic mutation in the mitochondrial DNA, 11 patients (55\%) had evidence of peripheral neuropathy. Most common type of neuropathy in patients with mitochondrial DNA point mutations was axonal neuropathy of sensorimotor, motor or sensory type. The only exception was a patient with mutation in m.9185T >C, who had demyelinating neuropathy. This patient presented with visual impairment, ataxia and paresthesias. Evaluation showed neurogenic muscle weakness, ataxia, retinitis pigmentosa and peripheral neuropathy suggesting NARP syndrome. All patients with m.8334A $>\mathrm{G}$ mutation in our cohort showed evidence of axonal neuropathy. On the other hand, only three patients out of nine patients with MELAS syndrome (33.3\%) had evidence of neuropathy.

\subsubsection{SURF1 mutations:}

Of the seven patients with SURF1 mutation, four $(57.1 \%)$ showed evidence of demyelinating neuropathy.

\subsubsection{POLG mutations:}

Of the 24 patients with POLG related disorders, three (12.5\%) had peripheral neuropathy. Two patients had clinical features of sensory ataxic neuropathy, while in the third patient, the neuropathy was subclinical. The patient with SANDO clinically had an ataxic neuropathy but the nerve conduction studies showed a demyelinating peripheral neuropathy. In the cohort of patients with mutations in POLG1, five 
patients manifested with chronic progressive ophthalmoplegia (CPEO) of which two had peripheral neuropathy. Of the remaining three patients without peripheral neuropathy only one patient had an autosomal dominant CPEO while the rest had isolated PEO.

Table 1: Phenotype genotype and type of peripheral neuropathy in patients with mitochondrial disorders

\begin{tabular}{|c|c|c|c|c|c|}
\hline $\begin{array}{l}\text { Sl. } \\
\text { No }\end{array}$ & $\begin{array}{l}\text { Age at } \\
\text { diagnosis } \\
\text { /Gender }\end{array}$ & Gene & Mutation & Diagnosis & $\begin{array}{l}\text { Type of } \\
\text { Neuropathy }\end{array}$ \\
\hline 1 & ${ }^{*} 12$ yrs/ F & mt-tRNA ${ }^{\text {Lys }}$ & $\mathrm{m} .8344 \mathrm{G}>\mathrm{A}$ & MERRF & $\begin{array}{l}\text { Sensory Motor } \\
\text { Axonal }\end{array}$ \\
\hline 2 & *8 yrs/ M & mt-tRNA ${ }^{\text {Lys }}$ & $\mathrm{m} .8344 \mathrm{G}>\mathrm{A}$ & MERRF & $\begin{array}{l}\text { Sensory motor } \\
\text { axonal }\end{array}$ \\
\hline 3 & 41 yrs/ M & mt-tRNA ${ }^{\text {Lys }}$ & $\mathrm{m} .8344 \mathrm{G}>\mathrm{A}$ & MERRF & Sensory Axonal \\
\hline 4 & $28 \mathrm{yrs} / \mathrm{M}$ & mt-tRNA ${ }^{\text {Lys }}$ & $\mathrm{m} .8344 \mathrm{G}>\mathrm{A}$ & MERRF & Sensory Axonal \\
\hline 5 & 17 yrs/ M & mt-tRNA ${ }^{\mathrm{Leu}}$ & n. $3243 \mathrm{~A}>\mathrm{G}$ & MELAS & $\begin{array}{l}\text { Sensory motor } \\
\text { Axonal }\end{array}$ \\
\hline 6 & 11 yrs/ F & $m t-t R N A^{\text {Leu }}$ & n. $3243 \mathrm{~A}>\mathrm{G}$ & MELAS & Motor Axonal \\
\hline 7 & 36 yrs/ F & $m t-t R N A^{\text {Leu }}$ & n. $3243 A>G$ & MELAS & Sensory axonal \\
\hline 8 & 13 yrs/ M & mt- RNA Lys & $\mathrm{m} .8363 \mathrm{~A}>\mathrm{G}$ & $\begin{array}{l}\text { Mitochondrial } \\
\text { recessive ataxia, } \\
\text { syndrome }\end{array}$ & Sensory Axonal \\
\hline 9 & 16 yrs/ F & $\mathrm{mt}-\mathrm{ND} 4$ & m.11778 G>A & $\begin{array}{l}\text { LHON plus } \\
\text { syndrome }\end{array}$ & Motor Axonal \\
\hline 10 & 7 yrs/ F & mt-ND5 & m.13514A>G & $\begin{array}{l}\text { Leigh like } \\
\text { syndrome }\end{array}$ & Motor Axonal \\
\hline 11 & 50 yrs/ M & Mt-ATP6 & m.9185 A>G & NARP & $\begin{array}{l}\text { Sensory motor } \\
\text { demyelinating }\end{array}$ \\
\hline 12 & $6 \mathrm{yrs} / \mathrm{M}$ & SURF1 & c.531-533delTAAA & Leighs syndrome & $\begin{array}{l}\text { Sensory Motor } \\
\text { Demyelinating }\end{array}$ \\
\hline 13 & 3 yrs/ F & SURF1 & c.G180R & Leighs syndrome & $\begin{array}{l}\text { Sensory Motor } \\
\text { Demyelinating }\end{array}$ \\
\hline 14 & 3 yrs/ F & SURF1 & c.792_793delAG & Leighs syndrome & $\begin{array}{l}\text { Sensory Motor } \\
\text { Demyelinating }\end{array}$ \\
\hline 15 & $18 \mathrm{mo} / \mathrm{M}$ & SURF1 & c.531_533delTAAA & Leighs syndrome & $\begin{array}{l}\text { Sensory motor } \\
\text { Demyelinating }\end{array}$ \\
\hline 16 & 10 yrs/ M & POLG1 & c. $911 \mathrm{~T}>\mathrm{G}$ & SANDO syndrome & $\begin{array}{l}\text { Sensory motor } \\
\text { demyelinating }\end{array}$ \\
\hline 17 & 26 yrs/ M & POLG1 & c. $911 \mathrm{~T}>\mathrm{G}$ & СРEO & $\begin{array}{l}\text { Sensory motor } \\
\text { demyelinating }\end{array}$ \\
\hline 18 & 6 yrs/ F & POLG1 & c. $911 \mathrm{~T}>\mathrm{G}$ & $\begin{array}{l}\text { Mitochondrial } \\
\text { spinocerebellar } \\
\text { ataxia epilepsy } \\
\text { syndrome }\end{array}$ & Motor axonal \\
\hline
\end{tabular}




\section{Chapter 3}

*Siblings,NARP-Neurogenic weakness, ataxia, and retinitis pigmentosa, MERRF- myoclonic epilepsy with ragged-red fibers, LHON- Leber's hereditary optic neuropathy, MELAS- Mitochondrial encephalopathy lactic acidosis and stroke like episodes, $\mathrm{CPEO}$ - Chronic progressive external ophthalmoplegia, ND-Not done, RRF-Ragged Red fibers, RBF-Ragged Blue fibers, COX-cytochrome C oxidase

Supplementary Table 1: Details of the nerve conduction studies in patients with mitochondrial disorders

\begin{tabular}{|c|c|c|c|c|c|c|c|c|}
\hline Pt No & $\begin{array}{l}\text { Age/Gender/ } \\
\text { Diagnosis }\end{array}$ & $\begin{array}{l}\text { Median } \\
\text { CMAP } \\
\text { DL/ } \\
\text { Amp/ } \\
\text { CV }\end{array}$ & $\begin{array}{l}\text { Ulnar } \\
\text { CMAP } \\
\text { DL/ } \\
\text { Amp/C } \\
\text { V }\end{array}$ & $\begin{array}{l}\quad \mathrm{CP} \\
\mathrm{DL} / \\
\mathrm{Amp} / \\
\mathrm{CV}\end{array}$ & $\begin{array}{l}\text { Median } \\
\text { SNAP } \\
\text { DL/ } \\
\text { Amp/ } \\
\text { CV }\end{array}$ & $\begin{array}{l}\text { Ulnar } \\
\text { SNAP } \\
\text { DL/ } \\
\text { Amp/ } \\
\text { CV }\end{array}$ & $\begin{array}{l}\text { Sural } \\
\text { SNAP } \\
\text { DL/ } \\
\text { Amp/ } \\
\text { CV }\end{array}$ & $\begin{array}{l}\text { Type of } \\
\text { Neuropathy }\end{array}$ \\
\hline 1 & ${ }^{*} 12$ yrs/ F & $\begin{array}{l}3.2 / 10.5 / \\
39\end{array}$ & $\begin{array}{l}3.6 / 6.8 / \\
47.2\end{array}$ & $\begin{array}{l}3.8 / 0.9 / \\
44.9\end{array}$ & $\begin{array}{l}2.5 / 6 / \\
50\end{array}$ & $\begin{array}{l}2.8 / 8 / \\
48.9\end{array}$ & Absent & $\begin{array}{l}\text { Sensory } \\
\text { Motor Axonal }\end{array}$ \\
\hline 2 & ${ }^{*} 8 \mathrm{yrs} / \mathrm{M}$ & $\begin{array}{l}2.6 / 9.9 / \\
45.9\end{array}$ & $\begin{array}{l}3.0 / 8.4 / \\
50.0\end{array}$ & Absent & $\begin{array}{l}2.8 / 12 / \\
46.2\end{array}$ & $\begin{array}{l}2.7 / 14 / \\
51.4\end{array}$ & Absent & $\begin{array}{l}\text { Sensory motor } \\
\text { axonal }\end{array}$ \\
\hline 3 & $41 \mathrm{yrs} / \mathrm{M}$ & $\begin{array}{l}3.9 / 14.8 / \\
58.1\end{array}$ & $\begin{array}{l}2.8 / 7.1 / \\
59.6\end{array}$ & $\begin{array}{l}4.2 / 4.6 / \\
45.6\end{array}$ & Absent & Absent & Absent & $\begin{array}{l}\text { Sensory } \\
\text { Axonal }\end{array}$ \\
\hline 4 & $28 \mathrm{yrs} / \mathrm{M}$ & $\begin{array}{l}2.7 / 14.3 \\
4 / 50\end{array}$ & $\begin{array}{l}2.5 / 8.1 / \\
57\end{array}$ & $\begin{array}{l}3.7 / 2.5 / \\
44\end{array}$ & $\begin{array}{l}2.7 / 1.8 / \\
52\end{array}$ & $\begin{array}{l}2.3 / 1.3 / \\
52\end{array}$ & $\begin{array}{l}3.5 / 0.5 / \\
40\end{array}$ & $\begin{array}{l}\text { Sensory } \\
\text { Axonal }\end{array}$ \\
\hline 5 & $17 \mathrm{yrs} / \mathrm{M}$ & $\begin{array}{l}3.2 / 9.5 / \\
64.5\end{array}$ & $\begin{array}{l}2.6 / 4.4 / \\
60\end{array}$ & $\begin{array}{l}5.1 / 0.8 / \\
52.0\end{array}$ & Absent & Absent & Absent & $\begin{array}{l}\text { Sensory motor } \\
\text { Axonal }\end{array}$ \\
\hline 6 & $11 \mathrm{yrs} / \mathrm{F}$ & $\begin{array}{l}3.2 / 12.9 / \\
51.9\end{array}$ & $\begin{array}{l}2.8 / 5.4 / \\
48.3\end{array}$ & $\begin{array}{l}4.4 / 1.9 / \\
47.5\end{array}$ & $\begin{array}{l}2.6 / 58 / \\
46.2\end{array}$ & $\begin{array}{l}1.9 / 54 / \\
41.7\end{array}$ & $\begin{array}{l}2.4 / 27 / \\
45.8\end{array}$ & Motor Axonal \\
\hline 7 & 36 yrs/ F & $\begin{array}{l}4.0 / 14.6 / \\
53.5\end{array}$ & $\begin{array}{l}3.6 / 7.5 / \\
57.1\end{array}$ & $\begin{array}{l}4.9 / 4.4 / \\
41.8\end{array}$ & Absent & Absent & Absent & $\begin{array}{l}\text { Sensory } \\
\text { axonal }\end{array}$ \\
\hline 8 & $13 \mathrm{yrs} / \mathrm{M}$ & $\begin{array}{l}3.2 / 11.2 / \\
63.2\end{array}$ & $\begin{array}{l}2.2 / 6.5 / \\
60.8\end{array}$ & $\begin{array}{l}3.8 / 2.5 / \\
50.9\end{array}$ & $\begin{array}{l}2.8 / 4.3 / \\
46.4\end{array}$ & $\begin{array}{l}1.8 / 4.2 / \\
52.1\end{array}$ & $\begin{array}{l}2.6 / 2.1 / \\
53.8\end{array}$ & $\begin{array}{l}\text { Sensory } \\
\text { Axonal }\end{array}$ \\
\hline 9 & $16 \mathrm{yrs} / \mathrm{F}$ & $\begin{array}{l}3.5 \\
/ 6.5 / 42.1\end{array}$ & ND & $\begin{array}{l}5.4 / 0.6 / \\
45.8\end{array}$ & ND & $\begin{array}{l}2.8 / 10.2 / \\
42.9\end{array}$ & $\begin{array}{l}1.6 / 7.2 / \\
56.2\end{array}$ & Motor Axonal \\
\hline 10 & $7 \mathrm{yrs} / \mathrm{F}$ & $\begin{array}{l}3.9 / 7.3 / \\
50\end{array}$ & $\begin{array}{l}2.6 / 8.1 / \\
58.3\end{array}$ & Absent & $\begin{array}{l}1.4 / 40 / \\
65.2\end{array}$ & $\begin{array}{l}1.4 / 46 / \\
62.5\end{array}$ & $\begin{array}{l}2.8 / 28 / \\
53.6\end{array}$ & Motor Axonal \\
\hline 11 & $50 \mathrm{yrs} / \mathrm{M}$ & $\begin{array}{l}3.5 / 16 / \\
52.1\end{array}$ & $\begin{array}{l}3.3 / 8.3 / \\
45.8\end{array}$ & $\begin{array}{l}7.6 / 0.6 / \\
36\end{array}$ & $\begin{array}{l}3.4 / 22 / \\
38.2\end{array}$ & $\begin{array}{l}2.8 / 17 / \\
37.9\end{array}$ & $\begin{array}{l}3.6 / 10 / \\
36.1\end{array}$ & $\begin{array}{l}\text { Sensory motor } \\
\text { demyelinating }\end{array}$ \\
\hline 12 & $6 \mathrm{yrs} / \mathrm{M}$ & $\begin{array}{l}2.4 / 3.2 / \\
21.6\end{array}$ & ND & $\begin{array}{l}3.9 / 2.2 / \\
22.9\end{array}$ & Absent & ND & Absent & $\begin{array}{l}\text { Sensory } \\
\text { Motor } \\
\text { demyelinating }\end{array}$ \\
\hline
\end{tabular}


Supplementary Table 1: continued

\begin{tabular}{|c|c|c|c|c|c|c|c|c|}
\hline Pt No & $\begin{array}{l}\text { Age/Gende } \\
\text { r/ } \\
\text { Diagnosis }\end{array}$ & $\begin{array}{l}\text { Median } \\
\text { CMAP } \\
\text { DL/ Amp } \\
\text { /CV }\end{array}$ & $\begin{array}{l}\text { Ulnar } \\
\text { CMAP } \\
\text { DL/ } \\
\text { Amp/CV }\end{array}$ & $\begin{array}{l}\mathrm{CP} \\
\mathrm{DL} / \\
\mathrm{Amp} / \\
\mathrm{CV}\end{array}$ & $\begin{array}{l}\text { Media } \\
\mathrm{n} \\
\text { SNAP } \\
\text { DL/ } \\
\text { Amp/ } \\
\text { CV }\end{array}$ & $\begin{array}{l}\text { Ulnar } \\
\text { SNAP } \\
\text { DL/ Amp/ } \\
\text { CV }\end{array}$ & $\begin{array}{l}\text { Sural } \\
\text { SNAP } \\
\text { DL/ Amp/ } \\
\text { CV }\end{array}$ & $\begin{array}{l}\text { Type of } \\
\text { Neuropath } \\
y\end{array}$ \\
\hline 13 & 3 yrs/ F & $\begin{array}{l}4.3 / 4.6 / \\
45.5\end{array}$ & $\begin{array}{l}1.7 / 7.1 / \\
51.2\end{array}$ & $\begin{array}{l}2.5 / 4.9 / \\
48.6\end{array}$ & $\begin{array}{l}2.8 / 14 / \\
30.4\end{array}$ & ND & $\begin{array}{l}2.2 / 17 / \\
31.8\end{array}$ & $\begin{array}{l}\text { Sensory } \\
\text { Motor } \\
\text { Demyelina } \\
\text { ting }\end{array}$ \\
\hline 14 & 3 yrs/ F & $\begin{array}{l}4.1 / 6.7 \text { / } \\
48.6\end{array}$ & $\begin{array}{l}3.8 / 4.2 / \\
47.5\end{array}$ & $\begin{array}{l}3.4 / \\
3.1 / 41.4\end{array}$ & $\begin{array}{l}2.9 / \\
16 / \\
37.9\end{array}$ & $\begin{array}{l}2.7 / \\
16 / 36.2\end{array}$ & $\begin{array}{l}3.1 / 9.6 / \\
35.5\end{array}$ & $\begin{array}{l}\text { Sensory } \\
\text { Motor } \\
\text { Demyelina } \\
\text { ting }\end{array}$ \\
\hline 15 & $18 \mathrm{mo} / \mathrm{M}$ & $\begin{array}{l}3.4 / 8.2 / \\
32.1\end{array}$ & $\begin{array}{l}2.2 \\
/ 6.1 / 32.7\end{array}$ & $\begin{array}{l}2.8 / 3.7 \\
/ 32.8\end{array}$ & $\begin{array}{l}2.2 / \\
13.4 / \\
31.4\end{array}$ & $\begin{array}{l}1.6 / 12.7 / \\
31.5\end{array}$ & Absent & $\begin{array}{l}\text { Sensory } \\
\text { motor } \\
\text { Demyelina } \\
\text { ting }\end{array}$ \\
\hline 16 & 10 yrs/ M & $\begin{array}{l}4.1 / 7.6 / \\
48.4\end{array}$ & $\begin{array}{l}2.8 / 6.5 / \\
48.6\end{array}$ & $\begin{array}{l}5.5 / 3.4 / \\
38.9\end{array}$ & $\begin{array}{l}4.4 / 5.1 \\
/ 27.3\end{array}$ & $\begin{array}{l}4.0 / 6.5 / \\
25\end{array}$ & Absent & $\begin{array}{l}\text { Sensory } \\
\text { motor } \\
\text { demyelina } \\
\text { ting }\end{array}$ \\
\hline 17 & 26 yrs/ M & $\begin{array}{l}3.5 / 9.5 / \\
54\end{array}$ & $\begin{array}{l}2.9 / 7.3 / \\
52.7\end{array}$ & $\begin{array}{l}7.1 / 4.1 / \\
43.9\end{array}$ & $\begin{array}{l}3.4 / 2.5 \\
/ 48.5\end{array}$ & ND & Absent & $\begin{array}{l}\text { Sensory } \\
\text { motor } \\
\text { axonal }\end{array}$ \\
\hline 18 & 6 yrs/ F & $\begin{array}{l}4.1 / 17 \\
/ 53.2\end{array}$ & $\begin{array}{l}2.1 / 14.5 / \\
50.1\end{array}$ & $\begin{array}{l}4.2 / 1.8 / \\
44.3\end{array}$ & $\begin{array}{l}2.8 / 26 / \\
51.8\end{array}$ & $\begin{array}{l}2.1 / 18 / \\
50.6\end{array}$ & $3.2 / 8 / 44.3$ & $\begin{array}{l}\text { motor } \\
\text { axonal }\end{array}$ \\
\hline $\begin{array}{l}\text { Normat } \\
\text { ive data } \\
\text { (Mean } \pm \\
2 \text { SD) }\end{array}$ & $\begin{array}{l}\text { DL } \\
\text { Amp. of } \\
\text { CMAP/SN } \\
\text { AP } \\
\text { Velocity }\end{array}$ & $\begin{array}{l}2.6 \pm 0.5 \\
14.5 \pm 3.4 \\
58.7 \pm 3.8\end{array}$ & $\begin{array}{l}2.0 \pm 0.5 \\
10.9 \pm 2.6 \\
59.9 \pm 4.8\end{array}$ & $\begin{array}{l}3.6 \pm 0.5 \\
8.02 \pm \\
2.9 \\
51.1 \pm \\
5.5\end{array}$ & $\begin{array}{l}-29.9 \pm \\
8.1 \\
59.5 \pm \\
4.2\end{array}$ & $\begin{array}{l}22.5 \pm 6.7 \\
56.2 \pm 4.1\end{array}$ & $\begin{array}{l}21.5 \pm 8.5 \\
48.4 \pm 4.7\end{array}$ & \\
\hline
\end{tabular}




\section{Discussion:}

This study analyzed the pattern of peripheral neuropathy in a cohort of genetically characterized patients with mitochondrial disorders. There are relatively few studies which focus on peripheral neuropathy in large cohorts of genetically characterized patients with mitochondrial disorders. ${ }^{8,9}$ Analysis of clinical features pertaining to peripheral neuropathy showed that the neuropathy was less severe and part of the multisystem involvement in majority of the patients. Symptomatic neuropathy was seen only in minority of the patients. The most common type of peripheral neuropathy noted in this cohort was the axonal neuropathy of sensory, motor or sensorimotor type as reported previously in the literature. ${ }^{6.8}$ Eventhough the phenotype genotype correlations are difficult to ascertain due to the small number of patients harbouring mutations in SURF1 and POLG1 genes, it is evident that the axonal neuropathy was the commonest type seen in patients with mitochondrial DNA point mutations and demyelinating neuropathy in patients with SURF1. Patients in the POLG1 group had both axonal and demyelinating neuropathy.

All patients with SURF1 mutations in the current study clinically had Leighs phenotype with demyelinating pattern on electrophysiology. There are few reports on the nerve conduction studies and detailed morphological observations in Leighs syndrome. ${ }^{19}$ In four unrelated children with Leighs syndrome and cytochrome c oxidase (COX) deficiency, sural nerve biopsy revealed loss of myelinated and unmyelinated axons along with evidence of primary demyelination and remyelination. ${ }^{20} \mathrm{It}$ has also been noted that the prevalence of peripheral neuropathy is more in COX deficient Leigh syndrome patients compared to children with Leighs syndrome with pyruvate dehydrogenase (PDH) deficiency or m.8993T $>\mathrm{C}$ mutations. ${ }^{21}$ Peripheral neuropathy has been reported in Leigh syndrome patients with COX deficiency and SURF1 mutation. ${ }^{22,23}$ In the report by Santoro et al, ultrastructural examination revealed large number of mitochondria with enlarged and rounded cristae in Schwann cells. ${ }^{23}$ SURF1 mutations have also been implicated in the etiology of demyelinating CMT disease too. ${ }^{24}$ In a multicentric study on patients with SURF1 deficiency, of the patients who underwent nerve conduction studies, $81 \%$ had peripheral neuropathy. ${ }^{25}$ While demyelinating neuropathy was seen in seven, axonal neuropathy was seen only in two. The pathogenetic mechanism underlying the propensity for SURF1 mutation to cause a demyelinating neuropathy is not clear.

Mutations in POLG1, a nuclear gene encoding the catalytic subunit of mitochondrial polymerase gamma leads to various neurological phenotypes which often includes peripheral neuropathy. ${ }^{26}$ Sensory neuronopathy is a common feature in patients with POLG1 related disorders and in some patients may be a presenting fea- 
ture. ${ }^{27}$ Two of the three patients with POLG1 mutations in the present study presented with a sensory ataxic neuropathy. A clinical phenotype dominated by neuronopathy leading to severe sensory ataxia and dysarthria and ophthalmoparesis in patients with SANDO is reported in literature and was also noted in the present study. ${ }^{28}$ Neuropathological studies have demonstrated severe respiratory chain deficiency and neuronal loss in dorsal root ganglia due to mitochondrial depletion and accumulation of mtDNA. ${ }^{27}$ Nerve biopsy reports in POLG1 related disorder are limited and have shown myelinated fiber loss, clusters of regenerating fibers, myelin modifications and onion bulb like formations. ${ }^{27}$

Peripheral neuropathies resulting from point mutations in mtDNA are common, but form a non-prominent feature of the phenotype. In the present study peripheral neuropathy was seen in patients with m.3243A>G, m.8334A $>\mathrm{G}, \mathrm{m} .8363 \mathrm{~A}>\mathrm{G}$, m.11788G $>A$ and $m .9185 A>G$ and $m .13514 A>G$ mutations as reported in literature. The common type of neuropathy associated with m.3243A $>\mathrm{G}$ mutation is axonal, but rarely demyelinating neuropathy is also reported. ${ }^{9,29}$ In contrast to the MELAS cohort, axonal neuropathy was noted in all four patients with m.8334A>G mutations. In MERRF, peripheral neuropathy either affects only the sensory nerves or both motor and sensory modalities and is usually slowly progressive. ${ }^{30}$ Demyelinating disease of both central and peripheral nervous system have been reported in a patient with m.8334A $>\mathrm{G}$ mutation. ${ }^{31}$ In a large cohort of patients with $\mathrm{m} .8334 \mathrm{~A}>\mathrm{G}$ mutation, peripheral neuropathy was noted in $14.7 \%$ of the patients. ${ }^{32}$ The patient with $\mathrm{m} .8363 \mathrm{~A}>\mathrm{G}$ mutation in our study had an ataxia neuropathy phenotype as reported by Pineda et al. ${ }^{33}$ In the latter study, authors have suggested that a mitochondrial disease should be considered in the differential diagnosis of children with heredo-ataxic syndrome and peripheral neuropathy of unknown origin.

Maternally inherited mutations in MTATP6 gene cause a range of phenotypes of varying severity. ${ }^{34}$ Isolated neuropathy associated with $\mathrm{m} .9185 \mathrm{~T}>\mathrm{C}$ or $\mathrm{m} .8993 \mathrm{~T}>\mathrm{C}$ mutations is recognized. ${ }^{10,11}$ In the current study, only one patient had m.9185A $>\mathrm{G}$ mutation in MTATP6. The clinical phenotype was consistent with NARP syndrome and nerve conduction showed a demyelinating sensory motor neuropathy. The frequency of m.9185A $>\mathrm{G}$ mutation in a large cohort of genetically undiagnosed CMT2 patients was $1.1 \% .{ }^{35}$ Even though the pattern of neuropathy in most reported patients with MTATP mutation is sensorimotor axonal type, isolated demyelinating neuropathy has also been reported. ${ }^{10}$

Demyelinating neuropathy has been earlier described in LHON patients with m.11778 G>A mutation. ${ }^{36}$ In contrast, our patient with LHON plus syndrome and m.11778G $>$ A mutation had sensorimotor axonal neuropathy. It has been suggested that demyelinating neuropathy should be considered part of the clinical spectrum of 
LHON patients secondary to $\mathrm{m} .11778 \mathrm{G}>\mathrm{A}$ mutations. ${ }^{36}$ It is interesting to note that our patient presented with a spastic dystonic syndrome and optic atrophy. Spinal cord degeneration in LHON has been reported earlier. ${ }^{37}$

Other well recognized mitochondrial syndromes associated with peripheral neuropathy which did not figure out in this study include mitochondrial neurogastrointestinal encephalopathy secondary to TYMPmutations, mutations in C10Orf2 encoding twinkle helicase and the mitochondrial CMT disease secondary to MFN2 and GDAP mutations. ${ }^{6}$ Ataxic neuropathy and SANDO have been described in association with mutations in C10Orf2 encoding twinkle helicase. ${ }^{38}$ Screening of MFN2 and GDAP1 mutations in the entire cohort would have yielded more patients with these disorders and may be possible in the future as the facilities are expanding. It is acknowledged that the small number of patients with each individual genes is a limitation of the study. Nevertheless, this study brings out the phenotypic spectrum and electrophysiological abnormalities in a cohort of patients with mitochondrial disorders. Peripheral neuropathy especially of the sensorimotor axonal type as part of multisystem involvement may point to a mitochondrial etiology. Specific pattern of neuropathy along with other clinical findings may direct genetic testing for mutations in specific genes. For instance, the presence of demyelinating neuropathy in Leighs syndrome may predict mutations in SURF1 gene, while sensory ataxic neuropathy in a patient with other mitochondrial signatures may point towards $P O L G 1$ related disorder. It is likely that more and more phenotypes of mitochondrial neuropathy will be unravelled in the near future as newer technologies such as whole exome sequencing are applied to patients with peripheral neuropathy. 


\section{References}

1. Sheng ZH. Mitochondrial trafficking and anchoring in neurons: New insight and implications. J cell biol. 2014;204:1087-98.

2. Sheng ZH, Cai Q. Mitochondrial transport in neurons: impact on synaptic homeostasis and neurodegeneration. Nature reviews Neuroscience . 2012;13:77-93.

3. Vital A, Vital C. Mitochondria and peripheral neuropathies. J Neuropathol Exp Neurol. 2012;71:1036-46.

4. Milone M, Benarroch EE. Mitochondrial dynamics: general concepts and clinical implications. Neurology . 2012;78:1612-9.

5. Menezes MP, Ouvrier RA. Peripheral neuropathy associated with mitochondrial disease in children. Dev Med Child Neurol . 2012;54:407-14.

6. Pareyson D, Piscosquito G, Moroni I, Salsano E, Zeviani M. Peripheral neuropathy in mitochondrial disorders. The Lancet Neurology . 2013;12:1011-24.

7. Finsterer J. Mitochondrial neuropathy. Clinical neurol and neurosurg . 2005;107:181-6.

8. Bouillot S, Martin-Negrier ML, Vital A, et al., Peripheral neuropathy associated with mitochondrial disorders: 8 cases and review of the literature. J peripher nerv syst. : JPNS . 2002;7:213-20.

9. Karppa M, Syrjala P, Tolonen U, Majamaa K. Peripheral neuropathy in patients with the $3243 \mathrm{~A}>\mathrm{G}$ mutation in mitochondrial DNA. Journal of neurology . 2003;250:216-21.

10. Childs AM, Hutchin T, Pysden K, et al., Variable phenotype including Leigh syndrome with a 9185T>C mutation in the MTATP6 gene. Neuropediatrics . 2007;38:313-6.

11. Gelfand JM, Duncan JL, Racine CA, et al., Heterogeneous patterns of tissue injury in NARP syndrome. J neurology. 2011;258:440-8.

12. Van Goethem G, Martin JJ, Dermaut B, et al., Recessive POLG mutations presenting with sensory and ataxic neuropathy in compound heterozygote patients with progressive external ophthalmoplegia. Neuromuscular disorders : NMD . 2003;13:133-42.

13. Bindu PS, Arvinda HR, Taly AB, et al., Magnetic resonance imaging correlates of genetically characterized patients with mitochondrial disorders: A study from south India. Mitochondrion. 2015;25:6-16

14. Gupta SK, Taly AB, Suresh TG, Rao S, Nagaraja D. Acute idiopathic axonal neuropathy (AIAN): a clinical and electrophysiological observation. Acta neurol Scand. 1994;89:220-4.

15. Taly AB, Prasad A, Vasanth A, Shankar SK, Nagaraja D. Acute ataxic neuropathy: a clinical, electrophysiological and morphological study. Acta neurol Scand .1991; 84:398-402.

16. Parano E, Uncini A, De Vivo DC, Lovelace RE. Electrophysiologic correlates of peripheral nervous system maturation in infancy and childhood. Jl of child neurol . 1993;8:336-8.

17. Gamstorp I. Normal conduction velocity of ulnar, median and peroneal nerves in infancy, childhood and adolescence. Acta paediatrica Supplementum . 1963:Suppl146:68-76.

18. Nevo Y, Topaloglu H. 88th ENMC international workshop: childhood chronic inflammatory demyelinating polyneuropathy (including revised diagnostic criteria), Naarden, The Netherlands, December 8-10, 2000. Neuromuscular disorders : NMD . 2002;12:195-200.

19. Moosa A. Peripheral neuropathy in Leigh's encephalomyelopathy. Developmental medicine and child neurology. 1975;17:621-4.

20. Goebel HH, Bardosi A, Friede RL, Kohlschutter A, Albani M, Siemes H. Sural nerve biopsy studies in Leigh's subacute necrotizing encephalomyelopathy. Muscle \& nerve. 1986;9:165-73.

21. Santorelli FM, Shanske S, Macaya A, DeVivo DC, DiMauro S. The mutation at nt 8993 of mitochondrial DNA is a common cause of Leigh's syndrome. Ann Neurol. 1993;34:827-34.

22. Bruno C, Biancheri R, Garavaglia B, et al., A novel mutation in the SURF1 gene in a child with Leigh disease, peripheral neuropathy, and cytochrome-c oxidase deficiency. J child neurol. 2002;17:233-6. 


\section{Chapter 3}

23. Santoro L, Carrozzo R, Malandrini A, et al., A novel SURF1 mutation results in Leigh syndrome with peripheral neuropathy caused by cytochrome c oxidase deficiency. Neuromuscular disorders : NMD . 2000;10:450-3.

24. Echaniz-Laguna A, Ghezzi D, Chassagne M, et al., SURF1 deficiency causes demyelinating CharcotMarie-Tooth disease. Neurology . 2013;81:1523-30.

25. Wedatilake Y, Brown RM, McFarland R, et al., SURF1 deficiency: a multi-centre natural history study. Orphanet journal of rare diseases . 2013;8:96.

26. Milone M, Massie R. Polymerase gamma 1 mutations: clinical correlations. The neurologist . 2010;16:84-91

27. Lax NZ, Whittaker RG, Hepplewhite PD, et al., Sensory neuronopathy in patients harbouring recessive polymerase gamma mutations. Brain : a journal of neurology . 2012;135:62-71.

28. Gago MF, Rosas MJ, Guimaraes J, et al., SANDO: two novel mutations in POLG1 gene. Neuromuscular disorders : NMD . 2006;16:507-9.

29. Rusanen H, Majamaa K, Tolonen U, Remes AM, Myllyla R, Hassinen IE. Demyelinating polyneuropathy in a patient with the tRNA(Leu)(UUR) mutation at base pair 3243 of the mitochondrial DNA. Neurology . 1995;45:1188-92.

30. Naumann M, Kiefer R, Toyka KV, Sommer C, Seibel P, Reichmann H. Mitochondrial dysfunction with myoclonus epilepsy and ragged-red fibers point mutation in nerve, muscle, and adipose tissue of a patient with multiple symmetric lipomatosis. Muscle \& nerve . 1997;20:833-9.

31. Erol I, Alehan F, Horvath R, Schneiderat P, Talim B. Demyelinating disease of central and peripheral nervous systems associated with a A8344G mutation in tRNALys. Neuromuscular disorders : NMD . 2009;19:275-8.

32. Mancuso M, Orsucci D, Angelini C, et al., Phenotypic heterogeneity of the 8344A $>$ G mtDNA "MERRF" mutation. Neurology . 2013;80:2049-54.

33. Pineda M, Solano A, Artuch R, et al., Peripheral neuropathy with ataxia in childhood as a result of the G8363A mutation in mitochondrial DNA. Pediatric research . 2004;56:55-9.

34. Uziel G, Moroni I, Lamantea E, et al., Mitochondrial disease associated with the T8993G mutation of the mitochondrial ATPase 6 gene: a clinical, biochemical, and molecular study in six families. J neurol, neurosurg, and psychiatry . 1997;63:16-22.

35. Pitceathly RD, Murphy SM, Cottenie E, et al., Genetic dysfunction of MT-ATP6 causes axonal Charcot-Marie-Tooth disease. Neurology . 2012;79:1145-54.

36. Gilhuis HJ, Schelhaas HJ, Cruysberg JR, Zwarts MJ. Demyelinating polyneuropathy in Leber hereditary optic neuropathy. Neuromuscular disorders : NMD (in eng). 2006;16:394-5

37. Jaros E, Mahad DJ, Hudson G, et al., Primary spinal cord neurodegeneration in Leber hereditary optic neuropathy. Neurology . 2007;69:214-6.

38. Hudson G, Deschauer M, Busse K, Zierz S, Chinnery PF. Sensory ataxic neuropathy due to a novel C10Orf2 mutation with probable germline mosaicism.Neurology;2005;64:371-3. 


\section{Chapter}

\section{Bilateral hypertrophic olivary nucleus degeneration on magnetic resonance imaging in children with Leigh and Leigh- \\ like syndrome}

Bindu PS, Taly AB, Sonam K, Govindaraju C, Arvinda HR, Gayathri N, Srinivas Bharath MM, Ranjith D, Nagappa M, Sinha S, Khan NA, Thangaraj K.

Br J Radiol 2014;87:20130478. 


\section{Abstract:}

Objectives: Bilateral hypertrophic olivary degeneration on brain magnetic resonance imaging has been reported in a few metabolic, genetic and neurodegenerative disorders including mitochondrial disorders. In this report we sought to analyse whether bilateral symmetrical inferior olivary nucleus hypertrophy is specifically associated with mitochondrial disorders in children.

Patients and Methods: This retrospective study included 125 children [Mean age -7.6 \pm 5 yrs; M:F - 2.6:1] diagnosed with various metabolic and genetic disorders during a period of 2005-2012. The routine MRI sequences (TI weighted images, T2 weighted images and Fluid attenuated inversion recovery sequences) were analyzed for the presence of bilateral symmetrical olivary hypertrophy and central tegmental tract or dentate nuclei signal changes. The other imaging findings and the final diagnoses were noted.

Results: The cohort included patients with Mitochondrial disease $(n=50)$, Wilson disease $(n=40)$, Glutaric aciduria Type $1(n=14)$, Maple syrup urine disease $(n=13)$, Giant axonal neuropathy $(n=5)$ and L-2 Hydroxy Glutaric aciduria $(n=3)$. Bilateral inferior olivary nucleus hypertrophy was noted in 10 patients. All belonged to the mitochondrial disease group and had a diagnosis of Leigh and Leigh like syndrome. This occurred both in association with and independent of central tegmental tract and dentate nucleus hypertrophy.

Conclusions: Bilateral hypertrophic olivary degeneration on magnetic resonance imaging is relatively often, but not routinely seen in children with Leigh and Leigh like syndrome. The findings should prompt the physician to carry out investigations to rule out a mitochondrial disorder.

Advances in knowledge: Bilateral inferior olivary nucleus hypertrophy on magnetic resonance imaging is more commonly seen in children with leigh and leigh like syndrome, compared to other metabolic disorders. Early detection of this finding by radiologists and physicians may facilitate targeted metabolic testing in these children. 


\section{Introduction:}

Hypertrophic olivary degeneration is a rare form of neuronal degeneration that results from disruption of the afferent fibers to the inferior olive within the dentaterubro-olivary tract otherwise known as triangle of Guillain-Mollaret. ${ }^{1}$ The first description of the enlargement of inferior olivary nucleus is by Oppenheim, in his post-mortem study. ${ }^{2}$ Since then a number of reports describing the clinical, histopathological and magnetic resonance imaging findings have been published. ${ }^{3-7}$

A variety of insults can lead to hypertrophic olivary degeneration of which most commonly reported are haemorrhage, infarct, trauma, surgery or tumour. ${ }^{8-13}$ The lesions result in loss of synaptic input to the inferior olivary nucleus and results in trans-synaptic neuronal degeneration. ${ }^{5}$ This has been considered as a unique morphologic form of trans-synaptic degeneration because it is associated with hypertrophy rather than atrophy, of the affected structure. ${ }^{14}$ Histopathologically it is characterised by neuronal enlargement of the olivary neurons, neuronal loss, vacuolation, demyelination and a marked astrogliosis., ${ }^{3,5,7}$ It is most often unilateral when it is secondary to structural lesion though bilateral changes are recognized ${ }^{8,15}$ and may occur if both the superior cerebellar peduncle and the central tegmental tracts are involved. ${ }^{16,17}$

Bilateral hypertrophic olivary degeneration has been reported in a few metabolic, genetic, neurodegenerative and toxic disorders. ${ }^{18-24}$ It has been previously noted that the presence of hypertrophic olivary degeneration in the appropriate clinical setting should alert the clinician to the possibility of a mitochondrial disorder ${ }^{20}$ In addition, the reports on the hypertrophic olivary degeneration in paediatric patients are limited. ${ }^{15,25-27}$ In this report we sought to analyse whether bilateral symmetrical ION hypertrophy is specifically associated with mitochondrial disorders in children.

\section{Patients and Methods:}

This retrospective study was carried out in the departments of neurology and neuroimaging and interventional neuroradiology at a university hospital, in South India. The study included 125 children [Mean age - $7.6 \pm 5$ yrs; M:F - 2.6:1] diagnosed with various metabolic and genetic disorders seen over a period of 8 years (2005-2012). The cohort included three groups: 1 . Twenty five children with Leigh and Leigh like syndrome [Mean age: $3.4 \pm 2.6 \mathrm{yrs}$; $\mathrm{M}: \mathrm{F}=3: 1]$; 2 . Twenty five children with mitochondrial disorders other than Leigh syndrome [Mean age: $8.8 \pm 4.3$ years]; 3 . Seventy five children with other metabolic and genetic disorders which included Wilson 
disease, Glutaric Aciduria Type1, Maple syrup urine disease, Giant axonal Neuropathy and L-2 Hydroxy Glutaric aciduria. These seventy-five patients were selected from a database of children with metabolic disorders with an MRI available for review. The inclusion of the these disorders was based on their propensity to involve the brainstem, central tegmental tracts or dentate nuclei on magnetic resonance imaging. This inclusion criteria was adopted to assess the presence of hypertrophic olivary degeneration in relation to the other components of the Guillain-Mollaret Triangle. Metabolic disorders without propensity to involve the brainstem or dentate nuclei were excluded.

All patients with Leighs and Leigh like syndrome fulfilled the criteria by Rahman et al., ${ }^{29}$ All underwent sequencing of the complete mitochondrial genome and the SURF1, one of the most common nuclear genes consistently associated with Leigh syndrome and cytochrome c oxidase deficiency. Four of them showed mutations in SURF1. Three of these patients had cytochrome c oxidase deficiency in both histopathology and respiratory chain enzyme assays. The fourth patient did not have the testing for cytochrome c oxidase deficiency. The clinical and imaging findings in these four patients have already been described..$^{30,31}$ The diagnosis of other mitochondrial disorders were based on the modified Walker criteria for definite mitochondrial disorders by Bernier et al., ${ }^{29}$ All of them had clinical features consistent with a mitochondrial encephalomyopathy along with one or more of the following: 1. Histopathological evidence of ragged red fibers or cytochrome c oxidase deficiency; 2. Residual respiratory chain complex activity of less than $20 \%$ in muscle tissue compared to controls using citrate synthase as the reference enzyme; 3 . known pathogenic mutations in the mitochondrial or nuclear genome. This group included Polymerase Gamma (POLG) related disorder ( $\mathrm{n}=4$ ); MELAS syndrome (Mitochondrial Encephalomyopathy Lactic acidosis and Stroke like episodes- $n=3$ ); Lebers hereditary optic neuropathy (LHON) plus syndrome $(n=1)$; MERRF syndrome (Myoclonic epilepsy with ragged red fibers- $n=2$ ) and other non- syndromic mitochondrial disorders $(\mathrm{n}=15)$.

The details of the non mitochondrial group and the criteria for diagnosis in each disease group are as follows. Wilsons disease [n=40; Age Range: 6-16 yrs; M: $F=$ 1.2:1]- presence of Kayser -Fleischer ring by slit lamp, low serum ceruloplasmin, and raised 24 hour urinary copper; Type 1 Glutaric aciduria [n=14; Age range: 8mo6yrs; $M: F=1: 1.3]$-Characteristic clinical and imaging findings with presence of elevated glutaryl carnitine on tandem mass spectrometry and /or urinary organic acid estimation.]; Maple syrup urine disease [n=13, Age range: 14 days -11 years; $M$ : $F=$ 1:1.6] - confirmed by elevated branched chain amino acids on tandem mass spectrometry of dried blood spots and /or high performance liquid chromatography ; 
Giant axonal neuropathy [n=5, Age range: 4-6 yrs; M: F= 4:1] -Presence of characteristic morphological features of frizzly hair, peripheral neuropathy, and cerebellar signs along with giant axons on sural nerve biopsy. L2 hydroxy glutaric aciduria [n=3, Age range $16-18$ yrs, M:F = 2:1]- Elevated L2-hydroxy glutaric acid on urinary organic acid estimation.

Magnetic resonance imaging was done after obtaining informed consent on Siemens-Magnetom vision 1.5 Tesla MRI scanner (Erlangen, Germany) using standard procedures and protocols. Spin echo T1-weighted (repetition time $[\mathrm{TR}]=650 \mathrm{~ms}$, echo time $[\mathrm{TE}]=14 \mathrm{~ms}$ ) images in axial and sagittal plane were taken, with acquisition time of $2.5 \mathrm{mt}$, matrix of $256 \times 256$ and a $230 \mathrm{~mm}$ field of view. T2-weighted images $(\mathrm{TR}=4000 \mathrm{~ms}, \mathrm{TE}=120 \mathrm{~ms})$ were acquired in axial and coronal planes. Fluid attenuated and inversion recovery (FLAIR) sequences were obtained in axial plane (TR = $9000 \mathrm{~ms}$, TE $=119 \mathrm{~ms}$, inversion time $=2457 \mathrm{~ms}$ ). The slice thickness was $5 \mathrm{~mm}$. MRI sequences included T1W (with and without contrast), T2W and FLAIR in all.

For those who underwent imaging in the Achieva $3 \mathrm{~T}$ MR imaging scanner (Philips Medical Systems, Netherlands), MRI scans were obtained by first performing a three-plane localizer scan, followed by an axial turbo spin-echo T2-weighted scan (TR/TE 3270/80 ms, flip angle 90degrees, FOV 250x 250 mm, ACQ voxel size 0.89/1.21/5.00 $\mathrm{mm}$, slice thickness/gap $5 \mathrm{~mm} / 1 \mathrm{~mm}$ ); T2 weighted FLAIR sense ( TR/TE 11000/120MS, flip angle 90degrees, FOV 250 × $250 \mathrm{~mm}$, ACQ voxel size 0.96/1.79/5.00 mm, slice thickness/gap 5mm/1mm).3D MPRAGE volumetric acquisition of the whole brain were acquired $(\mathrm{TR} / \mathrm{TE}=8.3 / 3.8 \mathrm{~ms}$, sense factor $=1.5$, flip angle $=8$ degrees, FOV=256, ACQ voxel size 1/1/1 mm).

Findings on magnetic resonance imaging at the level of the olives were evaluated by two neurologists (ABT, PSB) and one neuroradiologist (HRA) with emphasis on the lateral placement, signal intensity, and hypertrophy of the lesions. If the oval shape of the olive become round with an apparent bulge, it was classified as hypertrophic. ${ }^{5}$ Additional features noted include the presence of hyper intensity of dentate nuclei, central tegmental tract and midbrain signal changes. The clinicians were not blinded to the diagnoses. The neuroradiologists reviewed the images independently. A consensus was reached when there was a disagreement.

\section{Results:}

Of the 125 magnetic resonance imaging scans reviewed ten showed bilateral hypertrophic olivary degeneration. The inferior olivary nuclei were demonstrated as areas of high signal intensity on the T2 weighted and Fluid attenuated inversion recovery 
(FLAIR) images in all the patients (Fig1). The shape of the olivary nucleus was round in all patients with loss of serrated appearance (Fig.1). On T1 weighted images the nucleus appeared isointense. A focal enhancement of the hypertrophic olivary nuclei was noted in one patient. All the patients with the inferior olivary hypertrophy belonged to the mitochondrial disease group and had a diagnosis of Leigh and Leigh like syndrome as defined by the criteria by Rahman et al., ${ }^{28}$ The phenotypic features of these ten patients are shown in Table 1. Of the 25 patients who fulfilled the diagnostic criteria for Leigh syndrome, there were five patients with Leigh syndrome secondary to SURF1 mutation (Four patients with mutation positive and the sibling of one of the patient with mutation). All the five showed inferior olivary hypertrophy. Two other patients with cytochrome c oxidase deficiency, in the nonsyndromic mitochondrial group, but without a leighs phenotype did not show evidence of hypertrophic olivary degeneration. Dentate nucleus hyper intensity was noted in five patients, lesions of the pontine tegmentum in two and central tegmental tract in four patients in this group. The olivary degeneration occurred with or without central tegmental tract and dentate nucleus hyper intensity [Fig.2]. The duration of illness in these patients at the time of magnetic resonance imaging ranged from one month to five years. In two patients with leigh like syndrome ( $\mathrm{Pa}$ tient 9 \&10), the olivary degeneration was noted on follow up images.

In the Wilson disease group though ten patients had bilateral central tegmental tract involvement neither dentate nucleus hyper intensity nor inferior olivary hypertrophy was present. Out of the 14 patients with type 1 Glutaric aciduria, nine had both central tegmental tract and dentate nucleus hyperintensities and none had hypertrophic olivary degeneration. In the giant axonal neuropathy three patients had dentate nucleus hyper intensity but none had central tegmental tract or olivary nucleus hypertrophy. In Maple syrup urine disease there was extensive involvement of the brainstem, cerebellum and dentate nuclei in all patients associated with diffusion restriction. The medullary signal changes were involving both the dorsal and ventral medulla in some patients and the inferior olivary nucleus could not be clearly visible. All patients with L-2 hydroxy glutaric aciduria had dentate nucleus hyper intensity but did not have central tegmental tract or olivary nucleus involvement. 
Inferior Olivary Nucleus hypertrophy on MRI in Leigh syndrome

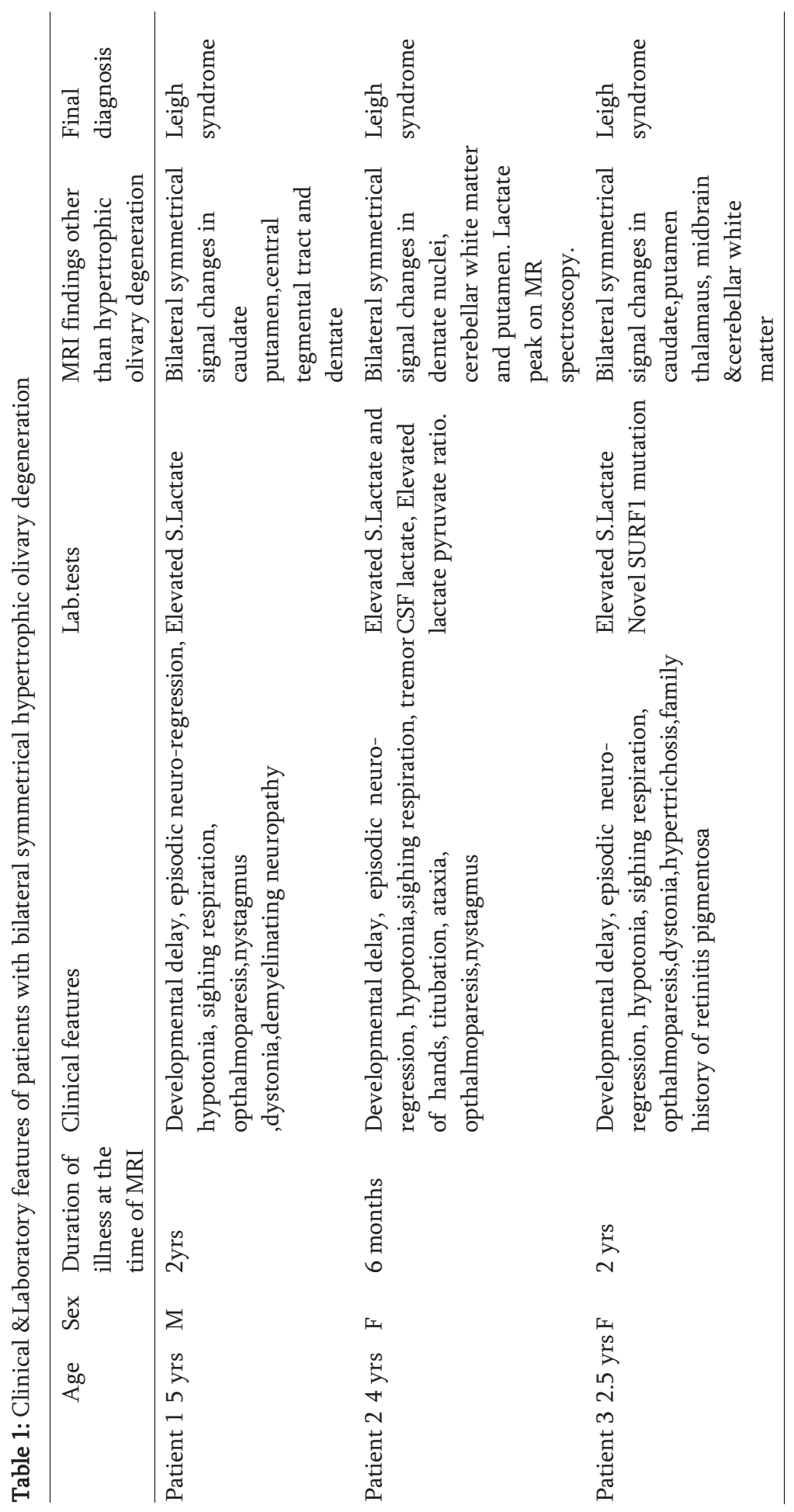




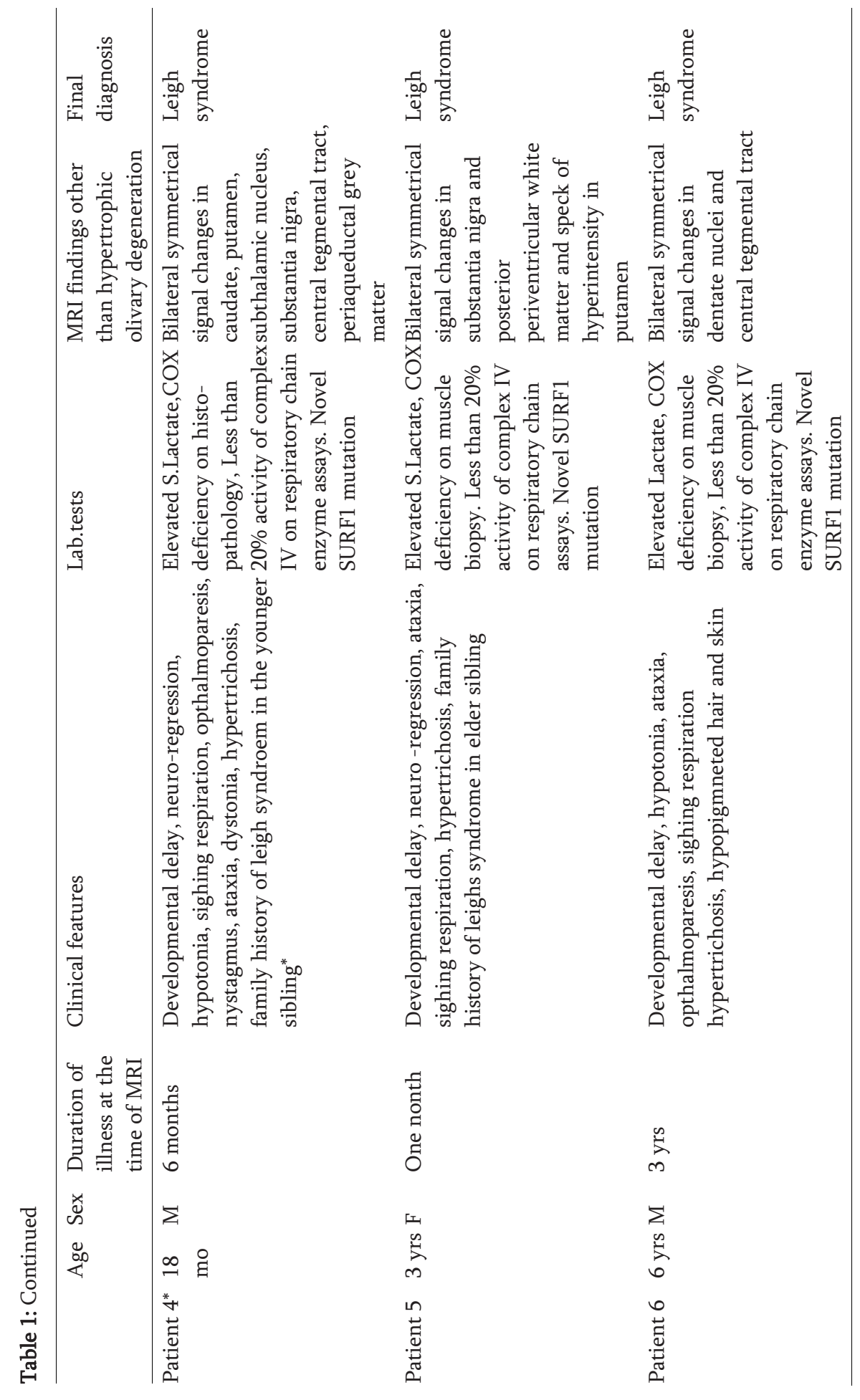


Inferior Olivary Nucleus hypertrophy on MRI in Leigh syndrome

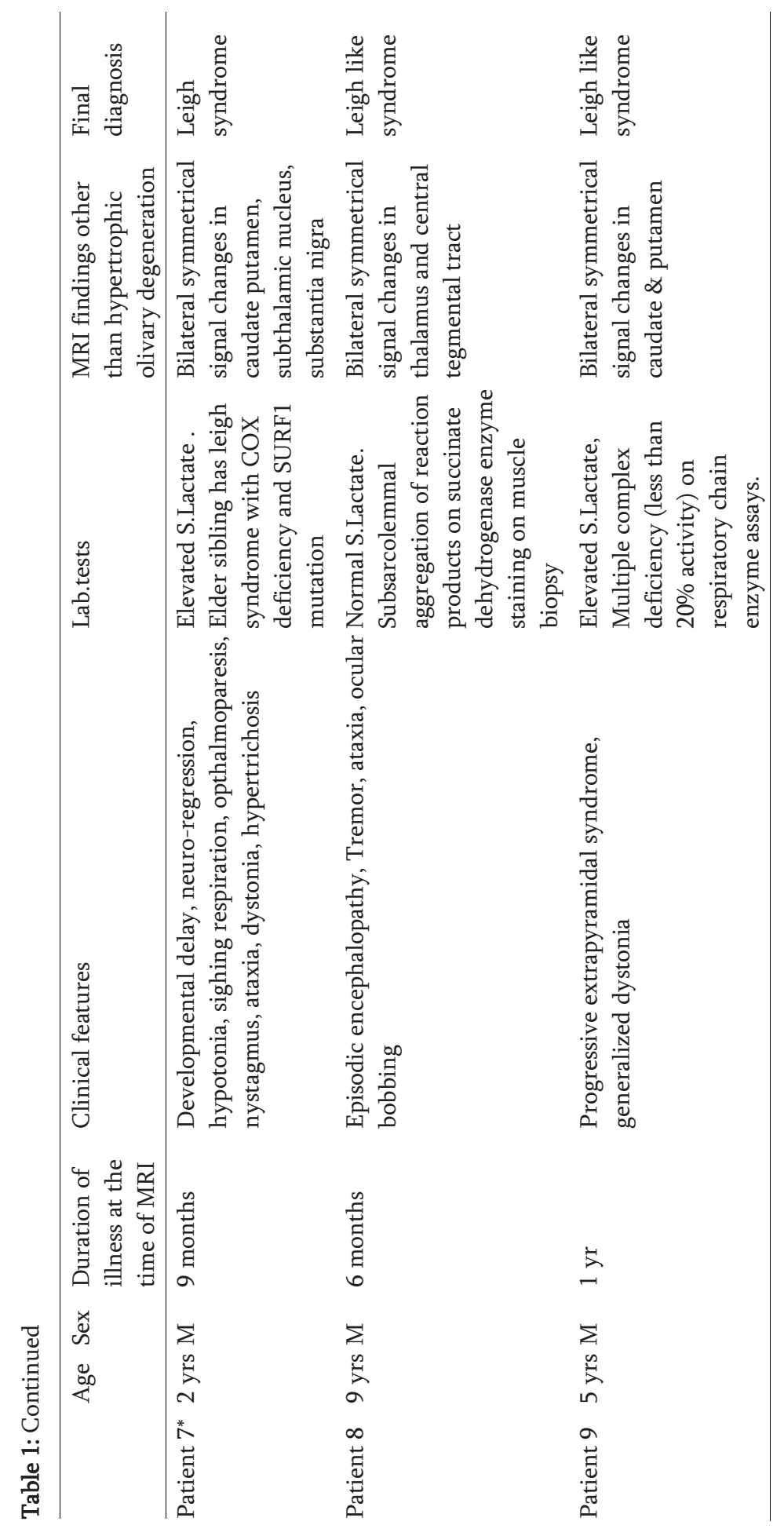


Chapter 4

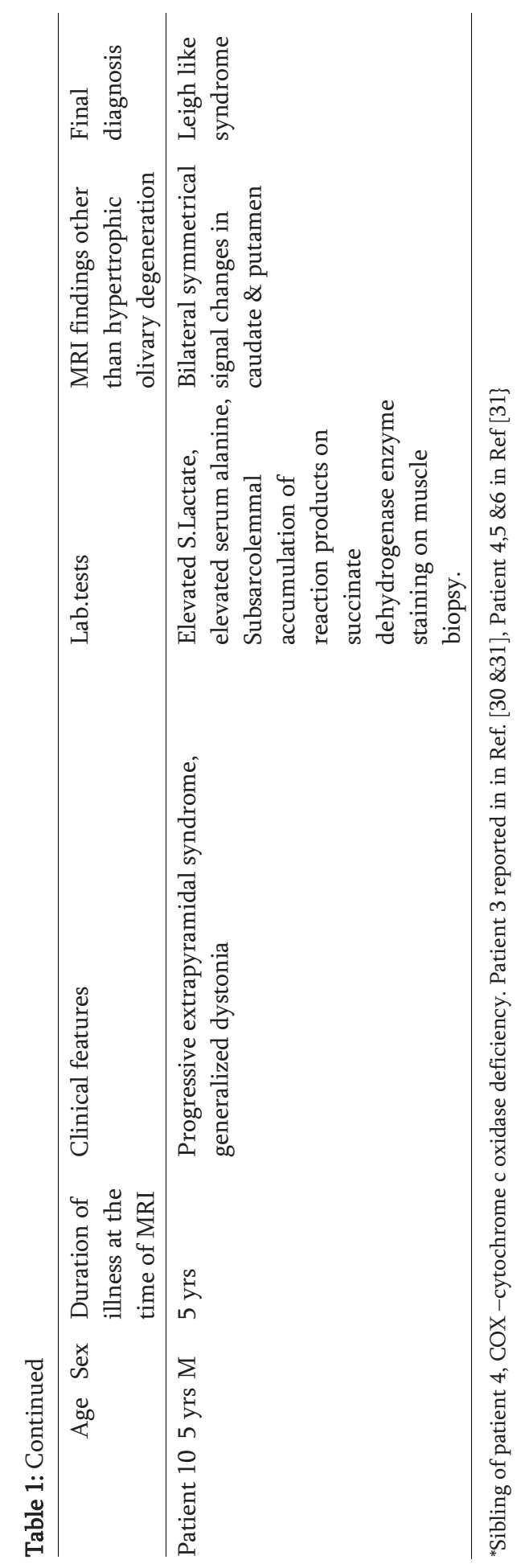




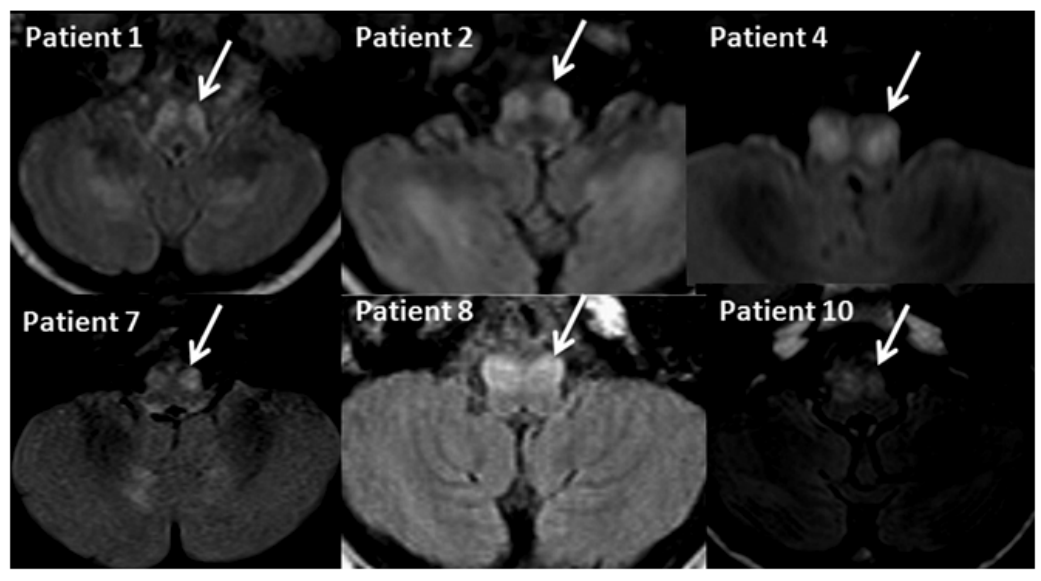

Figure 1. MRI brain fluid-attenuated and inversion-recovery axial views in different patients showing bilateral symmetrical signal changes in the inferior olivary nucleus. The margins of the nuclei are round and an apparent bulge (indicated by arrows) is noted.

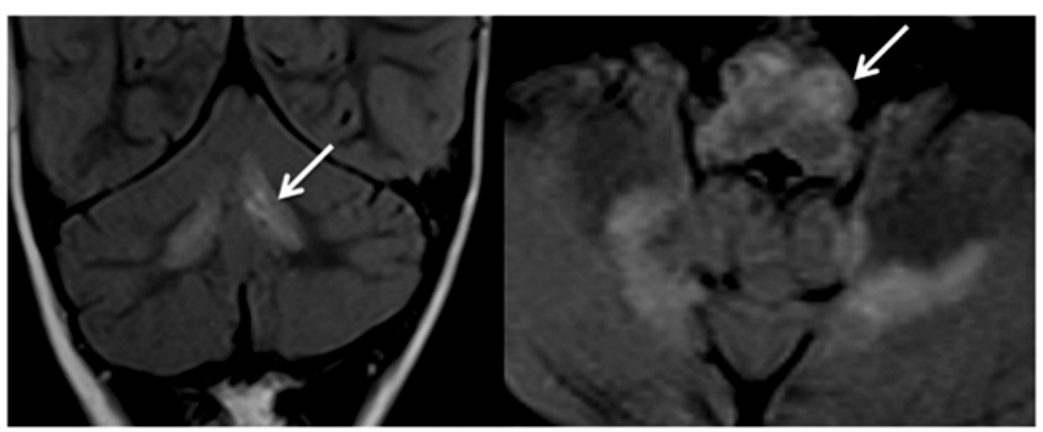

Figure 2. MRI scan of the brain in Patient 6. Fluid-attenuated inversion-recovery coronal and axial views showing bilateral symmetrical signal changes in dentate nuclei and inferior olivary hypertrophy (arrows) in this patient with cytochrome c oxidase deficiency and SURF1 mutation. 


\section{Discussion:}

This report describes the occurrence of hypertrophic olivary degeneration in a cohort of children with metabolic and genetic disorders. Our results suggest that this finding is most often associated with a mitochondrial disorder in children especially Leigh and Leigh like syndrome. Reports on bilateral hypertrophic olivary degeneration resulting from genetic or metabolic disorders are rare. There are a number of reports describing hypertrophy of the olivary nucleus in mitochondrial disorders. ${ }^{19,20}$ In a series of 26 children with polymerase gamma (POLG) related disorders bilateral hypertrophic olivary degeneration was observed in two patients and one of them had the clinical correlate of palatal myoclonus. ${ }^{19}$ It has also been described in Leigh syndrome secondary to $S U R F 1$ mutations. ${ }^{20}$ Review of the previously published magnetic resonance imaging studies in Leigh syndrome patients identified few reports describing the involvement of the olives. ${ }^{28,32-34}$ It is noteworthy that all but one of the patients in these reports had Cytochrome c oxidase deficiency and SURF1 mutations. The only exception was the patient with Leigh syndrome secondary to pyruvate dehydrogenase deficiency in the report by Medina et al. ${ }^{34}$ In this cohort, the hypertrophic olivary degeneration was seen in $40 \%$ of the children with Leighs and Leigh like syndrome and was not observed in other groups of metabolic disorders. Though all patients with SURF1 mutation had hypertrophic degeneration, it was also seen in patients without the mutations, indicating that it is not exclusively seen in this subtype of children with Leigh syndrome. In addition two children with cytochrome c deficiency but without the Leigh syndrome phenotype did not show this finding. Nevertheless, analysis of the whole cohort of children with metabolic and genetic disorders indicates that this imaging observation is more commonly seen in children with Leigh and Leigh like syndrome. None of the patients with mutation positive POLG related disorder had inferior olivary hypertrophy in the present study.

The bilateral inferior olivary hypertrophy seen in these children was not always associated with lesions of central tegmental tract or dentate nucleus suggesting an independent involvement of these nuclei in mitochondrial disorders. Neuropathological studies in mitochondrial diseases have shown that the olivary cerebellar system is involved in a variety of mitochondrial disorders and plays an important role in the pathogenesis of ataxia seen in these patients. ${ }^{35}$ This particular study involved 14 patients with definite mitochondrial diseases. There was variable neuronal loss in the dentate nuclei, inferior olives and purkinje cell system in these patients along with severe deficiency of respiratory chain enzymes in the remaining neurons. This shows that the inferior olivary nucleus is vulnerable to energy deficiency in patients 
with mitochondrial disorders. The magnetic resonance imaging correlates of these patients are not provided in the report. Nevertheless it will be interesting to see if the microscopic changes in these patients are associated with imaging changes.

Neuropathological studies in Leigh syndrome patients also have highlighted the occurrence of neuronal loss and vacuolar degeneration in inferior olives. ${ }^{35-37}$ The finding was most often noted in those patients who presented after the first year of life. This was attributed to the delayed maturation of the olivary -cerebellar system in children which occurs most often after infancy. The fact that hypertrophic olivary degeneration is present even in presence of neuronal loss is explained by pathological studies. The characteristic features that define hypertrophic olivary degeneration are overall enlargement of the olive in which convolutions are obscured. ${ }^{4}$ The neurons appear large and deformed and show marked astroglial reaction. Goulier and Blackwood had demonstrated that there is enlargement of both grey and white matter and the increased width of the grey lamina is in part due to hypertrophy of the nerve cell bodies and processes. ${ }^{3}$ They suggest that the eventual atrophy of the abnormal neurons is not accompanied by shrinkage of the glial mass so that the enlarged outline of the olive persists. This may be the explanation of hypertrophied olives even when there is neuronal loss in mitochondrial disorders.

The clinical correlates of the hypertrophic olivary degeneration in children and in patients with mitochondrial disorders have been variable. It was associated with palatal myoclonus in one of the two POLG related disorder patients described by Tzoulis et al., ${ }^{19}$ In the report by kinghorn et al, a generalized tremor was noted in the child with SURF1 mutations but was not present in the other two patients. ${ }^{18}$ In the report of Sanverdi et al none of the four children with hypertrophic olivary degeneration had palatal myoclonus. ${ }^{14}$ In the current study two patients had a generalised tremor associated with ocular bobbing. In two patients the clinical picture was dominated by generalised dystonia refractory to treatment with most of the anti-dystonia medications. It is difficult to comment about this finding in other patients, because it was not systematically looked for in most of the young patients.

The triangle of nerve tracts involved in the genesis of hypertrophic olivary degeneration is referred to the triangle of Guillain and Mollaret. ${ }^{1}$ These dentato-rubroolivary fibers connect the ipsilateral red nucleus and inferior olive with the contralateral dentate nucleus. Efferent fibers from the dentate nucleus course through the superior cerebellar peduncle, decussate in the brachium conjunctivum and then connect to the contralateral red nucleus. The efferent fibers from the red nucleus are connected to the olive through the central tegmental tract. The inferior olive is then connected to the contralateral cerebellum via the inferior cerebellar peduncle thus forming a triangle. It is pointed out that deafferentiating the inferior olivary 
nucleus is the key factor and typically lesions disrupting the superior cerebellar peduncle or central tegmental tract leads to hypertrophic olivary degeneration. The localisation of the olivary degeneration depends on the site of the lesion. Lesions of the red nucleus or central tegmental tract causes the hypertrophy of the ipsilateral nucleus and alternatively the lesions of the superior cerebellar peduncle or dentate nucleus causes hypertrophic olivary degeneration on the contra lateral side. ${ }^{9,12}$ Bilateral hypertrophy occurs when the lesion involves brachium conjunctivum, or interrupts both the central tegmental tract and superior cerebellar peduncle. ${ }^{16}$

In the cohort of children in the present study the hypertrophic olivary degeneration was associated with lesions of the central tegmental tract and dentate nucleus in most of the patients, but also occurred independently. In patients with Wilson disease, though ten patients had involvement of the central tegmental tract, hypertrophy of the inferior olivary nucleus was not observed. Diffusion tensor imaging (DTI) studies in patients with inferior olivary nucleus hypertrophy have demonstrated signal changes in all anatomical components of the Guillain Mollaret triangle even when conventional magnetic resonance imaging did not show any signs of involvement in the other components of Guillain Mollaret triangle ${ }^{39,40}$. It was also shown that the DTI parameters can reflect the spatiotemporal evolution of transneuronal degeneration associated with HOD in a manner consistent with the known pathologic stages of $\mathrm{HOD}^{26}$. In addition, susceptibility weighted imaging has been utilized to study the red nucleus degeneration and atrophy in children with hypertrophic olivary degeneration (HOD) after posterior fossa tumor resection. ${ }^{27}$ This indicates that quantitative imaging studies may better define the extent of the lesions in these patients and may be a future area of research.

In conclusion, this study on 125 children with various metabolic and genetic disorders suggests that bilateral hypertrophic olivary degeneration is relatively often, but not routinely seen in children with Leigh and Leigh like syndrome. Nevertheless, when compared to other metabolic disorders this finding was more commonly seen in children with Leigh and Leigh like syndrome. This occurred both independently and in association with central tegmental tract and dentate nuclei involvement. The findings suggest that bilateral inferior olivary hypertrophy should prompt the physician to carry out investigations to rule out a mitochondrial disorder. 


\section{References}

1. Guillian G, Mollaret P. Deux cas de myoclonies synchrones et rhythmes velopharyngo- laryngooculo-diaphragmatiques. Rev Neurol 1931; 2: 545- 66

2. Oppenheim H. Uber oliven degeneration bei atheromatose der basalen hinarterien . Berl Klin Wochenschr 1887; 34: 638-9.

3. Gautier JC, Blackwood W. Enlargement of the inferior olivary nucleus in association with lesions of the central tegmental tract or dentate nucleus. Brain 1961; 84: 341-61

4. Anderson JR, Treip CS. Hypertrophic olivary degeneration and Purkinje cell degeneration in a case of long-standing head injury. J Neurol Neurosurg Psychiatry 1973; 36: 826-32.

5. Kitajima M, Korogi Y, Shimomura O, et al., Hypertrophic olivary degeneration: MR imaging and pathologic findings. Radiology 1994; 192: 539-43

6. Goyal M, Versnick E, Tuite P et al., Hypertrophic olivary degeneration: metaanalysis of the temporal evolution of MR findings. AJNR Am J Neuroradiol 2000; 21:1073-77

7. Nishie M, Yoshida Y, Hirata Y, Matsunaga M. Generation of symptomatic palatal tremor is not correlated with inferior olivary hypertrophy. Brain 2002; 125:1348-57.

8. Salamon-Murayama N, Russell EJ, Rabin BM. Diagnosis please. Case 17: hypertrophic olivarydegeneration secondary to pontine haemorrhage. Radiology 1999; 213: 814-17.

9. Krings T, Foltys H, Meister IG, Reul J. Hypertrophic olivary degeneration following pontine haemorrhage: hypertensive crisis or cavernous haemangioma bleeding? J Neurol Neurosurg Psychiatry 2003 ; 74: 797-9.

10. Suzuki M, Takashima T, Ueda F, Fujinaga Y, Horichi Y,Yamashita J. Olivary Degeneration after intracranial haemorrhage or trauma: follow-up MRI. Neuroradiology 1999; 41: 9-12.

11. Hornyak M, Osborn AG, Couldwell WT. Hypertrophic olivary degeneration after surgical removal of cavernous malformations of the brain stem: report of four cases and review of the literature. Acta Neurochir (Wien) 2008; 150: 149-56

12. Choh NA, Choh SA, Jehangir M. Hypertrophic olivary degeneration: the forgotten triangle of Guillain and Mollaret. Neurol India 2009; 57: 507-9

13. Gatlin JL, Wineman R, Schlakman B, Buciuc R, Khan M. Hypertrophic olivary degeneration after resection of a pontine cavernous malformation: a case report. J Radiol Case Rep 2011; 5: 24-9.

14. Duchen LW. General pathology of neurons and neuroglia. In: Greenfield H, Corsellis JAN, Duchen LW, editors. Neuropathology $4^{\text {th }}$ ed. New York,NY: Wiley, 1984 p.18-9

15. Sanverdi SE, Oguz KK, Haliloglu G. Hypertrophic olivary degeneration in children: four new cases and a review of the literature with an emphasis on the MRI findings. Br J Radiol 2012; 85: 511-6

16. Conforto AB, Smid J, Marie SKN, et al., Bilateral Olivary Hypertrophy After Unilateral Cerebellar Infarction. Arq Neuropsiqulatr 2005; 63(2-A): 321-3.

17. Gerace C, Fele MR, Luna R, Piazza G. Neurologial Picture: Bilateral hypertrophic olivary degeneration. J Neurol Neurosurg Psychiatry 2006; 77: 73.

18. Kulkarni PK, Muthane UB, Taly AB, Jayakumar PN, Shetty R, Swamy HS. Palatal tremor, progressive multiple cranial nerve palsies, and cerebellar ataxia: a case report and review of literature of palatal tremors in neurodegenerative disease. Mov Disord 1999 ; 14:689-93

19. Tzoulis C, Engelsen BA, Telstad W, et al., The spectrum of clinical disease caused by the A467T and W748S POLG mutations: a study of 26 cases. Brain $2006 ; 129: 1685-92$

20. Kinghorn KJ, Kaliakatsos M, Blakely EL, et al., Hypertrophic olivary degeneration on magnetic resonance imaging in mitochondrial syndromes associated with POLG and SURF1 mutations. J Neurol 2013; 260: 3-9 


\section{Chapter 4}

21. Otto J, Guenther P, Hoffmann KT. Bilateral hypertrophic olivary degeneration in Wilson disease. Korean J Radiol 2013;14: 316-20

22. Hanihara T, Amano N, Takahashi T, Itoh Y, Yagishita S. Hypertrophy of the inferior olivary nucleus in patients with progressive supranuclear palsy. Eur Neurol 1998; 39:97- 102

23. Cazals X, Omoumi P, Agnard P, et al., Reversible metronidazole-induced encephalopathy and hypertrophic olivary degeneration . J Radiol 2010; 91: 304-6.

24. Seok JI, Yi H, Song YM, Lee WY. Metronidazole-induced encephalopathy and inferior olivary hypertrophy: lesion analysis with diffusion-weighted imaging and apparent diffusion coefficient maps. Arch Neurol 2003; 60: 1796-800.

25. Phatouros CC, McConachie NS. Hypertrophic olivary degeneration: case report in a child. Pediatr Radiol 1998; $28: 830-1$.

26. Meoded A, Poretti A, Ilica AT, et al., Diffusion Tensor Imaging in a Child with Hypertrophic Olivary degeneration. Cerebellum 2013 Jan 11.

27. Vossough A, Ziai P, Chatzkel JA. Red nucleus degeneration in hypertrophic olivary degeneration after pediatric posterior fossa tumor resection: use of susceptibility-weighted imaging (SWI). Pediatr Radiol 2012; 42: 481-5

28. Rahman S, Brown RM, Chong WK, Wilson CJ, Brown GK. A SURF1 gene mutation presenting as isolated leukodystrophy. Ann Neurol 2001; 49:797- 800

29. Bernier FP, Boneh A, Dennett X, Chow CW, Cleary MA, Thorburn DR. Diagnostic criteria for respiratory chain disorders in adults and children. Neurology 2002; 59: 1406-11

30. Sonam K,Khan NA, Bindu PS,Taly AB,Gayathri N,Srinivas Bharath MM et al., Clinical and Magnetic Resonance Imaging findings in Patients with Leigh syndrome and SURF1 mutations. Brain Dev. November 2013[Epub ahead of print]

31. Sonam K, Bindu PS, Gayathri N, et al., The double panda sign in Leigh disease J Child Neurol. 2014;29:980-82

32. Farina L, Chiapparini L, Uziel G, Bugiani M, Zeviani M, Savoiardo M. MR findings in Leigh syndrome with COX deficiency and SURF-1 mutations. AJNR Am J Neuroradiol 2002; 23 :1095-100.

33. Savoiardo M, Uziel G, Strada L, Visciani A, Grisoli M, Wang G. MRI findings in Leigh's disease with cytochrome- c-oxidase deficiency. Neuroradiology 1991;33(suppl): 507-8.

34. Medina L, Chi TL, DeVivo DC, Hilal SK. MR findings in patients with subacute necrotizing encephalomyelopathy (Leigh syndrome): correlation with biochemical defect. AJR Am J Roentgenol 1990; $154: 1269-74$

35. Lax NZ, Hepplewhite PD, Reeve AK, et al., Cerebellar ataxia in patients with mitochondrial DNA disease: a molecular clinicopathological study. J Neuropathol Exp Neurol 2012; 71: 148-61

36. Leigh D. Subacute necrotizing encephalomyelopathy in an infant. J Neurol Neurosurg Psychiatry $1951 ; 14: 216-21$

37. Dayan AD, Ockenden BG, Crome L. Necrotizing encephalomyelopathy of Leigh. Neuropathological findings in 8 cases. Arch Dis Child 1970; 45: 39-48

38. Cavanagh JB, Harding BN. Pathogenic factors underlying the lesions in Leigh's disease.Tissue responses to cellular energy deprivation and their clinico-pathological consequences. Brain 1994;117 $: 1357-76$.

39. Dinçer A, Ozyurt O, Kaya D, et al., Diffusion tensor imaging of Guillain-Mollaret triangle in patients with hypertrophic olivary degeneration J Neuroimaging 2011; 21: 145-51.

40. Shah R, Markert J, Bag AK, Curé JK. Diffusion tensor imaging in hypertrophic olivary degeneration. AJNR Am J Neuroradiol 2010; 31:1729-31 


\section{Chapter}

\section{Outcome of Epilepsy in patients with Mitochondrial Disorders: Phenotype Genotype and Magnetic Resonance Imaging Correlations}

Bindu PS, Sonam K, Govindaraj P, Govindaraju C, Chiplunkar S, Nagappa M, Kumar R, Vekhande CC, Arvinda HR, Gayathri N, Srinivas Bharath MM, Jessiena Ponmalar JN, Philip M, Vandana VP, Khan NA, Nunia V, Paramasivam A, Sinha S, Thangaraj K, Taly AB

Clinical Neurology Neurosurgery 2017;164:182-189 


\section{Abstract}

Objectives: Studies exploring the outcome of epilepsy in patients with mitochondrial disorders are limited. This study examined the outcome of epilepsy in patients with mitochondrial disorders and its relation with the clinical phenotype, genotype and magnetic resonance imaging findings. Patients and Methods: The cohort was derived from the database of 67 patients with definite genetic diagnosis of mitochondrial disorders evaluated over a period of 11 years (2006-2016). Among this, 27 had epilepsy and were included in final analysis. Data were analyzed with special reference to clinical phenotypes, genotypes, epilepsy characteristics, EEG findings, anti epileptic drugs used, therapeutic response, and magnetic resonance imaging findings. Patients were divided into three groups according to the seizure frequency at the time of last follow up: Group I- Seizure free; Group II- Infrequent seizures; Group IIIuncontrolled seizures. For each group the clinical phenotype, genotype, magnetic resonance imaging and duration of epilepsy were compared. Results: The phenotypes \& genotypes included Mitochondrial Encephalopathy Lactic Acidosis and Stroke like episodes (MELAS), m.3243A>G mutation ( $\mathrm{n}=10$ ), Myoclonic Epilepsy Ragged Red Fiber syndrome (MERRF), m.8344A $>\mathrm{G}$ mutation $(\mathrm{n}=4)$, Chronic Progressive External Ophthalmoplegia plus \& POLG1 mutation (CPEO, $n=6$ ), episodic neuroregression due to nuclear mutations ( $\mathrm{n}=6$; NDUFV1 ( $\mathrm{n}=3$ ), NDUFA1, NDUFS2, MPV17-1 one each), and one patient with infantile basal ganglia stroke syndrome, mineralizing angiopathy \& MT-ND5 mutations. Seven patients (25.9\%) were seizure free, seven had infrequent seizures (25.9\%), while thirteen (48.1\%) had frequent uncontrolled seizures at last follow up. Majority of the subjects in Group I (seizure free) had episodic neuroregression \& leukoencephalopathy due to various nuclear mutations (85.7\%); Group II- CPEO, POLG1 variation and a normal MRI $(71 \%)$ and in group III - MELAS, m.3243A $>\mathrm{G}$ mutation and stroke like lesions on MRI (62\%).

Conclusions: A fair correlation exists between the outcome of epilepsy, clinical phenotypes, genotypes and magnetic resonance imaging findings in patients with mitochondrial disorders. The recognition of these patterns is important clinically because of the therapeutic and prognostic implications. 


\section{Introduction}

Mitochondria are important subcellular organelles, which are central for various cellular processes that include ATP production, intracellular Ca signaling, and generation of reactive oxygen species. ${ }^{1}$ Physiological experiments have provided robust evidence that there is a fine-tuned coupling between neuronal activity and mitochondrial function, and mitochondria are of central importance for the complex behavior of neurons. ${ }^{1}$ Epilepsy is part of the clinical presentation in a broad variety of mitochondrial disorders. ${ }^{2,3}$ The exact prevalence of mitochondrial epilepsy is not known, but seizures have been reported to occur in 35 to $60 \%$ of individuals with biochemically confirmed mitochondrial disease. ${ }^{4-7}$ Epilepsy may be the presenting feature of mitochondrial disorders but is often a part of multisystem clinical presentation..$^{5-8}$ Mitochondrial epilepsy occurs in early-onset as well as late-onset syndromic and nonsyndromic mitochondrial disorders. ${ }^{3}$ More importantly, clinical diagnosis of mitochondrial epilepsy has both prognostic and therapeutic implications. Early recognition enables the physician to choose appropriate drugs and avoid mitochondrial toxins thus saving the patient from life threatening complications. ${ }^{9}$ Prompt and aggressive seizure management may play a role in modifying the epileptogenic process and improving survival. ${ }^{10}$

The factors determining the course, prognosis and therapeutic response of epilepsy in patients with mitochondrial disorders are largely unknown. This study examined the pattern of seizure control and factors determining the outcome in patients with mitochondrial epilepsy. Specifically the study looked at the correlation between phenotype, genotype, MRI findings and duration of epilepsy with outcome.

\section{Patients and methods:}

The cohort was derived from the database of patients who underwent evaluation for mitochondrial etiology over a period of 10 years (2006-2016). Patients were recruited into the study when they satisfied the clinical criteria of mitochondrial disorder as suggested by Bernier et $\mathrm{al}^{11}$ and a comprehensive evaluation, including serum lactate, muscle histopathology, respiratory chain complex assays, brain magnetic resonance imaging, nerve conduction studies, electroencephalography (EEG) and evoked potential studies tailored to the clinical phenotype suggested a probable diagnosis of mitochondrial disorder. Standard definitions were used for phenotypic characterization of classical mitochondrial syndromes. ${ }^{12}$ 
Genetic evaluation: All patients with known pathogenic variations in mtDNA were diagnosed by complete mitochondrial genome sequencing. The patients with nuclear mutations were identified using targeted exome sequencing. The gene panel consisted of 6440 genes inclusive of all nuclear-encoded mitochondrial genes that are strongly associated with a disease on online Mendelian inheritance in man (OMIM). All variants identified by exome sequencing were verified by Sanger sequencing and further validated by segregation analysis in first-degree relatives.

Detailed observations of magnetic resonance imaging findings and peripheral neuropathy in part of this cohort have already been published. ${ }^{12,13}$ There were 67 patients with a definite genetic diagnosis of mitochondrial disorders. Among this, 27 (Age range: 8 months-45 years, M: F- 1.8:1) had epilepsy and were included in final analysis. The phenotypic features, including characteristics of epilepsy, electroencephalographic findings, details of the antiepileptic drugs received and the response, magnetic resonance imaging findings and genetic diagnoses were reviewed and correlated. Epilepsy was classified according to the 2017 revised International League against Epilepsy (ILAE) guidelines. ${ }^{14,15}$ The outcomes were collected prospectively by the clinical team (ABT, SS, PSB, MN,) and designated in relation to the total duration of the illness at last follow up. The outcomes were classified into three groups as defined by Kuzmanovski et al., ${ }^{16}$ Group I- seizure free patients at the time of last follow up. Seizure freedom was defined as a period without seizures for a minimum of 12 months. ${ }^{17}$ Group II- Patients with intermittent seizures if they presented with only auras or infrequent non-disabling seizures such as eyelid myoclonia. Group IIIuncontrolled seizures or drug resistant epilepsy failure of adequate trials of two tolerated, appropriately chosen and used antiepileptic drug schedules (whether as monotherapies or in combination) to achieve sustained seizure freedom. The institute ethics committee approved the study and all subjects gave written informed consent.

Statistical Analysis: The data are presented as means, standard deviations or number and percentages. Phenotype and MRI finding were cross-tabulated with the three groups. Due to the small number of subjects Chi-square test was not attempted. Duration of illness was compared among the groups using Kruskal Wallis Test, as numbers of subjects in the groups were small. It indicated that the durations do not differ significantly among the groups 


\section{Results}

There were 27 patients (Age range: 7 months - 41 years, M: F- 2:1). Majority belonged to the pediatric age group ( $\mathrm{n}=21$, Age: $8.1 \pm 5.03$ years). Mean age in adults $(\mathrm{n}=6)$ was $38.6 \pm 6.3$ years. The phenotypes, genotypes, MRI and EEG findings and outcome in the whole group is provided in Table 1.

\subsection{Clinical Phenotypes:}

The clinical phenotypes included Mitochondrial Encephalopathy Lactic Acidosis and Stroke like episodes (MELAS, n=10), Myoclonic Epilepsy Ragged Red Fiber syndrome (MERRF, n=4), Chronic Progressive External Ophthalmoplegia plus (CPEO, $n=6)$, Mitochondrial leukoencephalopathy $(n=6)$, and one patient with infantile basal ganglia stroke syndrome due to mineralizing angiopathy.

\subsection{Genetic findings:}

The genotypes of the patients included mutations in mitochondrial DNA ( $\mathrm{n}=15)$; POLG1 (n=6); NDUFV1 (n=3), NDUFA1, NDUFS1, MPV17 one each

\subsection{Magnetic resonance imaging findings:}

MRI findings included Stroke- like- lesions (SLL: n=9, 33.3\%, Fig.1, 2 \&3); Leukoencephalopathy (LE: $\mathrm{n}=6,22.2 \%$, Fig.4); Cerebral/ cerebellar / brainstem atrophy $(\mathrm{n}=6,22.2 \%)$; Normal MRI ( $\mathrm{n}=5,18.5 \%)$; Asymmetric basal ganglia infarcts due to mineralizing angiopathy $(\mathrm{n}=1,3.7 \%)$.

\subsection{Epilepsy phenotypes \& EEG findings:}

Seizure types included Focal onset aware seizures ( $\mathrm{n}=17,62.9 \%)$ focal onset impaired awareness seizures $(\mathrm{n}=12,44.4 \%)$, focal to bilateral tonic clonic seizures $(n=15,55.5 \%)$, generalized onset tonic clonic seizures $(n=12,44.4 \%)$, generalized onset myoclonic seizures $(\mathrm{n}=4,14.8 \%)$, photosensitive eyelid myoclonia $(\mathrm{n}=5,18.5 \%)$. status epilepticus occurred in $11(40.7 \%)$ and epilepsia partialis continua in eight (29.6\%). Electroencephalogram findings included focal or multifocal spikes or sharp waves in 12 (44.4\%), generalized polyspikes in 7 (25.9\%) and normal sleep record in 5 (18.5\%). 


\subsection{Treatment:}

All patients received weight appropriate dosages of anti-epileptic drugs along with mitochondrial cocktail. The most commonly used drugs were levetiracetam $(n=21$, $77.7 \%)$, clobazam $(n=16,59.2 \%)$ and phenytoin $(n=12,44.4 \%)$. Other drugs used included carbamazepine, $n=5$; lamotrigine, $n=4$, topiramate and zonizamide one each. Prior to the diagnosis, three patients received sodium valproate. After the diagnosis it was replaced by levetiracetam and lamotrigine. The youngest child with m.3243A $>$ G mutation had a myo-cerebro-hepatopathy syndrome precipitated by use of sodium valproate and propofol anesthesia for magnetic resonance imaging study.

\subsection{Outcome of Epilepsy:}

At the time of last follow up there were seven patients in the seizure free group (Group I: $n=7,25.9 \%$ ), seven in the infrequent seizure group (Group II: $n=7,25.9 \%$ ), and thirteen in the frequent uncontrolled seizure group (Group III: $n=13,48.1 \%$ ). Data on the outcome of epilepsy in relation to clinical phenotype, genotype and MRI findings are provided in Table 2.

\subsubsection{Group I (Seizure free group):}

Majority of the patients in this group presented with episodic or relapsing remitting neurological illness. Seizures were isolated and precipitated by febrile episodes. In some patients the relapse of the episodes were heralded by seizures. MRI in all showed features of mitochondrial leukoencephalopathy viz. multifocal confluent signal changes, diffusion restriction and contrast enhancement and lactate peak on MRS (Fig.4). Only cortical structure involved was bilateral hippocampi, which showed T2/FLAIR hyper intensities and diffusion restriction (Fig.4). The single patient in this group had the ND5 mutations. Seizures were infrequent and were well controlled on a single antiepileptic drug.

\subsubsection{Group II (Intermittent non disabling seizures):}

Majority of the patients in this group had CPEO, eyelid myoclonia, POLG1 mutation and abnormal MRI. Additional 2 patients had MELAS, m.3243A>G mutation who had only intermittent auras on follow up.

\subsubsection{Group III (Uncontrolled seizures):}

Majority of the subjects in this group had MELAS and m.3243A>G mutation. In six patients, epilepsy occurred during the stroke like episodes and corresponded to the side of the cortical lesion and focal epileptic activity corresponding to the side of 
stroke like lesions [Fig 1a-d, Fig.2 a\&b]. Those children with an earlier age of onset and longer duration of symptoms had multiple small cortical lesions and they had seizures independent of the stroke-like episodes and multifocal epileptic activity on EEG [Fig 3a-c]. The other patients in this group included patients with MERRF syndrome, m.8344G $>$ A mutations \& cerebral atrophy. All had a course similar to neurodegenerative illness with progressive cognitive decline, refractory myoclonus and generalized tonic clonic seizures on follow up. One additional patient who had CPEO, POLG1 mutation and ataxia also had a progressive degenerative course with psychiatric manifestations, refractory seizures.

\subsection{Phenotypes, Genotypes and Outcome of epilepsy:}

It can be seen that majority of the subjects in group I (85.7 \%) had neuroregression \& other nuclear mutations, group II (71 \%) had CPEO \& POLG1 variation and in group III (62 \%) MELAS \& m.3243 A>G mutation. Phenotype seems to be different among the groups, however, due to the small number of subjects this could not be tested using Chi-square test.

Majority of the subjects in group I had leukoencephalopathy (85.7\%), group II (71 \%) normal MRI, and Group III (61.5 \%) had stroke like lesions on MRI (61.5\%). MRI findings seem to differ according to seizure control, however, due to the small number of subjects this could not be tested using Chi-square test.

Duration of illness was compared among the groups using Kruskal Wallis Test, as numbers of subjects in the groups were small. It indicated that the duration of epilepsy do not differ significantly among the groups. 
Chapter 5

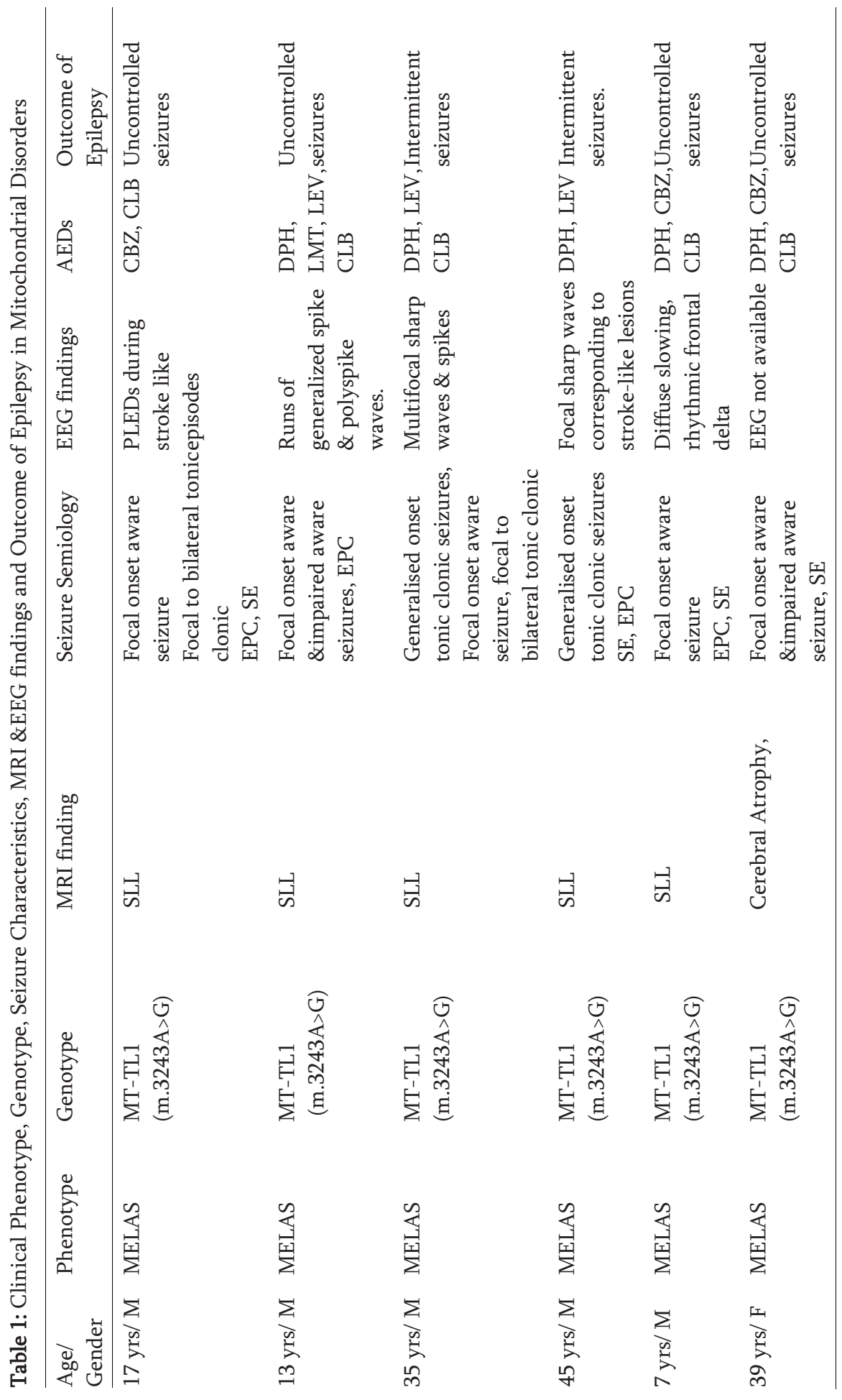




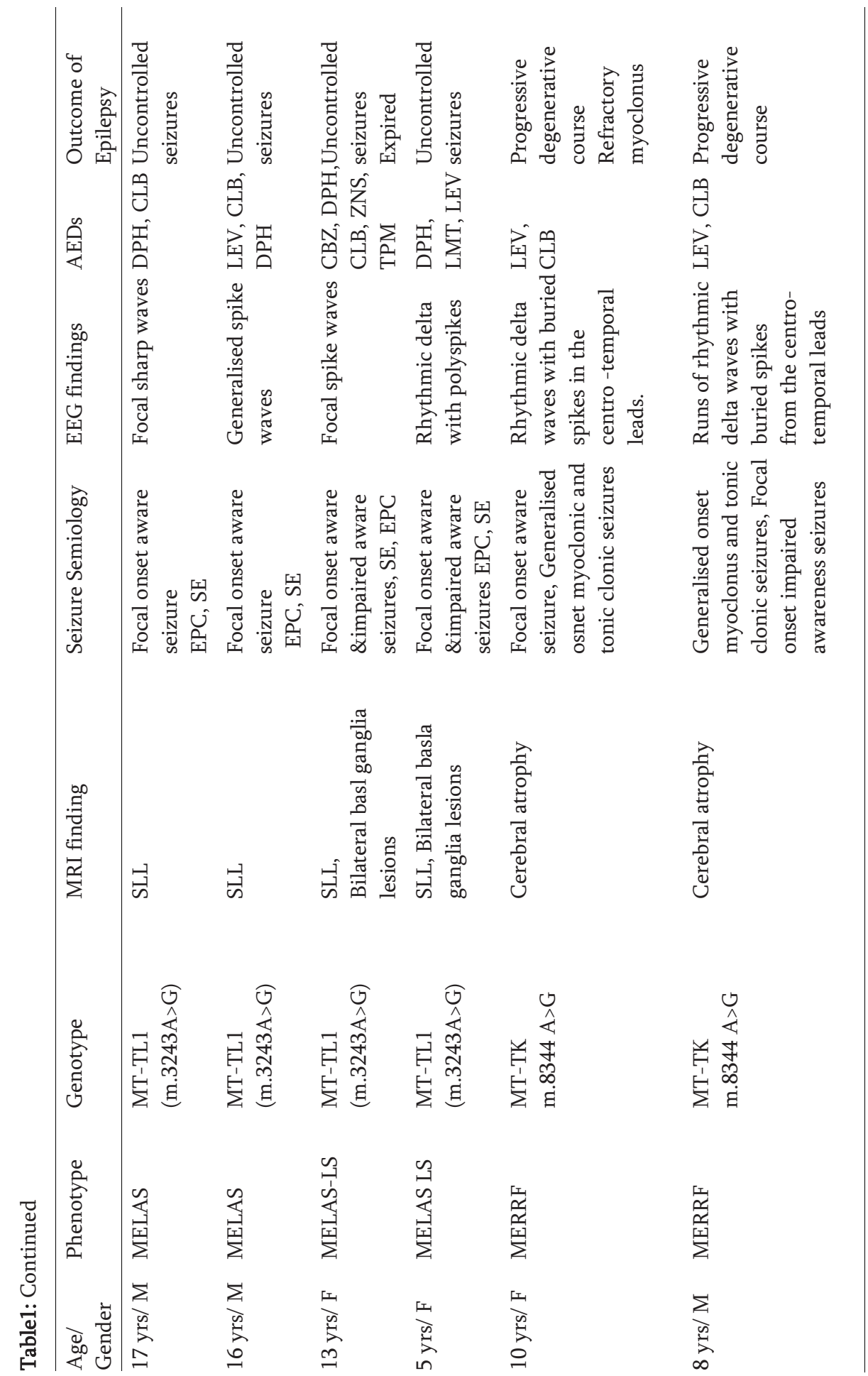




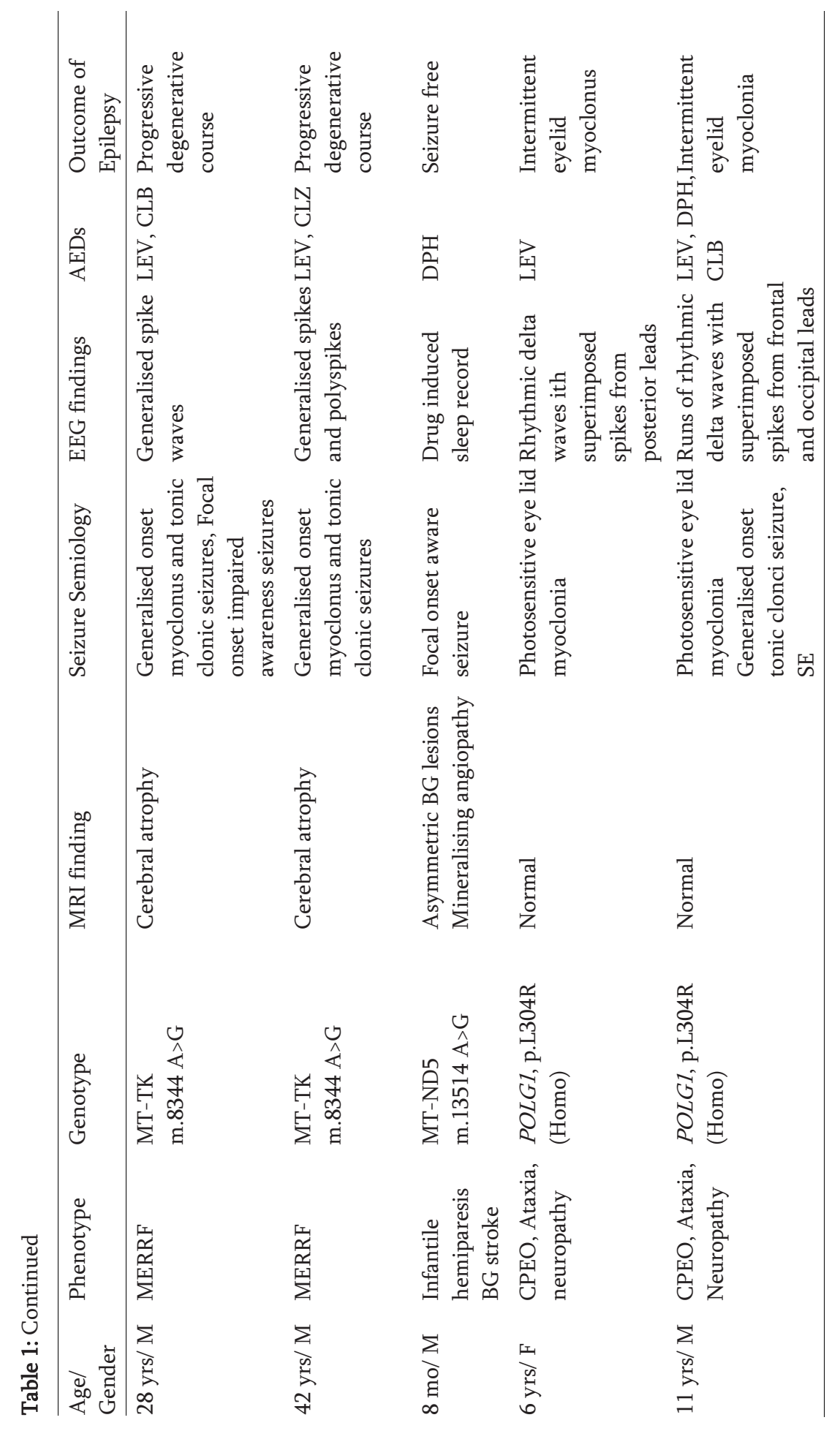




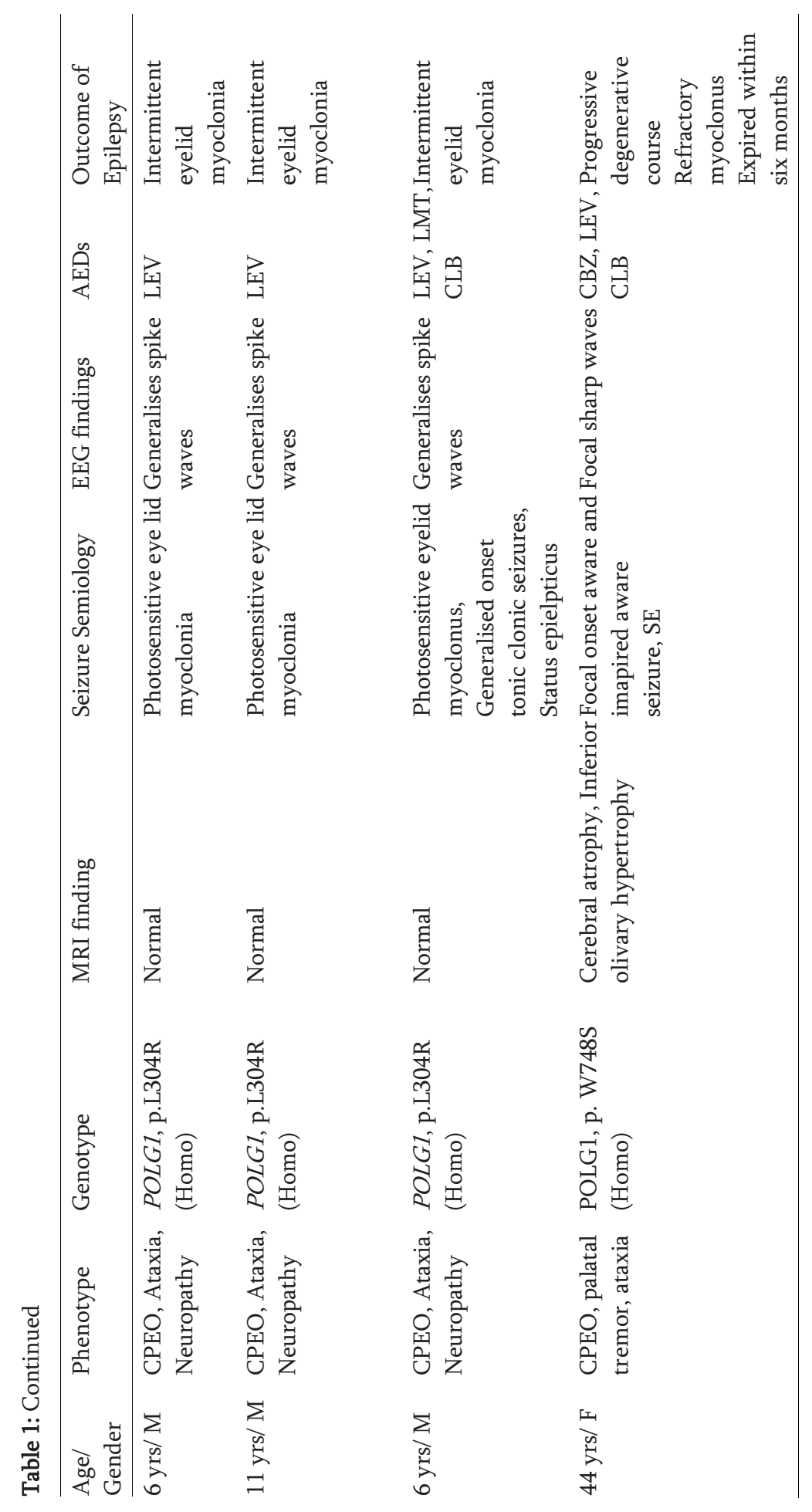




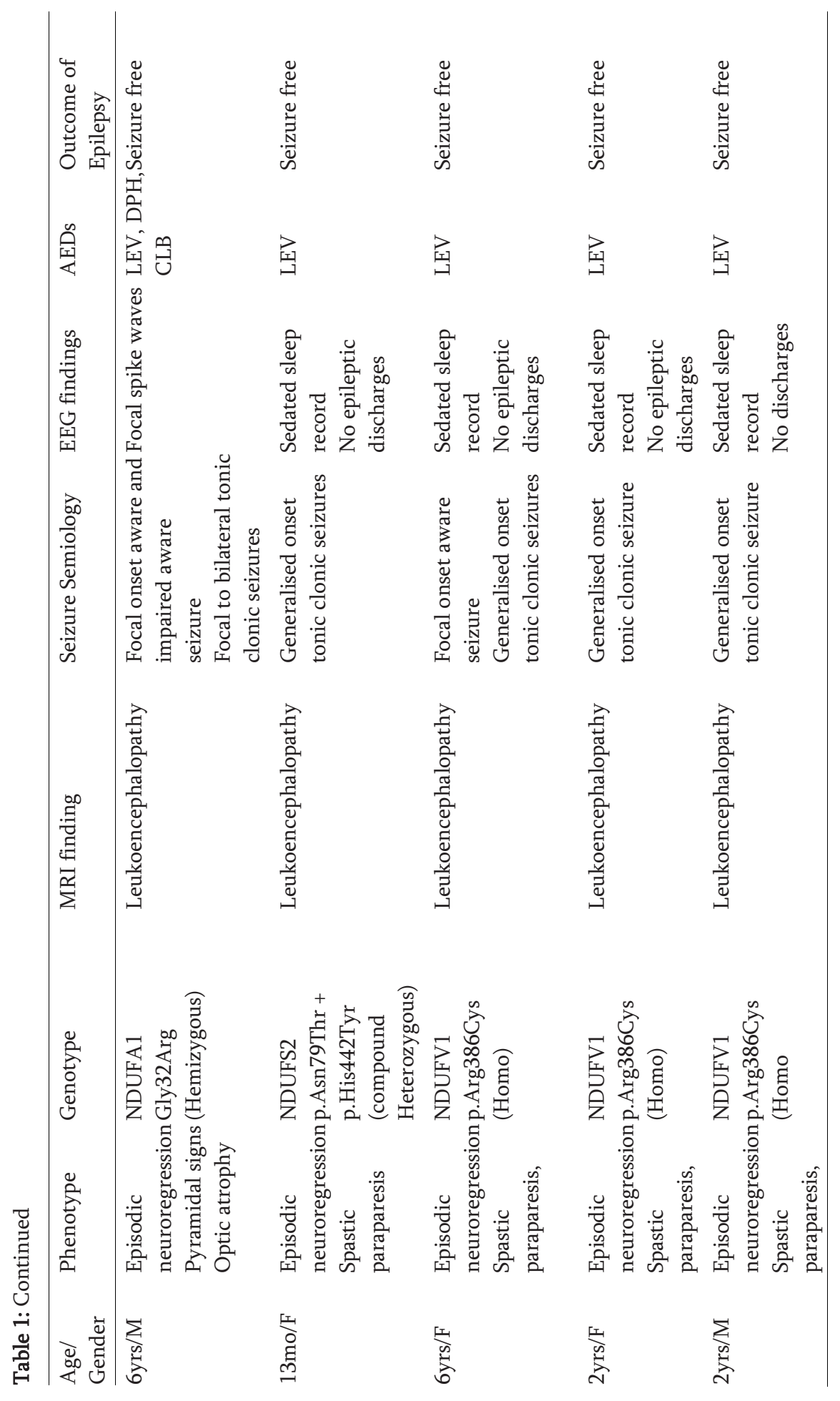


Outcome of Epilepsy in patients with Mitochondrial Disorders

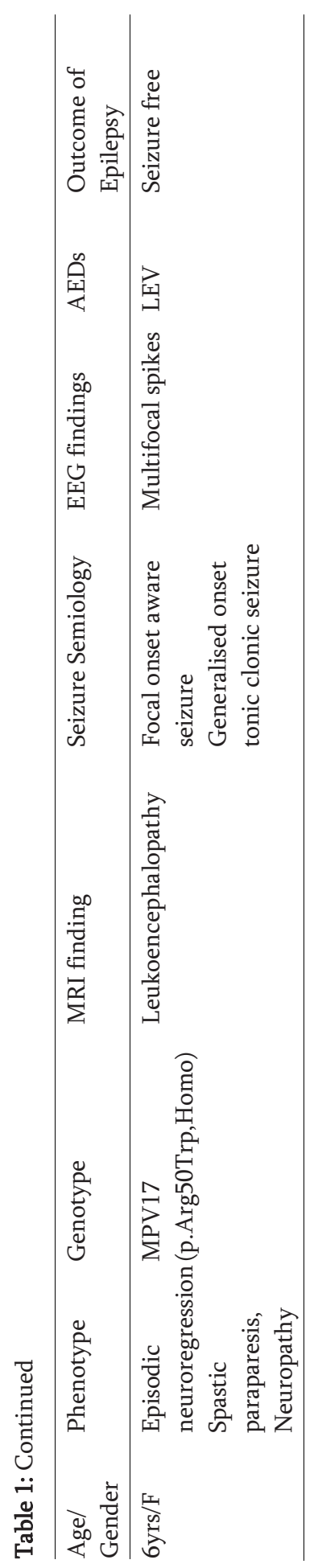


Table 2: Comparison of Phenotypes, genotypes, MRI findings and duration of epilepsy in three outcome groups of patients with mitochondrial Epilepsy

\begin{tabular}{|c|c|c|c|c|c|}
\hline \multirow{4}{*}{ Parameters } & & \multicolumn{3}{|l|}{ GROUPS } & \multirow{4}{*}{ Total } \\
\hline & & Group I & Group II & Group III & \\
\hline & & Seizure & Infrequent & Uncontrolled & \\
\hline & & \multicolumn{3}{|l|}{ Number (\%) } & \\
\hline \multirow[t]{5}{*}{ Phenotype } & MELAS & - & $2(28.6)$ & $8(61.5)$ & $10(37)$ \\
\hline & MERRF & - & - & $4(30.8)$ & $4(30.8)$ \\
\hline & Infantile BG stroke & $1(14.3)$ & - & - & - \\
\hline & CPEO/ Epilepsy & - & $5(71.4)$ & $1(7.7)$ & $6(22.2)$ \\
\hline & $\begin{array}{l}\text { Episodic } \\
\text { neuroregression }\end{array}$ & $6(85.7)$ & - & - & - \\
\hline \multirow[t]{5}{*}{ Genotype } & m.3243 A>G & - & $2(28.6)$ & $8(61.5)$ & $10(37)$ \\
\hline & $\mathrm{m} .8344 \mathrm{G}>\mathrm{A}$ & - & - & $4(30.8)$ & \\
\hline & $\mathrm{m} .13514$ & $1(14.3)$ & - & - & \\
\hline & POLG1 & - & $5(71.4)$ & $1(7.7)$ & \\
\hline & $\begin{array}{l}\text { Other Nuclear } \\
\text { mutations }\end{array}$ & $6(85.8)$ & - & - & $6(22.2)$ \\
\hline \multirow[t]{5}{*}{ MRI } & SLL & - & $1(14.3)$ & $8(61.5)$ & $9(33.3)$ \\
\hline & Leukoencephalopathy & $6(85.7)$ & - & - & $6(22.2)$ \\
\hline & Atrophy & - & $1(14.3)$ & $5(38.5)$ & $6(22.2)$ \\
\hline & Normal & - & $5(71.4)$ & - & $5(22.2)$ \\
\hline & $\begin{array}{l}\text { BG stroke \& } \\
\text { Mineralising } \\
\text { angiopathy }\end{array}$ & $1(14.3)$ & - & - & $1(3.7)$ \\
\hline Duration & Mean \pm SD & $4.43 \pm 2.64$ & $4.71 \pm 5.38$ & $6.15 \pm 4.54$ & 2 - value \\
\hline of epilepsy & Median (Range) & $4(1-8)$ & $2(1-13)$ & $4(2-17)$ & $\begin{array}{l}\text { (p-value) } \\
1.892 \\
(0.388)\end{array}$ \\
\hline
\end{tabular}



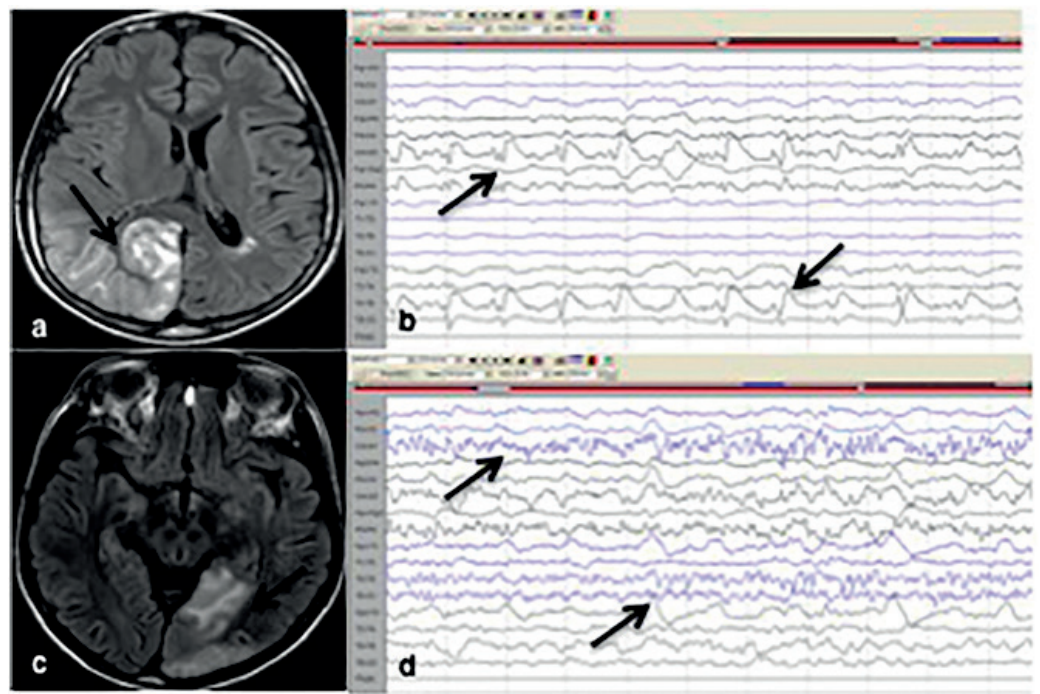

Fig.1 MRI brain in a 17 year old boy with MELAS syndrome secondary to m.3243 A>G mutation. (a) Axial FLAIR images during a stroke like episode showing signal changes in the parieto-occipital region on (R) side (arrow) (b) EEG during the episode shows periodic lateralised epileptiform discharges (PLEDS) from (R) posterior leads corresponding to the stroke like lesion(arrows) (c) Axial FLAIR images during another episode shows a stroke like lesion on (L) temporal region (d) EEG during this time demonstrates an electrographic seizure from the same region (arrows)
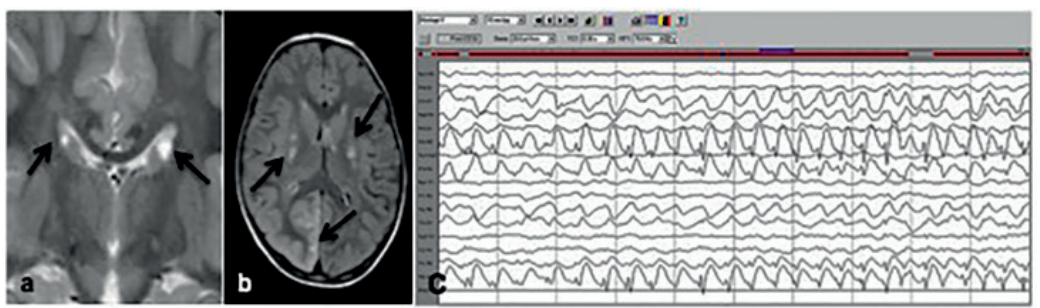

Fig.2 MRI brain in a 5 year old girl with m.3243 A>G mutation. (a) Axial T2WI shows bilateral symmetrical signal changes in caudate (b) putamen and (R) parieto-occipital region suggesting a MELAS-Leighs overlap syndrome. EEG during the episode shows rhythmic high amplitude delta waves with superimposed spikes from the $(\mathrm{R})$ posterior leads.

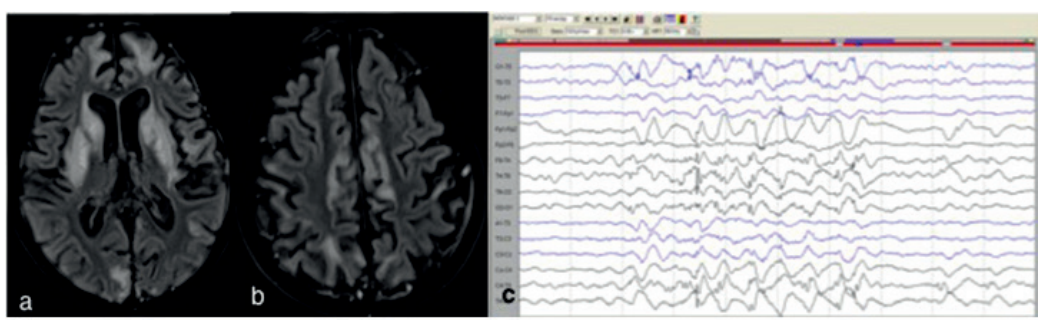

Fig.3 MRI brain in a 13 year old girl with $\mathrm{m} .3243 \mathrm{~A}>\mathrm{G}$ mutation with an earlier onset and longer duration of symptoms. (a) FLAIR axial view shows blateral symmetrical basal ganglia hyperintensities (b) multiple small stroke like lesions. (c) EEG shows multifocal epileptiform discharges. 


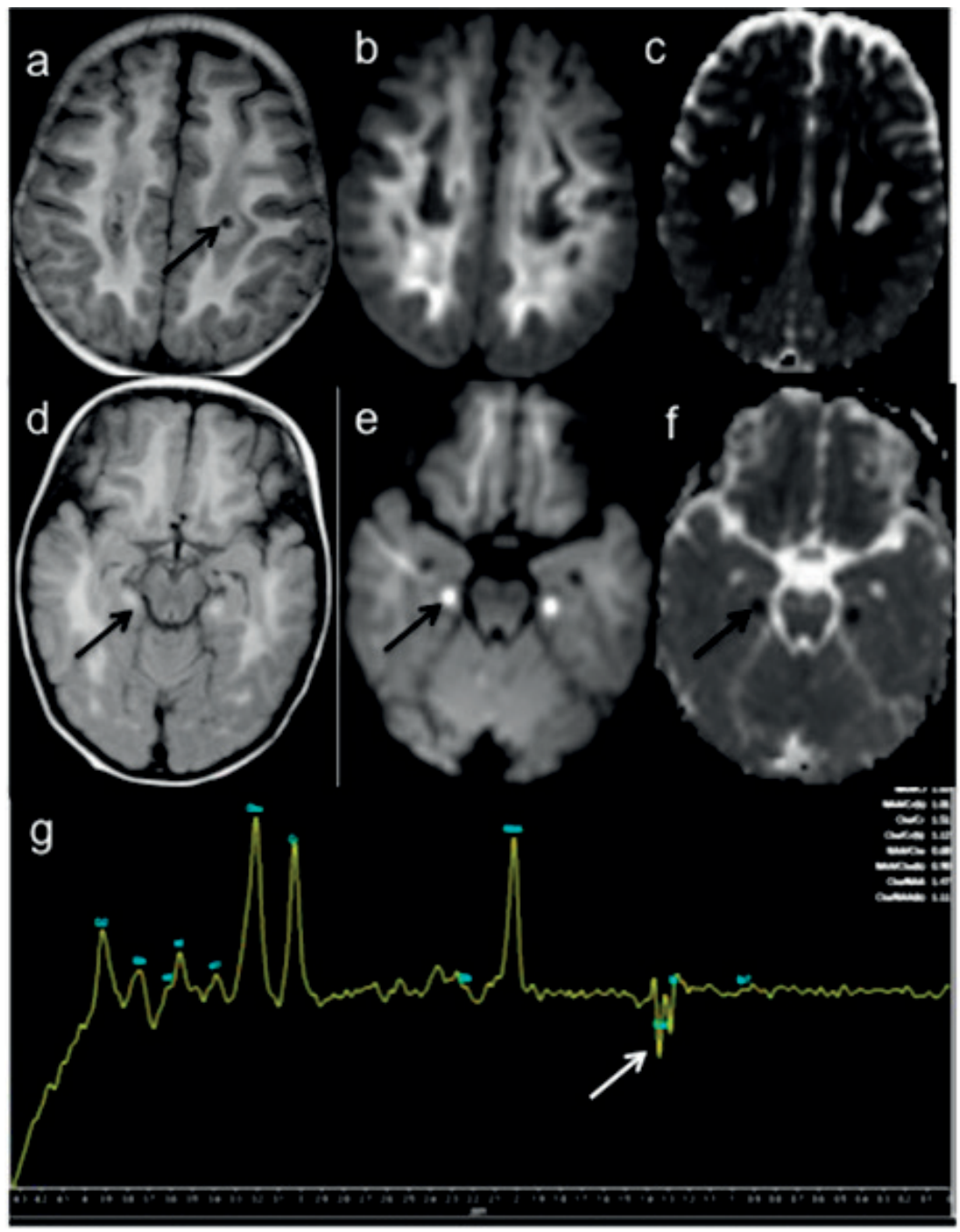

Fig.4 MRI brain in a 2 year old girl with homozygous NDUFV1 variation. (a) FLAIR axial view showing bilateral symmetrical signal changes in white matter with microcystic changes (arrows) (b) \& (c) DWI and ADC maps demonstrates restricted diffusion in the involved white matter(arrows) (d) FLAIR axial (e) DWI (f) ADC maps showing signal changes and restricted diffusion in bilateral hippocampi (arrows). (g) MRS shows lactate peak (arrows) 


\section{Discussion}

Epilepsy is frequent in patients with mitochondrial diseases, with varied prevalence reported in different studies. ${ }^{4,18}$ In children with respiratory chain enzyme deficiencies, diverse epileptic phenotypes and syndromes have been described. ${ }^{5,7}$ In the present series, which included both adults and children, seizures were noted in $41.7 \%$ of patients. In a cohort of adults with mitochondrial disorders diagnosed using the Walkers criteria and of different diagnostic certainty the prevalence was only $14 \% .^{19}$ In a recent series on adults with genetically characterized mitochondrial disorders $23.1 \%$ of the patients had seizures. ${ }^{20}$ The present studies and the previous studies show that seizures constitute an important central nervous system manifestation in both adults and children with mitochondrial disorders. The strength of the present study includes the correlation between outcome of epilepsy and three important attributes of mitochondrial disorders viz. clinical phenotype, genotype and MRI findings.

Group I or the seizure free group consisted of children with episodic neuroregression and leukoencephalopathy on MRI. All patients with leukoencephalopathy had complex I nuclear variations except in one patient who had the MPV17 variations. Of the nuclear subunits causing complex I deficiency, epilepsy has been associated with mutations in NDUFV1, NDUFS4, NDUFS8, and NDUFA1. ${ }^{21,22}$ Myoclonic epilepsy has also been reported in complex I assembly defects. ${ }^{23}$ Myoclonic seizures in nuclear-encoded complex I deficiency were apparently responsive to antiepileptic drugs compared to patients with $P O L G$ related disorders. ${ }^{23,}{ }^{24}$ Complex I defects are more potent generators of epilepsy than defects affecting the other complexes, perhaps because this complex is working close to its maximum in neurons. ${ }^{1}$ There were no cortical involvement on routine imaging in this group, however two patients showed signal changes in the hippocampus with restricted diffusion. The role of mitochondrial dysfunction in hippocampus has been studied in relation to the refractory complex partial seizures. ${ }^{25}$ But the role of hippocampal dysfunction in mitochondrial epilepsy have not been studied so far and needs further exploration. Even though the genetic etiology was heterogeneous in this group a pattern of convergence existed at the level of magnetic resonance imaging and epilepsy outcome in these children.

Patients with intermittent seizures or non-disabling seizures had CPEO, ataxia and neuropathy. Epilepsy is a common manifestation in POLG related disease and cause significant morbidity and mortality. ${ }^{10}$ It has been shown that the earliest factor leading to cellular dysfunction in POLG related epilepsy is mitochondrial depletion. ${ }^{26}$ This in turn leads to loss of mitochondrial respiratory chain complexes and 
defective energy metabolism. These results in two distinct pathological process namely neuronal degeneration and acute neuronal necrosis related to epileptic seizures. ${ }^{26}$ It is noteworthy that all patients in this group had the p.L304R variation located in the exonuclease domain of the POLG1. All of them presented after the age of five years with slowly progressive external ophthalmoplegia and developed seizures within 2-3 years of onset mainly characterized by photosensitive eyelid myoclonia and intermittent generalized onset tonic clonic seizures. In contrast to the present study, in a recent review on $P O L G$-related epilepsy the most common variation reported was p.A467T in the catalytic subunit. ${ }^{27}$ Further it was noted that homozygous or compound heterozygous variants located in exonuclease domain were very rare and associated with severe disease and early death. Long term follow up of the patients with p.L304R variation is needed to validate this observation. Even though the variations located in the linker domain are noted to have later age of onset and longer survival the patient with the p.W748S variation also had a severe clinical course in the present study. Probably phenotypic characterization and follow up in a large number of patients are required to delineate the exact phenotype genotype correlations in $P O L G$-related epilepsy.

Majority of the patients in the uncontrolled group had clinical phenotype of MELAS, m.3243A $>$ G mutations and stroke like lesions on MRI. The characteristic feature in this group included focal onset aware and impaired awareness seizure, focal to bilateral tonic clonic, epilepsia partialis continua and status epilepticus. The highest percentage of the status epilepticus patients were noted in this group compared with all other groups. The m.3243A $>$ G mutation is described as one of the 'hot spots' associated with epilepsy phenotypes. ${ }^{2}$ The occurrence of seizures is due to the dominant cortical involvement in patients with $\mathrm{m} .3243 \mathrm{~A}>\mathrm{G}$ mutations. ${ }^{28}$ This may be related to the mutation load in different tissues. A particularly high mutation load has been observed in cerebral vascular smooth muscle cells in patients with m.3243A $>\mathrm{G}$ mutation. ${ }^{29}$ The most important factor contributing to the pathogenesis of stroke like episodes is focal neuronal hyper excitability leading to epileptic seizures. ${ }^{30}$ The epileptic activity in turn causes marked increase in energy demand leading to cortical energy failure and has a role in the spread of stroke like lesions. ${ }^{31}$

The second major group in patients with uncontrolled epilepsy was MERRF syndrome \& m.8344G $>$ A mutation and cerebral atrophy on MRI. An additional patient in this group had the POLG related disorder \& homozygous W748S mutation. Patients with m.8344A $>\mathrm{G}$ mutations had progressive myoclonic epilepsy syndrome characterized by generalized onset tonic clonic seizure, myoclonic seizures ataxia and progressive cognitive decline as in previous studies. ${ }^{25}$ The single patient with $P O L G$ related disorder in this group had bilateral inferior olivary hypertrophy in 
addition to the atrophic changes. Neuropathological studies have shown that Purkinje cells and neurons of the dentate nucleus and inferior olivary nuclei have a special vulnerability to the effects of the m.8344A $>$ G mutation and $P O L G$ mutations as compared with other mtDNA mutations. ${ }^{32}$ All patients had a neurodegenerative course in this group. The molecular processes that lead to neuronal loss in various mitochondrial disorders remain elusive. ${ }^{33}$ However the autopsy studies have provided sufficient evidence for the neurodegenerative changes in mitochondrial disorders. ${ }^{33}$

Therapeutic response in patients with mitochondrial epilepsy is usually poor. The most common antiepileptic drugs used in the present cohort included leviteracetam and clobazam. Majority of the patients in this study also received mitochondrial cocktail medications. Studies have suggested that the anticonvulsants lamotrigine and levetiracetam may be neuroprotective, at least in experimental models of mitochondriopathies. ${ }^{34,35}$

In conclusion, this study highlights that a fair correlation exists between the outcome of epilepsy, clinical phenotypes, genotypes and magnetic resonance imaging findings in patients with mitochondrial disorders. The recognition of these patterns is important clinically because of the therapeutic and prognostic implications. It is acknowledged that the small sample size in each group is a limitation. However the trends emerged in this study may be of use to the clinicians involved in the care of patients with mitochondrial disorders.

\section{Acknowledgments:}

This study was supported by a grant from Dpt. of Biotechnology, Govt of India. (Grant No. BT/PR7470/MED/14/1011/2006) \& Indian council of Medical Research (Grant No. 54/9/2012-HUM-BMS)

Compliance with ethical standards 


\section{References}

1. Kann O, Kovacs R. Mitochondria and neuronal activity. Am J Physiol Cell Physiol 2007;292: C641657.

2. Rahman S. Mitochondrial disease and epilepsy. Developmental medicine and child neurology 2012;54:397-406.

3. Finsterer J, Zarrouk Mahjoub S. Epilepsy in mitochondrial disorders. Seizure 2012;21:316-321.

4. Debray FG, Lambert M, Chevalier I, et al., Long-term outcome and clinical spectrum of 73 pediatric patients with mitochondrial diseases. Pediatrics 2007;119: 722-733.

5. El Sabbagh S, Lebre AS, Bahi-Buisson N, et al., Epileptic phenotypes in children with respiratory chain disorders. Epilepsia 2010;51: 1225-1235.

6. Khurana DS, Salganicoff L, Melvin JJ, et al., Epilepsy and respiratory chain defects in children with mitochondrial encephalopathies. Neuropediatrics 2008; 39:8-13.

7. Lee YM, Kang HC, Lee JS, et al., Mitochondrial respiratory chain defects: underlying etiology in various epileptic conditions. Epilepsia 2008;49: 685-690.

8. Canafoglia L, Franceschetti S, Antozzi C, et al., Epileptic phenotypes associated with mitochondrial disorders. Neurology 2001; 56:1340-1346.

9. Zsurka G, Kunz WS. Mitochondrial dysfunction and seizures: the neuronal energy crisis. Lancet Neurol 2015;14: 956-966.

10. Hikmat O, Eichele T, Tzoulis C, Bindoff LA. Understanding the Epilepsy in POLG Related Disease. Int J Mol Sci 2017;18.

11. Bernier FP, Boneh A, Dennett X, Chow CW, Cleary MA, Thorburn DR. Diagnostic criteria for respiratory chain disorders in adults and children. Neurology 2002; 59:1406-1411.

12. Bindu PS, Arvinda HR, Taly AB, et al., Magnetic resonance imaging correlates of genetically characterized patients with mitochondrial disorders: A study from south India. Mitochondrion 2015.

13. Bindu PS, Govindaraju C, Sonam K, et al.,Peripheral neuropathy in genetically characterized patients with mitochondrial disorders: A study from south India. Mitochondrion 2016; 27:1-5.

14. Fisher RS, Cross JH, French JA, et al., Operational classification of seizure types by the International League Against Epilepsy: Position Paper of the ILAE Commission for Classification and Terminology. Epilepsia 2017;58:522-530.

15. Fisher RS, Cross JH, D'Souza C, et al., Instruction manual for the ILAE 2017 operational classification of seizure types. Epilepsia 2017;58:531-542.

16. Kuzmanovski I, Cvetkovska E, Babunovska M, et al., Seizure outcome following medical treatment of mesial temporal lobe epilepsy: Clinical phenotypes and prognostic factors. Clin Neurol Neurosurg 2016;144:91-95.

17. Kwan P, Arzimanoglou A, Berg AT, et al., Definition of drug resistant epilepsy: consensus proposal by the ad hoc Task Force of the ILAE Commission on Therapeutic Strategies. Epilepsia 2010; 51:1069-1077.

18. Scaglia F, Towbin JA, Craigen WJ, et al., Clinical spectrum, morbidity, and mortality in 113 pediatric patients with mitochondrial disease. Pediatrics 2004;114:925-931.

19. Finsterer J, Mahjoub SZ. Presentation of adult mitochondrial epilepsy. Seizure 2013; 22:119-123.

20. Whittaker RG, Devine HE, Gorman GS, et al., Epilepsy in adults with mitochondrial disease: A cohort study. Ann Neurol 2015.

21. Schuelke M, Smeitink J, Mariman E, et al., Mutant NDUFV1 subunit of mitochondrial complex I causes leukodystrophy and myoclonic epilepsy. Nat Genet 1999;21:260-261. 
22. van den Heuvel L, Ruitenbeek W, Smeets R, et al., Demonstration of a new pathogenic mutation in human complex I deficiency: a 5-bp duplication in the nuclear gene encoding the 18-kD (AQDQ) subunit. Am J Hum Genet 1998;62: 262-268.

23. Fassone E, Duncan AJ, Taanman JW, et al., FOXRED1, encoding an FAD-dependent oxidoreductase complex-I-specific molecular chaperone, is mutated in infantile-onset mitochondrial encephalopathy. Human molecular genetics 2010;19:4837-4847.

24. Fernandez-Moreira D, Ugalde C, Smeets R, et al., X-linked NDUFA1 gene mutations associated with mitochondrial encephalomyopathy. Ann Neurol 2007;61:73-83.

25. Folbergrova J, Kunz WS. Mitochondrial dysfunction in epilepsy. Mitochondrion 2012;12:35-40.

26. Tzoulis C, Tran GT, Coxhead J,et al., Molecular pathogenesis of polymerase gamma-related neurodegeneration. Ann Neurol 2014;76:66-81.

27. Anagnostou ME, Ng YS, Taylor RW, McFarland R. Epilepsy due to mutations in the mitochondrial polymerase gamma (POLG) gene: A clinical and molecular genetic review. Epilepsia 2016;57:15311545.

28. Cock H, Schapira AH. Mitochondrial DNA mutations and mitochondrial dysfunction in epilepsy. Epilepsia 1999;40 Suppl 3:33-40.

29. Betts J, Jaros E, Perry RH, et al., Molecular neuropathology of MELAS: level of heteroplasmy in individual neurones and evidence of extensive vascular involvement. Neuropathology and applied neurobiology 2006; 32:359-373.

30. Iizuka T, Sakai F, Suzuki N, et al., Neuronal hyperexcitability in stroke-like episodes of MELAS syndrome. Neurology 2002;59:816-824.

31. Iizuka T, Sakai F, Kan S, Suzuki N. Slowly progressive spread of the stroke-like lesions in MELAS. Neurology 2003;61:1238-1244.

32. Lax NZ, Hepplewhite PD, Reeve AK, et al., Cerebellar ataxia in patients with mitochondrial DNA disease: a molecular clinicopathological study. J Neuropathol Exp Neurol 2012;71:148-161.

33. Lax NZ, Jaros, E. Neurodegeneration in Primary Mitochondrial Disorders. In Mitochondrial Dysfunction in Neurodegenerative Disorders. . In: A.K.[Ed] IR, editor: Springer- Verlag London Limited 2012:21-41.

34. Lee WT, Shen YZ, Chang C. Neuroprotective effect of lamotrigine and MK-801 on rat brain lesions induced by 3-nitropropionic acid: evaluation by magnetic resonance imaging and in vivo proton magnetic resonance spectroscopy. Neuroscience 2000;95:89-95.

35. Gibbs JE, Walker MC, Cock HR. Levetiracetam: antiepileptic properties and protective effects on mitochondrial dysfunction in experimental status epilepticus. Epilepsia 2006;47:469-478. 



\section{Chapter}

\section{Mitochondrial Leukoencephalopathies: A Border Zone between Acquired and Inherited White matter Disorders in \\ Children?}

Bindu PS, Sonam K, Chiplunkar S, Govindaraj P, Nagappa M, Vekhande CC, Aravinda HR, Jessiena Ponmalar JN, Mahadevan A, Gayathri N, Srinivas Bharath MM, Sinha S, Taly AB

Mult Scler Relat Disord 2018;20:84-92 


\begin{abstract}
Background: There is emerging evidence implicating mitochondrial dysfunction in the pathogenesis of acquired demyelinating disorders such as multiple sclerosis. On the other hand, some of the primary mitochondrial disorders such as mitochondrial leukoencephalopathies exhibit evidence of neuroinflammation on MRI. The interrelationship between mitochondrial disorders and episodic CNS inflammation needs exploration because of the therapeutic implications.
\end{abstract}

Objective: We sought to analyze the clinical course and MRI characteristics in a cohort of patients with mitochondrial leukoencephalopathy to determine features, if any, that mimic primary demyelinating disorders. Therapeutic implications of these findings are discussed.

Patients and Methods: Detailed analysis of the clinical course, magnetic resonance imaging findings and therapeutic response was performed in 14 patients with mitochondrial leukoencephalopathy. The diagnosis was ascertained by clinical features, histopathology, spectrophotometric assays and exome sequencing.

Results: Fourteen patients [Age at evaluation: 2-7 yrs, M:F-1:1] were included in the study. Clinical Features which mimicked acquired demyelinating disorder included acute onset focal deficits associated with encephalopathy [10/14, 71\%], febrile illness preceding the onset $[7 / 14,50 \%]$ unequivocal partial or complete steroid responsiveness [11/11], episodic/ relapsing remitting neurological dysfunction [10/14, 71\%] and a subsequent stable rather than a progressive course [12/14, 85\%]. MRI characteristics included confluent white matter lesions [14/14, 100\%], diffusion restriction $[11 / 14,78.5 \%]$, contrast enhancement [13/13,100\%], spinal cord involvement [8/13,61.5\%], lactate peak on MRS [13/13] and white matter cysts [13/14, 92.8\%].

Conclusion: Clinical presentations of mitochondrial leukoencephalopathy often mimic an acquired demyelinating disorder. The therapeutic implications of these observations require further exploration. 


\section{Introduction}

White matter involvement is increasingly being recognized as a manifestation of mitochondrial disorders and the term mitochondrial leukoencephalopathy or leukodystrophy has been used to designate these disorders. ${ }^{1}$ They are mainly defined by the MRI characteristics such as cystic lesions in the abnormal white matter, additional gray matter lesions, restricted diffusion, contrast enhancement, and elevated lactate on magnetic resonance spectroscopy of the brain. ${ }^{2}$ Clinically, patients with mitochondrial leukoencephalopathy most often present with monophasic or recurrent episodes of neurological regression. ${ }^{3}$ Acute onset neurological deficits in combination with large confluent white matter lesions on MRI often lead to diagnosis of an acquired demyelinating disorder such as acute disseminated encephalomyelitis (ADEM). In some disorders, predominant visual impairment and white matter lesions may suggest diagnosis of neuromyelitis optica spectrum disorders, which are further emphasized by the presence of spinal cord signal changes on MRI.

On the other hand, it is increasingly being evident that mitochondrial abnormalities are involved in the development and progression of multiple sclerosis (MS). ${ }^{4}$ The most compelling evidence implicating the role of mtDNA comes from the observation of susceptibility of LHON [Leber's hereditary optic neuropathy] patients to develop white matter lesions resembling MS. ${ }^{5}$ However studies interrogating the presence of LHON-associated mutations in patients with multiple sclerosis ${ }^{6,7}$ as well as those probing an increased MS risk in particular mitochondrial haplogroups ${ }^{8-11}$, have revealed conflicting results. An exploratory study on the mitochondrial DNA variations and haplogroups in children with acquired demyelinating syndromes (ADS) have raised the possibility that mtDNA variants or haplogroups may influence the age at onset and subsequent MS risk. ${ }^{12}$ These observations suggest that the link between mitochondrial dysfunction and ADS is unclear and needs to be explored further.

Importance of MRI in the interpretation and diagnosis of mitochondrial leukoencephalopathies has been already emphasized. Even though the characteristics of mitochondrial leukoencephalopathy have been highlighted in literature, the therapeutic implications of these findings still needs to be elucidated. This study analyzed the clinical and MRI characteristics in a cohort of children with mitochondrial leukoencephalopathy so as to define the features that mimic acquired demyelinating disorders. 


\section{Patients and methods:}

The cohort was derived from a database of patients who underwent exome sequencing as part of a study on phenotype genotype correlations in mitochondrial disorders, over a period of two years (2015-2017) See Supplementary Table. The institute ethics committee approved the study and all subjects gave written informed consent.

\section{Phenotypic characterization.}

Patients were recruited into the study if they satisfied the clinical criteria of mitochondrial disorder as suggested by Bernier et $\mathrm{al}^{13}$ and a comprehensive evaluation, including estimation of serum lactate, muscle histopathology, assay of respiratory chain complex enzymes, brain magnetic resonance imaging, nerve conduction studies, electroencephalography (EEG) and evoked potential studies that were tailored to the clinical phenotype suggested a probable diagnosis of mitochondrial disorder. Exome sequencing was performed using illumina sequencing platform and the gene panel consisted of 6440 genes inclusive of all nuclear-encoded mitochondrial genes that are strongly associated with a disease on OMIM (Online Mendelian Inheritance in Man).

Among the 85 patients who underwent exome sequencing, 36 showed variations in mitochondrial disease related genes. Among these, 14 patients (Age range: 2-7 yrs, M: F- 1:1) displayed significant white matter involvement and qualified for a diagnosis of mitochondrial leukoencephalopathy and were included in final analysis. Their clinical features, MRI findings and therapeutic responses were analyzed retrospectively. All patients had significant white matter hyperintensities involving one or more of the white matter zones viz. periventricular, deep white matter and subcortical white matter as well as involvement of multiple lobes [frontal, parietal, temporal and occipital white matter]. The sequences analyzed included T1 weighted (T1W), T2 weighted (T2W) and Fluid attenuated inversion recovery (FLAIR) sequences in all. Additional sequences included diffusion weighted images (DW1, $n=13)$, Contrast images $(n=13)$ \& Magnetic resonance spectroscopy $(n=13)$. Majority of the children received evaluation and treatment during the acute phase in peripheral hospitals. The information on the CSF studies and the details of the immunomodulation was retrieved from the referral notes and treating physician's notes. All patients were evaluated and followed up by the same clinical team [PSB, ABT, MN \&SS]. MRI findings were independently reviewed by two neurologists (PSB \&ABT) and one neuroradiologist (HRA). 


\section{Results:}

The detailed clinical features, MRI characteristics, and immunomodulation and follow up are provided in Table 1. The genetic findings included variations in complex I nuclear genes [NDUFA1(1); NDUFV1(4); NDUFS2 (2); LYRM (2); MPV17(1); $B O L A 3(2) ; I B A 57(2)]$ The details of the genetic findings are provided in the supplementary table.

Clinical features: The age at onset of the symptoms in the patients ranged from 6 months to 5.5 years (Mean $\pm \mathrm{SD}-1.67 \pm 1.3$ yrs). In six children age of onset was in infancy. The period of follow up ranged from 1-7 years and the mean duration of illness at last follow up was $4.5 \pm 3.6$ years. Majority had an acute presentation $(\mathrm{n}=10)$. History of an inciting event was present in 10 [febrile illness, $\mathrm{n}=8$; jaundice, $\mathrm{n}=1$; minor head trauma, $\mathrm{n}=1]$. Infants in the cohort manifested with regression of acquired milestones. Neurological examination showed pyramidal signs in all and additional ataxia in four. Primary optic atrophy was present in eight (57\%). Even though visual loss was the presenting manifestation in two patients optic disc swelling was not reported. Except for three patients who had insidious onset of symptoms all received immunomodulation presuming a diagnosis of an acquired demyelinating syndrome and most common diagnosis considered was acute disseminated encephalomyelitis. The response to immunomodulation was either partial or complete. In those with partial response the residual deficits were spasticity in the lower limbs and mild incoordination of the upper limbs. Even those patients, who did not have overt spasticity, had pyramidal signs in lower limbs.

Relapses: Details of relapses are provided in Table 1. Ten patients had multiple episodes (median number of episodes -2). For seven patients the second episode occurred within 2 months of the first episode. Three children had multiple episodes [patient $1,9 \& 10$ ]. While the episodes were heralded by seizures in patient 1 , there were no seizures in patient 9 and 10 .

Cerebrospinal Fluid (CSF) Examination: Results of the cerebrospinal fluid examination during the acute presentation was available in 11 patients. Pleocytosis was noted in none while elevated CSF protein was noted in three.

Magnetic resonance imaging findings: Description of the MRI findings is provided in Table1 and summary is provided in Table 2. MRI findings included large confluent white matter signal changes that showed diffusion restriction and patchy contrast enhancement in the acute phase and on follow up, in some patients. In those children with discrete lesions in the initial scans, the signal changes tended to become 
confluent and bilaterally symmetrical on follow up images (Fig.1A-C). Cysts inside the white matter were evident in all except one, either at the time of acute presentation or on follow up (Fig.2B). Corpus callosal involvement was prominent in all but involvement of internal capsule, brainstem and pyramidal tract were seen in only one patient each. Likewise the presence of signal changes in basal ganglia, thalamus and dentate was seen in only one patient each.

Clinical and MRI findings in mitochondrial LE vs. acquired demyelinating syndrome: The clinical features and MRI findings in this cohort was compared with that of children with acute disseminated encephalomyelitis (ADEM). The cohorts included 35 children with ADEM presented to our institute as well as with another cohort from India ${ }^{14}$ and two recent series on ADEM from Japan ${ }^{15}$ and $\mathrm{UK}^{16}$.The age at onset, clinical features and MRI findings were compared and provided in Table 2. The patients with mitochondrial LE presented at a significantly younger age and had more chance of having residual motor deficits compared to children with ADEM ( $p$ value $<0.05$ ). Comparison of MRI features showed that presence of periventricular and deep white matter lesions, corpus callosal lesions, contrast enhancement and restricted diffusion were significantly higher compared to children with ADEM ( $p$ value $<0.05$ ). In contrast presence of subcortical/juxta cortical lesions were less common compared to ADEM. Even though the details of MRS and white matter cysts were not available for comparison in the ADEM series, both the features were consistently seen in mitochondrial LE.

\section{Clinical and MRI findings in Mitochondrial LE vs other mitochondrial disorders}

Clinical phenotypes in the rest of the children with mitochondrial disorders included Leigh and Leigh like syndrome $(n=15)$, encephalomyopathy $(n=2)$, chronic progressive external ophthalmoplegia with epilepsy $(n=4)$, and mitochondrial neurogastrointestinal encephalopathy (MNGIE, $\mathrm{n}=1$ ). The MRI findings included bilateral symmetrical signal changes in the basal ganglia, brain stem and cerebellum $(n=15)$ predominantly noted in children with Leigh and Leigh like syndrome. Normal MRI findings were noted in children with encephalomyopathy and chronic progressive external ophthalmoplegia. The child with MNGIE had bilateral symmetrical T2/FLAIR signal changes involving the periventricular and deep white matter without any contrast enhancement or diffusion restriction. Subcortical fibers were spared. There was presence of lactate peak on MRS.

The detailed case history and investigation results including brain biopsy findings of one of the patients is described below to demonstrate the diagnostic and therapeutic challenge posed by these patients. 
Patient 1: This 10 year old boy of Indian origin was the first child of nonconsanguineous parents with normal birth history and developmental milestones. He was apparently normal till 2.5 years when he developed ataxia, seizures and encephalopathy following a febrile illness. CSF study was normal. MRI demonstrated T2/FLAIR hyper intense lesions involving both gray and white matter with contrast enhancement (Fig.2A-C). He received pulse methyl prednisolone for presumptive diagnosis of acute disseminated encephalomyelitis and made complete clinical recovery. Thereafter he presented with multiple relapsing remitting neurological episodes characterized by seizures, hemiparesis and ataxia associated with relapsing remitting white matter lesions on MRI (Table 1, Fig.2D-H). He was referred to our institute at the age of 6 years during the fifth episode.

Review of the evaluations done elsewhere revealed high serum alanine, lactic acid metabolites on urinary organic acid estimation and an elevated serum lactate on multiple occasions. Muscle biopsy showed complex I deficiency on spectrophotometric enzyme assays. Complete mitochondrial DNA sequencing revealed only polymorphisms. Targeted sequencing of complex I nuclear genes revealed a previously reported hemizygous variation in NDUFA1 (c.94G>C, p.G32R), which was confirmed by Sanger sequencing. His mother and sister carried the same variation.

Biopsy from the right frontal cortex revealed a small fragment of cortex with white matter (Fig.3A). Extensive loss of myelin was seen on Luxol Fast Blue stain (Fig.3B). A few preserved strands of myelinated axons traversing the white matter was seen. In contrast, there was relative preservation of axonal tracts in the demyelinated segment (Fig.3C). Tissue response in the form of scattered CD68 labelled ramified microglia and few clusters of histiocytes were detected within the zone of demyelination (Fig.3D), in addition to fibrillary gliosis and several hypertrophic reactive astrocytes (Fig.3F). There was no perivenular demyelination or foamy histiocytes.

Prior to presentation to us, he had received methyl prednisolone injection during each episode followed by short and tapered steroid treatment. He also received Inj.Interferon for a brief period of time presuming a diagnosis of pediatric MS. In view of the relapsing remitting neurological episodes responsive to steroid therapy, the initial diagnosis considered was an acquired demyelinating disorder. In view of the multiple relapses, patient was initiated on monthly pulses of methyl prednisolone. He also received high dose vitamins. After the genetic report, the patient was maintained only on high dose vitamins. The patient remained relapse-free thereafter and is being maintained on high dose vitamins from the age of eight years. 


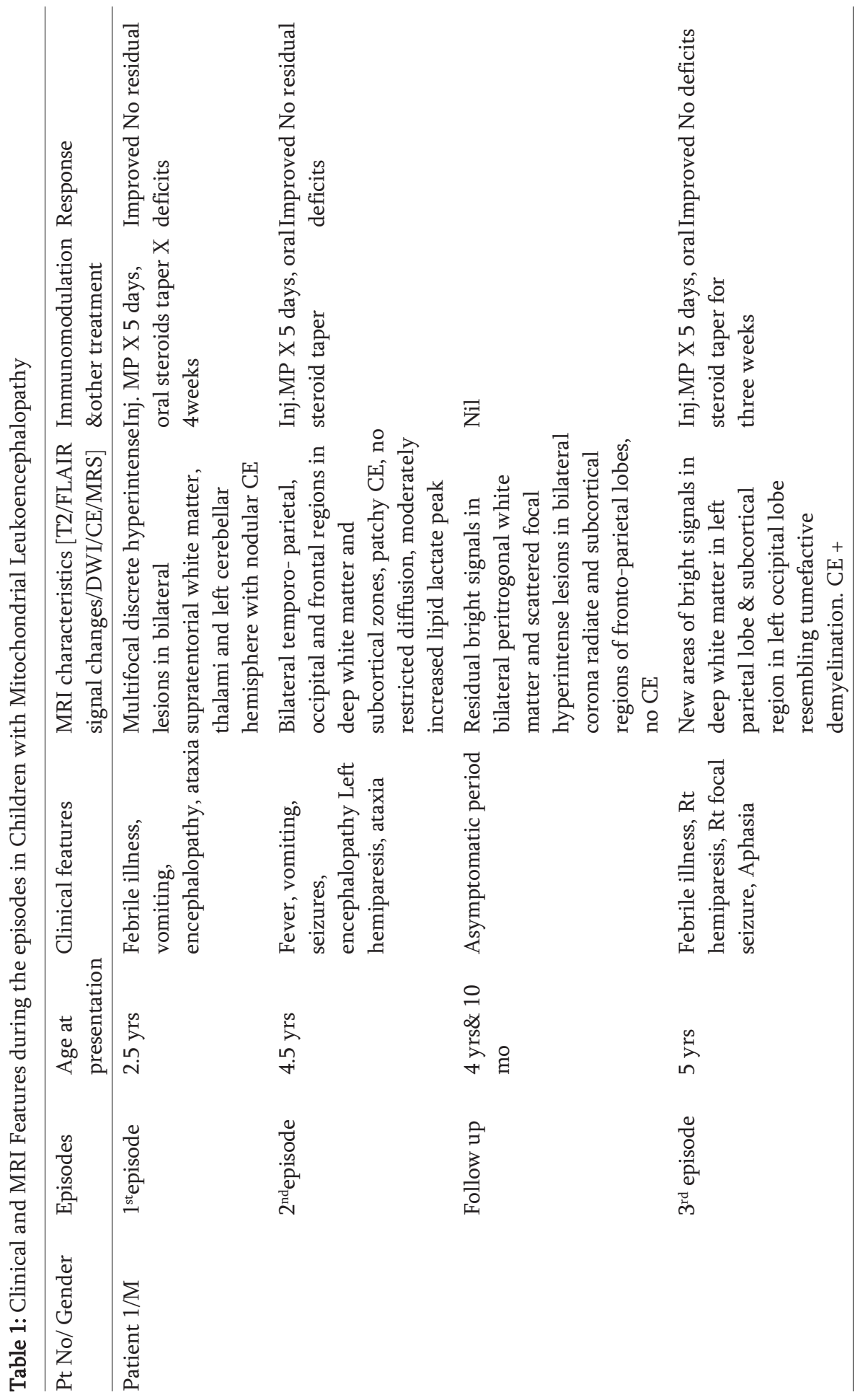


Mitochondrial Leukoencephalopathies

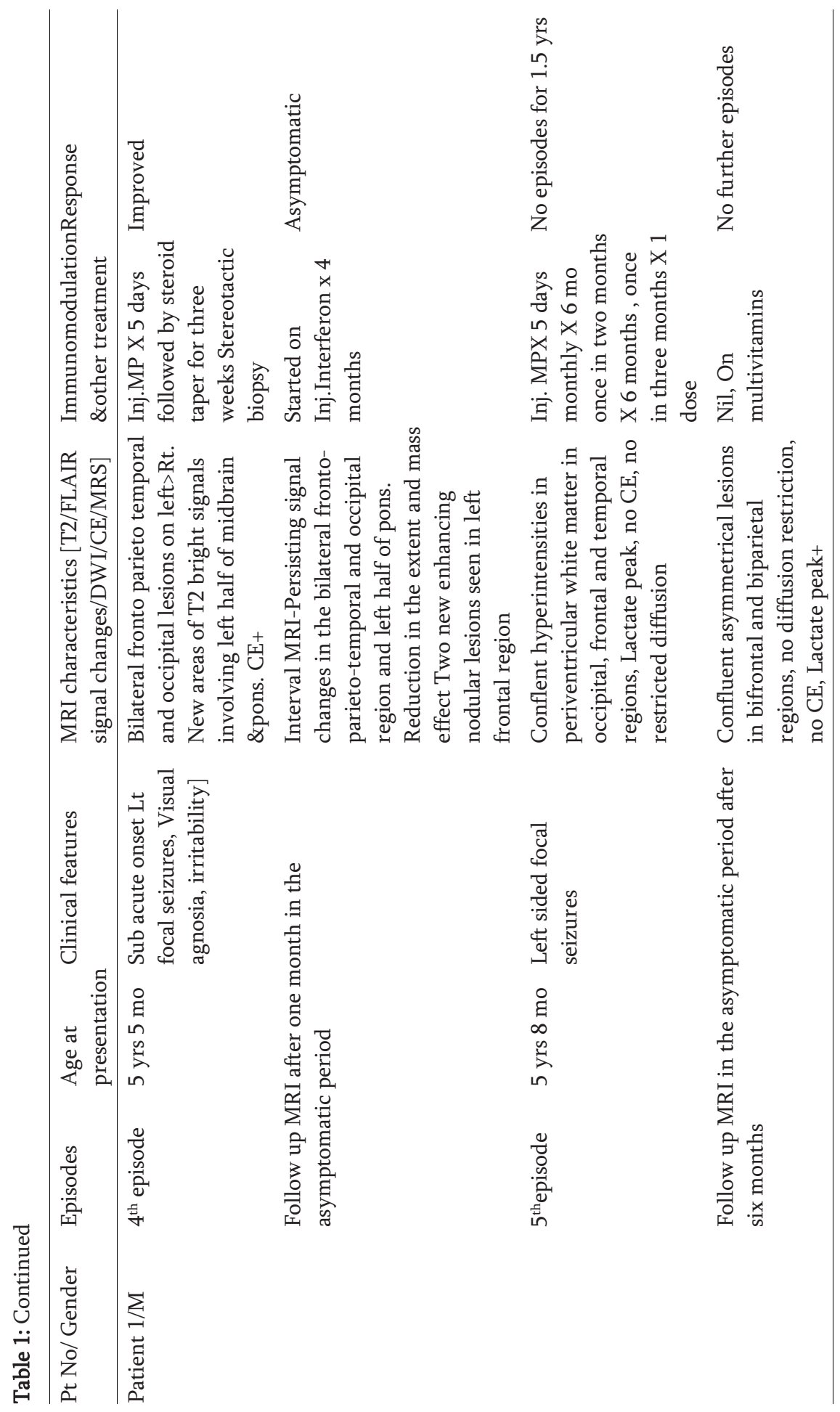




\section{Chapter 6}

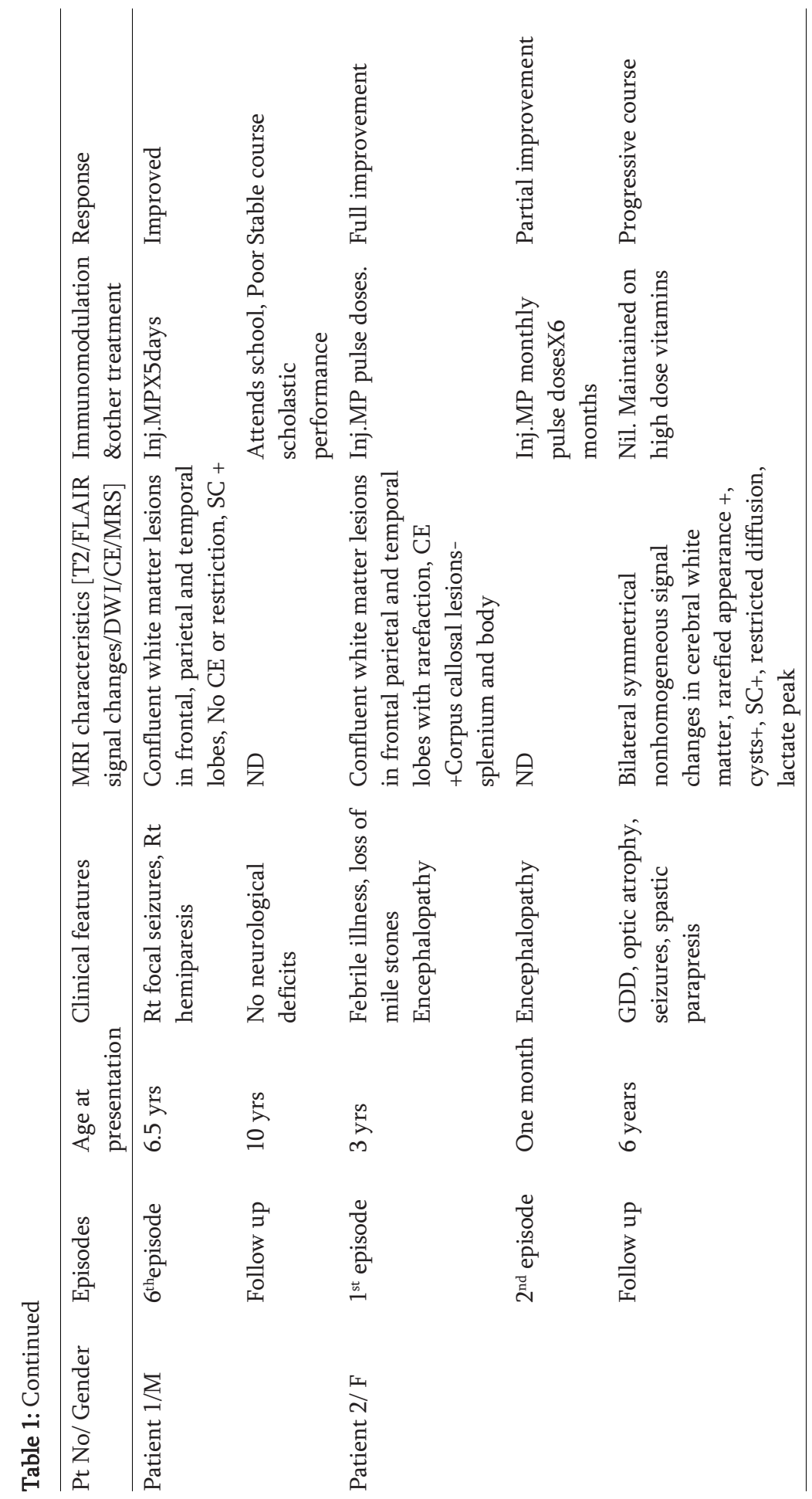


Mitochondrial Leukoencephalopathies

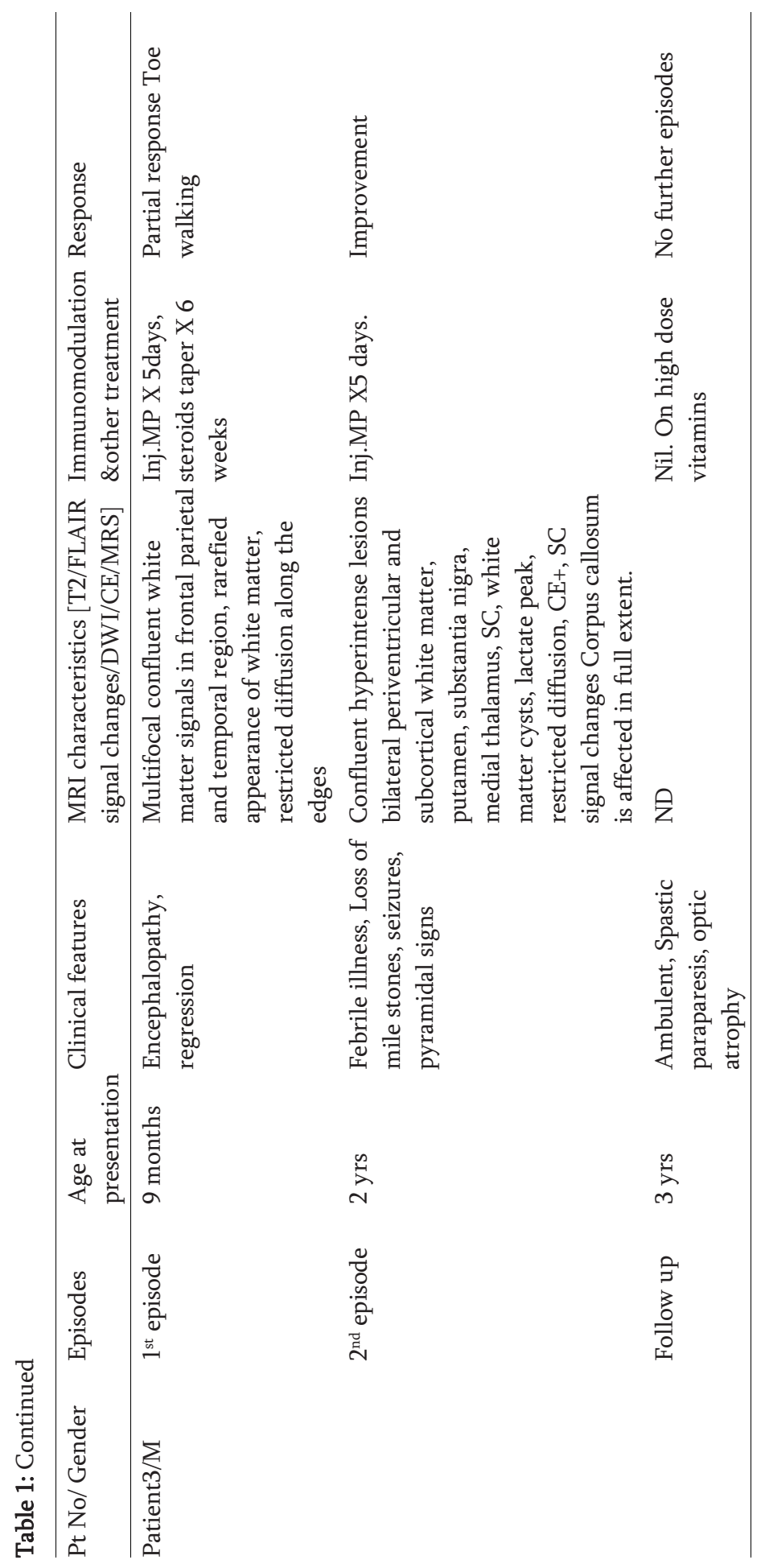




\section{Chapter 6}

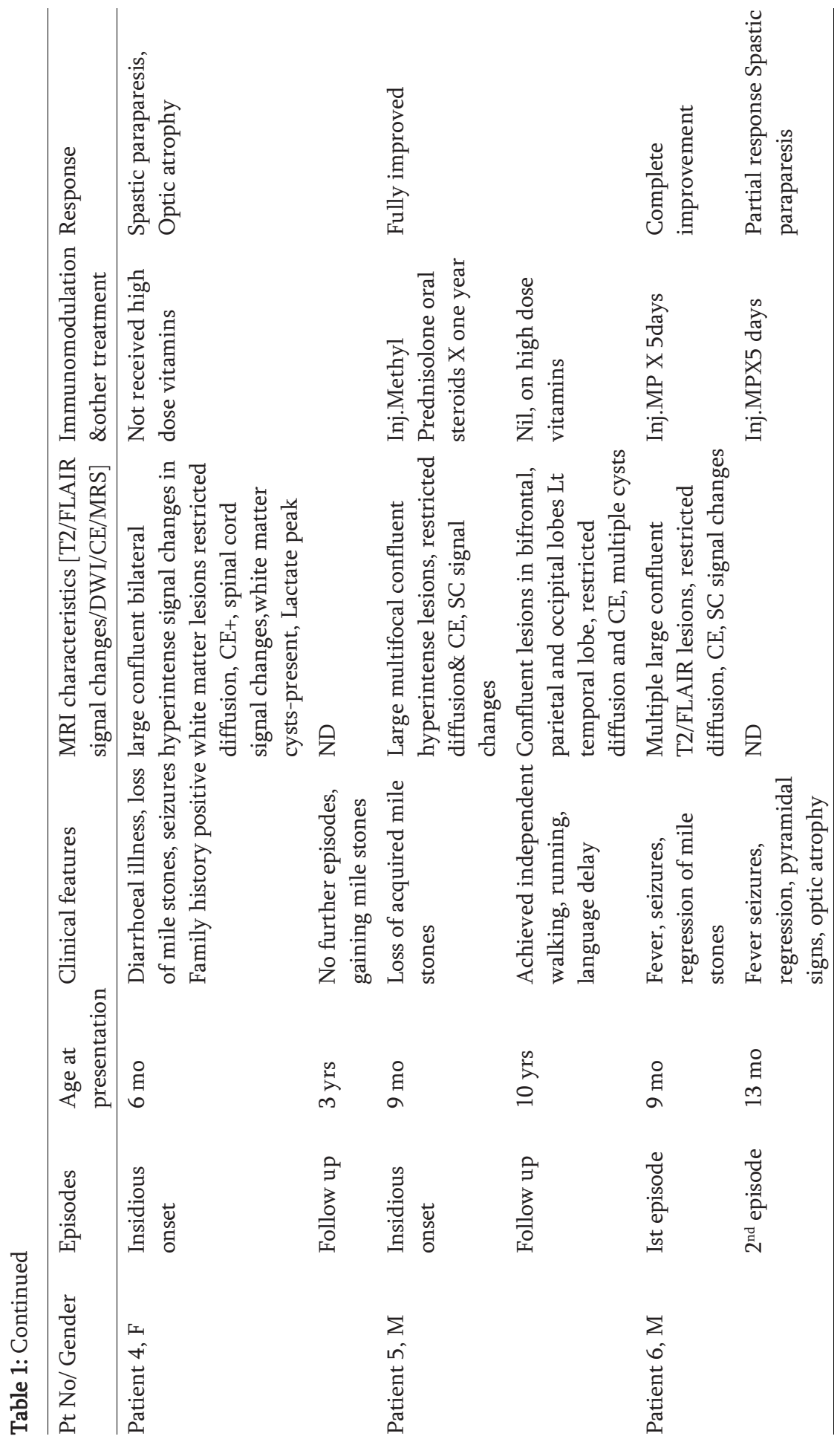


Mitochondrial Leukoencephalopathies

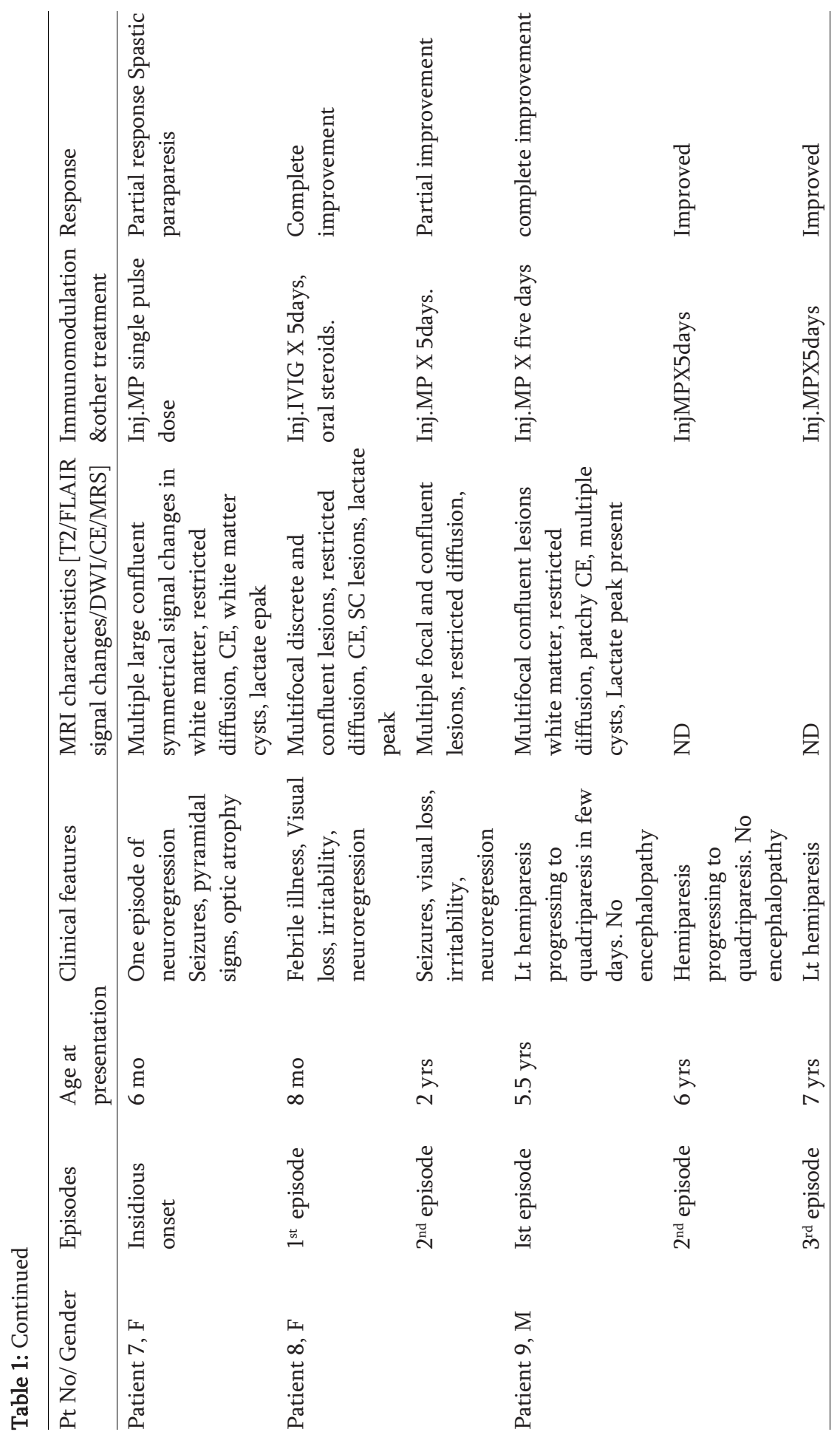




\section{Chapter 6}

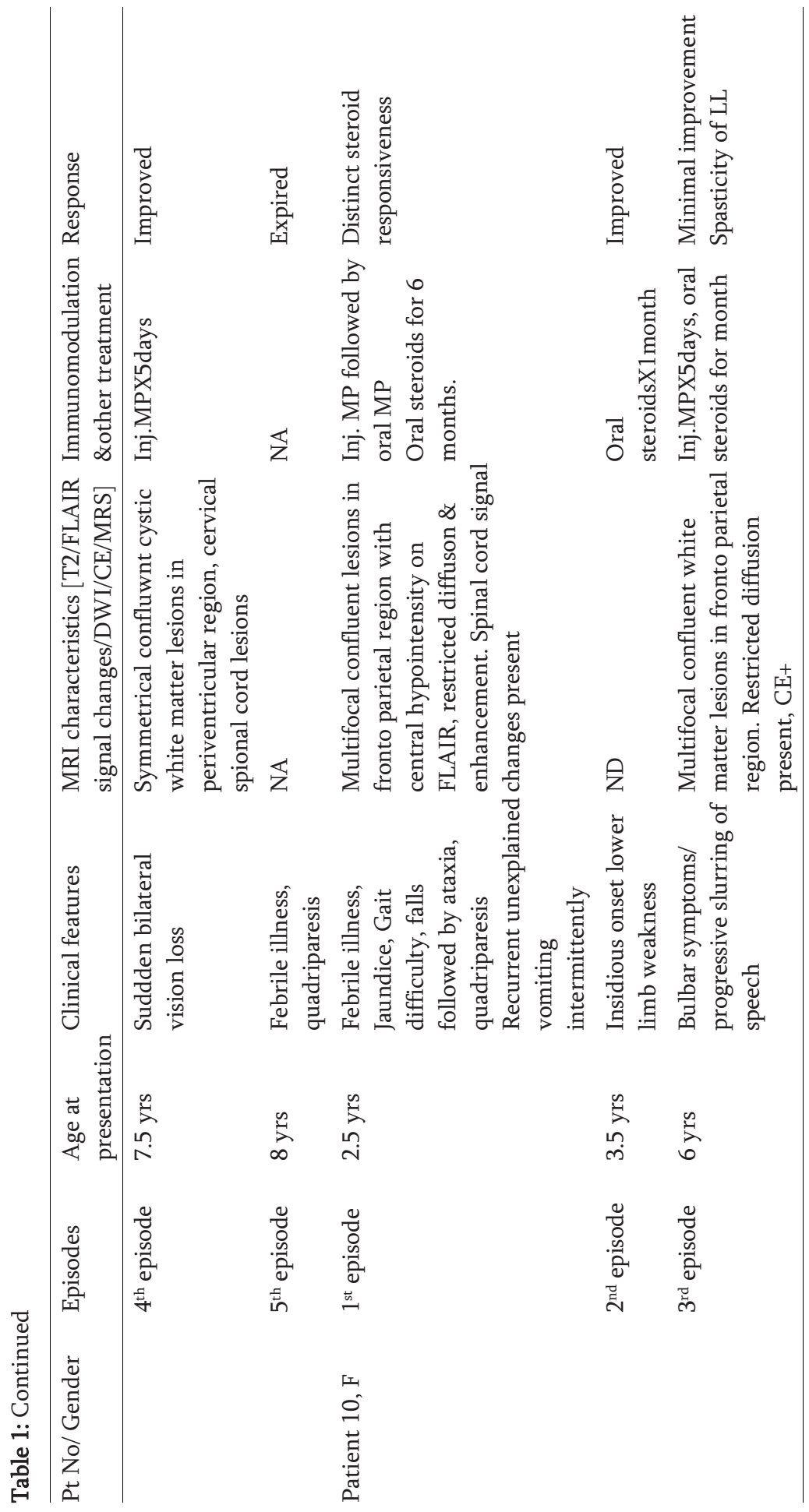


Mitochondrial Leukoencephalopathies

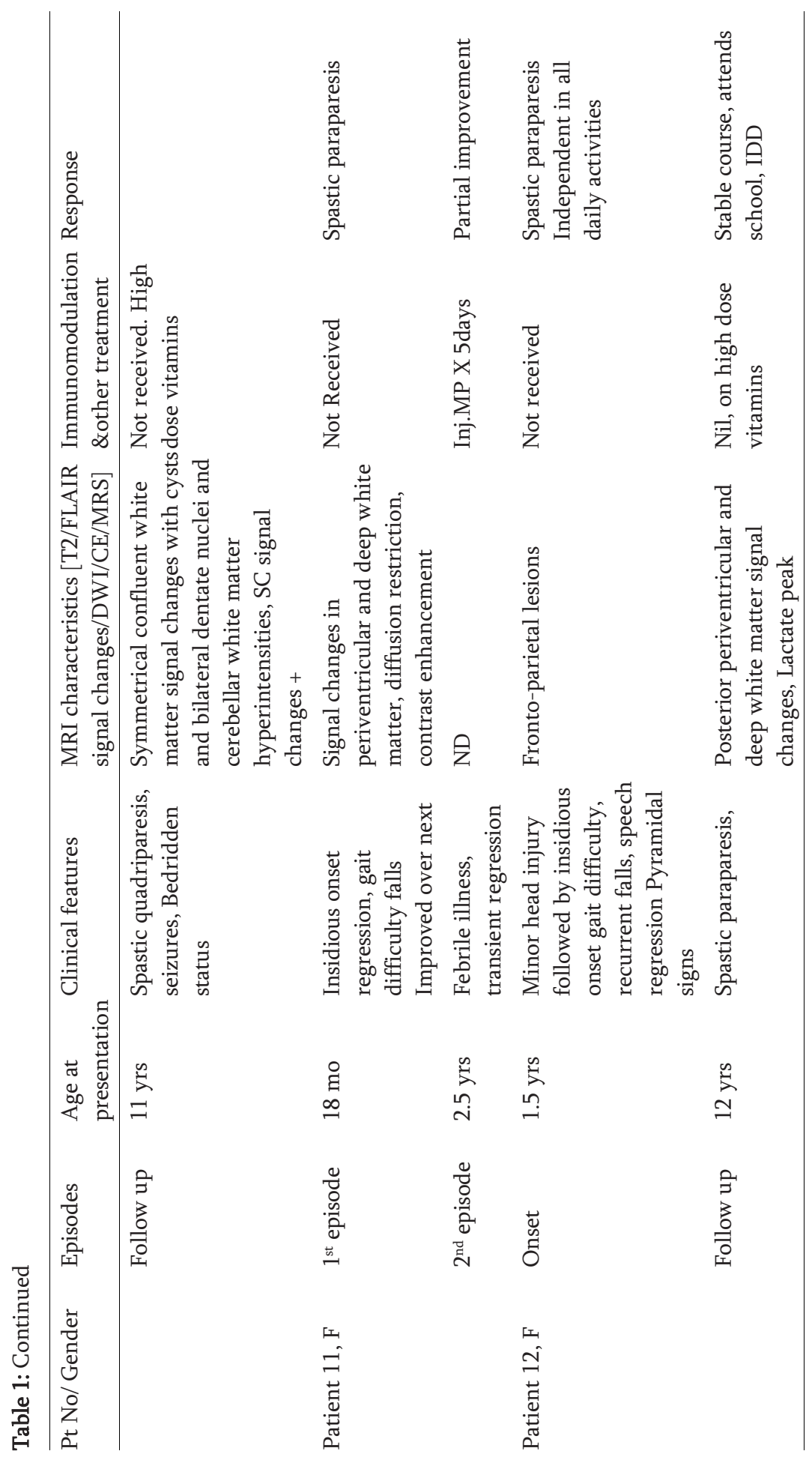




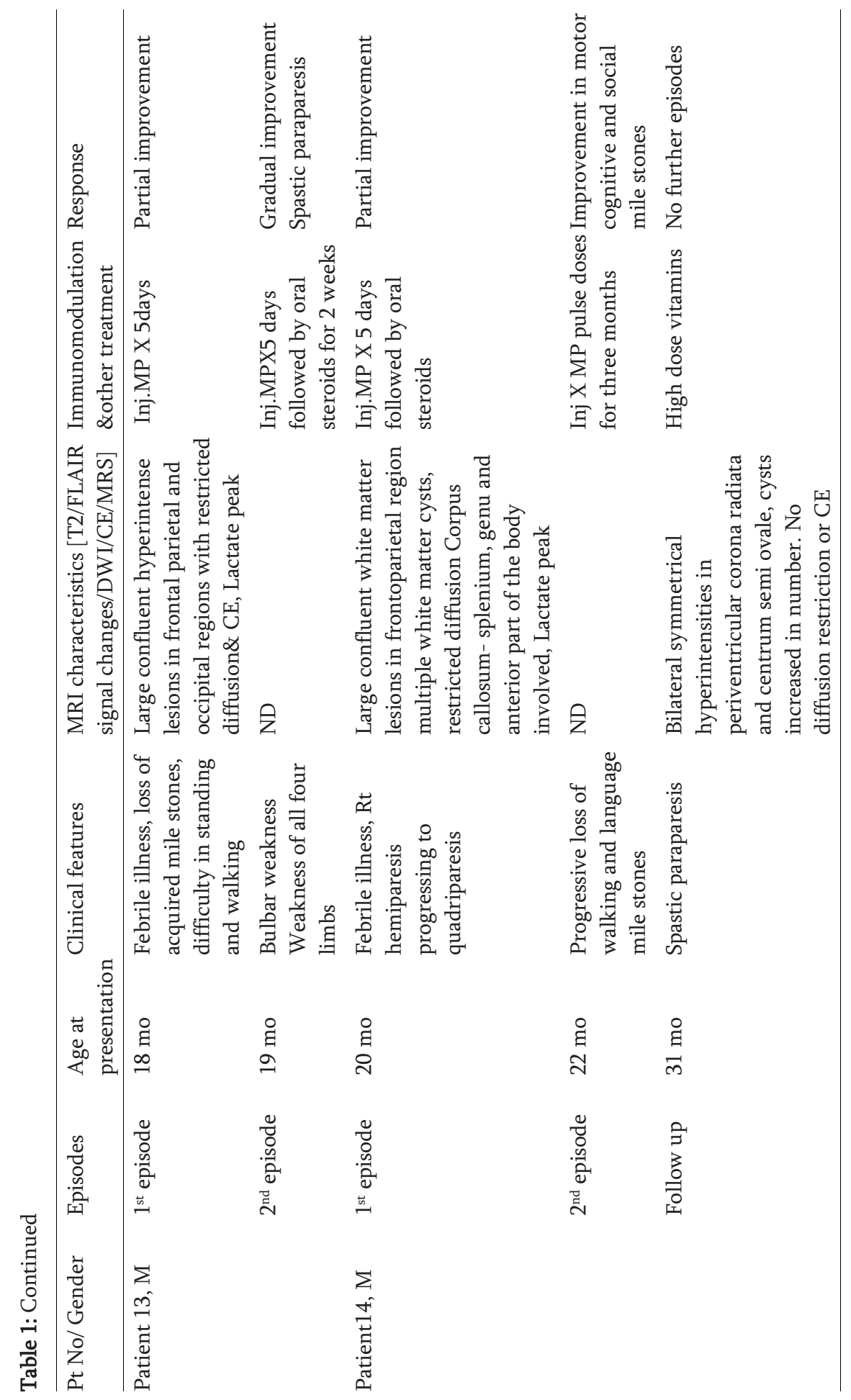


Table 2: Comparison of Clinical and MRI Features in Patients with Mitochondrial Leukoencephalopathy with Cohorts of Patients with ADEM

\begin{tabular}{|c|c|c|c|c|c|}
\hline Parameters & $\begin{array}{l}\text { Mito LE } \\
\text { (Present } \\
\text { study) }\end{array}$ & $\begin{array}{l}\text { ADEM-India } \\
\text { (Same } \\
\text { institute) }\end{array}$ & $\begin{array}{l}\text { ADEM- India } \\
\text { (Singhi et al) }\end{array}$ & $\begin{array}{l}\text { ADEM-Japan } \\
\text { (Yamaguchi et } \\
\text { al) }\end{array}$ & $\begin{array}{l}\text { ADEM-UK } \\
\text { (Absoud et al) }\end{array}$ \\
\hline No of patients & $\mathrm{N}=14$ & $\mathrm{~N}=35$ & $\mathrm{~N}=52$ & $\mathrm{~N}=66$ & $\mathrm{~N}=40$ \\
\hline $\begin{array}{l}\text { Mean Age at } \\
\text { onset }\end{array}$ & $1.67 \pm 1.3 \mathrm{yrs}$ & $8.2 \pm 4.1 \mathrm{yrs}^{*}$ & $6.14 \pm 3.17 \mathrm{yrs}^{*}$ & $5.5 \pm 3.8$ yrs* $^{*}$ & $\begin{array}{l}\text { Median age } \\
-5.3 y r s\end{array}$ \\
\hline Gender $[\mathrm{M}: \mathrm{F}]$ & $1: 1$ & $1.2: 1$ & $2.7: 1$ & $2: 1$ & $1.5: 1$ \\
\hline Febrile illness & $7[50 \%]$ & $31[88.8 \%]^{*}$ & 13 [25\%] & $45 / 66[68 \%]$ & NA \\
\hline \multicolumn{6}{|l|}{$\begin{array}{l}\text { Neurological } \\
\text { Features }\end{array}$} \\
\hline Encephalopathy & $9[64.2 \%]$ & $35[100 \%]$ & Majority & $66 / 66$ [100\%] & $40[100 \%]$ \\
\hline Pyramidal signs & $14[100 \%]$ & $13[37 \%]^{*}$ & $42[80.7 \%]$ & NA & $24[60 \%]^{*}$ \\
\hline Ataxia & $7[50 \%]$ & $8[25 \%]$ & $6[11.5 \%]^{*}$ & NA & 18 [45\%] \\
\hline Visual loss & $3[21.4 \%]$ & $5[14 \%]$ & 11 [21.2\%] & $7 / 66[11 \%]$ & $3[0.1 \%]^{*}$ \\
\hline Optic atrophy & $8[57 \%]$ & NA & NA & NA & NA \\
\hline Seizures & $8[57.1 \%]$ & $8[22 \%]^{*}$ & 19 [36.5\%] & $21 \quad[32 \%]$ & $8[20 \%]^{*}$ \\
\hline CSF pleocytosis & Nil & 18 [32\%] & Majority & $56 / 66[85 \%]$ & $23[58 \%]$ \\
\hline \multicolumn{6}{|l|}{ MRI Findings } \\
\hline $\begin{array}{l}\text { Periventricular } \\
\text { lesions }\end{array}$ & $14[100 \%]$ & $11[31 \%]^{*}$ & NA & $20 / 66[30 \%]^{*}$ & $9[22.5 \%]^{*}$ \\
\hline Lobar/DeepWM & $14[100 \%]$ & $18[51 \%]^{*}$ & NA & NA & $24[60 \%]^{*}$ \\
\hline Parameters & $\begin{array}{l}\text { Mito LE } \\
\text { (Present } \\
\text { study) }\end{array}$ & $\begin{array}{l}\text { ADEM-India } \\
\text { (Same } \\
\text { institute) }\end{array}$ & $\begin{array}{l}\text { ADEM- India } \\
\text { (Singhi et al) }\end{array}$ & $\begin{array}{l}\text { ADEM-Japan } \\
\text { (Yamaguchi et } \\
\text { al) }\end{array}$ & $\begin{array}{l}\text { ADEM-UK } \\
\text { (Absoud et al) }\end{array}$ \\
\hline $\begin{array}{l}\text { Subcortical/ } \\
\text { Juxtacortical }\end{array}$ & $6[15 \%]$ & $29[68 \%]^{*}$ & NA & $41 / 61[67 \%]^{*}$ & $20[50 \%]^{*}$ \\
\hline Cerebral cortex & Nil & $7[20 \%]$ & NA & $28 / 61[46 \%]$ & $14[35 \%]$ \\
\hline Corpus callosum & $14[100 \%]$ & $9[25.7 \%]^{*}$ & $7[13.5 \%]^{*}$ & $11 / 61[18 \%]^{*}$ & $3[0.1 \%]^{*}$ \\
\hline Thalamus & $2[14.3 \%]$ & $8[23 \%]$ & 16 [30.8\%] & $30 / 61[49 \%]^{*}$ & $24[60 \%]^{*}$ \\
\hline Basal Ganglia & 1 [7.0\%] & $6[17 \%]$ & 9 [17.3\%] & & \\
\hline Cerebellum & $4[28.6 \%]$ & $9[25.7 \%]$ & 14 [26.9\%] & $20 / 66[30 \%]$ & $17[42 \%]$ \\
\hline
\end{tabular}


Chapter 6

Table 2: Continued

\begin{tabular}{|c|c|c|c|c|c|}
\hline Parameters & $\begin{array}{l}\text { Mito LE } \\
\text { (Present } \\
\text { study) }\end{array}$ & $\begin{array}{l}\text { ADEM-India } \\
\text { (Same } \\
\text { institute) }\end{array}$ & $\begin{array}{l}\text { ADEM- India } \\
\text { (Singhi et al) }\end{array}$ & $\begin{array}{l}\text { ADEM-Japan } \\
\text { (Yamaguchi et } \\
\text { al) }\end{array}$ & $\begin{array}{l}\text { ADEM-UK } \\
\text { t(Absoud et al) }\end{array}$ \\
\hline Brainstem & $2 \quad[14.3 \%]$ & $14 \quad[40 \%]$ & $9 \quad[17.3 \%]$ & $19 / 66[29 \%]$ & $22 \quad[55 \%]^{*}$ \\
\hline Spinal cord & $8 \quad[61.5 \%]$ & ] $4 / 6$ [66\%] & $5 \quad[9.6 \%]^{*}$ & $16 / 42[38 \%]$ & $8 / 12[67 \%]$ \\
\hline $\begin{array}{l}\text { Contrast } \\
\text { enhancement }\end{array}$ & $13 / 13[100 \%]$ & $13 / 27[48 \%]^{*}$ & $5 \quad[48 \%]^{*}$ & NA & NA \\
\hline $\begin{array}{l}\text { Diffusion } \\
\text { restriction }\end{array}$ & $11 / 14[78.5 \%]$ & ] $8 / 26[30 \%]^{*}$ & NA & NA & NA \\
\hline $\begin{array}{l}\text { Lactate peak on } \\
\text { MRS }\end{array}$ & $13 / 13[100 \%]$ & NA & NA & NA & NA \\
\hline $\begin{array}{l}\text { White matter } \\
\text { cysts }\end{array}$ & $13 / 14[92.8 \%]$ & ]NA & NA & NA & NA \\
\hline Residual deficits & $12 \quad[92.3 \%]$ & ] $2 \quad[5.7 \%]^{*}$ & $20 \quad[38.7 \%]^{*}$ & $11 \quad[16.7 \%]^{*}$ & NA \\
\hline Death & $1 / 13[7.6 \%]$ & $1 / 35[2.9 \%]$ & none & none & $1 \quad[2.5 \%]$ \\
\hline
\end{tabular}

${ }^{*} \mathrm{P}<0.05$, Abbreviations: ADEM-Acute disseminated encephalomyelitis; NA-Not available; WM-white matter; CSF-cerebro spinal fluid; MRS-Magnetic resonance spectroscopy 


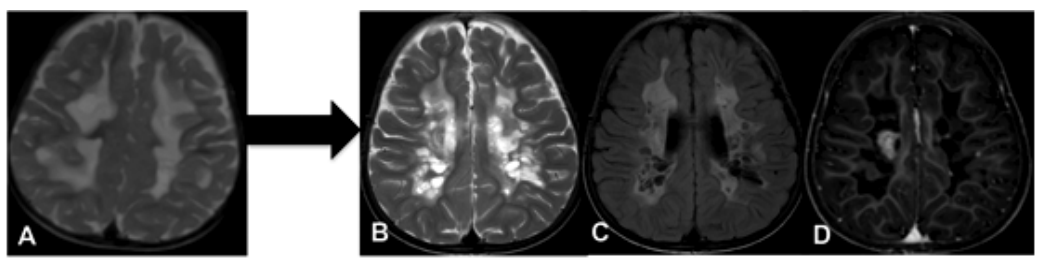

Fig.1: MRI Brain in a 2-year-old child with Mitochondrial leukoencephalopathy and mutations in IBA57 (Patient 14). A) T2W axial image at the time of first presentation shows large asymmetrical confluent white matter signal changes B-D) Follow up study shows rarefied white matter on T2W axial view (B), cysts inside the affected white matter on FLAIR(C), contrast enhancement (D)

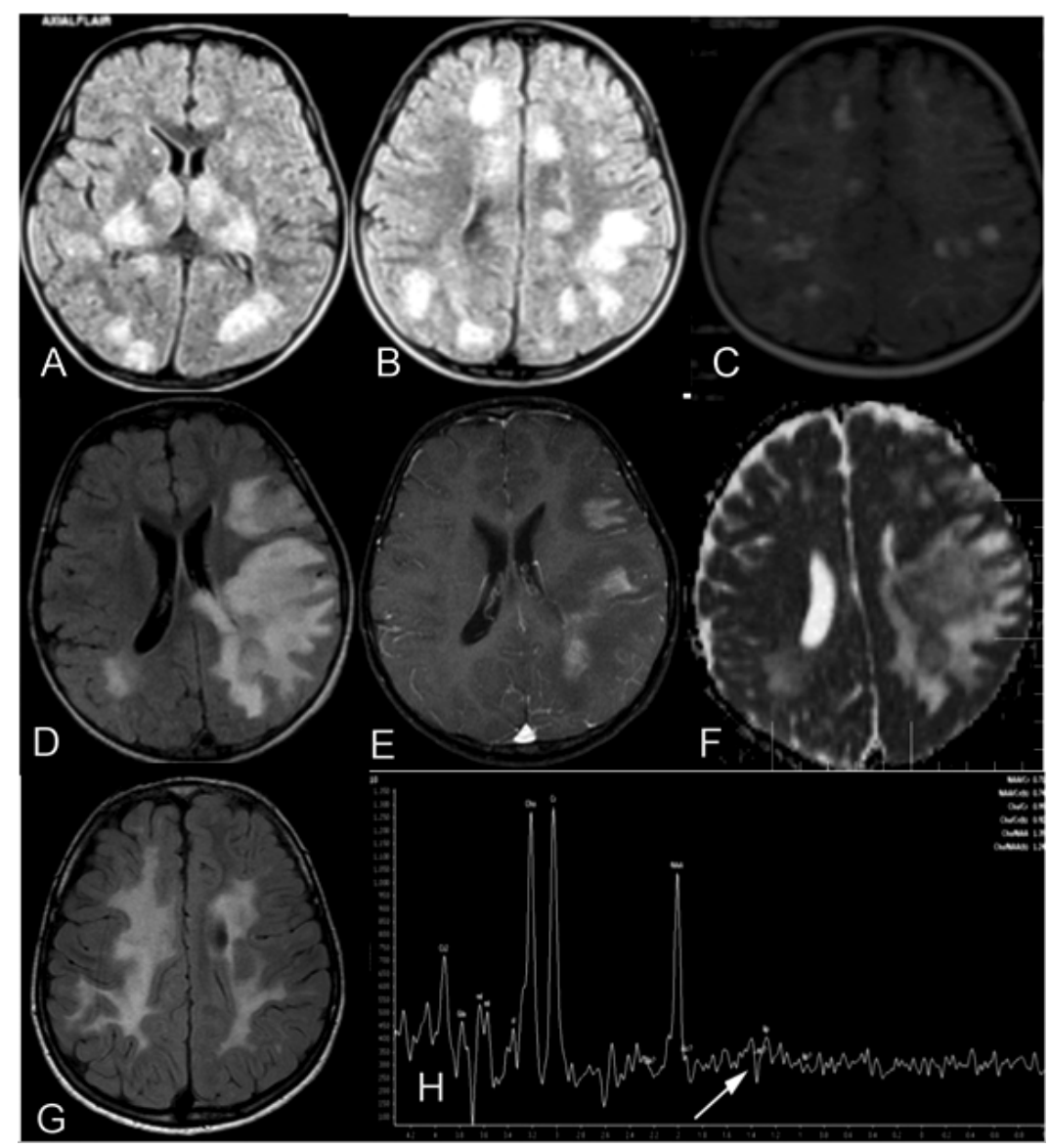

Fig.2: MRI brain in patient 1 with NDUFA1 variation

A-C -MRI at 2.5 yrs at the time of initial presentation shows multiple discrete white matter and gray matter T2/FLAIR hyper intensities with contrast enhancement.

D-F- MRI during the third episode at the age of 4.5 yrs shows large asymmetrical white matter lesions with contrast enhancement and patchy restricted diffusion 


\section{Chapter 6}

G. The lesions shows tendency to become symmetrical and diffuse on follow up imaging at $7.5 \mathrm{yrs} \mathrm{H}$. MRS shows lactate peak

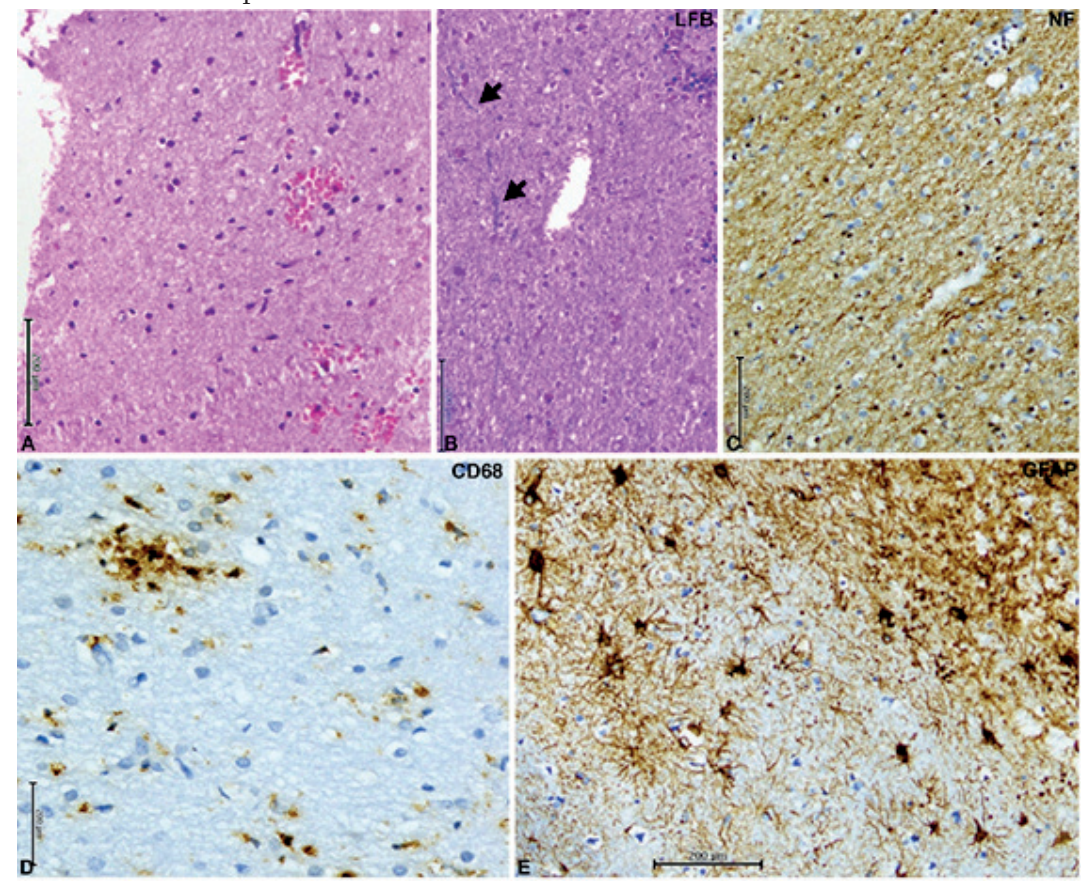

Fig.3 Brain biopsy findings in Patient 1 (A- F):

Brain biopsy included a small fragment of right frontal cortex with white matter (A) which reveals extensive loss of myelin (B). Note few preserved strands of myelinated axons traversing the white matter (arrows, B). In contrast, there is relative preservation of axonal tracts in the demyelinated segment (C). Tissue response in the form of scattered CD68 labelled ramified microglia and few clusters of histiocytes are seen within this zone (D) and several hypertrophic reactive astrocytes with fibrillary gliosis (F)

[A:H\&E; B: Luxol Fast Blue (LFB); C: Neurofilament; D: CD68; F:GFAP. Magnification= scale bar (200 micron)] 
Supplementary Table: Genetic Findings in children with Mitochondrial Leukoencephalopathy

\begin{tabular}{|c|c|c|c|c|c|}
\hline & Age/Gender & Gene & Zygosity & $\begin{array}{l}\text { Nucleotide } \\
\text { change }\end{array}$ & Aminoacid change \\
\hline 1 & 6yrs/M & NDUFA1 & Hemizygous & c. $94 \mathrm{G}>\mathrm{C}$ & p.Gly32Arg \\
\hline 2 & 3yrs/F & NDUFV1 & Homozygous & c. $1156 \mathrm{C}>\mathrm{T}$ & p.Arg386Cs \\
\hline 3 & $2 \mathrm{yrs} / \mathrm{M}$ & NDUFV1 & Homozygous & c. $1156 \mathrm{C}>\mathrm{T}$ & p.Arg386Cs \\
\hline 4 & $2 \mathrm{yrs} / \mathrm{F}$ & NDUFV1 & Homozygous & c. $1156 \mathrm{C}>\mathrm{T}$ & $\begin{array}{l}\text { p.Arg386Cys } \\
+ \text { NDUFS8 } \\
\text { p.Ala200Thr }\end{array}$ \\
\hline 5 & $9 \mathrm{mo} / \mathrm{M}$ & NDUFV1 & Homozygous & c. $1156 \mathrm{C}>\mathrm{T}$ & p.Arg386Cs \\
\hline 6 & $13 \mathrm{mo} / \mathrm{M}$ & NDUFS2 & $\begin{array}{l}\text { Comp. } \\
\text { Heterozygous }\end{array}$ & $\begin{array}{l}\text { c. } 236 \mathrm{~A}>\mathrm{C}+ \\
\text { c. } 1324 \mathrm{C}>\mathrm{T}\end{array}$ & $\begin{array}{l}\text { p.Asn79Thr + } \\
\text { p.His442Tyr }\end{array}$ \\
\hline 7 & 3yrs/F & NDUFS1 & Homozygous & c. $2032 \mathrm{~T}>\mathrm{G}$ & p.Tyr678Asp \\
\hline 9 & $2 \mathrm{yrs} / \mathrm{F}$ & LYRM7 & Homozygous & c. $2 \mathrm{~T}>\mathrm{C}$ & p.M1T \\
\hline 10 & 7yrs/M & LYRM7 & Homozygous & c. $25 \mathrm{C}>\mathrm{T}$ & p.Gln9Ter \\
\hline 8 & $6 y r s / F$ & MPV17 & Homozygous & c. $148 \mathrm{C}>\mathrm{T}$ & p.Arg50Trp \\
\hline 11 & $2 \mathrm{yrs} / \mathrm{F}$ & BOLA3 & Homozygous & c. $295 \mathrm{C}>\mathrm{T}$ & p.R99W \\
\hline 12 & ${ }^{*} 1.5 \mathrm{yrs} / \mathrm{M}$ & BOLA3 & Homozygous & c. $295 \mathrm{C}>\mathrm{T}$ & p.R99W \\
\hline 13 & $1.5 y r s / M$ & IBA57 & $\begin{array}{l}\text { Compound } \\
\text { Heterozygous }\end{array}$ & $\begin{array}{l}\text { c. } 738 \mathrm{C}>\mathrm{G}+ \\
\text { c. } 802 \mathrm{C}>\mathrm{T}\end{array}$ & $\begin{array}{l}\text { p.Asn246Lys } \\
+ \text { p.Arg268Cys }\end{array}$ \\
\hline 14 & $2 \mathrm{yrs} / \mathrm{M}$ & IBA57 & $\begin{array}{l}\text { Compound } \\
\text { Heterozygous) }\end{array}$ & $\begin{array}{l}\text { c. } 706 C>T+c .656 \\
A>G\end{array}$ & $\begin{array}{l}\text { p.Pro236 ser+ } \\
\text { p.Tyr219Cys }\end{array}$ \\
\hline
\end{tabular}




\section{Discussion}

We have described a cohort of children with mitochondrial leukoencephalopathy with special reference to clinical course, therapeutic response and MRI findings. Even though there are descriptions on clinical and MRI features of mitochondrial leukoencephalopathies in the literature, the specific evidence of neuroinflammation with therapeutic implications are relatively unknown highlighting the novelty of the present study.

The diagnoses most often considered by the referring physicians were acute disseminated encephalomyelitis (ADEM) or multiphasic ADEM. This was substantiated by the presence of acute onset focal deficit associated with encephalopathy as defined by international pediatric multiple sclerosis criteria. ${ }^{17},{ }^{18}$ History of febrile illness preceding the onset, unequivocal steroid responsiveness, and a subsequent stable course albeit with deficits rather than a progressive degenerative course also corroborated the diagnosis of an acquired demyelinating disorder. However, comparison of the clinical features with other cohorts of children with ADEM brought out the differences from the primary demyelinating disorder. One of the important differentiating features was an early age of presentation as compared to children with primary demyelinating disorder. The usual age of onset of ADEM in children ranges from 5 to 8 years. ${ }^{17,} 18$ On the other hand patients with mitochondrial LE presented either in the infantile or late infantile period and some of them had insidious rather than acute presentation. The second point pertains to the presence of primary optic atrophy in many patients at the time of initial presentation. Even though the information on optic atrophy was not available for comparison in the demyelination groups, primary optic atrophy was present in more than half of the patients in this series at the time of presentation. Thirdly, children with mitochondrial LE most often had residual motor deficits on follow up even though they showed complete or partial clinical response to steroids in the acute phase. On the other hand residual motor deficits are less commonly reported in ADEM. ${ }^{15,16}$ Seizures were a major part of the episodes and sometimes the heralding event in some patients as exemplified in the patient with NDUFA1 variation. The difference was significant compared to two out of three ADEM cohorts and may be another useful differentiating point.

The clinical features in other mitochondrial phenotypes and that of mitochondrial leukoencephalopathy also showed distinct differences. Systemic features such as peripheral neuropathy, auditory involvement, and myopathic features were absent in children with leukoencephalopathy. The clinical features were related to long tract involvement in comparison to other phenotypes. This also may pose a 
major diagnostic dilemma for suspecting a mitochondrial etiology in patients primarily presenting with neuroregression and leukoencephalopathy. But familiarity with the MRI patterns compared to other leukodystrophies may help the physician to suspect a mitochondrial etiology.

MRI in the acute phase demonstrated large asymmetrical confluent lesions simulating acute disseminated encephalomyelitis or tumefactive MS. The lesions most often involved the frontal and parietal region and the periventricular and deep white matter and corpus callosum compared to subcortical or juxta cortical regions and thalamus in children with acquired demyelinating disorders. Contrast enhancement, diffusion restriction, presence of lactate peak and white matter cysts were consistently seen in mitochondrial LE. The evidence of inflammation on MRI is one of the important defining feature of mitochondrial leukoencephalopathies ${ }^{1}$. Restricted diffusion without contrast enhancement is most often seen in ischemia and is attributed to cytotoxic edema. Delayed restricted diffusion with contrast enhancement has been described in tumefactive MS lesions. ${ }^{19}$ In lesions with restricted diffusion, presence of gadolinium enhancement has been used as a differentiating feature between acute demyelinating lesions and ischemia. ${ }^{20}$ This has been attributed to intramyelinic edema or myelin vacuolation as in toxic demyelination or inborn error of metabolism. ${ }^{21}$ Another alternative explanation is that the myelin breakdown may reduce the water movement in the extracellular space because of the reduced fiber tract organization. ${ }^{22}$ The presence of concomitant contrast enhancement along with restricted diffusion in mitochondrial leukoencephalopathies may suggest that the pathology is similar to acute demyelinating lesions.

The therapeutic implications of these findings in mitochondrial disorders have not been fully explored. The most important being the utility of glucocorticoid administration in acute stages, as in acute demyelinating disorders. Steroid responsiveness in patients with mitochondrial leukoencephalopathy has been described in patients with LYRM mutations and DARS associated leukoencephalopathy., ${ }^{23}$ Remarkable corticosteroid response and dependence have been described in patients with MELAS. ${ }^{24}$ The similarity in clinical presentation and overlap with primary demyelinating disorder such as MS is already emphasized in literature., ${ }^{5,25}$ In the sole autopsy study available in patients with LHON-MS, the inflammatory responses are highlighted in detail. ${ }^{26}$ Introduction of corticosteroids in this patient intermittently did improve the visual and neurological dysfunction suggesting an early immunological mechanism. It was proposed that mitochondrial dysfunction might occasionally aggravate or initiate the autoimmune process. ${ }^{26}$ It remains to be seen if maintenance of the steroid therapy as in other immune mediated disorders can keep a stable course in children with mitochondrial LE. The report of the relapsing remit- 


\section{Chapter 6}

ting MS-like illness in a child with NDUFA1 variation may support this hypothesis. The patient received steroids for achieving as well as maintaining remission. After the remission is maintained, the patient remained clinically stable on mitochondrial cocktail medications. As suggested in the study by Kowacs et $\mathrm{al}^{26}$ the mitochondrial dysfunction in this patient might have initiated the immune response, which got stabilized by the use of steroids. Various mechanisms have been postulated by which glucocorticoids exert its effect on mitochondria. ${ }^{27-29}$

In conclusion, this study highlights that episodic neuroinflammation is a feature of mitochondrial leukoencephalopathies as evidenced by the clinical presentation and MRI features. These features may overlap with acquired demyelinating disorders. The role of glucocorticoids in inducing and maintaining remission during the neurological episodes in patients with mitochondrial leukoencephalopathy needs to be explored further in prospective studies.

\section{Funding}

The authors disclose receipt of the following financial support for the research, authorship, and/or publication of this article: This study was supported by a grant from Indian council of Medical Research to PSB (Grant No. 54/9/2012-HUM-BMS) 


\section{References}

1. Kevelam SH, Steenweg ME, Srivastava S, et al., Update on Leukodystrophies: A Historical Perspective and Adapted Definition. Neuropediatrics 2016.

2. van der Knaap MS VJ. Magnetic Resonance of Myelin, Myelination and Myelin Disorders. erlin, Germany: Springer; 1995.

3. Dallabona C, Abbink TE, Carrozzo R, et al., LYRM7 mutations cause a multifocal cavitating leukoencephalopathy with distinct MRI appearance. Brain 2016;139:782-794.

4. Mao P, Reddy PH. Is multiple sclerosis a mitochondrial disease? Biochim Biophys Acta 2010;1802:66-79.

5. Matthews L, Enzinger C, Fazekas F, et al., MRI in Leber's hereditary optic neuropathy: the relationship to multiple sclerosis. J Neurol Neurosurg Psychiatry 2015;86:537-542.

6. Kalman B, Lublin FD, Alder H. Mitochondrial DNA mutations in multiple sclerosis. Multiple sclerosis 1995;1:32-36.

7. Hanefeld FA, Ernst BP, Wilichowski E, Christen HJ. Leber's hereditary optic neuropathy mitochondrial DNA mutations in childhood multiple sclerosis. Neuropediatrics 1994;25:331.

8. Kalman B, Li S, Chatterjee D, et al., Large scale screening of the mitochondrial DNA reveals no pathogenic mutations but a haplotype associated with multiple sclerosis in Caucasians. Acta neurologica Scandinavica 1999;99:16-25.

9. Otaegui D, Saenz A, Martinez-Zabaleta M, et al., Mitochondrial haplogroups in Basque multiple sclerosis patients. Multiple sclerosis 2004;10:532-535.

10. Tranah GJ SA, Caillier SJ, D'Alfonso S, Martinelli Boneschi F,, Hauser SL OJNJ. Mitochondrial DNA sequence variation in multiple sclerosis. Neurology 2015;85:325-330.

11. Ban M, Elson J, Walton A, et al., Investigation of the role of mitochondrial DNA in multiple sclerosis susceptibility. PloS one 2008;3:e2891.

12. Venkateswaran S ZK, Sacchetti M, Gagne D, Arnold DL, Sadovnick AD,, Scherer SW BB, Bar-Or A, Simon DK; Canadian Pediatric Demyelinating, Network. D. Mitochondrial DNA haplogroups and mutations in children with acquired central demyelination. Neurology 2011;76:774-780.

13. Bernier FP, Boneh A, Dennett X, Chow CW, Cleary MA, Thorburn DR. Diagnostic criteria for respiratory chain disorders in adults and children. Neurology 2002;59:1406-1411.

14. Singhi PD RM, Singhi S, Kumar Khandelwal Acute disseminated encephalomyelitis in North Indian children: clinical profile and follow-up. Journal of child neurology 2006;21:851-857.

15. Yamaguchi Y TH, Kira R, Ishizaki Y, et al.,,A nationwide survey of pediatric acquired demyelinating syndromes in Japan. Neurology 2016;8:2006-2015.

16. Absoud M, Lim MJ, Chong WK, et al., Paediatric acquired demyelinating syndromes: incidence, clinical and magnetic resonance imaging features. Multiple sclerosis 2013;19:76-86.

17. Krupp LB, Tardieu M, Amato MP, et al., International Pediatric Multiple Sclerosis Study Group criteria for pediatric multiple sclerosis and immune-mediated central nervous system demyelinating disorders: revisions to the 2007 definitions. Multiple sclerosis 2013;19:1261-1267.

18. Gordon-Lipkin E, Banwell B. An update on multiple sclerosis in children: diagnosis, therapies, and prospects for the future. Expert Rev Clin Immunol 2017:1-15.

19. Hyland M, Bermel RA, Cohen JA. Restricted diffusion preceding gadolinium enhancement in large or tumefactive demyelinating lesions. Neurology Clinical practice 2013;3:15-21.

20. Balashov KE, Aung LL, Dhib-Jalbut S, Keller IA. Acute multiple sclerosis lesion: conversion of restricted diffusion due to vasogenic edema. J Neuroimaging 2011;21:202-204.

21. Sener RN. Diffusion Magnetic Resonance Imaging Patterns in Metabolic and Toxic Brain Disorders. Acta Radiologica 2004;45:561-570. 


\section{Chapter 6}

22. Abou Zeid N, Pirko I, Erickson B, et al., Diffusion-weighted imaging characteristics of biopsyproven demyelinating brain lesions. Neurology 2012;78:1655-1662.

23. Wolf NI, Toro C, Kister I, et al., DARS-associated leukoencephalopathy can mimic a steroidresponsive neuroinflammatory disorder. Neurology 2015;84:226-230.

24. Gubbay SS, Hankey GJ, Tan NT, Fry JM. Mitochondrial encephalomyopathy with corticosteroid dependence. The Medical journal of Australia 1989;151:100-103, 106, 108.

25. Weisfeld-Adams JD, Katz Sand IB, Honce JM, Lublin FD. Differential diagnosis of Mendelian and mitochondrial disorders in patients with suspected multiple sclerosis. Brain : a journal of neurology 2015;138:517-539.

26. Kovacs GG, Hoftberger R, Majtenyi K, et al., Neuropathology of white matter disease in Leber's hereditary optic neuropathy. Brain : a journal of neurology 2005;128:35-41.

27. Lee SR, Kim HK, Song IS, et al., Glucocorticoids and their receptors: insights into specific roles in mitochondria. Prog Biophys Mol Biol 2013;112:44-54.

28. Psarra AM, Sekeris CE. Glucocorticoids induce mitochondrial gene transcription in HepG2 cells: role of the mitochondrial glucocorticoid receptor. Biochim Biophys Acta 2011;1813:1814-1821.

29. Tiao MM, Lin TK, Chen JB, et al., Dexamethasone decreases cholestatic liver injury via inhibition of intrinsic pathway with simultaneous enhancement of mitochondrial biogenesis. Steroids 2011;76:660-666. 


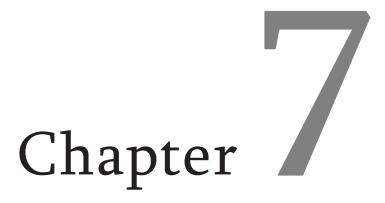

General Discussion 
Magnetic Resonance Imaging (MRI) plays an important role in the phenotypic characterization of patients with mitochondrial disorders by providing information on timing, extent and progression of neuronal injury. Studies on phenotype-genotype correlations are critical in understanding and identifying the range of disease manifestations in mitochondrial disorders. This in turn helps to fasten the diagnostic process, monitor the disease progression and objectively assess intervention effects. The overall aim of the thesis was to correlate MRI both to genetic defects and to disease manifestations, in order to guide prognosis and therapy. Specific aims were: 1. To correlate magnetic resonance imaging findings in patients with mitochondrial disorders and peripheral neuropathy with the underlying genetic defect; 2 . To discriminate mitochondrial disorders from other metabolic disorders by specific imaging findings; 3. To apply MRI for predicting prognosis and monitor therapy in specific subsets of patients

\section{MRI based phenotype genotype correlations}

Correlating genetic data with neuroimaging phenotypes is an emerging approach in neuroscience to better understand the complex imaging appearance of inherited metabolic disorders, and mitochondrial disease in particular. This approach is useful to neuroscientists by providing better genetic neuroimaging integration and to clinicians by providing a better diagnostic tool. MRI demonstration of CNS changes supplements the clinical information and helps defining the phenotype-genotype correlations for more effective treatment and prognostic information. ${ }^{1}$ Newer MRI techniques also help to define the metabolism, and hemodynamics. ${ }^{2,3}$ Previous studies on MRI in mitochondrial disorders have suggested that certain anatomical patterns can indicate the underlying etiology. ${ }^{4}$ Limited studies have so far attempted to identify correlations between the MRI findings and genetic defect. ${ }^{5}$

Chapter 1 provides an overview of the MRI findings in various mitochondrial patients, carrying different genetic defects, and demonstrates the advances made in the diagnostic evaluation in patients with mitochondrial disorders. The target areas involved in mitochondrial disorders are: 1. Deep gray matter structures including basal ganglia, thalamus and brainstem consistent with Leigh and Leigh-like syndrome; 2. White matter [Leukoencephalopathy]; 3. Cerebral cortex [stroke like lesions]. Cerebral and cerebellar atrophy may occur in isolation or in association with involvement of the target areas. ${ }^{1}$ Definite correlations between genotype and MRI patterns are emerging, including LSBL due to DARS2 mutations, LTBL due to EARS2 mutations, SDH related leukoencephalopathy, leukoencephalopathy due to $L Y R M$ and NUBPL mutations, 'putaminal eye' pattern in MEGDEL syndrome due to 
SERAC1 mutations and stroke like lesions in complex I deficiency due to mtDNA mutations, MELAS, POLG1 and ubiquinone deficiency. Given the rarity of mitochondrial disorders, these studies are essential to strengthen the phenotype genotype correlations in the diagnostic evaluation and interpretation of growing exome sequencing data.

In chapter 2, we explored the spectrum of MRI findings in patients with mitochondrial disorders in relation to the underlying genetic defects. The genotypes covered three groups, mtDNA point mutations \& deletions and mutations in the POLG1 \& SURF1 genes. The MRI patterns reflected the myriad of central nervous system manifestations in patients with mitochondrial disorders and included stroke-like lesions, laminar cortical necrosis, signal changes in basal ganglia, thalamus, dentate and brain stem nuclei, cerebral and cerebellar white matter signal changes, cerebral and cerebellar atrophy, intracerebral calcification and lactic acidosis. Comparison of the MRI findings in the three groups showed that cerebral and cerebellar atrophy, cortical signal changes and basal ganglia mineralization were seen mostly in patients with mtDNA mutations. Brainstem signal changes with or without striatal lesions were characteristically noted in SURF1 group. There was no consistent imaging pattern in POLG1 group. Stroke like lesions and basal ganglia mineralization were noted only in patients with $\mathrm{m} .3243 \mathrm{~A}>\mathrm{G}$ mutation. The preferential occurrence of stroke like lesions in patients with mtDNA mutations has been highlighted earlier. ${ }^{5}$

Chapter 2 also emphasizes the role of MRI based phenotypic characterization in non-syndromic mitochondrial disorders. Four of the six patients who underwent spinal cord imaging demonstrated signal changes in the cord. This is noteworthy since the signal changes in spinal cord may superficially support a diagnosis of neuromyelitis optica syndrome and give rise to diagnostic errors especially if the patient has additionally optic nerve involvement. Knowing that such a specific tract involvement can occur in mitochondrial disorders may help the physician in making an early diagnosis. Spinal cord involvement in the context of mitochondrial disorders has been classically described in patients with leukoencephalopathy with brainstem and spinal cord involvement and elevated lactate due to a DARS2 or DARS mutation. For mutations in the $D A R S$ gene hypomyelination with brainstem and spinal cord abnormalities and leg spasticity (HBSL) has been reported as well. ${ }^{6}$ The dorsal columns and spinothalamic tracts are selectively involved in this disorder. Spinal cord involvement as the only manifestation is exceptional for mitochondrial disorders and previously described in a patient with the m.3460G $>\mathrm{A}$ mutation. ${ }^{7}$ Spinal cord degeneration confined to posterior column has been reported also in POLG mutations. ${ }^{8}$ Dominant spinal cord involvement was described in a patient 
with the m.11788G $>$ A mutation, who presented with spastic dystonic syndrome and optic atrophy. As emphasized chapter 2, the recognition of mitochondrial etiology in patients with isolated spinal cord involvement has both therapeutic and prognostic implications. A useful differentiating point is the diffuse involvement of the cord in primary demyelinating disorders compared to the selective tract involvement in mitochondrial disorders. Description of more patients is required to confirm this observation.

Infantile basal ganglia stroke syndrome following minor trauma is another phenotype of mitochondrial disorder identified in the study. The CT scan in these patients shows punctate basal ganglia calcification and asymmetric basal ganglia infarcts. The syndrome is otherwise specified as infantile basal ganglia stroke syndrome secondary to mineralizing angiopathy. ${ }^{9}$ The patient with both the m.13513A $>$ G mutation and the basal ganglia stroke syndrome points towards a role for mitochondrial dysfunction in this peculiar stroke syndrome and mineralizing angiopathy. ${ }^{10}$ So far, the genetic etiology in this particular syndrome has been elusive. In chapter 2 I also discussed the application of advanced imaging techniques in the evaluation of patients with mitochondrial disorders. Susceptibility weighted imaging (SWI) studies revealed mineralization in 13/22, 59\% of the patients who underwent SWI. The pattern of mineralization was heterogeneous and included bilateral globus pallidus, punctate calcification involving the striatum and dense calcification of caudate and putamen. It is noteworthy that all patients with m.3243A $>$ G mutation had mineralization revealed by SWI. This finding supports the earlier studies that globus pallidus mineralization is the earliest imaging finding in MELAS. ${ }^{11}$ Pathological studies have shown that the calcification usually involves the blood vessel walls and neuronal populations are spared leading to mineralizing angiopathy.

\section{Specific MRI findings and role in diagnostic evaluation}

The vulnerability of specific neuronal groups in mitochondrial disorders led to different anatomical patterns on MRI and recognition of these patterns helped in phenotypic characterization. Prominent among them were leukoencephalopathies caused by mitochondrial as well as non-mitochondrial genes. Symmetrical involvement of the deep ganglionic and brainstem nuclei was observed in a number of disorders and in mitochondrial disorders it defined the Leighs syndrome. In Chapter 3 we investigated if specific anatomical structure involvement on MRI could differentiate mitochondrial disorders from other metabolic and genetic disorders with similar MRI findings. The aim was to facilitate targeted metabolic and genetic testing, in 
order to facilitate rapid and specific treatment. One hundred and twenty-five MRI scans from patients with different metabolic disorders were reviewed for the presence of hypertrophic olivary degeneration (HOD). Presence of HOD was noted exclusively in patients with Leigh and Leigh-like syndrome secondary to mitochondrial etiology. The findings reflected the selective vulnerability of specific neuronal groups in patients with mitochondrial disorders. ${ }^{12}$ The characteristic multifocal symmetrical destructive lesions in neuraxis demonstrated marked glial hyperplasia macrophage incursion and vascular proliferation with relative sparing of neurons. ${ }^{13}$ It has been postulated that the non random pattern of damage in the neuraxis will depend on the severity of enzyme defect, developmental age of the individual and functional activity of the different neuronal cell group. ${ }^{12,13}$ Literature review also supported the involvement of inferior olivary nucleus on MRI in many mitochondrial disorders compared to other inherited metabolic disorders. ${ }^{14-18}$ This is analogous to the observation in neuropathological studies by Cavanagh et al who observed that" in no other condition of which the author is aware are the inferior olives destroyed with such regularity, so that this phenomenon may be unique to Leigh's disease and perhaps other analogous metabolic disorders". ${ }^{19}$ Apart from the diagnostic significance, it remains to be seen if the unique involvement of inferior olives in mitochondrial disorders has therapeutic or prognostic significance.

\section{MRI based phenotype genotype correlations in Mitochondrial Epilepsy}

A detailed study of mitochondrial epilepsy (chapter 5) revealed interesting observations on the correlations between the outcome of epilepsy, phenotype genotype and magnetic resonance imaging findings. The MRI findings could be grouped into four major groups, stroke like lesions, atrophic changes, leukoencephalopathy and those with normal findings. Each of these four MRI groups had a fairly homogeneous clinical course, exemplifying the possible application of MRI in prognostication of mitochondrial epilepsy. Patients with stroke like lesions on MRI were associated with an episodic course and exacerbations characterized by epilepsia partialis continua. Seizures in this group were difficult to control even with multiple antiepileptic medications in optimal dosages. On the other hand, patients with atrophic changes on MRI had myoclonic seizures mainly and the course simulated a progressive degenerative disorder. The group with leukoencephalopathy had only intermittent seizures, which could be easily controlled with anti-epileptic drugs in all patients. Even though the MRI predominantly showed leukoencephalopathy, signal changes with restricted diffusion were noted in the hippocampus in two patients. 
The phenotypes of patients with normal MRI had homogeneous clinical and genetic findings. The clinical features were dominated by chronic progressive external ophthalmoplegia and a photosensitive eyelid myoclonia akin to Jevons's syndrome. Even though two patients had status epilepticus after presentation they had a stable course afterwards. Epilepsy with eyelid myoclonia (EMA) has been proposed to denote the onset of frequent eyelid myoclonia induced by eye closure and photic stimulation beginning in childhood. ${ }^{20}$ The molecular basis of EMA has not been characterized yet. Family studies in EMA were suggestive of complex inheritance with genetically overlapping with both classical genetic generalized epilepsy and generalized epilepsy with febrile seizure plus syndrome. ${ }^{20}$ The presence of epilepsy with eyelid myoclonia in patients with a specific POLG1 mutation and normal MRI suggests mitochondrial dysfunction as underlying pathology in epilepsy with eyelid myoclonia.

Mitochondrial dysfunction has been implicated as a potential cause of epileptic seizures and therapy-resistant forms of severe epilepsy. ${ }^{21}$ Mitochondrial complex I deficiency has been demonstrated in the epileptic foci of patients with temporal lobe epilepsy. ${ }^{22}$ Possible explanations for the role of mitochondria in epileptogenesis include: 1 . Mitochondrial oxidative phosphorylation is the major source of adenosine triphosphate in neurons; 2. Mitochondria participate in cellular $\mathrm{Ca}^{2+}$ homeostasis and thus can modulate neuronal excitability and synaptic transmission; 3. Mitochondria are intimately involved in pathways leading to the neuronal cell death characteristic for the areas of epileptogenesis. ${ }^{21}$

\section{Phenotype-Genotype correlations of peripheral neuropathy in Mitochondrial Disorders}

Phenotype-genotype correlations in patients with mitochondrial disorders are most often decided by the different systems involved. Peripheral neuropathy occurs as part of the multisystem involvement in many mitochondrial disorders. A subset of patients with mitochondrial disorders have peripheral neuropathy as the sole or unique manifestation and these are known as the mitochondrial CMTs. Mitochondrial ATP production supports important neuronal functions as maintaining the energy milieu, synapse assembly, generation of action potentials and synaptic transmission in peripheral nerves. Chapter 3 analyzed the characteristics of peripheral neuropathy in a cohort of patients with mitochondrial disorders. The patients in this cohort belonged to three groups, mtDNA point mutations, POLG1 and SURF1. Peripheral nerve involvement was mainly axonal in nature even though the SURF1 group had predominantly demyelinating neuropathy. This was mostly subclinical in 
nature and aided in diagnosis by defining the multiaxial involvement in patients. For example, presence of peripheral neuropathy in a patient with progressive myoclonic epilepsy $[\mathrm{PME}]$ should prompt the physician to investigate mitochondrial etiology rather than other causes of PME such as lafora body disease or neuronal lipofuscinosis. The sensory ataxic neuropathy in patients with POLG1 is also noteworthy. Sensory ataxic neuropathy in routine clinical practice is most often caused by acquired etiologies such as autoimmune vasculitis and nutritional disorders. Recognition of a genetic etiology has important prognostic and therapeutic connotations. Knowledge of major phenotypes of mitochondrial neuropathies is important to make an early diagnosis.

From a pathophysiological perspective, the differential involvement of sensory versus motor fibers and axonal versus myelin system in different types of mitochondrial disorders is intriguing. A chronic distal sensory axonal neuropathy is the most commonly reported mitochondrial neuropathy in syndromic mitochondrial disorders. ${ }^{23,24}$ This is likely to be the result of a "chronic energy deprivation syndrome". ${ }^{2}$ Neurons with long axons that carry the burden of large volumes of axonal cytoplasm or axonal membrane are more vulnerable to the chronic energy deprivation. Neurons are the only cells that extend over great distances. The growth of the axons to considerable distance depends on the relatively fast movement of the intracellular material and organelles, capacity of the cells to synthesize these materials and to regulate the synthesis. ${ }^{25}$ They are also among the most actively synthesizing cells and most of the energy is directed toward maintaining the axons. Energy utilized for the signaling process is less. Primary sensory cells being the largest are at greatest risk during energy deprivation and thus are most commonly affected. An acute neuropathy in the context of mitochondrial disorders is rare and only a single paper reported acute reversible axonal dysfunction related to energy failure in peripheral nerves during stroke-like episodes in MELAS. ${ }^{26}$

The pathophysiology of neuropathy in the POLG1 and SURF1 groups was also different. The sensory ataxia in $P O L G 1$ patients attributed mainly to a sensory neuropathy. ${ }^{27}$ The electrophysiological investigations showed reduced sensory nerve action potential with preserved conduction velocity. Neuropathological studies demonstrated severe respiratory chain enzyme deficiency and neuronal cells in the dorsal root ganglion due to mitochondrial DNA depletion and deletion. ${ }^{27}$ In SURF1 patients a demyelinating form of neuropathy was seen as reported previously. Ultrastructural examination of the sural nerve biopsy showed that myelin sheaths had only few lamellae and occasionally large axons were completely devoid of myelin sheath. A large number of mitochondria, some of which were enlarged and rounded cristae were found in Schwann cells. ${ }^{28}$ 
The mitochondrial CMT group is more consistent with a "chronic energy deprivation syndrome". The role of mitochondrial fission and fusion defects in these transport systems are increasingly being identified. Mouse experiments have provided further evidence that heterooligomeric complexes between MFN1 \&MFN2 are important for control of mitochondrial fusion. The additional functions include mitochondria tethering and control of mitochondrial transport in axons. It has been demonstrated in animal experiments that MFN2 has an essential role in regulating the terpenoid biosynthesis pathway, required to maintain mitochondrial coenzyme Q levels for optimal function of the respiratory chain. In addition it was shown that the coenzyme $\mathrm{Q}$ deficiency and the respiratory chain deficiency were partially rescued by coenzyme Q10 supplementation. ${ }^{29}$ Isolated case reports highlighted beneficial effects of CoQ supplementation in patients with MFN2 mutations. ${ }^{30}$

\section{MRI-based prognostic predictions}

The diagnostic process in patients with mitochondrial disorders is challenging because of the multisystem involvement, variable age of onset and genetic heterogeneity. The lengthy and complicated diagnostic evaluation, which most often involves invasive procedures, is stressful for the family. Even though the improvement in next-generation sequencing technology has shortened and simplified the diagnostic process considerably, generating a genetic diagnosis in $60-70 \%$ of the patients within months, cases with variants of unknown significance remain. Also, an accurate prognosis, based on confirmed pathogenic variants is often not possible, due to the clinical variability of these diseases, the often family-specific mutations and the lack of data on natural history. And although it opens-up opportunities for prevention by prenatal or preimplantation genetic diagnosis, patients and their parents are often motivated to get an investigation that would lead to more accurate prognosis and probable intervention options. ${ }^{31}$ Nevertheless, confirming a diagnosis ensure proper management, surveillance of complications, identify relatives at risk and allow more accurate risk estimation. Even though the diagnostic evaluation has progressed a lot in terms of finding out the genetic basis, information on the course and prognosis still remain grey areas and is the biggest challenge in patient management.

Prognosis of mitochondrial disorders is difficult, both within the families and between families with same mutation, because the disease course largely depends on the type of disease and organ system involved and limited knowledge exists on the impact of key modifying factors. ${ }^{32}$ Factors, which decide the prognosis in an individual patient, include, among others, the age of onset (pediatric patients being more severely affected than adult patients), physical fitness, duration of illness, various 
complications and their outcome. Because of these factors the exact prognosis of a mitochondrial disease in an individual patient is more often decided by a single mitochondrial disease related event or complications within a range, defined by individual entities or genetic basis. ${ }^{32}$ Routine surveillance and early recognition of organ system involvement and complications are important for prognosis and applying and monitoring treatment.

In this regard MRI, because of its non-invasive nature and the ability to define the anatomical pattern of brain injury overtime can play an important role in predicting the clinical course and monitoring treatment response in individual patients. The advantages of the newer imaging techniques to define the metabolic states of the brain and white matter integrity will further enhance their usefulness. Although analysis of clinical features and prognosis in relation to the MRI findings was only limitedly possible from the available literature, a few studies did address this issue. The available data indicated that certain MRI phenotypes were associated with a good prognosis and a stable clinical course. This was especially evident in patients with a leukoencephalopathy phenotype. ${ }^{33,34}$ Mitochondrial leukoencephalopathy associated with cytochrome oxidase deficiency and APOPT1 gene mutations appeared to be highly variable in onset, but irrespective of the severity of onset and initial evaluation, both the MRI lesions and clinical progression stabilized with a chronic long survival clinical course. ${ }^{35}$ All patients in the report were alive with the oldest one being in the third decade. The improvements in clinical course are paralled by an improvement in the MRI findings. The correlation of a variable clinical course with MRI lesions has also been reported in cohorts of patients with mutations in other genes. ${ }^{36,37}$ In children with early onset leukoencephalopathy with thalamus and brainstem involvement and elevated lactate and the same EARS2 mutation, two groups were identified based on the prognosis. The variation in the clinical phenotypes corresponded to the severity of MRI phenotypes. ${ }^{36}$ Striking improvement on MRI paralleling the improvement in clinical course was also reported in another patient with EARS2 mutations and an intermediate severity. ${ }^{34}$ This also holds true for the well-characterized leukoencephalopathy with brainstem and spinal cord involvement and elevated lactate due to DARS2 mutations. The neonatal and late infantile forms have a severe clinical course, in contrast to the adolescent and adult onset patients, the clinical severity correlating with the extent of white matter signal changes. ${ }^{37}$ Similarly a continuous development was noted in patients with leukoencephalopathy caused by NUBPL mutations, the chaperone involved in the ironsulfur cluster assembly in complex ${ }^{38}{ }^{38}$ The developmental progress in the patient was correlated with improvements in corpus callosal and cerebral white matter signal changes, although there were progressive cerebellar and brainstem abnormali- 
ties, which did not correlate. A mild or stable clinical course was described in patients with leukoencephalopathy on MRI and NDUFV1 mutations. ${ }^{39}$ The paper highlighted that mitochondrial encephalopathy associated with white matter signal changes was not necessarily associated with a severe course. A follow up MRI was not available to correlate imaging to the stable course. All these reports exemplify to a certain extent, the prognostic implications of MRI findings in mitochondrial disorders, where the severity of the disease course correlatesd with the severity of the MRI abnormalities.

Demonstrating additional lesions on MRI, which were unusual in patients with a particular genotype should alert the physician about a different course in a given patient as indicated in chapter 2 . In two children with the m.3243A $>\mathrm{G}$ mutation, MRI revealed additional basal ganglia lesions along with the stroke like lesions suggesting diagnosis of MELAS-Leigh-overlap syndrome. Both children developed severe swallowing difficulties over-time indicating brainstem involvement typical of Leigh syndrome children. Even though a follow-up MRI or autopsy studies were not available in these two children to objectively demonstrate the brainstem lesions, the clinical features and severity and subsequent fatal outcome in these two children early in the disease course indicated progressive involvement of the brain stem as depicted in previous studies on clinic-anatomic correlations of respiratory abnormalities in Leigh syndrome. ${ }^{40,41}$ These studies also demonstrated that the Leigh syndrome children with brainstem lesions have a worse prognosis than children with dominant basal ganglia lesions. ${ }^{41}$ Likewise, disappearance of brainstem lesions have been correlated with improvement in clinical symptoms in patients with Leigh-like syndrome. ${ }^{10}$ These findings suggest that anticipation of the clinical course and appropriate intervention based on MRI findings can improve the prognosis.

Chapter 2 also discussed follow-up MRIs and their correlation with the clinical course in a subset of patients. These studies showed progressive MRI changes and new anatomical areas of involvement. A shift from the episodic stroke-like lesions to progressive degenerative course was correlated with the atrophic changes on MRI in patients with the m.3243A>G mutation. Neuropathological studies on human postmortem CNS tissues provided insight into the distribution and severity of neuronal degeneration in patients harboring mitochondrial DNA defects. ${ }^{42}$ The neuronal degeneration on MRI is reflected as cerebral and cerebellar atrophy. The atrophic changes on MRI noted in MELAS, POLG1 and MERRF patients in chapter 2 and chapter 5 correlated with progressive cognitive decline and degenerative course on follow up. This is also supported by neuropathological studies. In a series of 15 brains from genetically diverse mitochondrial diseases, atrophy was noted in MELAS, POLG1 and MERRF patients. ${ }^{42}$ The duration of illness or imaging data of these 
patients were not mentioned and correlation with prognosis is therefore not possible. Study of the mechanisms underpinning neurodegenerative changes in primary mitochondrial disorders may improve the understanding of the role of mitochondria in neurodegeneration. MRI Volumetric studies and nuclear imaging studies can additionally support these studies. These findings highlight the importance of follow-up images in prognostication of patients with mitochondrial disorders.

\section{MRI-based therapeutic interventions}

In general, therapeutic implications of specific characteristics on MRI in subgroups of mitochondrial diseases need further exploration. In Chapter 5, we investigated the prognostic and therapeutic implications of MRI findings in patients with mitochondrial epilepsy. Our hypothesis was that the MRI findings might correlate with the therapeutic response in mitochondrial epilepsy. Of the 27 patients with epilepsy, the seizures were well controlled only in the subgroup of patients with leukoencephalopathy, which most often required immunotherapy only. The study also suggested that patients with stroke like lesions on MRI needed more intensive treatment than other subgroups of patients with either normal or atrophic changes on MRI.

One of the most important characteristics of MRI in mitochondrial leukoencephalopathies is the evidence of inflammation in several cases, as discussed in chapter 6. Similarity in clinical presentation and MRI findings in mitochondrial leukoencephalopathies, which overlap with primary demyelinating disorders such as acute disseminated encephalomyelitis or multiple sclerosis, were emphasized. The overlap or co-existence of mitochondrial disorders with acquired demyelinating disorders is well known for patients with LHON-MS. The entity LHON-MS denotes the coexistence of LHON and multiple sclerosis like MRI in the same individual. ${ }^{43}$ Autopsy study in a patient with LHON-MS highlighted the inflammatory response. ${ }^{44}$ The inflammatory changes were characterized by macrophages and lymphocytes within the lesion, which diffusely infiltrated the parenchyma and formed an inflammatory rim at the actively demyelinating edge of the lesion. Introduction of corticosteroids in this patient intermittently improved the visual and neurological dysfunction, suggesting an early immunological mechanism. It was proposed that mitochondrial dysfunction might occasionally aggravate or initiate the autoimmune process. ${ }^{44}$

Similar to the LHON-MS patients, MRI in mitochondrial leukoencephalopathy also exhibited signs of inflammatory response as evidenced by contrast enhancement and restricted diffusion in the acute stages. This is most often seen in ischemia and is attributed to cytotoxic edema. Delayed restricted diffusion with contrast enhance- 
ment has been described in tumefactive MS lesions. ${ }^{45}$ Lesions with restricted diffusion and presence of gadolinium enhancement have been shown to distinguish acute demyelinating lesions from ischemia. ${ }^{46}$ This has been attributed to intramyelinic edema or myelin vacuolization as well as to toxic demyelination or inborn error of metabolism. ${ }^{47}$ Another explanation was that the myelin breakdown could reduce the water movement in the extracellular space, because of the reduced fiber tract organization. ${ }^{48}$ The presence of concomitant contrast enhancement along with restricted diffusion in mitochondrial leukoencephalopathies may suggest that the pathology is similar to acute demyelinating lesions and may suggest cytotoxic edema.

The therapeutic implications of this clinical and MRI evidence of neuroinflammation in patients with mitochondrial leukoencephalopathies have not been explored extensively. Most important will be the utility of glucocorticoid administration in acute stages, similar to management of acute demyelinating disorders. There is data on steroid responsiveness during times of deterioration in patients with mitochondrial leukoencephalopathy even though description of the treatment regime is limited. ${ }^{49}$ Remarkable corticosteroid response and dependence has been described in patients with MELAS and it has been recommended that corticosteroid therapy should be considered as a standard treatment..$^{50}$ In a patient with MELAS, DWI and PET studies have demonstrated that the primary pathophysiological process leading to neuronal injury is actually a poorly regulated compensatory hyperperfusion response. ${ }^{51}$ The regional hyperperfusion leads to apoptotic cell death through progression from vasogenic to cytotoxic edema. The authors suggested that the prompt diagnosis and institution of treatment in the hyperperfusion stage might prevent progression to cytotoxic edema averting permanent neurological deficit. Studies have also shown corticosteroid receptors in mitochondria and increasing evidence that mitochondria are controlled by the action of glucocorticoids. ${ }^{52}$ Expression of mitochondrial genes is regulated by interaction of glucocorticoids with nuclear genes or by direct action of glucocorticoids on mtDNA and its respiratory chain. Glucocorticoids stimulate the mitochondrial transcription by the mitochondrial glucocorticoid receptor affecting respiratory chain biosynthesis. ${ }^{53}$ Glucocorticoids can enhance the mitochondrial biogenesis and modulate the extrinsic pathway of apoptosis. ${ }^{54}$ A number of other reports also highlight the beneficial effects of corticosteroids during the acute exacerbation and to prevent clinical deterioration. ${ }^{55}$ In patients with leukoencephalopathy there seems to intermittent responsiveness to steroids administration even though the information in the reports are limited. It remains to be seen if maintenance of the steroid therapy as in other immune mediated disorders can keep a stable course. The report of the relapsing remitting MS- 
like illness in a child with a NDUFA1 mutation described in chapter 6 may support this hypothesis. The child received a maintenance dose of steroids and remained clinically stable on mitochondrial cocktail medicines. The brain biopsy findings also demonstrated an inflammatory response. This may support the hypothesis that the primary lesions in mitochondrial leukoencephalopathies simulate demyelinating lesions and may respond to immunomodulation.

\section{MRI-based therapy monitoring}

Several therapeutic strategies for mitochondrial disorders are being developed and are in the preclinical stages and the biggest challenge is the lack of validated biomarkers to monitor the efficacy of treatment. ${ }^{56}$ Imaging findings are increasingly being identified and used for monitoring the progress in neuromuscualr disorders. ${ }^{57}$ The potential application of MRI as a 'rate biomarker' in mitochondrial disorders still needs to be explored. It has been pointed out that the common brain MRI features of mitochondrial disorders are not specific and highly variable making them unsuitable as a biomarker. ${ }^{56}$ But the potential application of MRI in assessing the disease progression and its usefulness in monitoring treatment has not been explored in large longitudinal studies so far. As evident from the review of the MRI findings in different genotypes of mitochondrial disorders in chapter 1, large homogenous patient groups can be achieved based on the neuroimaging findings.

An array of imaging modalities provides a non-invasive quantitative measurement of disease progression, which can be used for monitoring therapy. Eventhough elevated lactate is an established finding of brain MRS, there are only limited studies available which studied the effect of pharmaceutical agents on lactate levels. ${ }^{58-61} \mathrm{~A}$ recent study on $\mathrm{H}-\mathrm{MRS}$ in a large cohort of clinically heterogeneous individuals with the m.3243A $>\mathrm{G}$ mutation has shown that lactate and total choline levels were reliable biomarkers for predicting the risk of individual mutation carriers to develop the MELAS phenotype. ${ }^{62}$ Another study used Tc99m-HMPAO, a SPECT imaging biomarker of cerebral blood flow to monitor the effect of EPI-743 treatment in mitochondrial disorders. The study demonstrated significant correlation between change in cerebellar uptake of HMPAO and clinical improvement in all the patients. The role of MRI in treatment monitoring has also been demonstrated in a serial MRI studies after L-Arginine infusion therapy. ${ }^{63}$ These studies provide promising data to use MRI for therapy monitoring, which needs follow-up in larger patient cohorts. 


\section{Therapeutic Perspectives for mitochondrial disease}

Symptomatic management of patients with mitochondrial disorders requires evaluation by a multidisciplinary team including neurologists, cardiologists, ophthalmologist and rehabilitations specialists. The evaluations include periodic cardiac assessment with echocardiogram and cardiac MRI, eye examination including optical coherence tomography for conditions, which affect the eyes primarily such as Leber's hereditary neuropathy and optic atrophy plus syndrome. Epilepsy is common in patients with mitochondrial disorders and periodic EEG monitoring is required to identify the abnormalities and start treatment at the earliest possible moment. Respiratory assessment to find out the respiratory dysfunction early in the course to treat hypoxia is also an important part of management strategies. Treatment of tone abnormalities especially hypotonia, dystonia and hypertonia, necessitates consultation with a rehabilitation specialist.

The last couple of years have witnessed tremendous advancement in the understanding of the inherent complexities of the mitochondrial biology. In-depth studies have helped to elucidate the genetic causes and pathogenic mechanisms of mitochondrial disorders at an increasing pace over the last 25 years. The role of mitochondrial dysfunction in several other common neurological disorders is slowly unfolding. including Alzheimer's disease (AD), Parkinson's disease (PD), amyotrophic lateral sclerosis (ALS), Huntington's disease (HD), Friedreich ataxia and Hereditary Spastic Paraplegia. ${ }^{64}$ Several pathophysiological mechanisms which implicate mitochondrial dysfunction in these disorders are put forward ranging from direct gene defects to perturbation in mitochondrial dynamics. ${ }^{65}$ Translation of this huge body of knowledge to the patient's management is the next step. It is envisaged that the knowledge on the pathological mechanisms underlying both primary and secondary mitochondrial impairment may prompt the development of more effective evidence based therapeutic strategies. Even though the neurological progression over several decades in these disorders pose substantial morbidity, the current therapeutic strategies mainly concentrate on symptomatic management and improving the quality of life. A recent Cochrane review found no evidence of an effective intervention for any mitochondrial disorder. ${ }^{66}$ Nevertheless, specific treatment is available in a number of disorders such as CoQ10 replacement therapy in patients with mutations $\mathrm{CABC} 1$ and $\mathrm{ETFDH}^{67}$, riboflavin therapy in patients with mutations of ACAD $9^{68}$ and thiamin therapy in patients with SLC19A3 mutations, which prevents fatal Leigh syndrome ${ }^{69}$. The huge clinical, biochemical and genetic heterogeneity, which is the hallmark of mitochondrial disorders, is the major hindrance for collection of homogeneous cohorts of patients to establish the efficacy of a treat- 
ment. It remains to be seen if the convergence at the level of magnetic resonance imaging findings can overcome these barriers to certain extent. As discussed earlier the prognosis and therapy should be tailored to each patient and depends on individual clinical scenario, in which the gene defect complemented with MRI may be decisive. The potential of MRI findings to formulate this form of 'personalized medicine' is promising, but needs to be further explored.

The first attempts at treating mitochondrial disorders involved strategies to enhance the functioning of respiratory chain complex, which included compounds which increased substrate availability, augment the electron transfer within the respiratory chain, energy buffering and bypass the respiratory chain components. ${ }^{70}$ Compounds aimed at increasing the substrate availability include carnitine [which enhances the delivery of fatty acids], niacin [precursor of NADH which transfers electrons from intermediate metabolites to respiratory chain) and thiamine [which enhances pyruvate dehydrogenase activity thereby increasing the availability of pyruvate]. Agents which augment the electron transfer within the respiratory chain include riboflavin [precursor to flavin adenine dinucleotide [FAD]- electron carrier attached to complex I \& II], coenzyme $\mathrm{Q}$ an electron carrier from complex I \& II to complex III. There are compounds based on COQ and vitamin E such as idebenone and EPI-743, which increases the penetration of electron carrier to mitochondria. Substances which can bypass the function of specific respiratory chain include succinate (a citric acid cycle intermediate that donates electrons directly to FAD thus partially bypassing complex I), vitamin C\&K [bypass complex III]. Reduction of free radicals through anti oxidants is another approach and include vitamin $\mathrm{C}$, E, lipoic acid and dimethyl glycine. Increased ROS production occurs as a consequence of respiratory chain dysfunction and is the rational basis for the use of antioxidants in the therapy of mitochondrial disorders. Other compounds which have been used include L- Arginine for the treatment of stroke like episodes. It acts through the vasoactive effects mediated by the nitric oxide pathway, as L-arginine is a substrate for the Nitric oxide synthase (NO). The exact mechanism of action of L-Arginine in stroke-like episodes still needs to be resolved. Administration of L-Arginine has been shown to improve the regional perfusion in stroke like lesions in patients with MELAS, but the efficacy for treating MELAS patients is still not unambiguously demonstrated. 63

Various experimental therapies are being developed and include methods to increase the mitochondrial biogenesis, controlling autophagy and manipulating mitochondrial heteroplasmy. ${ }^{70}$ 


\section{Increasing mitochondrial biogenesis}

Mitochondrial biogenesis is increases the individual mitochondrial mass and mtDNA and mitochondrial copy number in a cell to increase the production of ATP as a response to increased energy expenditure. Mitochondrial diseases become manifest when the residual activity of the defective gene product, either mitochondrial or nuclear encoded, falls below a critical threshold. This may suggest that even partial restoration of the activity may be sufficient to rescue or at least ameliorate the phenotype. ${ }^{71}$ Mitochondrial biogenesis is an important factor deciding the severity of phenotype. Increased mitochondrial DNA copy number and mitochondrial biogenesis have been demonstrated in LHON carriers, compared to controls and affected patients, thereby supporting the notion that a high mitochondrial copy number protects carriers from developing clinical disease. ${ }^{72}$ The agents, which have been tried, include benzafibrate, and the AMPK agonist AICAR. AICAR has been shown the most effective compound in inducing mitochondrial biogenesis in complex I deficient cells, whereas benzafibrate gave erratic results. ${ }^{73}$

\section{Controlling autophagy- Role of mTOR inhibitors}

Rapamycin, an mTor inhibitor, has been used to treat the Ndufs4-/- mouse which lacks the $18 \mathrm{kDa}$ Ndufs4 subunit of complex I. Mutations of NDUFS4 are associated with autosomal recessive, severe infantile Leigh disease in humans and with rapidly progressive, early fatal neurological failure in the Ndufs4-/-mouse model. ${ }^{74}$ Chronic treatment with Rapamycin, which activates autophagy, significantly delayed both disease progression and fatal outcome in the Ndufs4-/- knock out mouse. Metabolomic analysis of Ndufs4-/-brains showed accumulation of pyruvate, lactate, and glycolytic intermediates, as well as reduced free amino acids, free fatty acids, nucleotides, and products of nucleotide catabolism, increased oxidative stress markers, and reduced levels of GABA and dopamine. While Rapamycin corrected many of these metabolic abnormalities, no effects were noted on complex1 activity.

\section{Manipulating mtDNA heteroplasmy}

Pathogenic mutations of mtDNA are often heteroplasmic. It is envisaged that eliminating or reducing the mutated DNA below the threshold of disease manifestation would be a promising therapeutic intervention. In cellular models this has been achieved by the use of mitochondrially targeted restriction endonucleases, zinc finger-endonucleases, or TALENs. ${ }^{71}$ Delivery of restriction enzymes into mitochondria is a novel strategy for gene therapy of special form of mitochondrial diseases. This has been used in m.8399T $>$ G NARP mutations which form a unique restriction site which is specific to restriction endonuclease Smal. ${ }^{75}$ Mitochondrially targeted re- 
combinant Smal variant was able to reduce the m.8993T > G mutation load in heteroplasmic mutant hybrids. This also resulted in repopulation of cells withwild type mtDNA, restoration of mtDNA membrane potential and increase in intracellular ATP levels. The disadvantage is that, this is applicable only when a unique restriction site is created by an mtDNA mutation. Alternate methods are use of mitochondrial TALENS and zinc finger endonucleases, both of which have been proven to eliminate heteroplasmic mutant mtDNA in cybrid cells carrying the m.8993T $>\mathrm{G}$ NARP mutation or the common deletions. ${ }^{76,77}$

- Prevention of transmission

Due to the inherent complexities of the mitochondrial genetics genetic counseling and prenatal diagnosis is difficult, not so much for nuclear gene mutation, but predominantly for primary mitochondrial DNA mutations. For de novo mutations with low recurrence risk, prenatal testing can be offered, whereas for inherited heteroplasmic mutations preimplantation genetic diagnosis (PGD) generally is the best option. ${ }^{78}$ Novel options under development include nuclear genome transfer involving maternal spindle transfer and pronuclear transfer which is suitable for both homoplasmic and heteroplasmic mutations. Even though these options appear exciting, they raise significant ethical issues and should be applied on an individual basis. ${ }^{78,79}$

- Gene Therapy

Molecular-based therapies have been hardly tried in mitochondrial disorders. Adeno-associated viral vectors mediated gene transfer have been tried in animal models of Ethyl malonic encephalopathy, MNGIE and MPV17 related disorders. ${ }^{80,82}$ Gene therapy for mitochondrial DNA disorders is challenging. Alternate methods of "allotopic expression" have been tried in complex I subunits with a view to treat the most common mitochondrial DNA disorder LHON. ${ }^{83.84}$

- Nucleoside Bypass Therapy

This is a form of treatment advocated for conditions with imbalanced nucleotide pools including mitochondrial DNA depletion syndromes. Among the mitochondrial depletion syndromes, TK2 deficiency has been specifically targeted. ${ }^{85}$ Thymidine kinase is a mitochondrial enzyme required for phosphorylation of the pyramidine nucleosides (thymidine \& deoxycytidine) to generate deoxy thymidine monophosphate and deoxycytidine monophosphate. ${ }^{86}$ Mutations in TK2 impair the mitochondrial nucleoside or nucleotide salvage pathways. ${ }^{87}$ TK2H126N knock-in mutant mouse ( $\mathrm{Tk}^{-/-}$) models manifest a phenotype strikingly similar to human infantile encephalomyopathy characterized by onset at 10 days with decreased ambulation, unstable gait, coarse tremor, growth retardation and mtDNA depletion progressing to early death. ${ }^{88}$ Oral administration of deoxycyti- 


\section{Chapter 7}

dine monophosphate (dCMP) and deoxy thymidine monophosphate (dTMP) delayed the disease onset, reduced the disease severity and prolonged the life span in mouse models. ${ }^{85}$ Further experiments have shown that the same results are achieved by administration of deoxythymidine (dT) or deoxycytidine(dC). ${ }^{89}$ This "nucleoside bypass therapy" (NBT) is expected to be an effective therapy not only for TK2 deficiency but also for other mitochondrial depletion syndromes.

Despite the lack of effective disease modifying treatment for mitochondrial disorders, there are lots of supportive treatment options that can be offered to the patient. Based on the current evidence and the extensive genotypic and phenotypic variability, the treatment approach needs to be individualized. Clinical course and complications in individual patient needs to be anticipated and appropriate preventive measures needs to be taken. Even though it has been suggested that the therapy in patients with mitochondrial disorders should be based on molecular pathways rather than phenotypes or genotypes, feasibility of a combined approach needs to be studied. The role of MRI in individualizing the treatment and follow up evaluations in a given patient needs to be explored in systematic manner in large longitudinal studies. 


\section{References}

1. Bricout M, Grevent D, Lebre AS, et al., Brain imaging in mitochondrial respiratory chain deficiency: combination of brain MRI features as a useful tool for genotype/phenotype correlations. J Med Genet. 2014; 51:429-35.

2. Haas R, Dietrich R. Neuroimaging of mitochondrial disorders. Mitochondrion 2004;4:471-90.

3. Finsterer J. Central Nervous System Imaging in Mitochondrial Disorders. Can J Neurol Sci. 2009; 36:143-53.

4. Sofou K, Steneryd K, Wiklund LM, Tulinius M, Darin N. MRI of the brain in childhood-onset mitochondrial disorders with central nervous system involvement. Mitochondrion 2013;13: 364-71.

5. Lebre AS, Rio M, Faivre d'Arcier L, Vernerey D, et al., A common pattern of brain MRI imaging in mitochondrial diseases with complex I deficiency. J Med Genet. 2011; 48:16-23.

6. Wolf NI, Toro C, Kister I, et al., DARS-associated leukoencephalopathy can mimic a steroidresponsive neuroinflammatory disorder. Neurology 2015;84:226-30.

7. Jaros E, Mahad DJ, Hudson G, et al., Primary spinal cord neurodegeneration in Leber hereditary optic neuropathy. Neurology 2007;69:214-6.

8. Tzoulis C, Engelsen BA, Telstad W, et al., The spectrum of clinical disease caused by the A467T and W748S POLG mutations: a study of 26 cases. Brain 2006;129:1685-92.

9. Lingappa L, Varma RD, Siddaiahgari S, Konanki R. Mineralizing angiopathy with infantile basal ganglia stroke after minor trauma. Developmental medicine and child neurology 2014; 56:78-84.

10. Sonam K, Bindu PS, Taly AB, et al., Clinical and Neuroimaging Features in Two Children with Mutations in the Mitochondrial ND5 Gene. Neuropediatrics. 2015; 46: 277-81.

11. Renard D, Campello C, Le Floch A, Castelnovo G, Taieb G. Globus pallidus and substantia nigra hypointensities on T2-weighted imaging in MELAS. J Neurol 2012; 259:2720-2.

12. JB C. Selective vulnerability in acute energy deprivation syndromes. Neuropathol Appl Neurobiol 1993;19:461-70.

13. Cavanagh JB HB. Pathogenic factors underlying the lesions in Leigh's disease. Tissue responses to cellular energy deprivation and their clinicopathological consequences. Brain 1994;117:1357-76.

14. Koch J, Freisinger P, Feichtinger RG, et al., Mutations in TTC19: expanding the molecular, clinical and biochemical phenotype. Orphanet J Rare Dis. 2015;10:40.

15. Kinghorn KJ, Kaliakatsos M, Blakely EL, et al., Hypertrophic olivary degeneration on magnetic resonance imaging in mitochondrial syndromes associated with POLG and SURF1 mutations. J Neurol 2013;260:3-9.

16. Sonam K, Khan NA, Bindu PS, et al., Clinical and magnetic resonance imaging findings in patients with Leigh syndrome and SURF1 mutations. Brain Dev 2014;36:807-12

17. Quattrocchi CC, Errante Y, Rossi Espagnet MC, et al., Magnetic resonance imaging differential diagnosis of brainstem lesions in children. World J Radiol. 2016;8:1-20.

18. Giribaldi G, Doria-Lamba L, Biancheri R, et al., Intermittent-relapsing pyruvate dehydrogenase complex deficiency: a case with clinical, biochemical, and neuroradiological reversibility. Dev Med Child Neurol 2012;54:472-6.

19. Cavanagh JB. Is Purkinje cell loss in Leigh's disease an excitotoxic event secondary to damage to inferior olivary nuclei? Neuropathol Appl Neurobiol 1994; 20:599-603.

20. Sadleir LG, Vears D, Regan B, Redshaw N, Bleasel A, Scheffer IE. Family studies of individuals with eyelid myoclonia with absences. Epilepsia. 2012; 53:2141-8.

21. Kunz WS. The role of mitochondria in epileptogenesis. Current Opinion in Neurology 2002;15:17984. 


\section{Chapter 7}

22. Kunz WS, Kudin AP, Vielhaber S, et al., Mitochondrial complex I deficiency in the epileptic focus of patients with temporal lobe epilepsy. Ann Neurol 2000; 48:766-73.

23. Menezes MP, Rahman S, Bhattacharya K, et al., Neurophysiological profile of peripheral neuropathy associated with childhood mitochondrial disease. Mitochondrion. 2016; 30:162-7.

24. Bindu PS, Govindaraju C, Sonam K, et al., Peripheral neuropathy in genetically characterized patients with mitochondrial disorders: A study from south India. Mitochondrion 2016; 27:1-5.

25. Cavanagh JB. The problems of neurons with long axons. Lancet. 1984;1:1284-7.

26. Farrar MA, Lin CS, Krishnan AV, Park SB, Andrews PI, Kiernan MC. Acute, reversible axonal energy failure during stroke-like episodes in MELAS. Pediatrics. 2010;126:e734-9.

27. Lax NZ, Whittaker RG, Hepplewhite PD, et al., Sensory neuronopathy in patients harbouring recessive polymerase gamma mutations. Brain 2012;135:62-71.

28. Santoro L CR, Malandrini A, Piemonte F, et al., A novel SURF1 mutation results in Leigh syndrome with peripheral neuropathy caused by cytochrome c oxidase deficiency. Neuromuscul Disord. 2000;10:450-3.

29. Mourier A, Motori E, Brandt T, et al., Mitofusin 2 is required to maintain mitochondrial coenzyme Q levels. J Cell Biol. 2015;208:429-42.

30. Takahashi R, Ikeda T, Hamaguchi A, Iwasa K, Yamada M. Coenzyme Q10 Therapy in Hereditary Motor Sensory Neuropathy Type VI with Novel Mitofusin 2 Mutation. Internal Medicine. 2012;51: 791-3.

31. Graungaard AH, Skov L. Why do we need a diagnosis? A qualitative study of parents' experiences, coping and needs, when the newborn child is severely disabled. Child Care Health Dev. 2007;33: 296-307.

32. Moggio M, Colombo I, Peverelli L, et al., Mitochondrial disease heterogeneity: a prognostic challenge. Acta myologica 2014;33: 86-93.

33. Taskin BD, Karalok ZS, Gurkas E, et al., Early-Onset Mild Type Leukoencephalopathy Caused by a Homozygous EARS2 Mutation. J Child Neurol 2016;31:938-41.

34. Biancheri R, Lamantea E, Severino M, et al., Expanding the Clinical and Magnetic Resonance Spectrum of Leukoencephalopathy with Thalamus and Brainstem Involvement and High Lactate (LTBL) in a Patient Harboring a Novel EARS2 Mutation. JIMD Rep. 2015; 23:85-9.

35. Melchionda L, Haack TB, Hardy S, et al., Mutations in APOPT1, encoding a mitochondrial protein, cause cavitating leukoencephalopathy with cytochrome c oxidase deficiency. Am J Med Genet A 2014;95:315-25.

36. Steenweg ME, Ghezzi D, Haack T, et al., Leukoencephalopathy with thalamus and brainstem involvement and high lactate 'LTBL' caused by EARS2 mutations. Brain 2012;135:1387-94.

37. Steenweg ME, van Berge L, van Berkel CG, de Coo IF, Temple IK, Brockmann K, et al., Early-onset LBSL: how severe does it get? Neuropediatrics. 2012;43:332-8.

38. Kevelam SH RR, Wolf NI, et al., NUBPL mutations in patients with complex I deficiency and a distinct MRI pattern. Neurology 2013;80:1577-83.

39. Zafeiriou DI, Rodenburg RJ, Scheffer H, et al., MR spectroscopy and serial magnetic resonance imaging in a patient with mitochondrial cystic leukoencephalopathy due to complex I deficiency and NDUFV1 mutations and mild clinical course. Neuropediatrics 2008;39:172-5.

40. Yasaki E, Saito Y, Nakano K, Katsumori H, et al., Characteristics of breathing abnormality in Leigh and its overlap syndromes. Neuropediatrics 2001;32:299-306.

41. Arii J TY. Leigh syndrome: serial MR imaging and clinical follow-up. AJNR Am J Neuroradiol 2000; 21:1502-9. 
42. Lax NZ, Jaros, E. Neurodegeneration in Primary Mitochondrial Disorders. In Mitochondrial Dysfunction in Neurodegenerative Disorders. In: A.K.[Ed] IR, editor.: Springer-Verlag London Limited; 2012. p. 21-41.

43. Matthews L, Enzinger C, Fazekas F, et al., MRI in Leber's hereditary optic neuropathy: the relationship to multiple sclerosis. J Neurol Neurosurg Psychiatry. 2015;86:537-42.

44. Kovacs GG, Hoftberger R, Majtenyi K, et al., Neuropathology of white matter disease in Leber's hereditary optic neuropathy. Brain 2005;128:35-41.

45. Hyland M, Bermel RA, Cohen JA. Restricted diffusion preceding gadolinium enhancement in large or tumefactive demyelinating lesions. Neurol Clin Pract 2013;3:15-21.

46. Balashov KE, Aung LL, Dhib-Jalbut S, Keller IA. Acute multiple sclerosis lesion : conversion of restricted diffusion due to vasogenic edema. J Neuroimaging 2011;21:202-4.

47. Sener RN. Diffusion Magnetic Resonance Imaging Patterns in Metabolic and Toxic Brain Disorders. Acta Radiologica. 2004;45:561-70.

48. Abou Zeid N, Pirko I, Erickson B, et al., Diffusion-weighted imaging characteristics of biopsyproven demyelinating brain lesions. Neurology 2012;78:1655-62.

49. Dallabona C, Abbink TE, Carrozzo R, et al., LYRM7 mutations cause a multifocal cavitating leukoencephalopathy with distinct MRI appearance. Brain 2016;139:782-94.

50. Gubbay SS, Hankey GJ, Tan NT, Fry JM. Mitochondrial encephalomyopathy with corticosteroid dependence. Med J Aust 1989;151:100-3

51. Walcott BP, Edlow BL, Xia Z, Kahle KT, Nahed BV, Schmahmann JD. Steroid responsive A3243G mutation MELAS: clinical and radiographic evidence for regional hyperperfusion leading to neuronal loss. Neurologist 2012;18:159-70.

52. Lee SR, Kim HK, Song IS, et al., Glucocorticoids and their receptors: insights into specific roles in mitochondria. Prog Biophys Mol Biol. 2013;112:44-54.

53. Psarra AM, Sekeris CE. Glucocorticoids induce mitochondrial gene transcription in HepG2 cells: role of the mitochondrial glucocorticoid receptor. Biochim Biophys Acta. 2011;1813:1814-21.

54. Tiao MM, Lin TK, Chen JB, et al., Dexamethasone decreases cholestatic liver injury via inhibition of intrinsic pathway with simultaneous enhancement of mitochondrial biogenesis. Steroids 2011;76: 660-6.

55. Rossi FH, Okun M, Yachnis A, Quisling R, Triggs WJ. Corticosteroid treatment of mitochondrial encephalomyopathies. Neurologist. 2002;8:313-5.

56. Steele HE, Horvath R, Lyon JJ, Chinnery PF. Monitoring clinical progression with mitochondrial disease biomarkers. Brain 2017;140: 2530-40

57. Morrow JM, Sinclair CDJ, Fischmann A, et al., MRI biomarker assessment of neuromuscular disease progression: a prospective observational cohort study. Lancet Neurol 2016;15:65-77.

58. Moller HE, Wiedermann D, Kurlemann G, Hilbich T, Schuierer G. Application of NMR spectroscopy to monitoring MELAS treatment: a case report. Muscle Nerve 2002;25:593-600.

59. Pavlakis SG, Kingsley PB, Kaplan GP, Stacpoole PW, O'Shea M, Lustbader D. Magnetic resonance spectroscopy: use in monitoring MELAS treatment. Arch Neurol 1998;55:849-52.

60. Lee SK, Kim J, Kim HD, Lee JS, Lee YM. Initial experiences with proton MR spectroscopy in treatment monitoring of mitochondrial encephalopathy. Yonsei Med J. 2010;51:672-5.

61. Kimura S, Ohtuki N, Nezu A, Tanaka M, Takeshita S. Clinical and radiologic improvements in mitochondrial encephalomyelopathy following sodium dichloroacetate therapy. Brain Dev 1997;19:53540 .

62. Weiduschat N KP, Mao X, Engelstad KM, Hinton V,, DiMauro S et al.,, Cerebral metabolic abnormalities in A3243G mitochondrial DNA mutation carriers. Neurology 2014;82:798-805. 


\section{Chapter 7}

63. Kitamura M, Yatsuga S, Abe T, et al., L-Arginine intervention at hyper-acute phase protects the prolonged MRI abnormality in MELAS. J Neurol 2016;263:1666-8.

64. Lezi E, Swerdlow RH. Mitochondria in neurodegeneration. Adv Exp Med Biol. 2012;942:269-86.

65. Johri A, Beal MF. Mitochondrial dysfunction in neurodegenerative diseases. J Pharmacol Exp Ther. 2012;342:619-30.

66. Pfeffer G, Majamaa K, Turnbull DM, Thorburn D, Chinnery PF. Treatment for mitochondrial disorders. Cochrane Database Syst Rev 2012;4:Cd004426.

67. Desbats MA, Lunardi G, Doimo M, Trevisson E, Salviati L. Genetic bases and clinical manifestations of coenzyme Q10 (CoQ 10) deficiency. J Inherit Metab Dis 2015;38:145-56.

68. Gerards M, van den Bosch BJ, Danhauser K, et al., Riboflavin-responsive oxidative phosphorylation complex I deficiency caused by defective ACAD9: new function for an old gene. Brain 2011;134:2109.

69. Gerards M, Kamps R, van Oevelen J, et al., Exome sequencing reveals a novel Moroccan founder mutation in SLC19A3 as a new cause of early-childhood fatal Leigh syndrome. Brain 2013;136:88290.

70. Finsterer J, Bindu PS. Therapeutic strategies for mitochondrial disorders. Pediatr Neurol. 2015;52:302-13.

71. Viscomi C, Bottani E, Zeviani M. Emerging concepts in the therapy of mitochondrial disease. Biochim Biophys Acta. 2015;1847:544-57.

72. Giordano C, Iommarini L, Giordano L, et al., Efficient mitochondrial biogenesis drives incomplete penetrance in Leber's hereditary optic neuropathy. Brain 2014;137:335-53.

73. Golubitzky A, Dan P, Weissman S, Link G, Wikstrom JD, Saada A. Screening for active small molecules in mitochondrial complex I deficient patient's fibroblasts, reveals AICAR as the most beneficial compound. PloS One. 2011;6:e26883.

74. Johnson SC, Yanos ME, Kayser EB, et al., mTOR inhibition alleviates mitochondrial disease in a mouse model of Leigh syndrome. Science. 2013;342:1524-8.

75. Tanaka M, Borgeld HJ, Zhang J, et al., Gene therapy for mitochondrial disease by delivering restriction endonuclease SmaI into mitochondria. J Biomed Sci 2002;9:534-41.

76. Gammage PA, Rorbach J, Vincent AI, Rebar EJ, Minczuk M. Mitochondrially targeted ZFNs for selective degradation of pathogenic mitochondrial genomes bearing large-scale deletions or point mutations. EMBO Mol Med 2014;6:458-66.

77. Bacman SR, Williams SL, Pinto M, Peralta S, Moraes CT. Specific elimination of mutant mitochondrial genomes in patient-derived cells by mitoTALENs. Nat Med. 2013;19:1111-3.

78. Smeets HJ, Sallevelt SC, Dreesen JC, de Die-Smulders CE, de Coo IF. Preventing the transmission of mitochondrial DNA disorders using prenatal or preimplantation genetic diagnosis. Ann N Y Acad Sci. 2015;1350:29-36.

79. Bredenoord A, Dondorp W, Pennings G, de Die-Smulders C, Smeets B, de Wert G. Preimplantation genetic diagnosis for mitochondrial DNA disorders: ethical guidance for clinical practice. Eur J Hum Genet. 2009;17:1550-9.

80. Di Meo I, Auricchio A, Lamperti C, Burlina A, Viscomi C, Zeviani M. Effective AAV-mediated gene therapy in a mouse model of ethylmalonic encephalopathy. EMBO Mol Med 2012;4:1008-14.

81. Torres-Torronteras J, Viscomi C, Cabrera-Perez R, et al., Gene therapy using a liver-targeted AAV vector restores nucleoside and nucleotide homeostasis in a murine model of MNGIE. Mol Ther. 2014;22:901-7.

82. Bottani E, Giordano C, Civiletto G, et al., AAV-mediated liver-specific MPV17 expression restores mtDNA levels and prevents diet-induced liver failure. Mol Ther 2014;22:10-7. 
83. Guy J, Qi X, Pallotti F, et al., Rescue of a mitochondrial deficiency causing Leber Hereditary Optic Neuropathy. Ann Neurol 2002;52:534-42.

84. Yu H KR, Chou TH, Porciatti V, et al., Gene delivery to mitochondria by targeting modified adenoassociated virus suppresses Leber's hereditary optic neuropathy in a mouse model. Proc Natl Acad Sci USA 2012a;109:E1238-47.

85. Garone C, Garcia-Diaz B, Emmanuele V, et al., Deoxypyrimidine monophosphate bypass therapy for thymidine kinase 2 deficiency. EMBO Mol Med 2014;6:1016-27.

86. Saada A, Shaag A, Mandel H, Nevo Y, Eriksson S, Elpeleg O. Mutant mitochondrial thymidine kinase in mitochondrial DNA depletion myopathy. Nat Genet 2001;29:342-4.

87. Saada A, Ben-Shalom E, Zyslin R, Miller C, Mandel H, Elpeleg O. Mitochondrial deoxyribonucleoside triphosphate pools in thymidine kinase 2 deficiency. Biochem Biophys Res Commun 2003;310:963-6.

88. Akman HO, Dorado B, Lopez LC, et al., Thymidine kinase 2 (H126N) knockin mice show the essential role of balanced deoxynucleotide pools for mitochondrial DNA maintenance. Hum Mol Gene 2008;17:2433-40.

89. Lopez-Gomez C, Levy RJ, Sanchez-Quintero MJ, et al., Deoxycytidine and Deoxythymidine Treatment for Thymidine Kinase 2 Deficiency. Ann Neurol. 2017;81:641-52. 

Summary 
Magnetic resonance imaging has been used extensively in the evaluation and follow up of neurometabolic disorders especially mitochondrial disorders. It offers a noninvasive way of assessing the structural, functional and metabolic state of the central nervous system and an easily available diagnostic modality in the early stages of evaluation. There are only few large studies, which focus on the magnetic resonance imaging findings in patients with mitochondrial disorders. More importantly the therapeutic and prognostic implications of specific MRI findings in routine clinical practice remains largely unexplored. Moreover the role of MRI in defining the phenotypes thereby providing valuable corroborative evidence for the potential pathogenic variants identified in exome sequencing is also emerging. With this background the study aimed to explore the prognostic and therapeutic significance of MRI findings in mitochondrial disorders. We studied the phenotype genotype correlations with special reference to MRI findings in specific subsets of mitochondrial disorders in order to guide prognosis and therapy [chapter 2], correlated peripheral neuropathy with underlying genetic defects [chapter 3], evaluated if specific imaging findings can discriminate mitochondrial disorders from other metabolic disorders [chapter 4], analyzed MRI findings in specific subset of patients to find out factors which can predict prognosis and monitor therapy [chapter 5\&6]. Chapter 7 discusses the relevance of the findings in a broader perspective of application in the clinical practice and future research.

Chapter 1 is introductory and reviews the current literature on the MRI findings in various mitochondrial disorders. The MRI findings of mitochondrial disorders in the context of ever expanding genotypes in the era of next generation sequencing were studied. Most of the studies report the cross sectional findings and detailed descriptions are lacking. Inspite of the myriad of genes and variations involved, the chapter demonstrated the convergence at the level of MRI findings amidst the clinical heterogeneity. The findings mainly converged to three important groups viz.bilateral symmetrical involvement of deep ganglionic structures suggestive of Leigh and Leigh like syndrome; leukoencephalopathy and stroke like lesions. In chapter 2, we analyzed the MRI findings in detail in a cohort of genetically defined patients with mitochondrial disorders. The study gives a detailed description of the anatomical pattern of CNS involvement identified by routine MRI sequences such as T1W, T2W and FLAIR sequences and the findings on various quantitative MR imaging studies such as DW1, MRS and SWI. Even though the study included only a limited number of genotypes it brought out a detailed description of the structural alterations in three different genotypes of mitochondrial disorders. Analysis of the special sequences revealed, basal ganglia mineralization, lactate peak on magnetic resonance 
spectrometry and diffusion restriction reflecting the various pathophysiological processes in these patients. Comparison of the magnetic resonance imaging findings in the three groups showed that cerebral atrophy and cerebellar atrophy, cortical signal changes and basal ganglia mineralization were seen mostly in patients with mitochondrial mutations. Brainstem signal changes with or without striatal lesions were characteristically noted in SURF1 group. There were no consistent MRI findings in patients in POLG1 group. The value of MRI based phenotypic characterization in non-syndromic mitochondrial disorders also has been emphasized in this chapter. The specific tract involvement of spinal cord in a patient with primary LHON mutation and identification of a mitochondrial variation in infantile onset basal ganglia stroke syndrome and mineralizing angiopathy are noteworthy. Followup images in a limited number of patients revealed that the findings are dynamic and revealed either progressive atrophy or involvement of new anatomical areas emphasizing the need for regular follow up evaluations. Next in chapter 3 we studied genetic basis of peripheral neuropathy in mitochondrial disorders and established correlations. Axonal neuropathy involving either sensory, motor or sensory motor nerves was the commonest nerve conduction abnormality identified. A demyelinating neuropathy was seen predominantly in patients with SURF1 mutations. Neuropathy was subclinical in majority of the patients and helped defining the multiaxial nature of the disease. It is intriguing to note the differential involvement of axons and myelin in mitochondrial disorders and their relationship with specific genetic variations. Even though the axonal involvement can be explained based on the chronic energy deprivation theory, the involvement of myelin especially in those with SURF1 variations is fascinating. This calls for more detailed studies to interrogate the interrelationship between $S U R F 1$ and peripheral myelin integrity.

In addition to studying the phenotype genotype correlations we also evaluated the role of specific MRI findings in differentiating mitochondrial disorders from other inherited metabolic disorders [chapter 4]. Bilateral symmetrical involvement of the basal ganglia and brainstem defining Leigh syndrome is an important MR imaging phenotype in mitochondrial disorders. Assigning a mitochondrial etiology will facilitate targeted metabolic and genetic testing leading to rapid and specific treatment. In chapter 4 analyses of MRI findings in a large cohort of 125 children with special reference to inferior olivary hypertrophy was done. The study emphasized the presence of inferior olivary involvement in Leigh syndrome secondary to mitochondrial disorders compared to other metabolic disorders. The study also found that that the presence of inferior olivary involvement occurred independently and not always associated with central tegmental tract or dentate nuclei involvement, implying the vulnerability of inferior olivary nuclei to mitochondrial dys- 
function. Apart from the role of MRI in defining the phenotype genotype correlations we also examined the prognostic and therapeutic implications of MRI findings in two subset of mitochondrial disorders namely mitochondrial epilepsy and mitochondrial leukoencephalopathies. In chapter 5, MRI findings in 27 patients with mitochondrial disorders and epilepsy were correlated with treatment response and long-term outcome. Clinical, genotype and MRI correlations included focal seizures, epilepsia partialis continua, status epilepticus and episodic progression in patients with stroke like lesions and $\mathrm{m} .3243 \mathrm{~A}>\mathrm{G}$ mutations; progressive degenerative course in patients with cerebral and cerebellar atrophy mostly secondary to $\mathrm{m} .8344 \mathrm{G}>\mathrm{A}$ mutation; Chronic progressive external ophthalmoplegia, photosensitive eye lid myoclonus and status epilepticus in patients with normal MRI and POLG1 mutations; Intermittent partial and generalized seizures in leukoencephalopathy of heterogeneous genetic etiology. The study highlighted that the anatomical patterns on MRI in patients with mitochondrial epilepsy may predict the genotype and phenotypes and recognition of these patterns may help clinicians in prognostication and therapy. In chapter 6, detailed analysis of the clinical course, MRI findings and therapeutic response to immunomodulation was performed in 14 patients with mitochondrial leukoencephalopathy. Clinical features which mimicked acquired demyelinating disorder included acute onset focal deficits associated with encephalopathy, febrile illness preceding the onset, unequivocal partial or complete steroid responsiveness, episodic/ relapsing remitting neurological dysfunction and a subsequent stable rather than a progressive course. MRI characteristics included multifocal asymmetric confluent white matter lesions, diffusion restriction, contrast enhancement, spinal cord involvement, and lactate peak on MRS. The study concluded that episodic neuroinflammation is a feature of mitochondrial leukoencephalopathies which may overlap with that of acquired demyelinating disorders in children. The response to immunomodulation was noteworthy and the therapeutic implications of these observations need to be explored in further studies. Chapter 7 discusses the relevance of our findings in the current scenario of paradigm shift in the diagnostic evaluation of mitochondrial disorders brought out by next generation sequencing. The chapter emphasizes the need for incorporating MRI studies in natural history studies. It also discusses the hitherto unexplored field of application of MRI findings in prognostication and therapy of patients with mitochondrial disorders and brings out avenues for future studies. Chapter 7 also discusses the emerging treatment options in mitochondrial disorders and the role of MRI in guiding and monitoring treatment response.

In this thesis, application of routine MRI in diagnostics, mainly based on phenotype genotype correlations has been studied in addition to its application in prognos- 
tication and therapy in limited subsets of patients. It is envisaged that extension of these studies to more subgroup of patients and the systematic application of advanced imaging techniques may bring out new avenues on the role of MRI in management of patients with mitochondrial disorders. These studies should lead to the routine and methodical use of MRI in natural history studies and also therapy monitoring. 

Valorisation 
Mitochondrial disorders, considered as the most common inborn error of metabolism in children and most prevalent group of inherited neurological disorders in adults, often cause multisystem dysfunction leading to a characteristically complex clinical picture with significant morbidity and mortality. ${ }^{1,2}$ While the inherent heterogeneity and complexity associated with these disorders pose diagnostic and management challenges to the physicians involved in the care of patients, the diagnosis or suspected diagnosis of a mitochondrial disorder, pose considerable challenges to the families as well. ${ }^{3}$ Firstly, the diagnostic evaluation in patients with suspected mitochondrial disorders is "time-consuming, logistically demanding, cost-intensive, and often associated with inconclusive or negative results, and above all, it is frequently not initiated at all, why many of these patients go undetected for years or forever". ${ }^{4}$ Secondly, even though there has been tremendous advancement in understanding the genetic basis of mitochondrial disorders in recent years, the information on the course and prognosis still remain the biggest challenge in patient management. Thirdly in view of the propensity to affect the central nervous system, chronic disability is the rule which cause considerable economic burden to families as well as to the health care system. ${ }^{3}$ Taking all these factors together, the individual disease burden is extensive, resulting in substantial direct and indirect health care costs to the patient and society as a whole. ${ }^{1}$

The studies in this thesis are relevant to address the above-mentioned issues faced by the families of patients with mitochondrial disorders. Our data (chapter 25) demonstrates that Brain MRI is an invaluable tool in guiding diagnosis, prognosis and therapy in mitochondrial disorders. This is important for clinical practice of adult and paediatric neurologists, geneticists, radiologists and for patients, patient organizations and advocacy groups themselves. Our results have substantial implications for evaluation, assessment of intervention outcomes and may guide evidence based management guidelines.

\section{Shortening the diagnostic odyssey thereby reducing the cost of diagnostic process}

The work described in this thesis examined three important aspects of mitochondrial disorders, the clinical phenotype, genetic basis and most importantly the Brain MRI findings. We first critically analyzed the brain MRI findings of mitochondrial disorders reported in literature. We then proceeded to characterize the MRI findings in specific genotypes in a relatively large cohort of patients to establish correlations between specific genotypes and MRI phenotypes. This study provides valuable data on the MRI phenotypes in a rare group of disorders (chapter 2). Mitochondrial disorders are rare and not many physicians are familiar with the clinical and MRI findings to suspect the diagnosis at an early stage. MRI is one of the earliest and easily 
available tools available to the clinician and knowledge of the various MRI findings and their correlation with the phenotype and genotype is of paramount importance in the diagnostic evaluation of patients and for optimal patient care. MRI helps the physician to suspect the diagnosis early in the clinical course and target the investigations in specific directions thereby reducing the cost and length of investigations. In other words, for the clinician, it gives a cost effective way of analyzing the problem, nature and extent of the CNS involvement and provides an easy objective measure of involvement of the CNS to be communicated to the patients and families.

While genetic diagnoses remain the ultimate end of the diagnostic odyssey in mitochondrial disorders, brain MRI plays an important role in shortening and finetuning this process. Our data (chapter 4) suggests ways to differentiate mitochondrial disorders from other neurometabolic disorders through specific findings on MRI, thereby helping the physician to target the genetic investigations and management, which is especially important in the many countries, where whole exome sequencing is not the diagnostic standard yet. The correlations described in the thesis help to direct the genetic testing and suggest the genes of interest thereby reducing the turn around time for targeted or exome sequencing. MRI also helps to define the phenotypes in individual patients better, thereby providing the valuable corroborative evidence for the potential pathogenic variants identified in exome sequencing studies. This in turn helps to reduce the cost of investigations and will be of direct benefit to patients and patient's families.. The exact economic impacts of these findings are difficult to ascertain, but it reduces the time to diagnosis considerably.

\section{Defining the course, prognosis and treatment}

As discussed in the thesis (chapter 7), defining the prognosis and course at a given point of time is the biggest challenge faced by the physician. The disease course largely depends on the organ system involved with the nature of the genetic variations being an important factor. We show in the thesis (chapter 5\&6) that the MRI phenotype might be used in the prognostication of mitochondrial disorders. Our data showed that certain MRI phenotypes such as leukoencephalopathy is associated with a better prognosis. It also showed that presence of additional lesions on MRI such as brain stem signal changes might decide the outcome in individual patients (chapter 2). As noted in the thesis "MRI, because of its non-invasive nature and the ability to define the anatomical pattern of brain injury overtime can play an important role in predicting the clinical course and monitoring treatment response in individual patients." Most importantly, we expect that our work will pave the way for the use of MRI in natural history studies. This has implications for patients and 
patient organizations in view of the objective nature in which the information can be communicated to the patients and their families.

One of the biggest challenges in developing a clinically relevant treatment strategy in mitochondrial disorders is lack of objective and validated outcome measures. ${ }^{6}$ Our data advocate the use of MRI. The outcome in certain mitochondrial disorders tends to correlate with the structural changes on MRI and there is an apparent convergence at the level of MRI findings even when the genotypes are different. It would, therefore, be an attractive option to construct MRI homogenous groups for clinical trials. So far, MRI has not been included as an outcome measure in mitochondrial treatment trials. Since the inception of this study another group has developed and validated a scoring system for MRI in mitochondrial disorders which can be used for rating disease progression and outcome after intervention in clinical trials. ${ }^{5}$ In this way, the studies presented in this thesis have broader implications for pharmaceutical companies, involved in the development of new therapies and drug trials.

In addition to the role of MRI in facilitating prognosis and therapy, we also examined three important neurological features in mitochondrial disease which include peripheral neuropathy, epilepsy and leukoencephalopathy. All the three features are important factors leading to chronic disability in mitochondrial disorders. Epilepsy is one of the key manifestations of neurological diseases caused by pathogenic mutations in many genes affecting mitochondrial function. ${ }^{7}$ It is one of the important features limiting the quality of life in many mitochondrial disorders especially MERRF and MELAS syndromes. ${ }^{8}$ In addition secondary mitochondrial dysfunction has been described in various epileptic disorders. ${ }^{9}$ Epilepsy being one of the common problems faced by the neurologist, characteristics of epilepsy associated with mitochondrial dysfunction improve both evaluation and management. The analysis of course and prognosis in relation to phenotype, genotype and MRI findings after a long period of follow up is one of the strengths of this thesis. Our data describe the most commonly used medications and the therapeutic response in specific subsets of patients and could be converted into management guidelines in mitochondrial epilepsy.

A potential relationship between immunological activation and mitochondrial dysfunction (chapter 6) in mitochondrial leukoencephalopathies is a relatively unexplored domain of mitochondrial medicine. Eventhough this has been suggested before, especially in multiple sclerosis and related disorders and LHON-MS, we have demonstrated that immune activation does exist in primary mitochondrial disorders. This has been amply substantiated by the MRI findings and therapeutic response to immune suppressive agents and a long-term follow up. These findings have implica- 
tions for the treatment of mitochondrial disorders, bringing out novel options, which has implications for the mitochondrial community as a whole and can contribute to the development of management guidelines in patients with mitochondrial leukoencephalopathy. 


\section{References}

1. Gorman GS, Schaefer AM, Ng Y, Gomez N, et al. Prevalence of nuclear and mitochondrial DNA mutations related to adult mitochondrial disease. Ann Neurol. 2015 ;77:753-9

2. Gorman GS, Chinnery PF, DiMauro S, et al. Mitochondrial diseases. Nat Rev Dis Primers. 2016 ; 2:16080

3. Sofou K. Mitochondrial disease: a challenge for the caregiver, the family, and society. J Child Neurol.2013; 28: 663-7.

4. Finsterer J, Zarrouk-Mahjoub S. Costs for mitochondrial medicine will remain high as long as mitochondrial disorders are misdiagnosed. Mol Genet Metab Rep. 2017 ;13:41.

5. Wong SS, Goraj B, Fung CW, Vister J, de Boer L, Koene S, Smeitink J. Radboud Centre for Mitochondrial Medicine Pediatric MRI score. Mitochondrion. 2017 ;32:36-41.

6. Koopman WJ, Beyrath J, Fung CW, Koene S, Rodenburg RJ, Willems PH, Smeitink JA. Mitochondrial disorders in children: toward development of small-molecule treatment strategies. EMBO Mol Med. ;8:311-27.

7. Zsurka G, Kunz WS, Mitochondrial dysfunction and seizures: the neuronal energy crisis, Lancet Neurol. 2015;14:956-966

8. Whittaker RG,Devine HE,Gorman G et al. Epilepsy in adults with mitochondrial disease: A cohort study.Ann Neurol 2015;78:949-57

9. Folbergrová J, Kunz WS. Mitochondrial dysfunction in epilepsy. Mitochondrion. 2012 ;12:35-40. 
Acknowledgements 
Writing this thesis has been a fascinating and rewarding experience. .... I would say that, being given the opportunity to do $\mathrm{PhD}$ under the supervision of Prof. dr. H.J.M Smeets is one of the best things which happened in my scientific career. It has been a rich educational experience and rare privilege to be Prof. Smeets's student and I owe him deepest gratitude. His constant guidance and careful planning made this work possible. Professor Smeets not only identified where my strength lies but also gave perfect shape to that in the form of this thesis. His suggestions always gave new dimension to my thoughts. As you rightly pointed out, it was nice to work as a team.

My co-supervisor Professor A. B. Taly whom I refer always as my philosopher and guide has been with me throughout this journey. I acknowledge with gratitude that, he introduced me to the fascinating field of mitochondrial medicine and gave opportunity to work and explore as much as I wanted. I acknowledge that his constant training and input shaped my academic career. His dedication to neurology, patient care and academic excellence has been a constant source of inspiration to me. I value the long hours of MRI discussions and his valuable contributions to each presentations and manuscripts.

My deepest gratitude for Drs. Madhu and Sanjib Sinha, my beloved colleagues who supported the mitochondrial research whole-heartedly. The interpretation of diagnostic evaluations and collective management decisions for each patient, from the clinical team, was invaluable and formed the basis of this thesis. I was immensely lucky and privileged to have colleagues like both of them. I also gratefully acknowledge the support and guidance from my other colleagues in Dept. of Neurology, NIMHANS, and Bangalore.

My whole hearted gratitude to Dr. Gayathri who is the heart of mitochondrial research in NIMHANS. Her excellent expertise in myopathology has always been an asset to the mitochondrial research. She always had answers and solutions to every problem and whole heartedly supported all the laboratory work which we proposed. I profusely thank her for being there always to support me in this endeavor.

My special thanks to Dr. Srinivas Bharath, without whom the mitochondrial research in NIMHANS would not have taken shape. His efforts to standardize the respiratory chain assays in the neuromuscular lab helped us to kick-start the programme and kept it going.

I would like to thank Dr. Aravinda neuroradiologist who contributed immensely to this work by analyzing and giving critical inputs to MRI reading. Words are not enough to express my immense gratitude to Aravinda for making significant contribution to the Mito research. Thanks are also due to Dr. Vandana, who meticulously carried out the Audiological evaluation for the patients, even with very short notice. 
I acknowledge the relentless support offered by Dr. Thangaraj Senior principal scientist, CSIR-Centre for Cellular and Molecular Biology, Hyderabad and his team in CSIR in carrying out the DNA analysis, without which this work would not have been possible. I express my deep gratitude to him.

My heart felt thanks to Dr. Sonam, Shwetha, Govindaraju C, Rakesh Kumar, Chetan k, Chetan V, Ramesh Siram, Akshatha and Akhilesh who have been the driving force for the work I have done in mitochondrial disorders. I would especially acknowledge Sonam with whom we started this journey altogether. A special thanks to Govindaraju P, the pillar of neuromuscular lab team to solve any questions related to mitochondrial DNA variations. The promptness with which he has responded to my queries has immensely helped me with interpreting patients' results and communication to them. A big thank you for Jessey and Deepha in the lab who always have been there to answer the queries related to samples.

I would like to thank NIMHANS- Maastricht team for paving the way for this $\mathrm{PhD}$. I would like to express my deepest gratitude to my committee chair Prof. Steinbush and other committee members for assessing the thesis.

And a big thank you to you, Diana and Bieke my paramymphs, for the enormous help with organizing meetings with Prof. Smeets, printing the thesis and organizing the defense.

A big thank you to my friends Anu \& Baiju who spent long hours, in formatting the thesis at the last minute. I acknowledge with gratitude that without you're their help I would not have finished this in time.

Last, and by no means least, I want to dedicate this conquest to my husband, Manoj and to my two little stars Adithya and Aparna for their support, love, and understanding during the process of preparing this work. Manoj, you always been there to do everything for me when I spent hours in front of the computer. Adi \& Aparna, who have always tolerated Amma's long hours of work. Aparna, for your daily prayers for your mom to successfully complete her PhD.... and Adi for your silent understanding....amazing kids both of you have been...

And above all, I express my deepest gratitude to the patients and families who were willing to participate in this research...To the parents, who placed such big hope on us to advance the knowledge in mitochondrial medicine.

Bindu 

Curriculum vitae 
Dr. Bindu Parayil Sankaran was born on 31 ${ }^{\text {st }}$ May 1971 in Angamaly, Kerala South India. She joined for undergraduate training in Medicine in Medical College Thrissur, Kerala in the year 1988 and obtained her MBBS degree in 1994 and finished her internship in 1995. She joined for postgraduate training in Pediatrics in Sree Avittom Thirunal Hospital, Medical College Trivandrum, Kerala in 1995 and obtained her MD degree in Paediatrics in 1999. She also qualified the diplomat of National Board of examination in Pediatrics in 2000. After finishing her postgraduate training in Pediatrics She worked in Amrita Institute of Medical Sciences, Cochin for one year as a senior registrar in Pediatrics. Subsequently with her interest in neurological disorders she joined for neurology training in National Institute of Mental Health and Neurological Sciences, Bangalore, India in the year 2001 and obtained DM degree in Neurology in 2004. After completing the training she continued to work in the Department of Neurology NIMHANS as a senior registrar and subsequently joined as a faculty in May 2006. Being a clinical scientist, trained in both pediatrics and neurology Dr.Bindu has a special interest in neurometabolic and neurogenetic disorders, mitochondrial disorders in particular. The pattern recognition on magnetic resonance imaging and its application in neurometabolic and neurogenetic disorders has always been a passion for her. This PhD work is based on her ongoing research work in NIMHANS, Bangalore in the field of mitochondrial disorders, which particularly focused on the application of Brain MRI findings in mitochondrial disorders. 
Publications 


\section{Publications}

1. Bindu PS, Sonam K, Chiplunkar S, et al., Mitochondrial leukoencephalopathies: A border zone between acquired and inherited white matter disorders in children? Mult Scler Relat Disord. 2018 ;20:84-92.

2. Bindu PS, Sonam K, Govindaraj P, et al., Outcome of epilepsy in patients with mitochondrial disorders: Phenotype genotype and magnetic resonance imaging correlations. Clinical Neurology Neurosurgery 2017;164:182-189

3. Bindu PS, Nagappa M, Bharath RD, Taly AB. Isolated Sulfite Oxidase Deficiency. 2017 Sep 21. In: Adam MP, Ardinger HH, Pagon RA, Wallace SE, Bean LJH, Mefford HC, Stephens K, Amemiya A, Ledbetter N, editors. GeneReviews® [Internet]. Seattle (WA): University of Washington, Seattle; 1993-2017. Available from http://www.ncbi.nlm.nih.gov/books/NBK453433

4. Bindu PS, Govindaraju C, Sonam K, et al., Peripheral neuropathy in genetically characterized patients with mitochondrial disorders: A study from south India. Mitochondrion. 2016; 27:1-5

5. Bindu PS, Arvinda H, Taly AB, et al., Magnetic resonance imaging correlates of genetically characterized patients with mitochondrial disorders: A study from south India. Mitochondrion. 2015; 25:6-16

6. Bindu PS, Taly AB, Sonam K, et al., Bilateral hypertrophic olivary nucleus degeneration on magnetic resonance imaging in children with Leigh and Leigh-like syndrome. Br J Radiol. 2014;87(1034):20130478. 


\section{Abstracts}

Asia-Oceanian Congress of Clincial Neurophysiology, 2017, Bangalore,India

Bindu PS, Nagappa M, Chiplunkar S, Kothari S, Govindaraj P, GayathriN, Sinha S, Taly AB. Peripheral Neuropathy in Mitochondrial Disorders: Electrophysiological observations in a cohort of Genetically defined patients. (Oral presentation)

T.S.S- NIMHANS Knowledge Conclave on Epilepsy Imaging and Genetics 2017,Bangalore, India

Bindu PS, Arvinda HR, Govindaraju C, Sonam K, Govindaraj P, Chiplunkar S, Rakesh K, Nagappa M,Sinha S, Gayathri N, Srinivas-Bharath MM, Khan NA, Vandana N, Paramasivam A, Thangaraj K, Taly AB. Prognostic and Therapeutic Implications of Magnetic Resonance Imaging Findings in Patients with Mitochondrial Epilepsy: A Study on 26 Patients [poster presentation]

43rd annual meeting of British Paediatric Neurology Association (BPNA) 2017, Cambridge, United Kingdom.

Bindu PS, Nagappa M, Chiplunkar S, Sonam K, Govindaraju P, Gayathri N, Srinivas Bharath MM, Arvinda HR, Sinha S, Taly AB. Targeted Exome Sequencing in Children with Mitochondrial Disorders: Study from a Tertiary Care University Hospital in South India. [poster presentation]

Pediatric Movement Disorders Update, 2nd Annual Conference,The Movement Disorders Society of India, 2017, Bangalore,India

Bindu PS Movement Disorders in Children with Neurometabolic Disorders including mitochondrial disorders [Oral Presentation ]

International Symposium on Acute Encephalopathy in Infancy and Its Related Disorders (ISAE 2016), 2016, Tokyo, Japan

Bindu P.S, Sonam K, Govindaraju C, Govindaraju P, Khan NA, Chiplunkar C, Nagappa M, Arvinda HR , Gayathri N, Srinivas Bharath MM, Nunia V, Thangaraj K, Sinha S,Taly AB. Clinical Phenotypes and Genetic findings in Children with Mitochondrial Encephalopathies: Study from a Tertiary Care University Hospital in South India. [Oral presentation] 